\title{
Essays in Financial Economics
}

\section{Citation}

Kang, Ho. 2012. Essays in Financial Economics. Doctoral dissertation, Harvard University.

\section{Permanent link}

http://nrs.harvard.edu/urn-3:HUL.InstRepos:9876086

\section{Terms of Use}

This article was downloaded from Harvard University's DASH repository, and is made available under the terms and conditions applicable to Other Posted Material, as set forth at http:// nrs.harvard.edu/urn-3:HUL.InstRepos:dash.current.terms-of-use\#LAA

\section{Share Your Story}

The Harvard community has made this article openly available.

Please share how this access benefits you. Submit a story.

Accessibility 
(c)[2012] - Ho Jin Kang

All rights reserved. 


\section{Essays in Financial Economics}

\section{Abstract}

In the first essay, I study stock price movements during the trading day and find that retail trading activity generates excess intraday volatility. I develop a simple econometric measure which reveals that volatility realized during the trading day is too high to be reconciled with volatility achieved over the entire trading day. High intraday volatility stocks temporarily outperform low intraday volatility stocks by approximately 59 basis points over the next month. This temporary outperformance is due to retail investor price pressure, which I identify using the detailed brokerage dataset of Barber and Odean (2000) as well as a novel time-series dataset obtained from parsing the financial statements of Charles Schwab and E TRADE.

The second essay considers how tax-motivated selling generates temporary distortions in stock prices around the turn of the tax year. As investors face the trade-off between selling a temporarily-depressed stock this year and selling next year but delaying tax implications by one year, the magnitude of the stock's price distortion is a function of its cost basis, the capital gains tax rate, and importantly, the interest rate. Each of these components explains variation in US stock returns as well as retail investor selling behavior around the turn of the tax year. Similar results in the UK provide out-of-sample confirmation, as tax and calendar years differ.

The third essay develops a real business cycle model with time-varying inflation risk and optimal, but infrequent, capital structure choice. In the model, more volatile inflation or more procyclical inflation leads to quantitatively important increases in credit spreads. Intuitively, this result obtains because inflation persistence generates large uncertainty about the price level at long maturities and because firms cannot adjust their capital structure immediately. Across a panel of six developed economies, credit spreads rise by 
15 basis points if either inflation volatility or the inflation-stock return correlation increases by one standard deviation. Firms counteract higher debt financing costs by adjusting their capital structure in times of higher inflation uncertainty. 


\section{Contents}

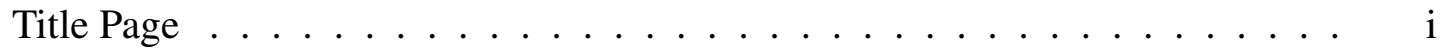

Abstract .......................... iii

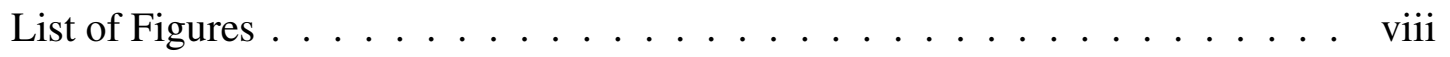

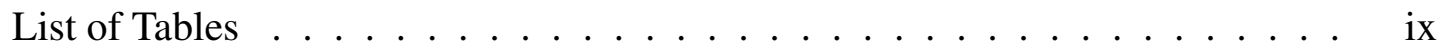

Acknowledgments . . . . . . . . . . . . . . . xi

1 Intraday Stock Volatility and Retail Trading Activity 1

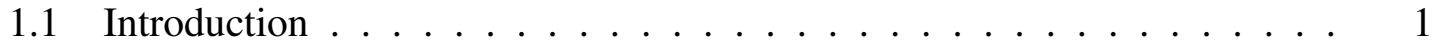

1.2 Literature Review . . . . . . . . . . . . . . . . . . 5

1.2.1 Variance Ratios . . . . . . . . . . . . . . . . . . . . 5

1.2 .2 Volatility Estimation . . . . . . . . . . . . . 6

1.2.3 Retail Trading Activity . . . . . . . . . . . . . . 7

1.3 Data and Methodology $\ldots \ldots \ldots \ldots$

1.3.1 Data Description . . . . . . . . . . . . . . . 8

1.3.2 Range Variance Ratio . . . . . . . . . . . . . . . . . . . . . 9

1.3.3 Retail Trading Activity . . . . . . . . . . . . . . . . . . . 10

1.4 Empirical Results . . . . . . . . . . . . . . . . . . . . . . . . . . 14

1.4.1 Intraday Stock Volatility . . . . . . . . . . . . . . . . . 14

1.4 .2 Price Pressure . . . . . . . . . . . . . . . . . . . 16

1.4.3 Time-series of Retail Trading Activity . . . . . . . . . . . . 20

1.4.4 Cross-section of Retail Trading Activity . . . . . . . . . . . 22

1.5 Robustness Tests . . . . . . . . . . . . . . . . . . 23

1.5.1 Lags and Exchange Effects . . . . . . . . . . . . . . . . 23

1.5.2 Liquidity and Market Microstructure . . . . . . . . . . . . . 25

1.5.3 Relation to Other Anomalies . . . . . . . . . . . . . . . . 28

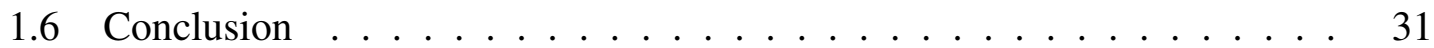


2 How Tax and Interest Rates Drive Stock Returns at the Turn of the Tax Year 32

2.1 Introduction . . . . . . . . . . . . . . . . . 32

2.2 The Setting . . . . . . . . . . . . . . . . . . . . . . . . . . . . . . . .

2.3 Data and Methodology . . . . . . . . . . . . . . . . 43

2.3.1 Data Description .................. 43

2.3.2 Tax-selling Premium . . . . . . . . . . . . . . . . 46

2.3.3 Capital Gains Overhang . . . . . . . . . . . . . . 46

2.3.4 Control Variables . . . . . . . . . . . . . . . . 47

2.3.5 Descriptive Statistics of Overhang Portfolios . . . . . . . . . . . 48

2.4 Empirical Results . . . . . . . . . . . . . . . . . . . 51

2.4.1 Cross-sectional and Time-series Variation in Firm-level Returns . 51

2.4.2 Cross-sectional and Time-series Variation in Trading Behavior . . 62

2.4.3 Implications for Performance Attribution . . . . . . . . . . . . . 69

2.5 Conclusion . . . . . . . . . . . . . . . . . . . 79

3 Inflation Risk in Corporate Bonds $\quad 81$

3.1 Introduction . . . . . . . . . . . . . . . . . 81

3.1 .1 Literature Review . . . . . . . . . . . . . . . . 85

3.2 A Dynamic Model of Inflation Risk in Corporate Bonds . . . . . . . . . . 86

3.2.1 Intuition: Contingent Claim Payoff Profiles . . . . . . . . . . . 87

3.2.2 Timing of Cohort $t \ldots \ldots . \ldots . \ldots 99$

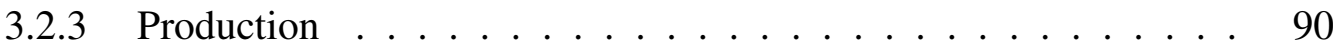

3.2 .4 Inflation . . . . . . . . . . . . . . . . 91

3.2 .5 Default Decision . . . . . . . . . . . . . . 92

3.2.6 Stochastic Discount Factor . . . . . . . . . . . . . . . . . . . . . . 94

3.2.7 Capital Structure Choice . . . . . . . . . . . . . . . . . 94

3.3 Calibrated Model . . . . . . . . . . . . . . . . . . . 96

3.3.1 Parameter Values and Model Moments . . . . . . . . . . . . 96

3.3.2 Model Implications for Credit Spreads . . . . . . . . . . . . . . . 101

3.4 Empirical Tests . . . . . . . . . . . . . . . . . . . . . . . . . . . . . . . . . . . . . . . . . . . .

3.4.1 Data Description . . . . . . . . . . . . . . 107

3.4 .2 Summary Statistics . . . . . . . . . . . . . . . . 111

3.4.3 Testing for Inflation Risk in Credit Spreads . . . . . . . . . . . . 116

3.4.4 Robustness of Benchmark Results . . . . . . . . . . . . . . . . . 124

3.4.5 Implications for Capital Structure . . . . . . . . . . . . . 126

3.5 Conclusion .......................... 130 
4 Appendices 132

4.1 Appendix to Chapter 1: Intraday Stock Volatility and Retail Trading Activity 132

4.1.1 Simulated RVR . . . . . . . . . . . . . . . . . . 132

4.2 Appendix to Chapter 2: How Tax and Interest Rates Drive Stock Returns at the Turn of the Tax Year . . . . . . . . . . . . . . . . . . 137

4.2.1 Alternative Specifications of the Tax-selling Premium . . . . . . 137

4.2.2 Estimated Taxes and Tax-loss Selling . . . . . . . . . . . . . . 142

4.2.3 Anticipated Changes in Captial Gains Tax Rates . . . . . . . . . 147

4.3 Appendix to Chapter 3: Inflation Risk in Corporate Bonds . . . . . . . . 148

4.3.1 Additional Empirical Results . . . . . . . . . . . . . . . . . 150

4.3.2 Computation of Asset Prices . . . . . . . . . . . . . 166 


\section{List of Figures}

1.1 Retail Investors and Mad Money $\ldots \ldots \ldots \ldots$

1.2 Time-Series of RVR . . . . . . . . . . . . . . . . . . . . . 11

1.3 Transaction Activity at Charles Schwab and E TRADE . . . . . . . . 13

2.1 Tax-Selling Propensity $\ldots \ldots \ldots \ldots \ldots \ldots$

2.2 Capital Gains Overhang . . . . . . . . . . . . . . . . . . . 72

2.3 January Returns of TAX factor $\ldots \ldots \ldots \ldots \ldots \ldots$

3.1 Credit Spreads and Inflation Uncertainty in the U.S. . . . . . . . . . 83

3.2 Contingent Claim Payoff Profiles . . . . . . . . . . . . . . . . . 88

3.3 Timeline of Firm Cohort t . . . . . . . . . . . . . . . . . . . . . 89

3.4 Model Credit Spreads, Stock Returns and Inflation Shocks _ . . . . . . 103

3.5 Model Impulse Responses . . . . . . . . . . . . . . . . . . . . . . . . 104

3.6 International Credit Spreads and Inflation Volatility . . . . . . . . . . 115

3.7 International Credit Spreads and Inflation-Stock Correlation . . . . . . 116

3.8 Empirical Credit Spreads, Stock Returns and Inflation Shocks _ . . . . . 122

3.9 Capital Structure and Inflation Uncertainty in the U.S. . . . . . . . . . . 128

$4.1 \quad$ RVR and Residual RVR Returns . . . . . . . . . . . . . . . . . 136

4.2 Time-series of the tax-selling premium, the interest rate, and the capital gains tax rate at the turn of the year . . . . . . . . . . . . 138

4.3 Time-series of the tax-selling premium, the interest rate, and the capital gains tax rate at the turn of the year . . . . . . . . . . . . . . . 139

4.4 Breakeven-Stock Correlation . . . . . . . . . . . . . . . . . . . . . 167

4.5 U.S. Credit Spreads and Inflation Shocks . . . . . . . . . . . . . . . . . 168

4.6 U.S. Stock Return Phillips Curve and Lagged Inflation Risk . . . . . . . . 169

4.7 Defaults, Stock Returns and Inflation Shocks _ . . . . . . . . . . 170 


\section{List of Tables}

1.1 Stock Characteristics by RVR Quintile $(1992-2010) \ldots \ldots \ldots$

1.2 Abnormal Returns $(1992-2010) \ldots \ldots \ldots \ldots \ldots \ldots$

1.3 Reversal in Abnormal Returns $(1992-2010)$. . . . . . . . . . . . . 20

1.4 Retail Trading Activity in the Time-Series $(1993-2010) \ldots \ldots . . .21$

1.5 Retail Trading Activity in the Cross-Section $(1992-1996) \ldots \ldots$

1.6 Robustness to Lags and Exchange Effects $(1992$ - 2010) _ . . . . . . . 25

1.7 Robustness to Liquidity and Microstructure Variables (1992 - 2010) . . . 26

1.8 Relation to Other Anomalies $(1992-2010)$. . . . . . . . . . . . . . 29

2.1 Descriptive Statistics . . . . . . . . . . . . . . . . . 50

2.2 Pooled Return Regression Estimates (1954-2008) . . . . . . . . . . . . 53

2.3 Daily Pooled Return Regression Estimates (1954-2008) . . . . . . . . . . 56

2.4 Pooled Return Regression Estimates (1954-2008) _ . . . . . . . . . . . . 61

2.5 Pooled Selling Pressure Regression Estimates (1954-2008) _ . . . . . . . 64

2.6 Aggregate Time-Series Regression Estimates (1954-2008) _ . . . . . . 70

2.7 Portfolio Time-Series Regression Estimates (1954-2008) _ . . . . . . . . 75

3.1 Model Parameters . . . . . . . . . . . . . . . . . . . . . . . . . . . 98

3.2 Empirical and Model Moments . . . . . . . . . . . . . . . . . . . . . . 99

3.3 Model Credit Spread Regressions _. . . . . . . . . . . . . . . 105

3.4 Summary Statistics . . . . . . . . . . . . . . . . . . . . . 112

3.5 Credit Spreads and Inflation Risk (1969.Q4-2010.Q4) . . . . . . . . . 118

3.6 Inflation and Growth Controls (1969.Q4-2010.Q4) . . . . . . . . . . 121

3.7 Credit Spread Regressions with Additional Controls (1989.Q1-2010.Q4) . 124

3.8 Leverage and Investment Regressions ． . . . . . . . . . . . . . . 129

4.1 Decile RVR Abnormal Returns $(1992-2010)$. . . . . . . . . . . . . . 134

4.2 Residual RVR Abnormal Returns $(1992$ - 2010) . . . . . . . . . . . 135 
4.3 Descriptive Statistics and Correlations of Macro Variables (1954-2003) . 141

4.4 Safe Harbor Case . . . . . . . . . . . . . . . . . . . . . . . . 145

4.5 International Corporate Bond Spread Data Sources . . . . . . . . . . . 152

4.6 Correlation Among Key Variables (1969.Q4-2010.Q4) . . . . . . . . . . 153

4.7 Individual Country Credit Spreads and Inflation Risk (1969.Q4-2010.Q4) 154

4.8 Credit Spread Regressions with Random Coefficients (1969.Q4-2010.Q4) 155

4.9 Inter-Quantile Regressions . . . . . . . . . . . . . . . . 156

4.10 U.S. BAA Over Government Spread (1969.Q4-2010.Q4) . . . . . . . . . 157

4.11 Controlling for GDP Volatility (1969.Q4-2010.Q4) . . . . . . . . . . 158

4.12 Smoothed Inflation Risk (1969.Q4-2010.Q4) . . . . . . . . . . . . 159

4.13 Additional Controls Smoothed (1989.Q1-2010.Q4) . . . . . . . . . . 160

4.14 International CPI and PPI Inflation (1969.Q4-2010.Q4) . . . . . . . . . 161

4.15 U.S. CPI and PPI Inflation (1969.Q4-2010.Q4) . . . . . . . . . . . . . . . . . . . 162

4.16 U.S. Credit Spread Changes (1969.Q4-2010.Q4) . . . . . . . . . . . . . 163

4.17 U.S. Credit Return Regressions . . . . . . . . . . . . . . . . . . . . . . 164

4.18 Decomposition of Inflation Risk Regimes . . . . . . . . . . . . . . 165 


\section{Acknowledgments}

I would like to thank my advisors, friends, and family for their support throughout graduate school.

First, I am grateful to the exceptional group of mentors comprising my Dissertation Committee. I would like to thank Erik Stafford, Lauren Cohen, and Christopher Malloy for taking such a genuine interest in developing me academically, personally, and professionally. I would like to thank John Campbell for encouraging me to pursue a Ph.D. in the first place and for teaching me so much throughout the program.

Second, I am grateful to my amazing group of friends and colleagues. I would like to thank my closest friends, Jason Paik, Michael Su, and Seung Han, for all the good times, especially those ahead of us. I would like to thank my colleagues, Alex Chernyakov, Sam Kruger, Carolin Pflueger, and Bob Turley, for making these years such an enjoyable time of learning.

Finally, I am extremely grateful to my family. To my extraordinary parents, Young Won Kang and Yeoung Hee Kang, thank you for sacrificing so much for our family and for raising us in the happiest of homes. To my incredible sisters, Miyun Kang and Julie Kang, thank you for raising me as you did, leading me by example and loving me without exception. To my mother-in-law and sister-in-law, Jamie Choo and Jina Choo, thank you for welcoming me into your wonderful family. To my precious daughter, Elise Kang, you are the most amazing gift, and I thank you for bringing so much joy into my life. And most importantly, to my wife, Christie Kang, I could not have pursued or achieved this accomplishment without you. But I am most thankful to you for making me the happiest husband and father each and every day. 


\section{Chapter 1}

\section{Intraday Stock Volatility and Retail Trading Activity}

\subsection{Introduction}

Daily highs and lows are particularly visible prices, and perhaps especially so for the typical retail investor. When tracking stock price movements throughout the day, a retail investor may find these extreme observations to be the most salient points in an intraday price graph. When reading a financial newspaper, a retail investor may scan through yesterday's highs and lows which are often reported alongside open and close prices. When generating stories during market hours, the financial news media may try to identify stocks with large intraday price swings. Ultimately, whether directly or indirectly transmitted, high and low stock prices are likely to grab the attention of retail investors and may even guide their trading decisions. Moreover, if retail investor trading activity were sufficiently correlated, then perhaps the collective irrational trading decisions of retail investors could temporarily impact prices.

To illustrate these propositions, consider the case of Shanda Interactive Entertainment (SNDA), a media stock recommended by Jim Cramer on January 3, 2006 (shown in Fig- 


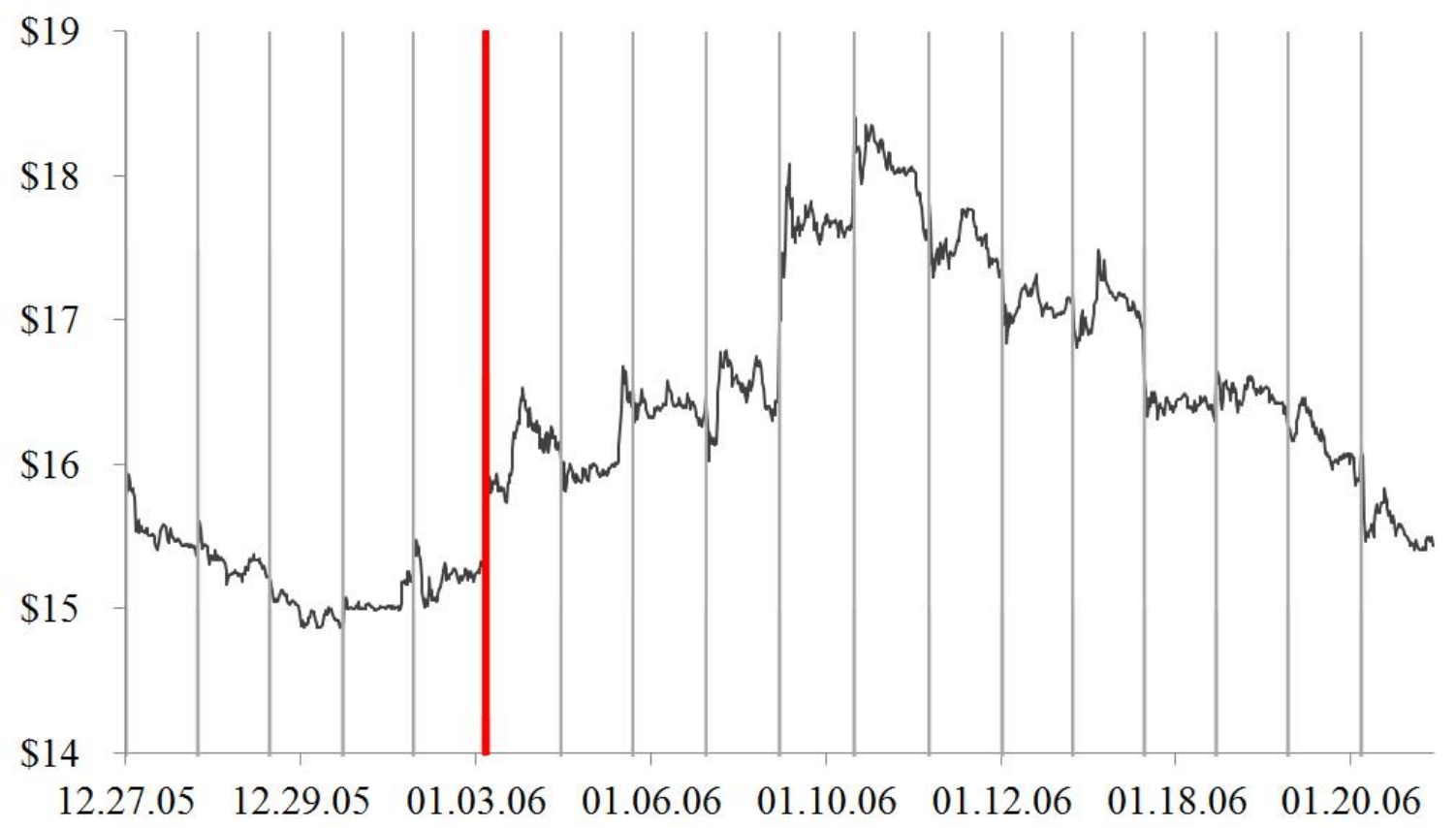

Figure 1.1: Retail Investors and Mad Money

This figure plots intraday price movements of Shanda Interactive Entertainment (SNDA), a media company recommended by Jim Cramer on the show Mad Money on January 3, 2006. The vertical grey lines are drawn to separate trading days. The vertical red line marks the date Jim Cramer recommended purchasing SNDA to his viewers. 
ure 1.1). At the time, Jim Cramer's television show Mad Money had been attracting widespread attention from retail investors. On the day after the stock recommendation, shares of SNDA rose 5.6 percent and closed at \$16.11 (versus a prior day close of \$15.25). In fact during the day, the stock reached an intraday high price of $\$ 16.53$. Over the next five days, SNDA climbed another $14 \%$ and hit a high of $\$ 18.40$ but eventually came all the way back down to its pre-recommendation price level by the end of the month. ${ }^{1}$

Closer examination of the intraday price movements in Figure 1.1 reveals that SNDA exhibited an increase in intraday volatility following Cramer's recommendation. A simple way to see this is to observe how much more pronounced high and low prices appeared in the days after the recommendation. In fact, intraday price volatility was $90 \%$ higher in the week after the recommendation compared to the week before based on a simple econometric measure to be proposed in this paper. Assuming retail investors were aggressively purchasing SNDA on these days without any clear economic justification, one might suspect that the abnormal retail trading activity generated excess intraday volatility as well as temporary price pressure.

In this paper, I test whether abnormal intraday volatility is indeed an indication of retail investor trading activity and hence whether the above example illustrates a more prevalent empirical phenomenon. To do so, I propose a simple econometric measure I call the Range Variance Ratio (RVR). RVR is defined as the ratio of variance based on high and low prices divided by variance based on open and close prices.

There are a couple reasons why RVR and its specification may be particularly appropriate for this endeavor. First, RVR is a formal statistical measure, and therefore, empirical estimates of RVR can be compared to both theoretical and simulated hypothetical values under varying distributional assumptions. This permits identification of excess intraday volatility, or equivalently intraday mean-reversion, relative to a counter-factual distribu-

\footnotetext{
${ }^{1}$ For comparison, the S\&P 500 was up only $0.4 \%$ on the day after the stock recommendation, although it rose $1.3 \%$ over the next five days and also come back down. The beta of SNDA to the S\&P 500 using daily returns over this window was only 1.0.
} 
tion.

Second, RVR distinguishes between volatility based on high and low prices in the numerator and volatility based on open and close prices in the denominator. This distinction is useful given that prices at the start and end of the day are determined by a disproportionate portion of the day's trading volume, which tends to be more institutional in nature particularly at the close (Cushing and Madhavan (2001)). Moreover, one might argue that highs and lows are likely footprints of uninformed traders, such as retail investors. Intuitively, informed traders tend to buy at prices that are too low, whereas uninformed traders tend to buy at prices that are too high.

I sort the cross-section of stocks by RVR on a monthly frequency and find that the empirical distribution of RVR suggests an intraday volatility too high to be reconciled with volatility achieved over the entire day. Hence I document an excess intraday volatility phenomenon. Next, I find that the highest RVR quintile stocks outperform the lowest RVR quintile stocks by a statistically significant 59 basis points over the next month. This outperformance is only temporary, however, as it entirely reverses within three months. ${ }^{2}$

To test whether the initial temporary outperformance of high RVR stocks is associated with price pressure generated by retail trading activity, I conduct both time-series and cross-sectional tests. By parsing the financial statements of Charles Schwab and E TRADE for quarterly transaction activity, I construct a novel time-series measure of aggregate retail trading intensity. By using this dataset along with the RVR spread portfolio returns, I find that periods of greater retail transaction activity correspond to periods of higher firstmonth RVR quintile spread returns. In addition, I find direct cross-sectional evidence that higher RVR corresponds to greater trading activity (and in particular buying) among retail investors using the detailed brokerage dataset of Barber and Odean (2000). Therefore, retail investor trading not only affects current prices but future prices as well.

These findings are robust to a number of controls including trading implementation

\footnotetext{
${ }^{2}$ Barber and Odean (2008) argue that retail investors are net buyers of attention-grabbing stocks, and thus, increases in investor attention should correspond to temporary positive price pressure.
} 
lags, proxies for illiquidity, and market microstructure effects. For instance, I find that the temporary price pressure exists even within a universe of predominantly large market capitalization stocks, as well as among the most liquid stocks. In addition, I find that while stocks with higher RVR tend to exhibit certain characteristics (e.g., lower bookto-market ratios, lower recent returns, and higher volatility), the stock return anomalies associated with these characteristics do not drive the temporary price pressure findings. In other words, the RVR portfolio returns are not driven by well-known empirical anomalies including size, value, momentum, reversal, and volatility.

The rest of this paper proceeds as follows. Section 1.2 provides a brief review of related literature. Section 1.3 describes the data and methodology. Section 1.4 establishes the main empirical results. Section 1.5 provides a series of robustness tests. Section 1.6 concludes.

\subsection{Literature Review}

\subsubsection{Variance Ratios}

A closely related paper by French and Roll (1986) documents that stock prices are more volatile when the market is open than when the market is closed. The authors test for excess volatility during market hours by comparing multiple to single day return variances around weekends and holidays. The authors argue that private information traded during market hours is the most likely explanation for their finding. In this paper, I propose an alternative variance ratio for the purpose of examining volatility within market hours. The conclusion I reach is that excess intraday volatility is likely related to the trading behavior of retail investors as opposed to privately informed traders.

Variance ratios have been used elsewhere in the financial econometric literature as well. Lo and Mackinlay (1988) present a variance ratio test to examine the hypothesis that stock prices follow a random walk. Over short horizons of one week, the authors find that 
stock returns are positively auto-correlated. Fama and French (1987) show that the slope coefficient in a multi-period auto-regressive return regression can be written as a variance ratio adjusted by a mean-reversion factor. For long horizon returns of three to five years, the authors find that stock returns are negatively auto-correlated. In this paper, I find that stock prices are excessively volatile over the intraday time interval which suggests that returns are negatively auto-correlated over these very short horizons. ${ }^{3}$

\subsubsection{Volatility Estimation}

The key variable proposed in this paper builds on volatility estimators derived previously in the econometric literature. Parkinson (1980) developed a volatility estimator using high and low prices for an underlying geometric Brownian motion with no drift. When compared to volatility using only close prices, the Parkinson measure is theoretically about five times more efficient. One of the author's main results is a closed-form derivation of the moment generating function for returns based on high divided by low prices. In a similar paper, Garman and Klass (1980) propose a closely related and even more efficient volatility estimator which uses high, low, open, and close prices. ${ }^{4}$

Like these papers, I am interested in estimating volatility using specific intraday prices. However, in this paper I attempt to explain the systematic differences in these estimates rather than determine the most efficient estimator. ${ }^{5}$ I argue that there are meaningful differences in interpreting open and close prices versus high and low prices, given that the latter set of prices are more likely driven by uninformed traders. My empirical results

\footnotetext{
${ }^{3}$ Heston, Korajczyk, and Sadka (2010) examine intraday stock price patterns using the TAQ database. The authors find continuation at half-hour intervals across trading days, which they attribute to institutional trading patterns, and they also find evidence of short-term intraday reversals.

${ }^{4}$ For both the Parkinson (1980) and Garman and Klass (1980) models, it should be noted that efficiency is conditional on the assumed geometric Brownian motion model. However, this paper suggests that such an assumed model is not correct.

${ }^{5}$ Nonetheless I did test whether RVR provided predictability of future volatility beyond that of realized and implied volatilities, but I did not find this to be the case.
} 
would thus suggest that modeling intraday volatility is structurally complicated by noise generated from retail investor trading activity. Using high-frequency data, Ait-Sahalia and Yu (2009) decompose stock return variances into fundamental and microstructure noise components, although these authors associate noise with illiquidity.

\subsubsection{Retail Trading Activity}

This paper closely relates to a recent strand of literature on retail investor trading activity and limited attention. Gervais, Kaniel, and Mingelgrin (2001) document a positive return premium to stocks with high abnormal trading volume. They suggest that shocks in trading volume contain information about future prices and affect the visibility of stocks to investors. Barber and Odean (2008) find that extreme returns, also interpreted as shocks to investor attention, lead to higher stock prices in the short-run, followed by reversals. Da, Engelberg, and Gao (2011) use Google search technology to identify investor attention directly and document that increases in search activity correspond to temporarily higher stock prices. The key variable in this paper can be thought of as another instrument for identifying attention-grabbing stocks or perhaps even as a mechanism for attentiongrabbing if one believes retail investor trading behavior is self-feeding.

Not only are certain stocks attention-grabbing, but they also tend to draw herd-like retail trading activity. Kumar and Lee (2006) find retail investor trades are systematic based on a comprehensive sample of individual trades at a large anonymous brokerage firm between 1991 and 1996. Barber, Odean, and Zhu (2009a) find that the trades of retail investors are highly correlated and persistent. The herd-like behavior of retail investor trades has been documented to affect market prices (Barber, Odean, and Zhu, 2009b). I find corroborating evidence that stocks more actively traded by retail investors tend to exhibit more correlated returns and generate temporary price pressure.

Barber and Odean (2000) find that the stocks individual investors buy underperform 
the stocks they sell. ${ }^{6}$ Consistent with this, I find that while stocks likely to have been actively traded by retail investors outperform over the first month, they underperform over the course of the year. Although these temporary mis-pricings should attract arbitrage capital, the corresponding trading strategy would incur significant portfolio turnover and transaction costs.

\subsection{Data and Methodology}

\subsubsection{Data Description}

The stock-level data is obtained from a few standard sources. The Center for Research in Securities Prices (CRSP) stock file provides daily prices, shares outstanding, trading volumes, and returns for all stocks listed on the NYSE, AMEX, and NASDAQ exchanges. Daily open, close, high, and low prices are all available for these securities beginning June 15, 1992. The COMPUSTAT North America annual file contains accounting information for most publicly traded U.S. firms. This dataset is used in conjunction with CRSP to compute book-to-market equity ratios. Earnings announcement dates and times are obtained from the Institutional Brokers' Estimate System (IBES) dataset. Short interest data is obtained from both Bloomberg and COMPUSTAT.

Upon merging these stock-level datasets, I apply a few filters to ensure a reasonably liquid and investable universe of securities and thereby reduce potential market microstructure effects. First, the universe is limited to U.S. common stocks by including only stocks with CRSP share codes 10 or 11 . Second, the universe is screened for stocks listed on NYSE, NASDAQ, and AMEX by identifying stocks with CRSP exchange codes 1, 2, or 3. Third, stocks with prices below $\$ 1$ and below-median market capitalizations (at the time of portfolio formation) are dropped. Overall, this amounts to 3,267 stocks per month

\footnotetext{
${ }^{6}$ As reported in Table II of Barber and Odean (2000), the average household's annual gross (net) return controlling for the three-factor model is approximately $-1.8 \%(-3.7 \%)$.
} 
on average and 725,328 total stock-month observations over the entire sample. Note that I consider further size and liquidity measures to constrain the universe of investable stocks later on in the robustness results section.

\subsubsection{Range Variance Ratio}

For the reasons stated in the introduction, high and low intraday prices are likely to be particularly visible to retail investors and may even guide their trading decisions. In addition, comparing high and low prices to open and close prices can offer information about excess volatility during the day versus volatility over the entire day. I incorporate both of these ideas in formulating a simple econometric measure that compares intraday volatility using high and low prices to day volatility using open and close prices. Over an interval of $\tau$ trading days, the variance estimate based on open and close prices is:

$$
\hat{\sigma}_{d}^{2}=\frac{1}{\tau-1} \sum_{t=1}^{\tau}\left(d_{t}-\bar{d}\right)^{2}
$$

where $d_{t}$ is the $\log$ of the close price divided by the open price and $\bar{d}$ is the mean day return. Similarly, the variance estimate based on high and low prices is:

$$
\hat{\sigma}_{r}^{2}=\frac{1}{\tau-1} \sum_{t=1}^{\tau}\left(r_{t}-\bar{r}\right)^{2}
$$

where $r_{t}$ is the $\log$ of the high price divided by the low price or the log of the low price divided by the high price (depending on whether the day return was positive or negative), and $\bar{r}$ is the mean range return. Finally, I define the Range Variance Ratio (RVR) estimate as the ratio of these two variances:

$$
R \hat{V} R=\frac{\hat{\sigma}_{r}^{2}}{\hat{\sigma}_{d}^{2}}
$$

I estimate RVR for all stocks in the sample at the end of each month using daily open, close, high, and low prices. 
As a statistical measure, RVR can be compared to hypothetical values under varying distributional assumptions. This permits identification of excess intraday volatility, or equivalently intraday mean-reversion, relative to a counter-factual distribution. For the specific case that log stock prices follow a Brownian motion with no drift, the limiting distribution of high divided by low price returns can be solved analytically using the moment generating function derived by Parkinson (1980) which is as follows:

$$
E\left[h_{t}^{p}\right]=\frac{4}{\sqrt{\pi}} \Gamma\left(\frac{p+1}{2}\right)\left(1-\frac{4}{2^{p}}\right) \zeta(p-1)(2 \sigma t)^{\frac{p}{2}}
$$

where $h_{t}$ denotes the high divided by low price return, $\Gamma$ is the Gamma function, and $\zeta$ is the Riemann zeta function. In order to generate hypothetical distributions of RVR for more general parameterizations, I use a Monte Carlo simulation procedure which is described in detail in the Appendix.

Figure 1.2 plots the time-series of twelve-month moving average median RVR values for the bottom, middle, and top quintiles. Note that the RVR values are scaled by the corresponding values from the counterfactual distribution described in the Appendix. If the distribution of RVR were purely random and constant over time (and of course, consistent with the simulation's assumptions), then the plot would show values of one over time for each of the quintiles. But this is not the case. The top quintile of RVR stocks have always been excessively volatile (having values above one) and increasingly so over time. The middle and bottom quintiles have also exhibited increasing intraday volatility over time, although these series were both below one earlier on.

\subsubsection{Retail Trading Activity}

I extract a novel dataset on aggregate retail investor trading activity from the $10 \mathrm{~K}$ and 10Q filings of Charles Schwab and E TRADE for the periods 1992-2010 and 19952010, respectively. These filings were obtained from the EDGAR Online database as made publicly available by the Securities and Exchange Commission (SEC). For each reporting quarter, data on the number of transactions executed within the quarter was parsed from 


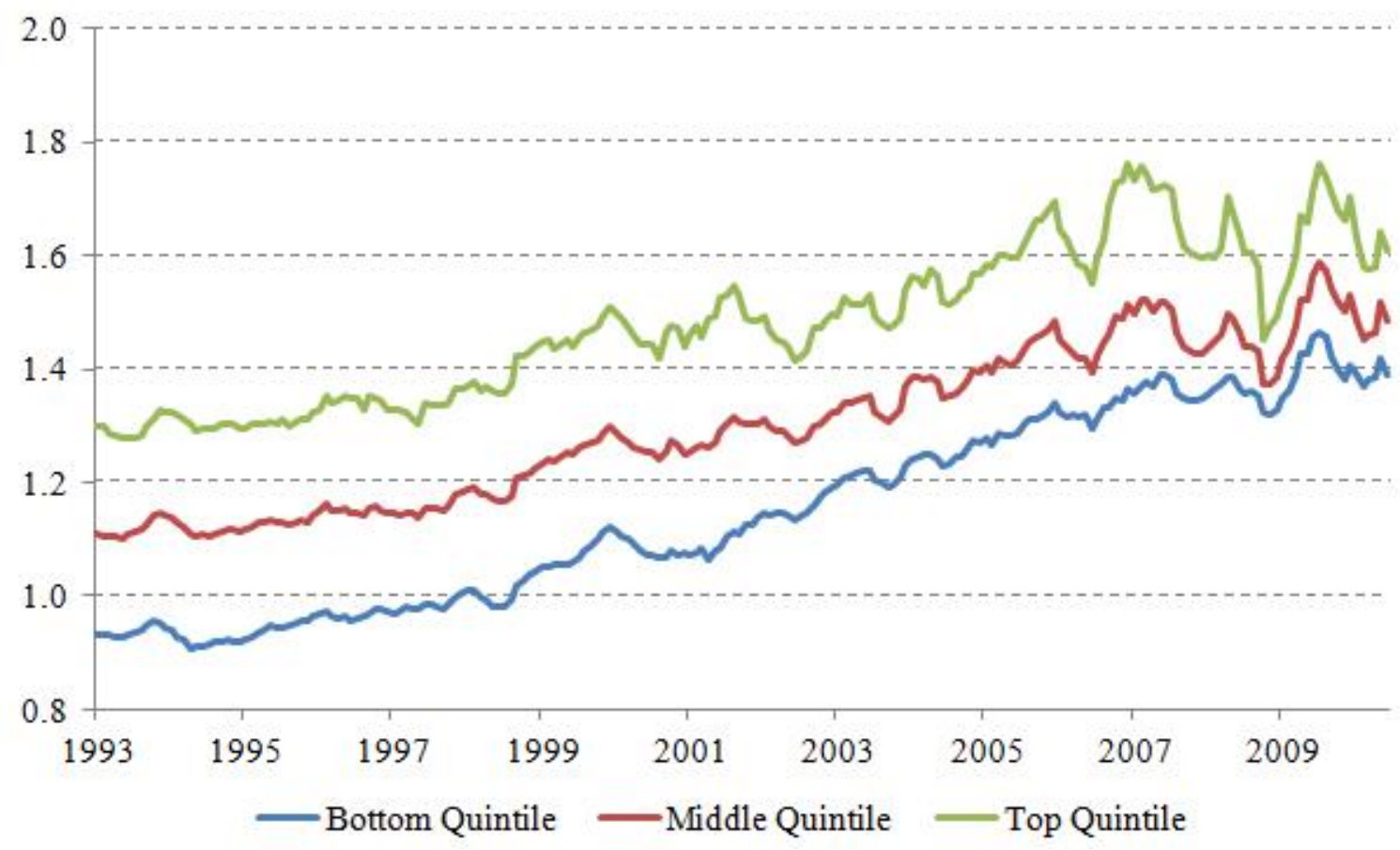

Figure 1.2: Time-Series of RVR

This figure shows the distribution of scaled RVR over time. Scaled RVR is the empirical range variance ratio divided its theoretical counterpart from a simulated Brownian motion (as described in the text). Six-month moving averages are shown for the median values within the bottom, middle, and top quintiles. 
the accounting statements. ${ }^{7}$ Note that retail transaction activity differs from retail trading volume, although the two are likely to be very highly correlated. At either brokerage firm, a single transaction may correspond to one or multiple shares having been traded. ${ }^{8}$

Figure 1.3 plots the time series of quarterly transaction activity (in millions of transactions per quarter) at each of the brokerage firms. The two series are very highly correlated which suggests that aggregate retail investor trading behavior is quite systematic across these large brokerage firms. This pattern is consistent with cross-sectional evidence that retail investor trades tend to be correlated (Kumar and Lee, 2006 and Barber, Odean, and Zhu, 2009a).

Individual retail investor trading activity data is from Barber and Odean (2000), which provides a detailed description of the data. This dataset offers an in-depth view into the trading decisions of retail investors at a large anonymous discount brokerage firm. It records all investor trades and positions between January 1991 and December 1996, and contains over 66,000 individuals and 1.85 million trades. Using this data, I construct four monthly measures of stock-level buys, sells, buys plus sells, and buys minus sells as follows:

$$
\begin{aligned}
\text { BuyRatio }_{t} & =\frac{\sum_{i=1}^{N} B_{i, t}}{\text { SharesOut }_{t}} \\
\text { SellRatio }_{t} & =\frac{\sum_{i=1}^{N} S_{i, t}}{\text { SharesOut }_{t}} \\
\text { TotalRatio }_{t} & =\frac{\sum_{i=1}^{N} B_{i, t}+\sum_{i=1}^{N} S_{i, t}}{\text { SharesOut }_{t}} \\
\text { NetRatio }_{t} & =\frac{\sum_{i=1}^{N} B_{i, t}-\sum_{i=1}^{N} S_{i, t}}{\text { SharesOut }_{t}}
\end{aligned}
$$

where $N$ denotes the number of investors, $B_{i, t}$ and $S_{i, t}$ denote the number of shares bought

\footnotetext{
${ }^{7}$ The 10Q's provide information on quarterly transaction quantities, and the 10K's provide annual data. Annual quantities are converted into quarterly quantities using the preceding 10Q's. For restated financial statements, I use the data as first reported.

${ }^{8}$ Between 1991 and 1996, the median retail investor transaction in the Barber and Odean (2000) dataset was about $\$ 4,988$ and 217 shares.
} 


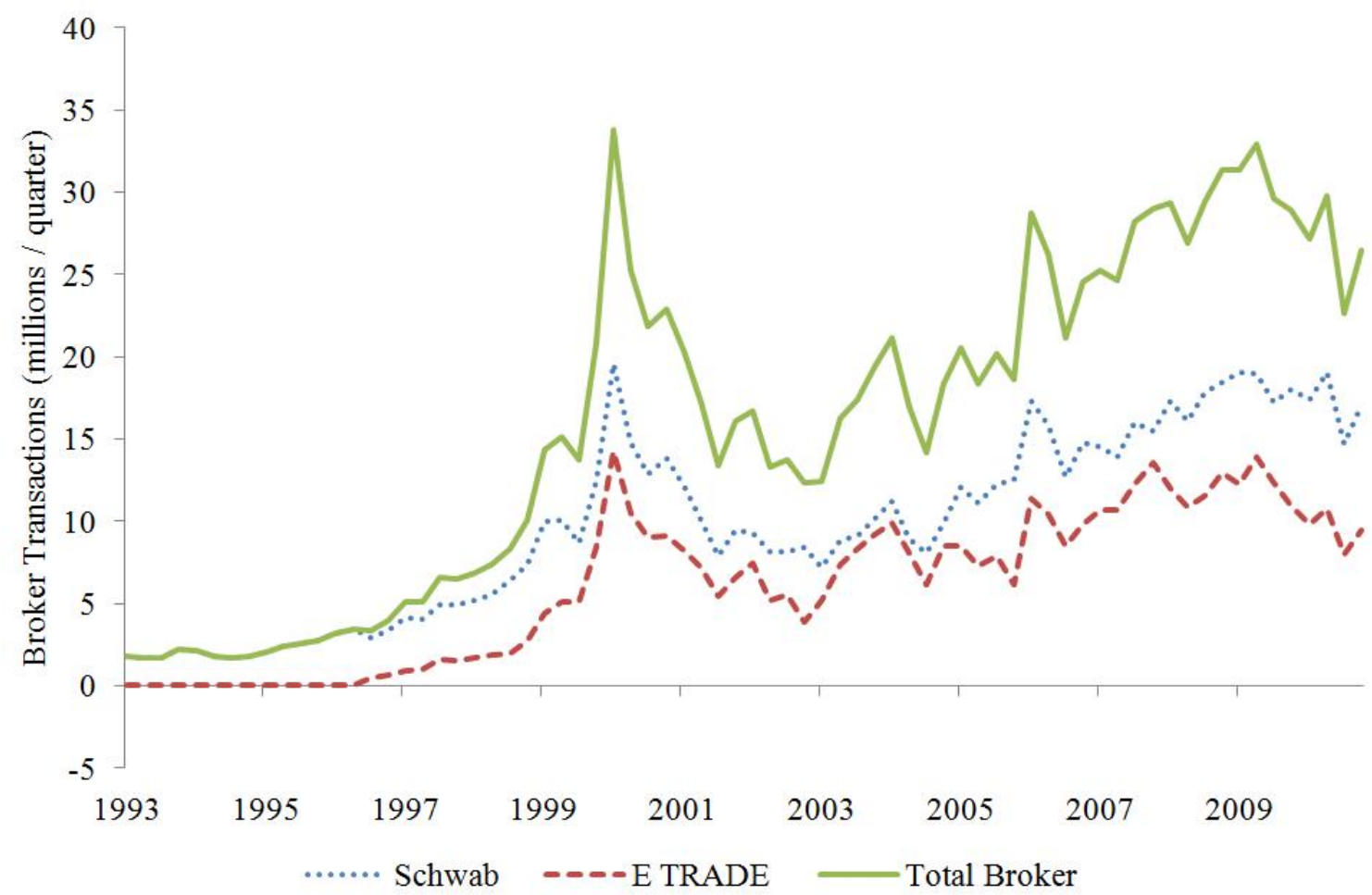

Figure 1.3: Transaction Activity at Charles Schwab and E TRADE

This figure shows aggregate quarterly transaction activity of individual investors at Charles Schwab and E TRADE between January 1993 and December 2010. The data is obtained from parsing the 10K and 10Q filings of each company. Total Broker is the sum of broker transactions at both brokerage firms. 
and sold by investor $i$ during month $t$, and SharesOut $t_{i, t}$ denotes the number of shares outstanding for the given stock.

\subsection{Empirical Results}

The main findings of this paper are that stock prices are excessively volatile intraday, that this excess volatility corresponds to retail investor trading activity, and that this trading activity generates temporary price pressure. I provide empirical justification for these findings in this section.

\subsubsection{Intraday Stock Volatility}

As discussed earlier, RVR compares the volatility of extreme stock price movements during the day to stock price movements over the entire day. And in order to establish a pattern of excess intraday volatility, empirical RVR estimates can be compared to corresponding values from a simulated distribution. The first row of Table 1.1 summarizes average monthly RVR values scaled by their simulated counterparts. A scaled RVR above (below) one indicates an excessively high (low) intraday volatility. The middle quintile value of 1.29 suggests that the median stock has exhibited excess intraday volatility over time on average; this value is significantly different from one at the $5 \%$ significance level. ${ }^{9}$ The highest and lowest quintile ratios of 1.48 and 1.14 , respectively, are also statistically significant.

Table 1.1 also reports stock-level characteristics by RVR quintile. At the end of each month, median stock characteristics are recorded within each RVR quintile, and the average of these monthly medians over the sample period are shown in the table. The higher quintile RVR stocks had lower stock prices but larger market capitalizations, more trad-

\footnotetext{
${ }^{9}$ Significance levels are determined based on simulated p-values from the Monte Carlo procedure described in the Appendix.
} 
ing volume, and narrower bid-ask spreads. In addition, these stocks tended to be less volatile, higher beta, growth-oriented, under-performing, and more heavily shorted. The higher beta with lower stock volatility pattern implies that higher RVR stocks are more correlated. While perhaps interpretable as greater systematic risk, this result is more likely consistent with previous findings of correlation across retail investor trades (Kumar and Lee, 2006 and Barber, Odean, and Zhu, 2009a). Since some of these patterns are possibly indicative of market microstructure effects or other empirical anomalies, these issues will be assessed in subsequent robustness tests. 
Table 1.1: Stock Characteristics by RVR Quintile (1992 - 2010)

This table reports stock characteristics of monthly RVR quintile portfolios for the period June 1992 through December 2010. At the end of each month, median stock characteristics are recorded within each quintile, and the average of these monthly medians over the sample period are reported in this table. Scaled RVR is the empirical range variance ratio divided its theoretical counterpart from a simulated Brownian motion (as described in the text). Price is stock price in dollars, size is market capitalization in millions of dollars, volume is millions of shares traded in a month, bid-ask spread is the average of end of day relative bid-ask spreads, stock volatility is annualized volatility from daily returns, betas are based on daily returns versus the CRSP value-weighted market, book-to-market is book equity divided by market equity, return $(-1,-12)$ is trailing twelve month return excluding the recent month, return $(0,-1)$ is recent one-month return, and short interest is the ratio of short interest divided by shares outstanding.

\begin{tabular}{rrrrrr}
\hline & Q1 & Q2 & Q3 & Q4 & Q5 \\
\hline Scaled RVR & 1.14 & 1.23 & 1.29 & 1.36 & 1.48 \\
Price & 22.81 & 22.81 & 22.29 & 21.26 & 18.74 \\
Size & 504 & 691 & 723 & 712 & 580 \\
Volume & 36 & 54 & 61 & 62 & 55 \\
Bid-Ask Spread & $1.3 \%$ & $1.0 \%$ & $1.0 \%$ & $1.0 \%$ & $1.1 \%$ \\
Stock Volatility & $42 \%$ & $42 \%$ & $41 \%$ & $40 \%$ & $38 \%$ \\
Beta & 0.97 & 1.08 & 1.11 & 1.11 & 1.09 \\
Book-to-Market & 0.50 & 0.44 & 0.42 & 0.41 & 0.41 \\
Return (-1,-12) & $15.0 \%$ & $16.0 \%$ & $16.0 \%$ & $15.7 \%$ & $14.7 \%$ \\
Return (0,-1) & $1.9 \%$ & $1.6 \%$ & $1.1 \%$ & $0.4 \%$ & $-0.6 \%$ \\
Short Interest & $1.5 \%$ & $1.9 \%$ & $2.0 \%$ & $2.1 \%$ & $2.0 \%$ \\
\hline
\end{tabular}

\subsubsection{Price Pressure}

Given that retail investors are net purchasers of attention-grabbing stocks, variables which capture increases in retail investor attention should correspond to positive price pressure followed by negative reversal (Barber and Odean (2008)). This implies that stocks with high RVR should exhibit positive short-term returns, followed by subsequent negative returns. To test these hypotheses, I run simple returns tests on portfolios of stocks formed 
on the basis of RVR.

Table 1.2 reports abnormal returns of monthly RVR quintile portfolios for the period June 1992 through December 2010. Returns are first reported in excess of the risk-free rate and then controlled for the Fama and French (1993) factors, the momentum factor (Carhart, 1997), and a liquidity factor (Pastor and Stambaugh, 2003). Results are shown both value-weighted (Panel A) and equal-weighted (Panel B). 
Table 1.2: Abnormal Returns (1992 - 2010)

This table reports abnormal returns of monthly RVR quintile portfolios for the period June 1992 through December 2010. At the end of each month, stocks are ranked in ascending order on the basis of RVR computed over that month. The ranked stocks are then assigned to one of five quintile portfolios, which are constructed either value-weighted (Panel A) or equal-weighted (Panel B). Excess returns are simply monthly returns in excess of the one-month Treasury bill rate. 3-factor alphas correspond to alphas from the Fama and French (1993) model. 4-factor alphas incrementally control for the momentum factor following Carhart (1997). 5-factor alphas further control for the Pastor and Stambaugh (2003) liquidity factor. Returns and alphas are shown in monthly percent, with t-statistics shown below in brackets.

Panel A: Value-weighted returns

\begin{tabular}{lrrrrrr}
\hline & Q1 & Q2 & Q3 & Q4 & Q5 & L/S \\
\hline Excess return & 0.30 & 0.40 & 0.44 & 0.71 & 0.76 & 0.46 \\
& {$[0.9]$} & {$[1.3]$} & {$[1.4]$} & {$[2.3]$} & {$[2.5]$} & {$[2.2]$} \\
3-factor alpha & -0.31 & -0.15 & -0.08 & 0.22 & 0.24 & 0.54 \\
& $-[2.1]$ & $-[2.0]$ & $-[1.1]$ & {$[2.7]$} & {$[2.4]$} & {$[2.6]$} \\
4-factor alpha & -0.26 & -0.17 & -0.10 & 0.19 & 0.24 & 0.50 \\
& $-[1.7]$ & $-[2.2]$ & $-[1.5]$ & {$[2.4]$} & {$[2.4]$} & {$[2.4]$} \\
5-factor alpha & -0.19 & -0.15 & -0.08 & 0.18 & 0.23 & 0.42 \\
& $-[1.2]$ & $-[1.9]$ & $-[1.2]$ & {$[2.1]$} & {$[2.3]$} & {$[2.0]$} \\
\hline
\end{tabular}

Panel B: Equal-weighted returns

\begin{tabular}{rrrrrrr}
\hline & $\mathrm{Q} 1$ & $\mathrm{Q} 2$ & $\mathrm{Q} 3$ & $\mathrm{Q} 4$ & $\mathrm{Q} 5$ & $\mathrm{~L} / \mathrm{S}$ \\
\hline \multirow{2}{*}{ Excess return } & 0.53 & 0.63 & 0.76 & 0.84 & 0.99 & 0.46 \\
& {$[1.6]$} & {$[1.6]$} & {$[1.9]$} & {$[2.0]$} & {$[2.3]$} & {$[2.2]$} \\
3-factor alpha & -0.32 & -0.21 & -0.07 & 0.03 & 0.20 & 0.52 \\
& $-[3.7]$ & $-[3.1]$ & $-[1.0]$ & {$[0.4]$} & {$[1.7]$} & {$[3.7]$} \\
4-factor alpha & -0.26 & -0.15 & 0.00 & 0.12 & 0.33 & 0.59 \\
& $-[3.1]$ & $-[2.3]$ & {$[0.1]$} & {$[1.7]$} & {$[3.1]$} & {$[4.2]$} \\
5-factor alpha & -0.25 & -0.15 & 0.01 & 0.11 & 0.32 & 0.57 \\
& $-[3.0]$ & $-[2.3]$ & {$[0.1]$} & {$[1.5]$} & {$[2.9]$} & {$[4.0]$} \\
\hline
\end{tabular}


Going down the rows for both the value-weighted and equal-weighted panels shows a monotonic relationship of returns increasing in RVR. In Panel A, we can observe that the highest quintile returns are statistically significant with t-statistics ranging between 2.3 and 2.5. These returns in fact drive the long-short portfolio quintile spread returns shown in the last column, which range from a 42 to 54 basis point monthly alpha with t-statistics between 2.0 and 2.6. Note that while the bottom quintile portfolio risk-adjusted returns are negative, they are not always statistically significant. However, the short side does contribute significantly to the quintile spread returns for the equal-weighted results in Panel B. Decile portfolio results hold similarly and are shown in Table 4.1.

It is important to determine whether these abnormal returns persist or reverse in subsequent months. The former would suggest that RVR reflects either a cross-sectional mispricing or a risk premium, whereas the latter would be consistent with temporary price pressure. Table 1.3 examines this issue by looking at cumulative average abnormal returns over the subsequent twelve months for each of the equal-weighted quintile portfolios. Recall that the quintile spread four-factor alpha was 59 basis points in the first month following portfolio formation. Over the next three months, this spread falls by 63 basis points as shown in the table. While not shown the cumulative abnormal return including the first month ceases to be significant by this point as the abnormal return has entirely reversed. Over the course of the next nine months, the spread falls another 76 basis points (or about 8 basis points per month) but this is not statistically significant. Note that alphas across rows are not directly comparable. For instance, the first-month alpha was 59 basis points, whereas the next twelve-month average monthly alpha is only -12 basis points (that is, 139 basis points divided by 12 months). 
Table 1.3: Reversal in Abnormal Returns (1992 - 2010)

This table reports average cumulative abnormal returns over the subsequent $m$ months (i.e., from $t+1$ to $\mathrm{t}+\mathrm{m}+1$ ) for equal-weighted quintile portfolios formed monthly on RVR for the period June 1992 through December 2010. Abnormal returns are calculated based on the four-factor model of Carhart (1997). Alphas are shown in cumulative m-month percentage terms, with t-statistics shown below in brackets using NeweyWest standard errors with m lags.

\begin{tabular}{rrrrrrr}
\hline Month & Q1 & Q2 & Q3 & Q4 & Q5 & L/S \\
\hline \multirow{2}{*}{1} & 0.05 & 0.00 & 0.01 & 0.01 & 0.00 & -0.04 \\
& {$[0.6]$} & {$[0.0]$} & {$[0.1]$} & {$[0.2]$} & {$[0.0]$} & $-[0.3]$ \\
2 & 0.18 & -0.05 & 0.03 & 0.00 & -0.04 & -0.22 \\
& {$[1.2]$} & $-[0.5]$ & {$[0.2]$} & {$[0.0]$} & $-[0.3]$ & $-[1.0]$ \\
3 & 0.41 & 0.00 & 0.07 & -0.17 & -0.22 & -0.63 \\
& {$[1.7]$} & {$[0.0]$} & {$[0.5]$} & $-[1.1]$ & $-[1.0]$ & $-[1.8]$ \\
6 & 0.56 & -0.04 & -0.12 & -0.36 & -0.64 & -1.21 \\
& {$[1.2]$} & $-[0.1]$ & $-[0.5]$ & $-[1.3]$ & $-[1.6]$ & $-[1.7]$ \\
9 & 0.66 & -0.05 & -0.05 & -0.58 & -0.77 & -1.43 \\
& {$[1.1]$} & $-[0.2]$ & $-[0.1]$ & $-[1.6]$ & $-[1.4]$ & $-[1.7]$ \\
12 & 0.69 & -0.09 & 0.07 & -0.53 & -0.70 & -1.39 \\
& {$[1.1]$} & $-[0.2]$ & {$[0.1]$} & $-[1.1]$ & $-[0.9]$ & $-[1.4]$ \\
\hline
\end{tabular}

\subsubsection{Time-series of Retail Trading Activity}

I propose both time-series and cross-sectional tests to assess whether RVR is related to retail investor trading activity. In the time-series, I examine whether RVR is associated with aggregate transaction activity at two large retail brokerage firms, Charles Schwab and E TRADE. I first take quarterly retail transaction activity for each of these brokerage firms and divide it by quarterly CRSP stock volume aggregated across all stocks. I then normalize this measure by its sample mean and standard deviation. When retail trading activity is a larger (smaller) proportion of stock market volume, this normalized measure should be higher (lower). 
In Table 1.4, I regress quarterly RVR returns onto this normalized retail transaction activity measure (labeled Retail in the table), as well as the four-factor model components. A positive slope coefficient on Retail would indicate that high RVR returns, or temporary cross-sectional price pressure, is associated with greater retail trading. This is what we find in the second row of the table, which reports that the Retail coefficients are positive for Schwab, E TRADE, and Combined, with t-statistics ranging from 1.91 to 2.07.

Table 1.4: Retail Trading Activity in the Time-Series (1993 - 2010)

This table reports quarterly time-series regressions of RVR quintile spread returns onto proxies for retail trading activity for the period January 1993 through December 2010. The Schwab and E TRADE columns indicate that the Retail variable corresponds to quarterly transaction activity at that brokerage firm divided by total quarterly CRSP volume across all stocks, normalized by its sample mean and standard deviation. Retail transactions per quarter were obtained by parsing each firm's 10K's and 10Q's. The Column column's Retail variable reflects the sum of quarterly transaction activity at both Schwab and E TRADE. Coefficients are reported, with t-statistics shown below in brackets.

\begin{tabular}{rrrr}
\hline & Schwab & E TRADE & Combined \\
\hline Intercept & $1.7 \%$ & $1.7 \%$ & $1.7 \%$ \\
& {$[2.30]$} & {$[1.95]$} & {$[2.25]$} \\
Retail & 0.01 & 0.02 & 0.01 \\
& {$[2.07]$} & {$[1.91]$} & {$[1.95]$} \\
RMRF & -0.01 & 0.02 & 0.02 \\
& $-[0.14]$ & {$[0.20]$} & {$[0.17]$} \\
SMB & -0.06 & -0.11 & -0.09 \\
& $-[0.49]$ & $-[0.83]$ & $-[0.82]$ \\
HML & -0.16 & -0.19 & -0.17 \\
& $-[1.34]$ & $-[1.43]$ & $-[1.40]$ \\
UMD & -0.06 & -0.04 & -0.04 \\
& $-[0.71]$ & $-[0.49]$ & $-[0.47]$ \\
R-squared & 0.01 & 0.00 & 0.00 \\
\hline
\end{tabular}




\subsubsection{Cross-section of Retail Trading Activity}

To test whether RVR can be linked to retail trading activity in the cross-section of stocks, I use actual retail investor trades from the Barber and Odean (2000) dataset for the period 1992 and 1996. As discussed in the data section, I constructed four variables which reflect aggregate retail investor buying, selling, both buying and selling, and net buying of a given stock within a given month. If RVR is indeed related to retail investor trading activity, then stocks with higher RVR values should be associated with both greater buying as well as greater selling activity.

In Table 1.5, I show regressions of each of these retail trading measures onto stocklevel characteristics, including size, book-to-market, momentum over the past month and year, and RVR. The first, second, third, and fourth columns in the table correspond to buys, sells, both (i.e., buys plus sells), and net (i.e., buys minus sells), respectively. The regressions indicate that retail trading is concentrated among smaller market capitalization, growth-oriented stocks, with higher recent returns, and importantly higher range variance ratios. As shown in the bottom row, RVR is statistically significant for buys, sells, both, and net, providing strong evidence that RVR is related to stock-level retail trading. The fact that RVR reflects retail investor buying more so than selling is consistent with the finding in Barber, Odean, and Zhu (2009) that buying is more concentrated in fewer stocks than selling. 
Table 1.5: Retail Trading Activity in the Cross-Section (1992 - 1996)

This table reports monthly panel regressions of retail investor buys and sells onto stock-level characteristics for the period June 1992 through December 1996. Buys and sells are the sum of monthly buying and selling across all retail investors at a large brokerage firm using the data of Barber and Odean (2000). Columns 1, 2, 3, and 4 report regressions of buys, sells, buys plus sells, and buys minus sells, respectively, each divided by shares outstanding. Coefficients are reported, with t-statistics shown below in brackets. Standard errors are clustered both by month and by stock.

\begin{tabular}{crrrr}
\hline & $(1)$ & $(2)$ & $(3)$ & $(4)$ \\
\hline Intercept & 0.39 & 0.38 & 0.77 & 0.01 \\
& {$[21.2]$} & {$[22.3]$} & {$[22.3]$} & {$[1.7]$} \\
Log Size & -0.03 & -0.03 & -0.06 & 0.00 \\
& $-[59.8]$ & $-[61.6]$ & $-[69.4]$ & $-[3.4]$ \\
Log BM & -0.01 & -0.01 & -0.02 & -0.01 \\
& $-[2.7]$ & $-[1.6]$ & $-[2.3]$ & $-[1.7]$ \\
Ret (-12,-1) & 0.05 & 0.05 & 0.11 & 0.00 \\
& {$[15.1]$} & {$[17.1]$} & {$[17.3]$} & $-[1.4]$ \\
Ret (-1,0) & 0.08 & 0.14 & 0.22 & -0.06 \\
& {$[6.8]$} & {$[11.9]$} & {$[10.1]$} & $-[7.3]$ \\
RVR & 0.05 & 0.04 & 0.09 & 0.01 \\
& {$[4.3]$} & {$[3.9]$} & {$[4.1]$} & {$[2.5]$} \\
R-squared & 0.05 & 0.05 & 0.06 & 0.00 \\
\hline
\end{tabular}

\subsection{Robustness Tests}

\subsubsection{Lags and Exchange Effects}

In this section, I test the robustness of the price pressure findings to trading implementation assumptions. I first consider the effects of trading delays by incorporating lags of up to two full days. In addition, I measure price pressure effects separately across both the NYSE and Nasdaq exchanges. One might suspect that there exist relevant structural 
differences across these exchanges such as in the behavior of intraday volatility among Nasdaq stocks during the tech bubble.

Table 1.6 provides empirical tests which report the sensitivity of the main results to trading implementation lags and specific exchange effects. The base case row contains the simple equal-weighted RVR spread portfolio, which as shown before earns a significant 59 basis point four-factor alpha within the first month. The subsequent rows show abnormal returns for the same portfolio but constructed with a lag. Incorporating lags of one and two days yield long-short quintile alphas of 59 and 65 basis points, respectively, each with tstatistics above 4 . These significant alphas thus suggest that the main results are unaffected by the immediacy of the trading strategy.

The bottom rows of Table 1.6 investigate whether the RVR spread returns are related to an exchange-specific phenomenon. Upon forming quintile portfolios on RVR within universes of just NYSE and just Nasdaq listed stocks, I find statistically significant alphas of 44 and 64 basis points, respectively. This slightly stronger alpha among Nasdaq stocks seems likely to be related to more active trading of technology stocks by retail investors during the tech bubble. 
Table 1.6: Robustness to Lags and Exchange Effects (1992 - 2010)

This table reports the robustness of RVR quintile spread abnormal returns to trading lags and exchange effects for the period June 1992 through December 2010. Abnormal returns are calculated based on the four-factor model of Carhart (1997). The Base Case row corresponds to monthly rebalanced equal-weighted quintile portfolios. The Lag 1 day and Lag 2 day rows impose 1 and 2 day trading implementation lags, respectively. The NYSE Only and Nasdaq Only rows form portfolios on just NYSE and Nasdaq stocks, respectively. Alphas are shown in monthly percent, with t-statistics shown below in brackets.

\begin{tabular}{rrrrrrr}
\hline & Q1 & Q2 & Q3 & Q4 & Q5 & L/S \\
\hline Base Case & -0.26 & -0.15 & 0.00 & 0.12 & 0.33 & 0.59 \\
& $-[3.1]$ & $-[2.3]$ & {$[0.1]$} & {$[1.7]$} & {$[3.1]$} & {$[4.2]$} \\
Lag 1 day & -0.23 & -0.12 & 0.00 & 0.14 & 0.36 & 0.59 \\
& $-[1.6]$ & $-[0.9]$ & {$[0.0]$} & {$[1.0]$} & {$[2.2]$} & {$[4.0]$} \\
Lag 2 days & -0.37 & -0.19 & -0.15 & -0.01 & 0.29 & 0.65 \\
& $-[2.1]$ & $-[1.1]$ & $-[1.0]$ & {$[0.0]$} & {$[1.7]$} & {$[4.5]$} \\
NYSE Only & -0.19 & 0.08 & 0.11 & 0.19 & 0.25 & 0.44 \\
& $-[1.6]$ & {$[0.7]$} & {$[1.1]$} & {$[1.8]$} & {$[2.4]$} & {$[3.7]$} \\
Nasdaq Only & -0.31 & -0.23 & -0.07 & 0.17 & 0.32 & 0.64 \\
& $-[3.1]$ & $-[2.7]$ & $-[0.7]$ & {$[1.3]$} & {$[2.1]$} & {$[3.9]$} \\
\hline
\end{tabular}

\subsubsection{Liquidity and Market Microstructure}

The universe of firms included in the sample was originally screened with standard filters to exclude very small and illiquid stocks. However, liquidity and market microstructure effects are still reasonable concerns since the universe filtering procedure was certainly not comprehensive. To see whether these issues are related to or perhaps even generate the temporary price pressure observed in higher RVR stocks, I estimate RVR quintile spread returns while conditioning on various stock-level proxies for liquidity and market microstructure.

Table 1.7 reports abnormal quintile returns of RVR portfolios formed within terciles of size, volume, turnover, bid-ask spread, and illiquidity. This procedure provides a more 
specific universe filter in examining the significance of the RVR returns. All returns shown are adjusted for the four-factor model, and the rightmost column in each panel contains the significance of quintile long-short portfolios. As shown in Panel A, the one-month quintile spread return is 56 basis points for the smallest third of stocks, 70 basis points for the middle third, and 58 basis points for the largest third, all of which are statistically significant. Hence, these results suggest that short-term retail price pressure exists even within a universe of very large market capitalization stocks.

The same holds true in Panels B through E of Table 1.7. That is, the RVR spread return is not concentrated in illiquid stocks based on a few different measures of liquidity. For instance, among stocks with the lowest trading volume as shown in Panel B, the RVR spread alpha remains a significant 51 basis points. Even among stocks with the widest bid-ask spreads, the RVR long-short alpha is a significant 55 basis points. The same holds true for stocks with the largest price impact of trades as proxied for by Amihud (2002) ILLIQ measure.

Table 1.7: Robustness to Liquidity and Microstructure Variables (1992 - 2010)

This table reports the robustness of RVR quintile spread abnormal returns to liquidity and microstructure variables for the period June 1992 through December 2010. Abnormal returns are calculated based on the four-factor model of Carhart (1997). In each of the panels below, equal-weighted quintile portfolios are formed on RVR within terciles of the specified stock-level variables. Size is simply market capitalization, volume is total dollar trading volume over the past month, bid-ask spread is based on end of day averages over the past month, and ILLIQ is the Amihud (2002) measure of illiquidity. Alphas are shown in monthly percent, with t-statistics shown below in brackets.

Panel A: Size

\begin{tabular}{rrrrrrr}
\hline & Q1 & Q2 & Q3 & Q4 & Q5 & L/S \\
\hline Lower & -0.23 & -0.21 & 0.05 & 0.23 & 0.33 & 0.56 \\
& $-[2.0]$ & $-[2.1]$ & {$[0.4]$} & {$[1.9]$} & {$[1.9]$} & {$[2.9]$} \\
Middle & -0.27 & -0.17 & -0.02 & 0.09 & 0.43 & 0.70 \\
& $-[2.3]$ & $-[1.8]$ & $-[0.2]$ & {$[0.8]$} & {$[3.4]$} & {$[4.3]$} \\
Upper & -0.25 & -0.17 & -0.04 & 0.11 & 0.33 & 0.58
\end{tabular}


Table 1.7 (Continued)

$-[2.3] \quad-[2.2] \quad-[0.6] \quad[1.4] \quad[3.6] \quad[3.9]$

Panel B: Volume

\begin{tabular}{rrrrrrr}
\hline & Q1 & Q2 & Q3 & Q4 & Q5 & L/S \\
\hline Lower & -0.27 & -0.14 & -0.13 & 0.18 & 0.24 & 0.51 \\
& $-[2.3]$ & $-[1.2]$ & $-[1.1]$ & {$[1.5]$} & {$[1.6]$} & {$[3.1]$} \\
Middle & -0.23 & -0.06 & 0.05 & 0.13 & 0.51 & 0.74 \\
& $-[2.0]$ & $-[0.5]$ & {$[0.5]$} & {$[1.2]$} & {$[3.5]$} & {$[4.1]$} \\
Upper & -0.27 & -0.23 & -0.01 & 0.06 & 0.36 & 0.64 \\
& $-[2.4]$ & $-[2.2]$ & $-[0.1]$ & {$[0.6]$} & {$[3.2]$} & {$[3.8]$} \\
& \multicolumn{7}{c}{ Panel C: Turnover } \\
\hline
\end{tabular}

\begin{tabular}{ccccccc}
\hline & Q1 & Q2 & Q3 & Q4 & Q5 & L/S \\
\hline Lower & -0.17 & -0.08 & 0.03 & 0.07 & 0.23 & 0.39 \\
& $-[1.4]$ & $-[0.7]$ & {$[0.2]$} & {$[0.6]$} & {$[2.1]$} & {$[3.5]$} \\
Middle & -0.18 & -0.04 & -0.04 & 0.11 & 0.26 & 0.44 \\
& $-[1.5]$ & $-[0.4]$ & $-[0.4]$ & {$[1.2]$} & {$[2.5]$} & {$[3.5]$} \\
Upper & -0.17 & -0.19 & -0.16 & 0.06 & 0.42 & 0.59 \\
& $-[1.1]$ & $-[1.2]$ & $-[1.1]$ & {$[0.4]$} & {$[2.6]$} & {$[3.0]$} \\
& \multicolumn{7}{c}{ Panel D: Bid-Ask } & Spread & & \\
\hline \multirow{2}{*}{ Lower } & -0.13 & 0.01 & 0.05 & 0.18 & 0.44 & 0.57 \\
& $-[1.3]$ & {$[0.1]$} & {$[0.4]$} & {$[1.6]$} & {$[3.3]$} & {$[4.0]$} \\
Middle & -0.24 & -0.14 & 0.09 & 0.17 & 0.34 & 0.58 \\
& $-[2.1]$ & $-[1.4]$ & {$[0.9]$} & {$[1.5]$} & {$[2.6]$} & {$[3.3]$} \\
Upper & -0.31 & -0.32 & -0.14 & 0.06 & 0.24 & 0.55 \\
& $-[2.5]$ & $-[2.4]$ & $-[1.0]$ & {$[0.4]$} & {$[1.5]$} & {$[3.1]$} \\
& \multicolumn{7}{c}{ Panel E: ILLIQ } & Q3 & Q4 & Q5 & L/S \\
\hline \multirow{2}{*}{ Lower } & -0.10 & -0.01 & 0.08 & 0.18 & 0.36 & 0.46 \\
& $-[1.0]$ & $-[0.1]$ & {$[1.0]$} & {$[2.2]$} & {$[3.8]$} & {$[3.8]$} \\
Middle & -0.20 & -0.09 & -0.03 & 0.16 & 0.48 & 0.68 \\
\hline
\end{tabular}


Table 1.7 (Continued)

$\begin{array}{ccccccc} & -[1.7] & -[0.8] & -[0.4] & {[1.5]} & {[4.1]} & {[4.4]} \\ \text { Upper } & -0.32 & -0.50 & -0.10 & 0.07 & 0.23 & 0.55 \\ & -[3.1] & -[4.7] & -[0.8] & {[0.5]} & {[1.3]} & {[2.8]}\end{array}$

\subsubsection{Relation to Other Anomalies}

I next examine whether RVR spread returns are related to other anomalies documented in the literature. One might suspect that the temporary abnormal RVR returns are associated with or caused by factors driving other known anomalies. For instance, the stock-level characteristics shown in Table 1.1 suggested that stocks with higher RVRs tended to be less volatile stocks with poorer recent performance. To measure the sensitivity of RVR returns to other anomalies, I consider two approaches. First, I measure RVR spread portfolio returns within terciles of stock-level variables corresponding to different anomalies. Second, I measure returns for portfolios sorted on the residual of RVR to stock-level variables instead of on RVR itself.

Table 1.8 reports four-factor model alphas and t-statistics for RVR spread portfolios formed within terciles of several stock-level characteristics associated with empirical anomalies. In Panel A, I find that quintile spread portfolio returns are significant across value through growth stocks. However, the returns are perhaps more significant for value stocks ( 89 basis points) than for growth stocks (46 basis points). Panels B and C also show significant spread returns across stocks based on their exposures to the momentum and reversal anomalies identified based on past twelve-month returns (excluding the recent month) and past one-month returns, respectively. Nonetheless, spread returns are larger for stocks with poor performance both over the past year and over the recent one month. Panel D reports significant RVR spread returns across low, medium, and high volatility stocks. The effect appears to be stronger among higher volatility stocks (72 basis points) than lower volatility stocks (24 basis points), although both are statistically significant. 
Table 1.8: Relation to Other Anomalies (1992 - 2010)

This table reports the relation of RVR quintile spread abnormal returns to other anomalies for the period June 1992 through December 2010. Abnormal returns are calculated based on the four-factor model Carhart (1997). In each of the panels, equal-weighted quintile portfolios are formed on RVR within terciles of the specified stock-level variables. Value is book-to-market, momentum is past twelve-month return (excluding the last month), reversal is past one-month return, and volatility is daily return volatility over the past month. Alphas are shown in monthly percent, with t-statistics shown below in brackets.

\begin{tabular}{|c|c|c|c|c|c|c|}
\hline \multicolumn{7}{|c|}{ Panel A: Value } \\
\hline & Q1 & Q2 & Q3 & Q4 & Q5 & $\mathrm{L} / \mathrm{S}$ \\
\hline \multirow[t]{2}{*}{ Lower } & -0.43 & -0.57 & -0.29 & -0.13 & 0.03 & 0.46 \\
\hline & $-[4.0]$ & $-[5.0]$ & $-[2.8]$ & $-[1.2]$ & {$[0.3]$} & [2.9] \\
\hline \multirow[t]{2}{*}{ Middle } & -0.33 & -0.17 & 0.05 & 0.07 & 0.22 & 0.55 \\
\hline & $-[3.1]$ & $-[1.7]$ & {$[0.5]$} & {$[0.7]$} & [1.9] & {$[4.0]$} \\
\hline \multirow[t]{4}{*}{ Upper } & -0.07 & 0.17 & 0.28 & 0.48 & 0.81 & 0.89 \\
\hline & $-[0.7]$ & [1.6] & {$[2.8]$} & [3.9] & [5.9] & {$[5.2]$} \\
\hline & \multicolumn{6}{|c|}{ Panel B: Momentum } \\
\hline & Q1 & Q2 & Q3 & Q4 & Q5 & $\mathrm{L} / \mathrm{S}$ \\
\hline \multirow[t]{2}{*}{ Lower } & -0.28 & -0.03 & 0.13 & 0.49 & 0.71 & 0.98 \\
\hline & $-[2.3]$ & $-[0.2]$ & [1.1] & {$[3.5]$} & [4.7] & [5.9] \\
\hline \multirow[t]{2}{*}{ Middle } & -0.07 & -0.12 & -0.02 & 0.11 & 0.16 & 0.23 \\
\hline & $-[0.6]$ & $-[1.1]$ & $-[0.2]$ & {$[1.2]$} & [1.6] & {$[2.0]$} \\
\hline \multirow[t]{4}{*}{ Upper } & -0.21 & -0.15 & -0.09 & 0.06 & 0.25 & 0.46 \\
\hline & $-[2.2]$ & $-[1.4]$ & $-[0.8]$ & {$[0.6]$} & {$[2.0]$} & [2.9] \\
\hline & \multicolumn{6}{|c|}{ Panel C: Reversal } \\
\hline & Q1 & Q2 & Q3 & Q4 & Q5 & $\mathrm{L} / \mathrm{S}$ \\
\hline \multirow[t]{2}{*}{ Lower } & -0.26 & -0.12 & -0.10 & 0.25 & 0.47 & 0.73 \\
\hline & $-[1.5]$ & $-[0.6]$ & $-[0.5]$ & {$[1.2]$} & [2.1] & [3.9] \\
\hline \multirow[t]{2}{*}{ Middle } & -0.06 & -0.07 & 0.12 & 0.19 & 0.24 & 0.30 \\
\hline & $-[0.6]$ & $-[0.8]$ & [1.4] & [2.2] & [2.3] & [2.4] \\
\hline \multirow[t]{2}{*}{ Upper } & -0.37 & -0.17 & -0.11 & 0.03 & 0.14 & 0.51 \\
\hline & $-[2.8]$ & $-[1.0]$ & $-[0.7]$ & {$[0.2]$} & [0.9] & {$[3.2]$} \\
\hline
\end{tabular}


Table 1.8 (Continued)

Panel D: Volatility

\begin{tabular}{rrrrrrr}
\hline & Q1 & Q2 & Q3 & Q4 & Q5 & L/S \\
\hline \multirow{2}{*}{ Lower } & 0.16 & 0.20 & 0.16 & 0.26 & 0.40 & 0.24 \\
& {$[1.4]$} & {$[1.8]$} & {$[1.4]$} & {$[2.3]$} & {$[3.3]$} & {$[2.8]$} \\
Middle & -0.07 & 0.08 & 0.11 & 0.27 & 0.34 & 0.41 \\
& $-[0.6]$ & {$[0.8]$} & {$[1.1]$} & {$[2.9]$} & {$[3.1]$} & {$[2.8]$} \\
Upper & -0.62 & -0.64 & -0.35 & -0.18 & 0.10 & 0.72 \\
& $-[4.6]$ & $-[4.6]$ & $-[2.2]$ & $-[1.1]$ & {$[0.5]$} & {$[3.3]$}
\end{tabular}

Next, I look at the performance of portfolios formed on residual RVR instead of just RVR in Table 4.2. First, I regress RVR onto several variables including log size, log bookto-market, past twelve-month return (excluding the recent month), past one-month return, stock return volatility, and turnover as follows:

$$
R V R_{i, t}=\sum_{f=1}^{F} \beta_{f} X_{f, i, t}+\epsilon_{i, t}
$$

where $X_{f, i, t}$ denotes the stock $i$ value corresponding to factor $f$ (e.g., log size). Then, I form monthly equal-weighted quintile portfolios on the residuals $\epsilon_{i, t}$ and compute the time-series of their returns. Value-weighted portfolio results are shown in Panel A, and equal-weighted results are shown in Panel B. The final two rows in Panel B report four and five factor alphas of 41 and 43 basis points, respectively. While these alphas are slightly lower than the 59 and 57 basis point equivalents from Table 1.2, they are each statistically significant with t-statistics well above 3 . The cumulative returns for the RVR and residual RVR quintile spread portfolios are shown in Figure 4.1.

Overall, these results suggest that while stocks with higher RVR tend to have certain characteristics which resemble other known anomalies (e.g., momentum or volatility), the abnormal returns associated with the RVR variable are distinct from these other anomalies. The returns cannot be explained away by either the universe of stocks chosen or the orthogonal component of RVR. 


\subsection{Conclusion}

This paper finds that stock prices demonstrate excess intraday volatility, that this excess volatility is generated by retail investor trading activity, and finally that this trading activity generates short-term price pressure in stock returns. Importantly, all of these findings are attained using a simple econometric measure which compares volatility based on high and low prices to volatility based on open and close prices.

The findings presented in this paper suggest other interesting avenues for further research. One could use RVR to examine intraday volatility in other markets or asset classes. For instance, one might consider investigating the Taiwanese stock market since it consists of heavy retail trading activity, with a large proportion of day traders in particular. Or perhaps one might study certain commodities markets that contain significant amounts of uninformed trading.

An interesting pattern identified in this paper is that excess intraday stock volatility has been steadily increasing over time. A possible explanation for this pattern perhaps relates to the growth in high-frequency trading. Given their comparative advantages in terms of technology and execution, one could imagine that this group of traders consistently capitalizes on trades at intraday high and low prices. The important question then is whether such traders engage in systematic strategies to effectively inflate intraday volatility which could translate into greater trading profits. 


\section{Chapter 2}

\section{How Tax and Interest Rates Drive Stock Returns at the Turn of the Tax Year}

\subsection{Introduction}

Previous research has argued that a tax-motivated seller should sell losers early and hold on to winners under the assumption that tax-selling behavior does not create distortions in market prices (Constantinides $(1983,1984)$ ). However, recent research has argued that such tax-selling behavior at the turn of the year does generate seasonality in the crosssection of stock returns, whose magnitude depends on the level of the capital gains tax rate (in particular, Poterba and Weisbenner (2001) and Grinblatt and Moskowitz (2004)). We build on these results and show that (because interest rates determine the present value of the tax gain/loss) the impact of tax-motivated selling also depends on the level of interest rates. In the presence of downward sloping demand curves for stocks and limits to arbitrage, both interest rates and capital gains tax rates drive the extent to which past losers trade at a temporary low price at the end of the year.

Our framework suggests that the magnitude of the January rebound return because of tax-loss selling at the end of the year should vary both in the cross-section and in the time- 
series. The cross-section of average January returns should vary with a stock's capital gains overhang, defined as the ratio of the cumulative gain since the stock's purchase to its current price. ${ }^{1}$ For a given level of capital gains overhang, time-series variation in the January rebound return should depend on macroeconomic variables: the capital gains tax rate (which determines the magnitude of the tax payment or credit) and the interest rate (which drives the personal benefit/cost of delaying that tax payment/credit). In particular, we link the interest-rate component of this time-series variation to the one-year interest rate since the decision to delay the sale of the stock from the last trading day of December to the first trading day of January results in the delay of any tax benefit/cost by one year. Rather than file and receive the tax credit in early January, the investor must wait a year to capture the tax savings.

In summary, while previous literature has shown that variation in capital gains tax rates appears to forecast variation in the degree of selling pressure for loser stocks, we argue that variation in interest rates is at least as important. ${ }^{2}$ We first provide an exact formulation for the way these two rates drive the stock return seasonal caused by tax-motivated selling. We then show that this formulation does a good job describing relevant aspects of the data.

The following example clarifies the intuition behind our idea. Suppose a taxable investor in the $30 \%$ tax bracket bought a stock at $\$ 100$ several years ago. The stock has declined in value since this purchase and is currently trading at $\$ 4$. Selling the stock at $\$ 4$ on the last trading day of December would generate a capital loss of $\$ 96$ and offer a tax deduction of $\$ 28.80(30 \% * \$ 96)$. Thus, proceeds total $\$ 32.80$ : $\$ 28.80$ from the tax deduction and $\$ 4$ from the stock sale.

\footnotetext{
${ }^{1}$ The terminology capital gains overhang is standard in this literature (see for example Grinblatt and Han (2005)).

${ }^{2}$ In our formulation, the tax-selling premium is the amount of January rebound return for a unit spread in capital gains overhang and is a function of interest rates and tax rates. Variation in this premium is primarily due to interest rates. If one were to fix interest rates at their average level over the sample, only allowing tax rates to vary, the resulting variation in the tax-selling premium is roughly one-third of the variation in the premium we document.
} 
Alternatively, the investor could wait to sell the stock on the first trading day in January. The decision to wait provides January sales proceeds of $\$ 4$ (ignoring the small discounting across the turn of the year), but now the tax benefit will not occur until one year later and thus must be discounted by the one-year rate relevant to this investor, here assumed to be $5 \%$. The total present value of the proceeds from waiting until January now equals $\$ 31.43$ : $\$ 4$ due to the sale and $\$ 27.43$ due to the present value of the tax benefit (30\%*\$96/1.05). Waiting to sell the stock on the first trading day in January results in a loss of $\$ 1.37$ in present value due to the deferral of the tax savings by one year. This analysis makes it clear that the investor would be willing to sell the stock below the $\$ 4$ fair value in December, but only to a certain limit.

Assuming that the beginning-of-January price remains at the fair value of $\$ 4$, what December price, $P$, would make the investor indifferent between selling in December versus January? To be indifferent, the proceeds of the sale at the end of the year, $P$ $30 \% *(P-\$ 100)$, must equal the present value of the proceeds from selling the stock at the beginning of next year $\$ 4-30 \% *(\$ 4-\$ 100) / 1.05$. By equating these two values, one finds that the stock can sell as low as $\$ 2.04$ implying a $\$ 1.96$ discount relative to its fair value. This lower bound limits the extent to which price pressure can drive the stock price down in December and thus limits the magnitude of the January rebound. This lower bound depends on interest rates and capital gains tax rates in addition to the level of the capital loss. Below \$2.04, the investor delays selling the stock, at $\$ 2.04$ the investor is indifferent, and anywhere above $\$ 2.04$ the investor is better off selling now rather than waiting. In Section 2.1 we derive an explicit formula based on this example. The formula shows a stock's January rebound return depends on that stock's December capital gains overhang as well as interest and tax rates.

The example above highlights the importance of interest rates in the decision process. Suppose that the interest rate in the previous example were zero. Since there would be no benefit for accelerating the tax benefit to occur this year rather than the next, the solution for $P$ is clearly $\$ 4$. More generally, at very low interest rates, a rational tax-motivated 
seller tolerates very little mispricing.

We take these predictions to the data. We create a proxy for a stock's capital gains overhang following the methodology of Grinblatt and Han (2005). Specifically, we use past volume to weight past prices in order to create a proxy for a stock's tax basis and therefore the capital gains overhang of the marginal seller of the stock. Just as the example above suggests, we show that the ability of this variable to describe cross-sectional variation in average returns at the turn of the year is a function of interest rates and tax rates, which we dub the tax-selling premium. This predictability is robust to including controls for various firm characteristics (size, book-to-market, trading volume, and past return patterns) in our regression analysis.

We carefully explore the nature of this documented cross-sectional and time-series variation in expected returns to show that it is consistent with our economic explanation. We find that the majority of the effect occurs in the days surrounding the turn of the year, but this effect is also present on a smaller scale during the entire month of December and even earlier. Though we primarily analyze U.S. data, we also find similar time-series and cross-sectional variation in expected returns in U.K. data during the turn of that country's tax year. ${ }^{3}$ As the U.K. tax year ends in April, we argue that these international results provide strong evidence that our U.S. findings are consistent with a tax-selling explanation. ${ }^{4}$

Moreover, we document that this phenomenon shows up in the trading volume of individual investors. We examine the trading behavior of individual investors using two different methods. First, using the TAQ database, we find that stocks with low capital gains overhang have more selling pressure at the turn of the year than stocks with high capital gains overhang and that this imbalance varies as a function of our tax-selling premium. Our second method directly measures investors' propensity to sell using the actual

\footnotetext{
${ }^{3}$ Reinganum and Shapiro (1987) show that after the introduction of capital gains taxes in the U.K., the difference in April returns between winners and losers becomes significantly greater than zero, consistent with a tax-loss selling story. Our empirical contribution is to show that this premium varies with the interest rate as predicted by our formulation.
}

${ }^{4}$ We thank the editor, Cam Harvey, for this suggestion. 
trades from the large discount brokerage studied in Odean (1998). We show that not only are investors more likely to harvest capital losses before the turn of the year but also this tendency to accelerate the realization of capital losses is much stronger in the years where interest rates and tax rates are high.

Since these firm-level findings make us confident that the tax-based pricing model is a useful description of average returns at the turn of the year, we then examine the way that tax-based cross-sectional and time-series variation in expected returns affects standard monthly performance attribution regressions. We first show that tax-loss selling effects are also present at the aggregate level. Specifically, we document that the return on the market portfolio in January has a similar predictable component that is a function of interest rates, tax rates, and the market's capital gains overhang. Since this is the case, one might expect that measures of risk can be driven by cross-sectional variation in the covariance of firm-level and market capital gains overhang. We confirm that our tax-selling variables drive the alpha and market beta of a long-short overhang portfolio. Moreover, similar predictable patterns can be found in the Fama-French (1993) and Carhart (1997) factors. These findings have important implications for researchers examining economic stories describing time-variation in the risks and returns of these factors. ${ }^{5}$

In short, our empirical results are consistent with the view that tax-motivated selling in the presence of downward-sloping demand curves results in stock return seasonality (a turn-of-the-tax-year effect) where the extent of the resulting price pressure depends on the level of interest rates and capital gains tax rates. Consequently, our results have a practical implication for those trying to exploit the January effect, as we show that the magnitude of the anomaly should and does vary over time. In years when capital gains overhang is limited, capital gains tax rates are low, and interest rates are also low, one should not expect a large January effect.

\footnotetext{
${ }^{5}$ For example, Chordia and Shivakumar (2002) and Cooper, Gutierrez, and Hameed (2004) forecast returns on momentum strategies with variables that are clearly related to the variables our tax-based approach suggests.
} 
This time variation has a related implication. Note that some market commentators have argued that savvy investors must have eliminated the January effect since recent returns to strategies exploiting that phenomenon have been low. However, as interest rates have also been quite low in recent data, we provide an alternative explanation for this recent poor performance. In fact, we show that the time-series variation in the tax-selling premium that we document is not subsumed by the inclusion of a time trend.

Nevertheless, as is the case with other financial anomalies, it is always difficult to explain the reason this inefficiency has not been arbitraged away. We suggest a few explanations for the limits to arbitrage in this case. First, unlike the value and momentum anomalies, the return pattern discussed here cannot be exploited on a regular basis but at most only once a year during the turn of the tax year. Hence, arbitrageurs may be reluctant to allocate a significant fraction of their risk capital to exploit this return pattern. Second, most arbitrageurs may not be aware of the time variation in the profitability of the January effect that our analysis documents. Finally, these effects should be stronger in stocks where there are many taxable investors. Presumably, the market for these stocks may be less efficient.

One can also question the reasons investors do not trade earlier in the year to try to avoid the clumping that appears to occur. We argue that investors may naturally display inattention to this decision because it is costly to observe and process information. ${ }^{6}$ This argument is consistent with a growing recent literature that has used investor inattention to understand patterns in financial markets. Reis (2006) develops a model of optimal inattention for a consumer who faces a cost of observing additive income, such as labor income. Gabaix and Laibson (2002) model the cost of observing the stock market as a utility cost. Huang and Liu (2007) apply the concept of rational inattention to study the optimal portfolio decision of an investor who can obtain costly noisy signals about a state variable governing the expected growth rate of stock prices. Abel, Eberly, and Panageas (2007)

\footnotetext{
${ }^{6}$ Stokey (2009) presents an extensive analysis of the issues related to inaction and infrequent adjustment that occur in stochastic control models with fixed costs.
} 
study optimal inattention to the stock market in the context of Merton's (1971) model and the presence of information and transaction costs. Though modeling the dynamic nature of the problem we study is beyond the scope of this paper, these papers suggest that inattention might play an important role in such an analysis. ${ }^{7}$ Anecdotally many investors do seem to make portfolio decisions infrequently. ${ }^{8}$ Moreover, our empirical results are consistent with the clumping of tax-motivated trades occurring and generating price impact.

Finally, our work also relates to a growing empirical literature documenting price pressure in asset markets, a phenomenon initially suggested by Scholes (1972). Mitchell, Pulvino, and Stafford (2004) document price pressure subsequent to merger announcements and show that the trades of hedge funds appear to move prices away from fundamentals. Coval and Stafford (2007) document that extreme mutual fund flows result in forced trading that temporarily moves prices away from fundamental values. ${ }^{9}$ These price pressure findings are not restricted to equity markets; Ellul, Jotikasthira, and Lundblad (2010) and Mitchell, Pedersen, and Pulvino (2007) document price pressure in the bond and convertible bond markets respectively. In fact, the 2010 American Finance Association presidential address of Darrell Duffie (Duffie (2010)) uses the aforementioned assumption of investor inattention to model exactly these types of price pressure effects.

This paper is organized as follows. Section 2.1 briefly summarizes the most relevant recent literature and shows why both tax and interest rates should explain seasonal patterns in returns. Section 2.2 describes the data and the construction of our main variables.

\footnotetext{
${ }^{7}$ Intuitively, one is adding additional costs (the cost of observing and processing information, i.e. paying attention) and benefits (avoiding the clumping of trades near the turn of the tax year) to the dynamic problem studied in Constantinides (1984). It seems plausible that reasonable calibrations of the more complicated version of Constantinides exist where investors are reluctant to incur both transaction and attention costs until the end of the tax year draws near.

${ }^{8}$ Both Ameriks and Zeldes (2004) and Mitchell, Mottola, Utkus and Yamaguchi (2006) provide striking evidence that investors' portfolio adjustments are far from frequent.

${ }^{9}$ Recent papers have explored some implications of the results of Coval and Stafford (2007). Lou (2009) shows that flow-driven demand shocks more generally affect prices than just in the extreme fire-sale situations of Coval and Stafford. Anton and Polk (2010) show that stocks that are relatively more connected by common institutional ownership covary more together, generating a cross-reversal effect.
} 
Section 2.3 analyzes the empirical implications for the cross-section and time-series of U.S. and U.K. stock returns, U.S. trading volume, and actual individual investor trading behavior, as well as the implications for performance attribution. Section 2.4 provides the conclusions.

\subsection{The Setting}

A large previous literature has examined the turn-of-the-year effect in stock returns resulting from tax-motivated selling. ${ }^{10}$ Recent empirical work by Klein (2001a, 2001b), Grinblatt and Han (2005), Frazzini (2006), and Jin (2006) has more carefully examined this effect by studying the direct empirical links between a proxy for a stock's tax basis and patterns in returns. All of these papers relate measures of capital gains or losses to subsequent stock returns. Like these papers, our work exploits cross-sectional variation in a proxy for capital gains overhang; however, we also model and test a specific prediction about the magnitude of the effect for a given level of overhang.

A few researchers have also exploited time-series variation when testing the general predictions of a tax-based explanation for the turn-of-the-year effect. Most prominently, Poterba and Weisbenner (2001) study the way variation in the turn-of-the-year effect can be linked to changes in capital gains tax rates/regimes. Grinblatt and Moskowitz (2004) investigate the extent to which tax-loss selling drives the profits on technical trading strate-

\footnotetext{
${ }^{10}$ The tax-selling hypothesis has been directly considered as an explanation for stock return seasonality by Wachtel (1942), Rozeff and Kinney (1976), Branch (1977), Dyl (1977), Roll (1983), Reinganum (1983), Chan (1986), Schultz (1985), Jones, Pearce and Wilson (1987), Reinganum and Shapiro (1987), Sims (1995), Reese (1998), Poterba and Weisbenner (2001), Grinblatt and Moskowitz (2004), and Ivković, Poterba and Weisbenner (2004).

Dammon, Dunn and Spatt (1989) study the valuation of tax options when short and long term capital gains tax rates differ. Bossaerts and Dammon (1994) study the option value to time the realization of capital gains and losses and Dammon and Spatt (1996) consider transaction costs and long and short term capital gains tax rates. Dammon, Spatt and Zhang (2001) build a dynamic consumption and portfolio decision model in the presence of capital gains taxes and short-sale restrictions. Dammon, Spatt and Zhang (2004) examine optimal asset allocation and location between taxable and tax-deferred accounts.
} 
gies based on past return patterns. They find that trading profits are only statistically significant during high tax regimes. ${ }^{11}$ The key contributions of our paper are to argue that interesting variation should also come from the interest rate channel and to provide empirical evidence that this channel is important.

Thus, the objective of this section is to build a measure that relates the maximum price distortion in December (or the turn-of-the-year effect) to all the relevant factors in a simple setting: the marginal seller's personal tax rate, the personal interest rate, and the capital gain/loss. We take the point of view of a marginal tax-motivated seller at the end of December. ${ }^{12}$ The seller is a rational investor, implying that his expectations of the price in January are unbiased. This investor evaluates the benefit of selling his holdings at the end of December (time $t$ ) at a distorted price in order to receive the tax benefit associated with realizing capital losses one year earlier (the current tax year instead of the following one).

For the sake of simplicity, assume the investor can sell stock $i$ in January (time $t+$ 1) at the true value of $P_{i, t+1}$ with no uncertainty. Under the assumption of downward sloping demand curves, tax-motivated selling will result in price pressure in December. Consequently, the investor must determine the lowest price at which he would be willing to sell the stock in December. To be clear, the investor solves for the December price $P_{i, t}$ that makes him indifferent between selling in either December or January and takes all other inputs as given. The reference price, $R P_{i}$, the price originally paid for the stock, determines the investor's cost basis for the purpose of taxation. The two other important parameters of this tax-loss harvesting decision are the capital gains tax rate, $\tau_{t}$, and the one-year discount factor, $B_{t}=\frac{1}{1+r_{t}}$, that accounts for the time-value of money as well

\footnotetext{
${ }^{11}$ A recent paper by Sialm (2007) studies dividend taxes and stock returns more generally to show that before-tax returns are higher for those stocks that have higher effective tax rates.

${ }^{12}$ The arguments in this section are made for a loser stock; however, a similar rationale applies to winner stocks as well.
} 
as the creditworthiness of the investor through an interest rate, $r_{t}{ }^{13}$ This discount factor takes into account the present value cost of the tax consequences of selling in January rather than December.

We emphasize that a one-year discount factor is appropriate despite the fact that there is only a one-day difference between trading days in our framework. ${ }^{14}$ The reason for using a one-year discount factor is that delaying the sale by one day has the impact of delaying the tax benefit by one year. Therefore in our framework, the magnitude of the January rebound in stock returns depends on the one-year time value of the tax benefit. Note that for simplicity, we do not have a subscript $i$ on $\tau$ or $r$ since we are assuming the same tax and interest rate for all stocks at time $t$.

We equate the after tax proceeds of the sale in December and January:

$$
\begin{aligned}
\text { [Proceeds in December }] & =\text { [Proceeds in January }] \\
P_{i, t}-\tau_{t}\left(P_{i, t}-R P_{i}\right) & =P_{i, t+1}-\tau_{t}\left(P_{i, t+1}-R P_{i}\right) B_{t} .
\end{aligned}
$$

This equation can be rearranged into

$$
-\tau_{t}\left(P_{i, t}-R P_{i}\right)\left(1-B_{t}\right)=\left(P_{i, t+1}-P_{i, t}\right)\left(1-B_{t} \tau_{t}\right) .
$$

The equation above highlights the condition that makes the marginal seller indifferent. The equation says that the present-value loss of delaying the tax-credit must be compensated by the after-tax January rebound. For the sake of concreteness, we return to the example given in the introduction. At the temporarily low price of $\$ 2.04$, the investor can generate tax savings this year equal to $-30 \% *(\$ 2.04-100)=\$ 29.39$ by harvesting the capital loss now. At an interest rate of 5\%, delaying the harvest of this tax loss by one day results in

\footnotetext{
${ }^{13}$ There are several complications of the tax code that are not considered in our analysis. For example, there is a cap on the size of the capital loss deduction one can make against personal income in any one year. Also, typically short-term capital gains are taxed at a higher rate than long-term capital gains. Moreover, the ability to implement a short-the-box strategy has changed over the time period we study. Finally, there are of course portfolio aspects of the decision. We ignore these complications for the sake of simplicity.

${ }^{14}$ Note that we ignore the one-trading-day discount effect on the sale proceeds for the sake of simplicity.
} 
a present value loss of $\$ 29.39 *(1-1 / 1.05)=\$ 1.40$, as the investor must wait one year to receive the tax credit. This dollar amount is the value of the left-hand side of equation (2). However, this delay allows the investor to capture the January price rebound of (\$4-\$2.04) $=\$ 1.96$ which results in an after-tax gain of $\$ 1.96 *(1-30 \% / \$ 1.05)=\$ 1.40$, as the tax on the realized capital gain is paid in one-year's time.

Dividing by $P_{t}$ and rearranging gives the stock's January rebound in units of return as

$$
\frac{P_{i, t+1}-P_{i, t}}{P_{i, t}}=-\tau_{t} \frac{\left(1-B_{t}\right)}{\left(1-B_{t} \tau_{t}\right)} \frac{P_{i, t}-R P_{i}}{P_{i, t}} .
$$

This equation shows that the stock's January rebound (the return from December to January) is a function of the capital gains tax rate, the level of the interest rate, and the capital gains overhang of the stock, $g_{i, t}=\frac{P_{i, t}-R P_{i}}{P_{i, t}}$. We further define $\gamma_{t} \equiv \tau_{t}\left(\frac{1-B_{t}}{1-B_{t} \tau_{t}}\right)$ in order to write the stock's tax-selling rebound in January as

$$
\text { January rebound }=-\gamma_{t} g_{i, t}
$$

We dub $\gamma_{t}$ the tax-selling premium. Under our assumptions, this equation applies for all stocks. The capital gains overhang, $g_{i, t}$, is different for every stock, driving the crosssectional variation in the effect, but the tax-selling premium, $\gamma_{t}$, is the same for all stocks, driving the time-series variation in the effect. Our description has focused on the case where the marginal investor in the stock has a negative capital gains overhang, and thus a positive January rebound return. Nevertheless, a similar rationale applies to stocks where the marginal investor has a positive capital gains overhang. A tax-motivated investor sells a winner stock this year rather than next year only if $P_{i, t}$ is so (temporarily) high that it compensates the investor for the present value loss of paying taxes this year rather than next year.

Our subsequent analysis exploits cross-sectional variation in $g_{i, t}$ and time-series variation in $\gamma_{t}$ to explain return patterns in December and January. In particular, we measure the 
extent to which temporary price pressure occurs in December and dissipates in January. ${ }^{15}$ We emphasize that the interest rate channel that our novel formulation identifies generates significantly more variation in the predicted magnitude of the effect than the tax rate channel (in fact, more than twice as much). The predicted value of $\gamma$, based on realized values of the two rates in question, varies from 8 to 660 basis points over the sample. This variation is primarily due to interest rates. If one were to fix interest rates at their average level over the sample, only allowing tax rates to vary, the resulting variation in $\gamma$ is much smaller (97 to 338 basis points), roughly one-third of the variation in $\gamma$ seen in the sample we study.

\subsection{Data and Methodology}

In this section, we provide a description of the data and methodology used for our empirical tests. We first describe the raw data sources. We then explain the way we compute our two key explanatory variables, the capital gains overhang, $g$, and the taxselling premium, $\gamma$, and then describe the various control variables we employ.

\subsubsection{Data Description}

The raw U.S. firm-level data come from five different databases. The first of these, the Center for Research in Securities Prices (CRSP) stock file, provides daily prices, shares outstanding, trading volumes, and returns for all NYSE, AMEX, and NASDAQ listed stocks. The second database, the Compustat North America annual file, contains the relevant accounting information for most publicly traded U.S. stocks. The third database is the Trade and Quote (TAQ) trade-level data, which is used to compute the selling pressure

\footnotetext{
${ }^{15}$ The mispricing we investigate in December is equal to the mispricing in January in terms of dollars. However, when measured in returns, the alpha in December is not exactly equal to the alpha in January because the base price on which the return occurs is different. Our empirical work takes this difference into account. However, our description of the intuition ignores this difference for simplicity.
} 
variable. The fourth database contains the trades and positions of individual investors from a large discount brokerage, described in Odean (1998). ${ }^{16}$

We measure the log book-to-market equity ratio (denoting the transformed quantity by $B M$ in contrast to simple book-to-market by $B E / M E$ ) as of the end of June in year $t$. We measure $B E$ for the fiscal year ending in calendar year $t-1$, and $M E$ (market value of equity) at the end of June of year $t$. Following Fama and French, we define $B E$ as stockholders' equity, plus balance sheet deferred taxes (Compustat data item 74) and investment tax credit (data item 208) (if available), plus post-retirement benefit liabilities (data item 330) (if available), minus the book value of preferred stock. ${ }^{17}$ We require each firm-year observation to have a valid past $B E / M E$ ratio that must be positive in value. Moreover, in order to eliminate likely data errors, we censor the $B E / M E$ variables of these firms to the range $(.01,100)$ by adjusting the book value. To avoid influential observations created by the log transform, we first shrink the $B E / M E$ towards one by defining $B M \equiv \log [(.9 B E+.1 M E) / M E]$.

As mentioned in the paper, we examine individual trading behavior using two data sources. First, we follow Lee and Ready (1991) and Hvidkjaer (2005) to form a selling pressure variable from the 1993-2005 TAQ dataset. Buy versus sell trades are identified in terms of their relation to the midpoint of the bid-ask spread. We classify trades as individual or institutional based on trade size, identifying individual trades as those trades under a $\$ 10,000$ cutoff. We define selling pressure $(\mathrm{Sell}$ ) as the ratio of sell trades to all trades for that classification. Second, we analyze individual investor trades using the

\footnotetext{
${ }^{16}$ We generously thank Terry Odean for providing the database.

${ }^{17}$ Depending on availability, we use redemption (data item 56), liquidation (data item 10), or par value (data item 130) (in that order) for the book value of preferred stock. We calculate stockholders' equity used in the above formula as follows. We prefer the stockholders' equity number reported by Moody's, or Compustat (data item 216). If neither one is available, we measure stockholders' equity as the book value of common equity (data item 60) plus the book value of preferred stock. (Note that the preferred stock is added at this stage, because it is later subtracted in the book equity formula.) If common equity is not available, we compute stockholders' equity as the book value of assets (data item 6) minus total liabilities (data item 181), all from Compustat.
} 
Odean dataset, which contains the 1.27 million transactions of retail clients of a US based brokerage from 1991 until 1996. We identify purchase and sell orders at the firm-level using cusip codes.

The raw U.K. firm-level data come from the Compustat Global database. We obtain daily prices, shares outstanding, trading volumes, and returns from the Security Data tables. We obtain accounting information from the Fundamentals Annual tables in order to construct log book-to-market equity $(B M)$ and book-to-market $(B E / M E)$ ratios as defined for the U.S. 


\subsubsection{Tax-selling Premium}

In theory, $\gamma$ should be a function of the marginal investor's capital gains tax rate and interest rate. Our implementation computes the U.S. version of $\gamma$ using the one-year FamaBliss interest rate and the maximum capital gains tax rate each year, available from the Internal Revenue Service website. ${ }^{18}$ The U.K. version of $\gamma$ is computed using the Bank of England base rate and the maximum capital gains tax rate each year, available from the HM Revenue \& Customs website.

Although the appropriate interest rate depends on the credit worthiness of the marginal investor, we find that different interest rates imply similar variation in the U.S. version of $\gamma$. In the analysis that follows, we use the one-year Fama-Bliss interest rate primarily because this proxy has a long time-series. Section 2 of the online Appendix documents that using other interest-rate proxies that include an explicit credit component, such as the rates on auto and personal loans, generates very similar variation in $\gamma$ over most of the common sample period.

\subsubsection{Capital Gains Overhang}

In theory, the relevant capital gains overhang, $g_{i, t}$, is that of the marginal seller, but this value obviously cannot be identified. Therefore, we use the capital gains overhang variable proposed by Grinblatt and Han (2005). They define capital gains overhang as the percentage deviation of a proxy for the stock's current reference price, $R P_{i, t}$, from the current price, $P_{i, t}$, where the proxy for a stock's current reference price is estimated using a turnover-weighted sum of end-of-week prices over the past 260 weeks, where $T O_{i, t}$ is the turnover of stock $i$ in week $t$. Specifically, we measure $T O_{i, t}$ as the sum of daily trading volume relative to shares outstanding. Suppressing the subscript $i$ for readability,

\footnotetext{
${ }^{18} \mathrm{By}$ using the rates that were applied for each year $t$ in question, we ignore the possibility that investors may anticipate that capital gains tax rates may change.
} 
the relevant equations are

$$
\begin{aligned}
g_{t} & =\frac{P_{t}-R P_{t}}{P_{t}} \\
\text { with } R P_{t} & =\phi^{-1} \sum_{n=0}^{260} \widehat{V}_{t, t-n} P_{t-n} \\
\text { where } \widehat{V}_{t, t-n} & =T O_{t-n}\left[\prod_{\tau=1}^{n-1}\left(1-T O_{t-n+\tau}\right)\right] \\
\text { and } \phi & =\sum_{n=0}^{260} \widehat{V}_{t, t-n}
\end{aligned}
$$

Therefore, the weights, $\widehat{V}_{t, t-n} / \phi$, given to each past price, $P_{t-n}$, can be interpreted as the probability that the marginal seller bought the stock at that price, where $\widehat{V}_{t, t-n}$ is a function of the past turnover from $t-n$ to $t-1$. Hence this probability is also equal to the probability that the reference price is equal to the price at $t-n$. Averaging over all possible reference prices yields the estimated cost basis.

The capital gains overhang measure has the following intuitive interpretation. If a stock had relatively high turnover exactly one year ago, but volume has been very low ever since, then the current shareholders are more likely to have bought the stock a year ago. Consequently, the price one year ago is a good proxy for the marginal investor's purchase price. Conversely, if that stock instead had relatively high turnover in the most recent month, then last month's price is a good proxy for the marginal investor's purchase price. Note that we compute $g$ for each firm using price and volume data from the CRSP database for U.S. firms and the Compustat Global database for U.K. firms.

\subsubsection{Control Variables}

We conduct cross-sectional regressions using both returns and selling pressure as dependent variables. The returns-based regressions consist primarily of daily firm-level returns, which are obtained from the CRSP database for U.S. firms and from Compustat 
Global for U.K. firms. The selling-pressure regressions, used for analyzing investor behavior, are also conducted at the daily frequency. We compute selling pressure, Sell, defined as the ratio of sell trades to all trades, following Lee and Ready (1991) and Hvidkjaer (2005) using the TAQ database. We further compute versions of selling pressure for small $\left(S_{e l l}\right)$ and large $\left(S_{e l l}\right)$ trades. Following Lee and Ready (1991), we set the cutoff point separating a large trade from a small trade at $\$ 10,000$.

The key variables in our regression are a firm's capital gains overhang and the taxselling premium. However, in most of the specifications, we also include other standard control variables. We include the book-to-market equity ratio $(B M)$ in the regressions in order to capture the well-known value effect in the cross-section of average stock returns (Fama and French (1992)). We control for size $(M E)$ given the evidence in Fama and French (1992) that size plays some role in describing the cross-section of average returns. We control for past returns over the last three years and trading volume as in Grinblatt and Han (2005), since our capital gains variable uses both as inputs. In particular, we decompose returns over the last three years into the one-month return, $r_{-1: 0}$; the one-year return (excluding the past one-month return), $r_{-12:-1}$; and the three-year return (excluding the past one-year return), $r_{-36:-12}$. We calculate two measures of volume. The first is the

average monthly turnover, $\bar{V}$, from the past 12 months. The second is monthly turnover, $T U R N$, which is simply the sum of daily turnover for the month in question. For both volume measures, note that we divide Nasdaq volume by two in an attempt to minimize the double counting of trades on that exchange.

\subsubsection{Descriptive Statistics of Overhang Portfolios}

Though our analysis uses firm-level regressions, we first look at the characteristics of portfolios sorted on $g$ to summarize how $g$ varies in the cross-section and is related to other variables used in the finance literature to forecast cross-sectional variation in stock returns.

Table 2.1 reports equal-weight average characteristics for portfolios formed monthly 
on capital gains overhang. We choose equal-weight to correspond to our firm-level regressions which weight stocks equally. By definition, past returns are correlated with stocks' capital gains overhang. ${ }^{19}$ Nevertheless, it is interesting to see the extent to which there is spread in past returns over different horizons because of the capital gains overhang sort and the way that translates into characteristics that are indirectly driven by past returns, $S I Z E$ and $B M$. We find that high overhang stocks are typically large value momentum stocks while low overhang stocks are typically small growth losers. This tendency does not have to be true for every single stock (in fact, our stock-level regressions hope to separate these two sources of independent variation), but it is the case at the level of quintile portfolios. Note that seasonal effects have been documented in the average returns associated with many of these variables. By suggesting that previous analyses merely identified a tax-selling seasonal that varies through time, our framework provides an alternative explanation.

\footnotetext{
${ }^{19}$ One possible concern is that variation in overhang is simply variation in momentum. In their Table 2.1 Panel B, Grinblatt and Han (2005) study the cross-sectional determinants of the capital gains overhang and show that about $59 \%$ of the cross-sectional variation in the capital gains variable can be explained by differences in past returns (over the past month, past year, and past three years), past turnover (over the past month, past year, and past three years), and firm size. Given that more than $40 \%$ of the variation remains unexplained and that all seven variables are each very significant, it is not just returns over the past year that are driving cross-sectional variation in overhang. Indeed, the thesis of Grinblatt and Han (2005) is that overhang clearly and reliably drives out $r_{-12:-1}$ in cross-sectional regressions forecasting returns.
} 
Table 2.1: Descriptive Statistics

This table reports various characteristics of capital-gains-overhang-sorted quintile portfolios formed each month. These portfolios are equal-weight portfolios. We compute capital gains overhang, $g$, as in Grinblatt and Han (2005). The characteristics include a decomposition of returns over the last three years into the onemonth return, $r_{-1:-0}$; the one-year return (excluding the past one-month return), $r_{-12:-1}$; and the three-year return (excluding the past one-year return), $r_{-12:-36}$. Market capitalization, $M E$, and the book-to-market equity ratio, $B M$, are computed as in Fama and French (1992). $B M$ is the previous fiscal year's ending book value divided by the corresponding year's December market value. $M E$ is the latest end-of-June market value in thousands. We also report the average monthly turnover, $\bar{V}$, from the past 12 months as well as the monthly turnover, $T U R N$, the sum of daily turnover within the past month. For both volume measures, we divide Nasdaq volume by two in an attempt to make volume numbers comparable across exchanges. We compute Sell as the fraction of seller-initiated trades relative to all trades for both small (S) and large (L) trades. The cut-off delimiting a small versus a large trade is $\$ 10,000$, as in Lee and Ready (1991). The sample starts in February of 1954 and ends in December 2008.

Panel A: December

\begin{tabular}{ccccccccccc}
\hline & $g$ & $r_{-1: 0}$ & $r_{-12:-1}$ & $r_{-36:-12}$ & $M E$ & $B M$ & $\bar{V}$ & TURN & Sell $_{S}$ & Sell $_{L}$ \\
\hline $\mathrm{H}$ & 0.28 & 0.043 & 0.512 & 0.717 & 1856 & 0.66 & 0.043 & 0.047 & 0.51 & 0.52 \\
4 & 0.09 & 0.023 & 0.251 & 0.494 & 2015 & 0.78 & 0.054 & 0.052 & 0.52 & 0.51 \\
3 & -0.07 & 0.011 & 0.124 & 0.391 & 1546 & 0.87 & 0.057 & 0.054 & 0.53 & 0.52 \\
2 & -0.33 & 0.000 & 0.000 & 0.294 & 887 & 0.97 & 0.055 & 0.055 & 0.56 & 0.54 \\
$\mathrm{~L}$ & -1.90 & -0.021 & -0.198 & 0.065 & 190 & 1.29 & 0.044 & 0.053 & 0.61 & 0.57
\end{tabular}

Panel B: January

\begin{tabular}{ccccccccccc}
\hline & $g$ & $r_{-1: 0}$ & $r_{-12:-1}$ & $r_{-36:-12}$ & $M E$ & $B M$ & $\bar{V}$ & TURN & Sell $_{S}$ & Sell $_{L}$ \\
\hline $\mathrm{H}$ & 0.30 & 0.054 & 0.544 & 0.741 & 1719 & 0.68 & 0.039 & 0.052 & 0.51 & 0.52 \\
4 & 0.11 & 0.042 & 0.264 & 0.505 & 1955 & 0.79 & 0.050 & 0.058 & 0.52 & 0.51 \\
3 & -0.03 & 0.040 & 0.133 & 0.402 & 1529 & 0.87 & 0.053 & 0.058 & 0.52 & 0.51 \\
2 & -0.27 & 0.048 & 0.016 & 0.318 & 936 & 0.97 & 0.054 & 0.057 & 0.52 & 0.51 \\
$\mathrm{~L}$ & -1.70 & 0.082 & -0.170 & 0.085 & 195 & 1.27 & 0.043 & 0.043 & 0.54 & 0.54
\end{tabular}

Panel C: February-November

\begin{tabular}{ccccccccccc}
\hline & $g$ & $r_{-1: 0}$ & $r_{-12:-1}$ & $r_{-36:-12}$ & $M E$ & $B M$ & $\bar{V}$ & TURN & Sell $_{S}$ & Sell $_{L}$ \\
\hline $\mathrm{H}$ & 0.29 & 0.040 & 0.527 & 0.681 & 1672 & 0.69 & 0.040 & 0.050 & 0.51 & 0.52 \\
4 & 0.12 & 0.018 & 0.266 & 0.461 & 1972 & 0.80 & 0.051 & 0.055 & 0.51 & 0.51 \\
3 & -0.02 & 0.008 & 0.132 & 0.369 & 1660 & 0.87 & 0.054 & 0.055 & 0.52 & 0.51 \\
2 & -0.24 & 0.000 & 0.008 & 0.287 & 956 & 0.96 & 0.054 & 0.052 & 0.53 & 0.52 \\
$\mathrm{~L}$ & -1.48 & -0.008 & -0.189 & 0.065 & 198 & 1.23 & 0.044 & 0.040 & 0.55 & 0.55
\end{tabular}


Also of particular interest is the fact that though there is no pattern in average monthly turnover over the past year, there is a pattern in the most recent monthly volume. Stocks with a low $g$ experience relatively high turnover in December, while stocks with a high $g$ experience relatively high turnover in January. Even stronger patterns can be seen in our selling pressure variable Sell. Stocks with a low cost basis relative to price are being sold by both small $\left(S e l_{S}\right)$ and large $\left(S e l_{L}\right)$ investors in December. These patterns are consistent with optimal tax-selling behavior in the context we consider here.

\subsection{Empirical Results}

Our empirical analysis consists of three parts. First, we consider the ability of the product of $g$ and $\gamma$ to forecast cross-sectional and time-series variation in stock returns. Second, we examine the implications for trading volume and the trading behavior of individual investors. Finally, we analyze the consequences for aggregate returns and performance attribution.

\subsubsection{Cross-sectional and Time-series Variation in Firm-level Returns}

In this subsection, we focus on the analysis of the cross-sectional and time-series variation in firm-level returns. In particular, we show that the product of the tax-selling premium ( $\gamma$, a function of capital gains rates and interest rates) and a stock's capital gains overhang $(g)$ forecasts firm-level returns around the turn of the tax year. We first examine U.S. data and then turn to the U.K., where the tax and calendar year end do not coincide. In these regressions, we first cross-sectionally demean all firm-level data.

\section{U.S. Return Regressions}

Since our hypothesis has both cross-sectional and time-series implications, in Table 2.2 we estimate pooled regressions examining whether the interaction between $\gamma$ and $g$ 
forecasts either weekly or daily returns. Panels A and B of Table 2.2 report the main result; the remaining Panel estimates our benchmark specification over different subsamples for robustness.

We first estimate a regression forecasting weekly returns using the product of $\gamma$ and $g$, as well as interacting that variable with nine dummy variables, eight for the four December and four January weeks and one for the rest of the year, February through November,

$$
\begin{aligned}
r_{i, t}= & a_{1} \gamma_{t-1} g_{i, t-1} F N \\
& +a_{2} \gamma_{t-1} g_{i, t-1} D 1+a_{3} \gamma_{t-1} g_{i, t-1} D 2+a_{4} \gamma_{t-1} g_{i, t-1} D 3+a_{5} \gamma_{t-1} g_{i, t-1} D 4 \\
& +a_{6} \gamma_{t-1} g_{i, t-1} J 1+a_{7} \gamma_{t-1} g_{i, t-1} J 2+a_{8} \gamma_{t-1} g_{i, t-1} J 3+a_{9} \gamma_{t-1} g_{i, t-1} J 4+\varepsilon_{i, t}
\end{aligned}
$$

Standard errors are robust to cross-sectional correlation using the method of Rogers $(1983,1993) .{ }^{20}$ The first regression in Panel A shows that the effect of $\gamma * g$ is statistically significant in December and January using weekly dummies. The results are consistent with December momentum in stock returns which is explained by $\gamma * g$ and a subsequent reversal around the turn-of-the-year. Interestingly, the reversal seems to start during the last week of December.

The remaining regressions in Panel A add standard controls to the specification in equation (2.9). These controls include $M E, B M$, and $g$. These variables control for the well-known size, value, and momentum patterns in the cross-section of returns. We use $g$ to control for momentum given Grinblatt and Han's finding that $g$ subsumes simple price momentum's ability to describe the cross-section of average returns; however, note that we do include controls for past returns in subsequent regressions. We also interact $M E$ with a dummy variable for January. Finally, we split the interaction, $\gamma * g * F N$, into $\gamma * g *$ FebJun and $\gamma * g *$ JulNov.

\footnotetext{
${ }^{20}$ See Petersen (2009) for a careful study of the appropriateness of Rogers' $(1983,1993)$ estimator in various contexts.
} 
These controls have little impact on our findings as the turn-of-the-year effect remains strong. However, the last week rebound becomes smaller and statistically insignificant. In all cases, we find that most of the January reversal occurs in the first week of January. We find that the ability of $\gamma * g$ to predict returns in February through November occurs entirely in the second-half of the year. This result is consistent with the potential clumping of tax-loss harvesting investors trades being partially anticipated by the market.

In Panel B of Table 2.2, we re-estimate our benchmark regression over different subperiods. Consistent with our hypothesis, $\gamma * g$ has the expected effect around the turn-ofthe-year in all sub-periods.

Table 2.2: Pooled Return Regression Estimates (1954-2008)

We report the results from pooled regressions of day or week $t$ stock returns on $t-1$ characteristics. Characteristics are measured on a weekly basis for conciseness. All firm-specific variables, defined in Table 2.1, are cross-sectionally demeaned, and when appropriate, interacted with our proposed tax-selling premium variable, $\gamma_{t}=\tau_{t}\left(\frac{1-B_{t}}{1-B_{t} \tau_{t}}\right)$, a function of capital gains tax rates $\left(\tau_{t}\right)$ and interest rates $\left(r_{t}=\right.$ $\frac{1}{B_{t}}-1$ ) as derived in Section 2.1, and with dummy variables for different periods of the year. The dummy variables are $F N, D(W)$, and $J(W)$ for February-November, December, and January respectively and refer to the month of the return being predicted, with $W$ indicating the week of the particular month in question. T-statistics (in parentheses) are robust to cross-correlation in the residuals using the clustered standard errors of Rogers $(1983,1993)$. We also consider a case where we split the dummy variable $F N$ into two halves: FebJun and JulNov. The sample starts in February of 1954 and ends in December 2008. Panel A presents weekly regressions of returns on weekly interactions of weekly dummies, $g$ and $\gamma$, also including $g, M E$ and $B M$ as controls. Panel B shows sub-sample analysis of the first regression in Panel B. The regressions correspond to the sub-periods 1963-2008, 1954-2008, 1980-2008, and 1993-2008 respectively.

Panel A

\begin{tabular}{llllll}
\hline & \multicolumn{1}{l}{$(1)$} & $(2)$ & \multicolumn{1}{l}{$(3)$} & \multicolumn{1}{l}{$(4)$} & $(5)$ \\
\hline$\gamma * g * F N$ & -0.035 & -0.024 & 0.056 & 0.054 & \\
& $(-3.91)$ & $(-2.63)$ & $(2.68)$ & $(2.60)$ & \\
$\gamma * g * D 1$ & 0.135 & 0.126 & 0.207 & 0.205 & 0.204 \\
& $(1.71)$ & $(1.57)$ & $(2.50)$ & $(2.49)$ & $(2.48)$ \\
$\gamma * g * D 2$ & 0.155 & 0.127 & 0.208 & 0.206 & 0.202
\end{tabular}




\begin{tabular}{|c|c|c|c|c|c|}
\hline \multicolumn{6}{|c|}{ Table 2.2 (Continued) } \\
\hline & $(3.08)$ & $(2.02)$ & $(3.21)$ & $(3.19)$ & $(3.06)$ \\
\hline \multirow[t]{2}{*}{$\gamma * g * D 3$} & 0.216 & 0.219 & 0.299 & 0.298 & 0.294 \\
\hline & $(4.51)$ & $(4.04)$ & $(4.97)$ & $(4.96)$ & $(4.90)$ \\
\hline \multirow[t]{2}{*}{$\gamma * g * D 4$} & -0.134 & -0.159 & -0.079 & -0.081 & -0.076 \\
\hline & $(-2.27)$ & $(-2.50)$ & $(-1.20)$ & $(-1.22)$ & $(-1.15)$ \\
\hline \multirow[t]{2}{*}{$\gamma * g * J 1$} & -1.000 & -1.009 & -0.927 & -0.913 & -0.914 \\
\hline & $(-5.08)$ & $(-5.38)$ & $(-5.02)$ & $(-4.98)$ & $(-4.99)$ \\
\hline \multirow[t]{2}{*}{$\gamma * g * J 2$} & -0.391 & -0.383 & -0.301 & -0.286 & -0.286 \\
\hline & $(-3.05)$ & $(-2.79)$ & $(-2.27)$ & $(-2.17)$ & $(-2.19)$ \\
\hline \multirow[t]{2}{*}{$\gamma * g * J 3$} & -0.271 & -0.244 & -0.162 & -0.146 & -0.149 \\
\hline & $(-2.73)$ & $(-3.07)$ & $(-2.00)$ & $(-1.85)$ & $(-1.87)$ \\
\hline \multirow[t]{2}{*}{$\gamma * g * J 4$} & -0.312 & -0.300 & -0.219 & -0.203 & -0.199 \\
\hline & $(-4.81)$ & $(-4.17)$ & $(-2.89)$ & $(-2.70)$ & $(-2.66)$ \\
\hline \multirow[t]{2}{*}{$\gamma * g *$ FebJun } & & & & & 0.015 \\
\hline & & & & & $(0.62)$ \\
\hline \multirow[t]{2}{*}{$\gamma * g * J u l N o v$} & & & & & 0.086 \\
\hline & & & & & $(4.13)$ \\
\hline \multirow[t]{2}{*}{$g$} & & & -0.002 & -0.002 & -0.002 \\
\hline & & & $(-4.01)$ & $(-4.01)$ & $(-4.00)$ \\
\hline \multirow[t]{2}{*}{$\ln (M E)$} & & -0.020 & -0.012 & -0.009 & -0.011 \\
\hline & & $(-3.11)$ & $(-1.87)$ & $(-1.34)$ & $(-1.65)$ \\
\hline \multirow[t]{2}{*}{$\ln (B M)$} & & 0.057 & 0.049 & 0.049 & 0.022 \\
\hline & & (3.13) & $(2.68)$ & $(2.68)$ & $(1.60)$ \\
\hline \multirow[t]{2}{*}{$\ln (M E) * J$} & & & & -0.044 & -0.045 \\
\hline & & & & $(-8.95)$ & $(-8.94)$ \\
\hline
\end{tabular}

Panel B

\begin{tabular}{ccccc}
\hline & $1963-2008$ & $1954-1980$ & $1980-2008$ & $1993-2008$ \\
\hline$\gamma^{*} g * F N$ & $(1)$ & $(2)$ & $(3)$ & $(4)$ \\
& 0.008 & 0.002 & 0.002 & -0.049 \\
$\gamma^{*} g * D 1$ & $(2.14)$ & $(0.32)$ & $(0.34)$ & $(-4.24)$ \\
& 0.036 & 0.043 & 0.021 & 0.034 \\
& $(2.26)$ & $(2.69)$ & $(1.14)$ & $(1.00)$
\end{tabular}




\begin{tabular}{|c|c|c|c|c|}
\hline \multirow{2}{*}{$\gamma^{*} g * D 2$} & \multicolumn{4}{|c|}{ Table 2.2 (Continued) } \\
\hline & 0.029 & 0.047 & 0.006 & -0.002 \\
\hline & $(1.42)$ & $(3.91)$ & $(0.27)$ & $(-0.08)$ \\
\hline \multirow[t]{2}{*}{$\gamma^{*} g * D 3$} & 0.055 & 0.025 & 0.065 & 0.169 \\
\hline & $(4.68)$ & $(2.77)$ & $(3.36)$ & $(2.07)$ \\
\hline \multirow{2}{*}{$\gamma^{*} g * D 4$} & 0.045 & 0.040 & 0.036 & 0.064 \\
\hline & $(4.46)$ & $(3.04)$ & $(2.59)$ & $(1.42)$ \\
\hline \multirow[t]{2}{*}{$\gamma * g * J 1$} & -0.169 & -0.201 & -0.165 & -0.516 \\
\hline & $(-5.02)$ & $(-6.67)$ & $(-3.30)$ & $(-15.01)$ \\
\hline \multirow[t]{2}{*}{$\gamma * g * J 2$} & -0.037 & -0.046 & -0.042 & -0.201 \\
\hline & $(-2.33)$ & $(-3.38)$ & $(-1.70)$ & $(-2.00)$ \\
\hline \multirow[t]{2}{*}{$\gamma * g * J 3$} & -0.021 & -0.042 & -0.020 & -0.142 \\
\hline & $(-1.61)$ & $(-2.49)$ & $(-1.24)$ & $(-3.58)$ \\
\hline \multirow[t]{2}{*}{$\gamma * g * J 4$} & -0.037 & -0.076 & -0.028 & -0.111 \\
\hline & $(-2.48)$ & $(-3.24)$ & $(-1.84)$ & $(-3.64)$ \\
\hline \multirow[t]{2}{*}{$\gamma^{*} g * X E$} & -0.124 & -0.109 & -0.139 & -0.192 \\
\hline & $(-6.63)$ & $(-4.09)$ & $(-5.28)$ & $(-2.39)$ \\
\hline \multirow[t]{2}{*}{$\gamma^{*} g * N Y E$} & -0.262 & -0.320 & -0.222 & -0.845 \\
\hline & $(-3.84)$ & $(-8.45)$ & $(-2.33)$ & $(-3.80)$ \\
\hline \multirow[t]{2}{*}{$g$} & -0.001 & 0.000 & -0.001 & 0.000 \\
\hline & $(-7.57)$ & $(-0.94)$ & $(-6.32)$ & $(-1.75)$ \\
\hline \multirow[t]{2}{*}{$\ln (M E)$} & -0.007 & -0.007 & -0.007 & -0.017 \\
\hline & $(-5.31)$ & $(-3.48)$ & $(-4.68)$ & $(-6.74)$ \\
\hline \multirow[t]{2}{*}{$\ln (B M)$} & 0.013 & -0.002 & 0.016 & 0.003 \\
\hline & $(3.34)$ & $(-0.40)$ & $(3.21)$ & $(1.29)$ \\
\hline \multirow[t]{2}{*}{$\ln (M E)^{*} J$} & -0.009 & -0.010 & -0.008 & -0.006 \\
\hline & $(-8.67)$ & $(-7.11)$ & $(-6.38)$ & $(-3.94)$ \\
\hline
\end{tabular}

Table 2.3 estimates a daily version of the fourth regression in Panel A in order to shed more light on the effect seen during the last week of December. We continue to use weekly dummy variables to facilitate comparison with the weekly return regressions, but we also add dummies for the business day before December 25th (XE dummy) and the business 
day before New Year's Day (NYE dummy). After including these XE and NYE dummies, the last week of December exhibits a positive slope on the interaction $\gamma * g$. This result is consistent with tax-loss harvesting by taxable investors throughout the last week of the year, but with savvy investors purchasing temporarily depressed stocks on the last working days of the year.

Table 2.3: Daily Pooled Return Regression Estimates (1954-2008)

This table reports daily return regressions using weekly variables for conciseness and direct comparison with Table 2.2 Panel A. We expand the set of interactions to also include dummies for the business day before Christmas $(X E)$ and the business day before New Year's Day ( $N Y E$ ). Regression (2) accounts for a possible trend in the effect of $g$ on returns. Regression (3) considers the possibility that the trend depends on the month, week, or day of the year. Regression (4) analyzes whether the interactive effect of $\gamma$ can be explained simply through interactions with its components, interest rates $(r)$ or capital gains tax rates $(\tau)$ individually. Regression (5) considers an alternative set of controls using the same variables as in Grinblatt and Han (2005), also defined in Table 2.1.

\begin{tabular}{|c|c|c|c|c|c|c|c|}
\hline & \multirow[t]{2}{*}{ (1) } & \multirow[t]{2}{*}{ (2) } & \multicolumn{2}{|c|}{$\begin{array}{l}\text { (3) } \\
\text { interact dummies } \\
\text { with both }\end{array}$} & \multicolumn{2}{|c|}{$\begin{array}{c}\text { (4) } \\
\text { replace } \gamma \\
\text { with both }\end{array}$} & \multirow[t]{2}{*}{ (5) } \\
\hline & & & $\gamma * g$ & $g *$ trend & $r$ & $\tau$ & \\
\hline$\gamma * g * F N$ & $\begin{array}{l}0.007 \\
(1.95)\end{array}$ & $\begin{array}{l}-0.003 \\
(-0.66)\end{array}$ & $\begin{array}{l}-0.002 \\
(-0.50)\end{array}$ & $\begin{array}{r}-1.5 \mathrm{E}-05 \\
(-2.86)\end{array}$ & $\begin{array}{l}0.115 \\
(4.58)\end{array}$ & $\begin{array}{l}-0.004 \\
(-1.81)\end{array}$ & $\begin{array}{l}0.006 \\
(1.72)\end{array}$ \\
\hline$\gamma * g * D 1$ & $\begin{array}{l}0.036 \\
(2.24)\end{array}$ & $\begin{array}{l}0.025 \\
(1.58)\end{array}$ & $\begin{array}{l}0.021 \\
(1.19)\end{array}$ & $\begin{array}{r}7.6 \mathrm{E}-06 \\
(0.48)\end{array}$ & $\begin{array}{l}0.059 \\
(0.42)\end{array}$ & $\begin{array}{l}-0.015 \\
(-2.53)\end{array}$ & $\begin{array}{l}0.040 \\
(2.46)\end{array}$ \\
\hline$\gamma * g * D 2$ & $\begin{array}{l}0.028 \\
(1.39)\end{array}$ & $\begin{array}{l}0.017 \\
(0.87)\end{array}$ & $\begin{array}{l}0.021 \\
(1.08)\end{array}$ & $\begin{array}{r}-2.9 \mathrm{E}-05 \\
(-2.25)\end{array}$ & $\begin{array}{l}0.173 \\
(0.93)\end{array}$ & $\begin{array}{l}-0.008 \\
(-2.95)\end{array}$ & $\begin{array}{l}0.038 \\
(2.43)\end{array}$ \\
\hline$\gamma * g * D 3$ & $\begin{array}{l}0.055 \\
(4.64)\end{array}$ & $\begin{array}{l}0.044 \\
(3.49)\end{array}$ & $\begin{array}{l}0.030 \\
(3.14)\end{array}$ & $\begin{array}{r}4.9 \mathrm{E}-05 \\
(2.24)\end{array}$ & $\begin{array}{l}0.105 \\
(0.46)\end{array}$ & $\begin{array}{l}-0.005 \\
(-1.73)\end{array}$ & $\begin{array}{l}0.057 \\
(5.49)\end{array}$ \\
\hline$\gamma * g * D 4$ & $\begin{array}{l}0.044 \\
(4.41)\end{array}$ & $\begin{array}{l}0.033 \\
(3.28)\end{array}$ & $\begin{array}{l}0.033 \\
(3.42)\end{array}$ & $\begin{array}{r}-1.2 \mathrm{E}-05 \\
(-0.84)\end{array}$ & $\begin{array}{l}0.352 \\
(2.46)\end{array}$ & $\begin{array}{l}-0.007 \\
(-1.58)\end{array}$ & $\begin{array}{l}0.048 \\
(4.11)\end{array}$ \\
\hline$\gamma * g * J 1$ & $\begin{array}{l}-0.173 \\
(-5.04)\end{array}$ & $\begin{array}{l}-0.184 \\
(-5.13)\end{array}$ & $\begin{array}{l}-0.174 \\
(-5.33)\end{array}$ & $\begin{array}{r}-5.3 \mathrm{E}-05 \\
(-1.15)\end{array}$ & $\begin{array}{l}-0.181 \\
(-0.45)\end{array}$ & $\begin{array}{l}-0.004 \\
(-0.69)\end{array}$ & $\begin{array}{l}-0.171 \\
(-4.89)\end{array}$ \\
\hline$\gamma * g * J 2$ & -0.039 & -0.050 & -0.039 & $-6.0 \mathrm{E}-05$ & 0.063 & -0.011 & -0.044 \\
\hline
\end{tabular}




\begin{tabular}{|c|c|c|c|c|c|c|c|}
\hline & & & e 2.3 & nued) & & & \\
\hline & $(-2.43)$ & $(-2.90)$ & $(-2.63)$ & $(-1.55)$ & $(0.33)$ & $(-1.44)$ & $(-2.84)$ \\
\hline$\gamma * g * J 3$ & -0.023 & -0.034 & -0.035 & $-9.6 \mathrm{E}-06$ & 0.020 & 0.000 & -0.032 \\
\hline & $(-1.71)$ & $(-2.35)$ & $(-2.60)$ & $(-0.41)$ & $(0.13)$ & $(0.24)$ & $(-1.91)$ \\
\hline$\gamma * g * J 4$ & -0.038 & -0.048 & -0.052 & 4.1E-06 & 0.068 & -0.007 & -0.056 \\
\hline & $(-2.56)$ & $(-3.15)$ & $(-3.26)$ & $(0.21)$ & $(0.30)$ & $(-5.45)$ & $(-3.78)$ \\
\hline$\gamma * g * X E$ & -0.126 & -0.126 & -0.122 & $-4.8 \mathrm{E}-06$ & -0.507 & 0.007 & -0.133 \\
\hline & $(-6.61)$ & $(-6.61)$ & $(-6.29)$ & $(-0.14)$ & $(-1.61)$ & (2.09) & $(-6.98)$ \\
\hline$\gamma * g * N Y E$ & -0.263 & -0.263 & -0.235 & $-1.2 \mathrm{E}-04$ & -0.895 & -0.008 & -0.277 \\
\hline & $(-3.85)$ & $(-3.85)$ & $(-3.30)$ & $(-1.96)$ & $(-1.25)$ & $(-8.61)$ & $(-4.48)$ \\
\hline$g$ & -0.001 & 0.000 & 0.000 & & -0.004 & & -0.001 \\
\hline & $(-7.52)$ & $(-2.48)$ & $(-2.71)$ & & $(-4.55)$ & & $(-8.34)$ \\
\hline$g *$ trend & & $-1.6 \mathrm{E}-05$ & & & & & \\
\hline & & $(-2.85)$ & & & & & \\
\hline $\ln (M E)$ & -0.006 & -0.007 & -0.007 & & 0.000 & & \\
\hline & $(-5.22)$ & $(-5.53)$ & $(-5.92)$ & & $(-0.20)$ & & \\
\hline $\ln (B M)$ & 0.009 & 0.011 & 0.005 & & -0.003 & & \\
\hline & $(2.50)$ & (3.17) & (1.69) & & $(-1.21)$ & & \\
\hline $\ln (M E) * J$ & -0.008 & -0.008 & -0.008 & & 0.001 & & \\
\hline & $(-8.86)$ & $(-8.87)$ & $(-8.81)$ & & $(0.41)$ & & \\
\hline$r_{-1: 0}$ & & & & & & & -0.003 \\
\hline & & & & & & & $(-6.02)$ \\
\hline$r_{-12:-1}$ & & & & & & & 0.000 \\
\hline & & & & & & & $(4.46)$ \\
\hline$r_{-36:-12}$ & & & & & & & 0.000 \\
\hline & & & & & & & $(-2.00)$ \\
\hline $\mathrm{V}$ & & & & & & & -0.001 \\
\hline & & & & & & & $(-3.03)$ \\
\hline $\ln (\mathrm{ME})$ & & & & & & & -0.007 \\
\hline & & & & & & & $(-5.72)$ \\
\hline
\end{tabular}

Overall, Tables 2.2 and 2.3 suggest that tax-motivated selling, captured by the interaction of $\gamma * g$, can explain the cross-section of firm level returns during the turn of the 
year. We test for the joint significance of December weekly coefficients for both tables, finding that December coefficients are always jointly significant at the $1 \%$ level, with the exception of the second regression in Table 2.2 Panel A, where the December coefficients are significant at the $5 \%$ level. January coefficients are jointly statistically significant at the $1 \%$ level for all regressions in both tables. ${ }^{21}$

We consider regression (1) in Table 2.3 to be our benchmark specification. The remaining regressions in Table 2.3 use this specification to test alternative hypotheses as well as document the robustness of our findings to different subsamples.

One alternative hypothesis is that $\gamma$ is simply capturing a downward trend in the capital gains overhang effect, instead of the joint effect of interest rates and capital gains tax rates as specified in the formulation we derived. As a consequence, regression (2) in Table 2.3 interacts a linear time trend (trend) with $g$. We find a negative and statistically significant coefficient on trend $* g$, which is consistent with a decreasing effect of $g$. However, this interaction does not subsume the $\gamma * g$ effect in December and January as coefficients remain roughly the same in magnitude and statistical significance. Regression (3) in considers the possibility that the interaction between $g$ and the linear time trend differs as a function of the week of the year. This more flexible trend specification still does not subsume the $\gamma * g$ effect as coefficients and t-statistics associated with $\gamma * g$ remain strong in the weeks around the turn of the year.

Another alternative hypothesis is that it is really only one component of $\gamma$ (either the interest rate or the capital gains tax rate) that is providing the forecasting power. Hence, we test whether interest rates $(r)$ or tax rates $(\tau)$ are individually important in explaining the time-series variation in the capital gains overhang effect. Regression (4) in Table 2.3 shows that neither $\tau$ nor $r$ in isolation interacts with $g$ in a consistent fashion, providing additional support for our claim that $\gamma$ is the correct conditioning variable.

\footnotetext{
${ }^{21}$ The test for $(J 1+J 2+J 3+J 4)+(D 1+D 2+D 3+D 4)=0$ yields an F-statistic of 3.85 with a p-value of 0.0499 . Thus, we just reject the hypothesis that the sum of December and January coefficients are equal.
} 
In order to test the robustness of our results, we also estimate a regression with the same specification as in Grinblatt and Han (2005) in regression (5). In this regression we measure the seasonal pattern in our suggested variable, $\gamma * g$, while controlling for patterns in average returns related to the one-month return, $r_{-1: 0}$, the one-year return $r_{-12:-1}$, the three-year return $r_{-36:-12}$, the average monthly turnover $\bar{V}$ over the past 12 months, and $S I Z E .^{22}$

$$
\begin{aligned}
r_{i, t}= & a_{1} \gamma_{t-1} g_{i, t-1} F N \\
& +a_{2} \gamma_{t-1} g_{i, t-1} D 1+a_{3} \gamma_{t-1} g_{i, t-1} D 2+a_{4} \gamma_{t-1} g_{i, t-1} D 3+a_{5} \gamma_{t-1} g_{i, t-1} D 4 \\
& +a_{6} \gamma_{t-1} g_{i, t-1} J 1+a_{7} \gamma_{t-1} g_{i, t-1} J 2+a_{8} \gamma_{t-1} g_{i, t-1} J 3+a_{9} \gamma_{t-1} g_{i, t-1} J 4 \\
& +a_{10} g_{i, t-1}+a_{11} r_{i,-1: 0}+a_{12} r_{i,-12:-1}+a_{13} r_{i,-36:-12} \\
& +a_{14} \bar{V}_{i, t-1}+a_{15} \ln M E_{i, t-1}+\varepsilon_{i, t}
\end{aligned}
$$

Again we find that the product of $\gamma$ and $g$ predicts returns in a manner consistent with our hypothesis. ${ }^{23}$

\section{U.K. Return Regressions}

The fact that the turn-of-the-tax-year coincides with the turn-of-the-calendar-year in the U.S. has resulted in a long debate as to whether tax-motivated trading or window dressing is causing the turn-of-the-year effect. Researchers have argued that window dressing could explain similar return patterns as fund managers sell losers and buy winners at the end of the reporting period to make their year-end portfolios look strong. Our approach

\footnotetext{
${ }^{22}$ Grinblatt and Han (2005) use a slightly different measure of size than Fama and French (1992). For consistency's sake, we use the appropriate definition in the corresponding specification. However, we ignore the minor difference between these two definitions of size when describing the results.

${ }^{23}$ We have re-estimated these equations using different tax rates, including both the average maximum tax rate and the average federal marginal tax rate from the NBER's TAXSIM dataset [see Feenberg and Coutts (1993)]. Our conclusions remain qualitatively the same. We report results using the maximum capital gains tax rate as that tax rate is available over the longest time period.
} 
helps distinguish between these two hypotheses as there does not seem to be any obvious reason that the magnitude of the window dressing effect would be related to time-series variation in $\gamma \cdot{ }^{24}$ Nevertheless, we take this concern seriously and turn to international data for further insight.

We test the same hypothesis with international data, choosing the U.K. because its tax year does not coincide with the calendar year. Specifically, the tax year in the U.K. begins on the 6th of April and ends on the 5th of April of the next calendar year. As a result, the U.K. provides a clean setup to test these two plausible hypotheses. Any seasonality in the U.K. stock market around the turn-of-the-tax-year would be strong evidence for tax-motivated trading causing seasonality in stock returns.

We are not the first to use U.K. data to test the tax-selling hypothesis. In particular, Reinganum and Shapiro (1987) show that after the introduction of capital gains taxes in the U.K., the difference in April returns between winners and losers becomes significantly greater than zero, consistent with a tax-loss selling story. Our primary empirical contribution is to show that this premium varies with the interest rate as predicted by our formulation. $^{25}$

The results using U.K. data provide further evidence of tax-motivated trading, as Table 2.4 shows results similar to Table 2.3. Seasonality in U.K. returns indeed occurs at the turn-of-the-tax-year and varies as a function of our tax-selling premium. All coefficients are positive in March and negative in April. Coefficients are jointly statistically significant at the $1 \%$ level in both March and April.

\footnotetext{
${ }^{24}$ Other researchers have examined tax-motivated price pressure stories that occur at times other than the turn of the year to rule out alternative explanations such as window dressing. See, for example, Guenther and Willenborg (1999), Blouin, Raedy and Shackelford (2003), and Dai, Maydew, Shackelford and Zhang (forthcoming).

${ }^{25}$ Other differences include the fact that Reinganum and Shapiro (1987) examine only monthly stock returns and use an arguably cruder proxy for a stock's capital gains overhang. In contrast, we use daily returns and measure capital gains overhang as in Grinblatt and Han (2005).
} 
Table 2.4: Pooled Return Regression Estimates (1954-2008)

We report the results from pooled regressions of day $t$ stock returns on $t-1$ characteristics using U.K. data. Characteristics are measured on a weekly basis for conciseness. All firm-specific variables, defined in Table 2.1 but computed with U.K. data, are cross-sectionally demeaned, and when appropriate, interacted with our proposed tax-selling premium variable $\gamma$, defined in Table 2.2 but computed with U.K. data, along with monthly or weekly dummy variables. The dummy variables are $R o Y$ and $U K(X)$ for the rest of the tax year and specific weeks of the tax year respectively, with $X$ representing the week of the tax year. Since the end of the tax year in the U.K. is the 5th of April, we define these weeks in relation to the end of the tax year. Therefore, the last week of the year is in effect the last 5 days before the end of the tax year, including days in April and March potentially. T-statistics (in parentheses) are robust to cross-correlation in the residuals using the clustered standard errors of Rogers (1983, 1993). The sample starts in January 1996 and ends in December 2008.

\begin{tabular}{ccc} 
& $(1)$ & $(2)$ \\
\hline$\gamma * g * R o Y$ & 0.032 & 0.041 \\
$\gamma * g * U K 49$ & $(1.58)$ & $(1.71)$ \\
& 0.131 & 0.142 \\
$\gamma * g * U K 50$ & 0.176 & 0.187 \\
& $(2.30)$ & $(2.38)$ \\
$\gamma * g * U K 51$ & 0.058 & 0.068 \\
& $(0.40)$ & $(0.47)$ \\
$\gamma * g * U K 52$ & 0.050 & 0.061 \\
& $(0.61)$ & $(0.72)$ \\
$\gamma * g * U K 1$ & -0.124 & -0.112 \\
& $(-1.41)$ & $(-1.28)$ \\
$\gamma * g * U K 2$ & -0.231 & -0.221 \\
& $(-2.47)$ & $(-2.33)$ \\
$\gamma * g * U K 3$ & -0.223 & -0.212 \\
& $(-2.34)$ & $(-2.20)$ \\
$\gamma * g * U K 4$ & -0.079 & -0.067 \\
& $(-1.44)$ & $(-1.19)$ \\
$\ln (M E)$ & & 0.000
\end{tabular}


Table 2.4 (Continued)

$\ln (B M) \quad 0.045$

$r_{-1: 0} \quad 0.000$

$r_{-12:-1} \quad 0.001$

$r_{-36:-12} \quad-0.001$

$(-2.69)$

\subsubsection{Cross-sectional and Time-series Variation in Trading Behavior}

The time-series and cross-sectional patterns we have found in firm-level returns are consistent with tax-motivated selling pressure. In this section, we examine further implications of that explanation, particularly the way our suggested variables explain sellerinitiated volume and the behavior of individual investors. First, we examine all trading volume at the turn of the year. Unlike previous research, we exploit a long panel of trading data, namely the TAQ database, and categorize all trades over the 1993-2005 period as small or large, buy or sell. ${ }^{26}$ Second, we also examine trading patterns by studying the actual trades of individual investors, obtained from Odean's dataset, to confirm that these investors harvest (defer) capital losses (gains) based on the level of our tax-selling premium.

\section{Seller-initiated Trading Volume}

We build on the results of the previous subsection to test our framework's ability to explain time-series and cross-sectional variation in seller-initiated trades as a whole as well

\footnotetext{
${ }^{26}$ In contrast, Sias and Starks (1997) use TAQ data from only December 1990 and January 1991 to examine a similar question.
} 
as in small and large trade subsets. We examine these subsets as previous research has argued that small trades are primarily from individuals while large trades are primarily from institutions. We would expect negative overhang stocks to have high selling pressure in December followed by low selling pressure in January. Similarly, we expect the opposite effect in the case of positive overhang stocks.

In Table 2.5, we forecast the level of selling pressure $\left(S e l l, S e l l_{S}, S e l l_{L}\right)$ in Panel A and the first difference of those variables in Panel B. Throughout the Table, we use the same independent variables as Table 2.2 Panel B regression (5). Specifically, we estimate

$$
\begin{aligned}
\text { Sell }_{i, t}= & a_{1} \gamma_{t-1} g_{i, t-1} F N \\
& +a_{2} \gamma_{t-1} g_{i, t-1} D 1+a_{3} \gamma_{t-1} g_{i, t-1} D 2+a_{4} \gamma_{t-1} g_{i, t-1} D 3+a_{5} \gamma_{t-1} g_{i, t-1} D 4 \\
& +a_{6} \gamma_{t-1} g_{i, t-1} J 1+a_{7} \gamma_{t-1} g_{i, t-1} J 2+a_{8} \gamma_{t-1} g_{i, t-1} J 3+a_{9} \gamma_{t-1} g_{i, t-1} J 4 \\
& +a_{10} g_{i, t-1}+a_{11} r_{i,-1: 0}+a_{12} r_{i,-12:-1}+a_{13} r_{i,-36:-12} \\
& +a_{14} \bar{V}_{i, t-1}+a_{15} \ln M E_{i, t-1}+\varepsilon_{i, t}
\end{aligned}
$$

in Panel A and

$$
\begin{aligned}
\text { Sell }_{i, t}- & \text { Sell }_{i, t-1}=a_{1} \gamma_{t-1} g_{i, t-1} F N \\
& +a_{2} \gamma_{t-1} g_{i, t-1} D 1+a_{3} \gamma_{t-1} g_{i, t-1} D 2+a_{4} \gamma_{t-1} g_{i, t-1} D 3+a_{5} \gamma_{t-1} g_{i, t-1} D 4 \\
& +a_{6} \gamma_{t-1} g_{i, t-1} J 1+a_{7} \gamma_{t-1} g_{i, t-1} J 2+a_{8} \gamma_{t-1} g_{i, t-1} J 3+a_{9} \gamma_{t-1} g_{i, t-1} J 4 \\
& +a_{10} g_{i, t-1}+a_{11} r_{i,-1: 0}+a_{12} r_{i,-12:-1}+a_{13} r_{i,-36:-12} \\
& +a_{14} \bar{V}_{i, t-1}+a_{15} \ln M E_{i, t-1}+\varepsilon_{i, t}
\end{aligned}
$$

in Panel B. Note that we expect both $S e l l_{i, t}$ and $S e l l_{i, t}-S e l l_{i, t-1}$ to move in the opposite direction of the predicted return; and, therefore, we now expect a positive (negative) slope 
in January (December) on our tax-selling variable. As in the return regressions, all firmlevel variables are cross-sectionally demeaned. Standard errors are robust to simultaneous correlation both across firms and across years (Thompson, 2011).

We do find that both returns and selling pressure exhibit similar seasonality, as selling pressure results are consistent with the return regressions shown in Table 2.2. Panel A in Table 2.5 reports the results from regressions forecasting the level of selling pressure. We find that December slopes on $\gamma * g$ are all negative and highly statistically significant, indicating taxable investors are selling negative overhang stocks and holding on to positive overhang stocks in December. As expected, January exhibits the opposite pattern.

For example, in the last week of December, the coefficient on $\gamma * g$ is -1.893 with a $t$-statistic in excess of 11 . Then, in the case of a negative overhang stock, selling pressure reverses into buying pressure after the turn of the year as slopes on $\gamma * g$ turn positive in January. Specifically, we find a reversal in selling pressure in the first week of January with a statistically-significant coefficient of 1.718. These results are economically quite large, at least when compared to the coefficient on $\gamma * g$ of -0.001 throughout February and November. We also find that the coefficients associated with the business days before Christmas and New Year's Day are consistent with the corresponding coefficient estimates of the return regressions.

Table 2.5: Pooled Selling Pressure Regression Estimates (1954-2008)

We report the results from pooled regressions of the day $t$ change in (or level of) selling pressure (for either small or large sized trades) on $t-1$ characteristics. Characteristics are measured on a weekly basis for conciseness. Panel A reports results with the level of selling pressure, while Panel B shows results with the change in that level. In both cases, we split the sample into small and large trades. All firm-specific variables, defined in Table 2.1, are cross-sectionally demeaned, and when appropriate, then interacted with our tax-selling premium variable, $\gamma$, and with dummy variables corresponding to different periods of the year. These dummy variables as well as $\gamma$ are defined in Table 2.2. T-statistics (in parentheses) are robust to simultaneous correlation both across firms and across years based on the method developed by Thompson (2011). The sample starts in February of 1993 and ends in January 2005.

Panel A

Panel B 
Table 2.5 (Continued)

\begin{tabular}{|c|c|c|c|c|c|c|}
\hline & & \\
\hline & $\begin{array}{l}\text { all } \\
(1)\end{array}$ & $\begin{array}{c}\text { small } \\
(2)\end{array}$ & $\begin{array}{c}\text { large } \\
(3)\end{array}$ & $\begin{array}{l}\text { all } \\
(1)\end{array}$ & $\begin{array}{c}\text { small } \\
(2)\end{array}$ & $\begin{array}{l}\text { large } \\
(3)\end{array}$ \\
\hline \multirow[t]{2}{*}{$\gamma * g * F N$} & -0.001 & -0.080 & -0.799 & -0.020 & -0.027 & -0.013 \\
\hline & $(-0.01)$ & $(-0.48)$ & $(-3.98)$ & $(-1.29)$ & $(-1.6)$ & $(-0.44)$ \\
\hline \multirow[t]{2}{*}{$\gamma * g * D 1$} & -0.946 & -1.165 & -1.201 & -0.126 & -0.146 & 0.015 \\
\hline & $(-4.67)$ & $(-4.75)$ & $(-4.26)$ & $(-1.42)$ & $(-2.02)$ & $(0.12)$ \\
\hline \multirow[t]{2}{*}{$\gamma * g * D 2$} & -0.965 & -1.304 & -1.151 & -0.040 & -0.081 & 0.002 \\
\hline & $(-6.93)$ & $(-5.8)$ & $(-7.11)$ & $(-0.77)$ & $(-1.7)$ & $(0.02)$ \\
\hline \multirow[t]{2}{*}{$\gamma * g * D 3$} & -1.380 & -1.608 & -1.859 & -0.141 & -0.142 & -0.225 \\
\hline & $(-8.88)$ & $(-7.52)$ & $(-10.54)$ & $(-1.97)$ & $(-1.96)$ & $(-1.5)$ \\
\hline \multirow[t]{2}{*}{$\gamma * g * D 4$} & -1.893 & -1.965 & -2.241 & -0.176 & -0.079 & -0.233 \\
\hline & $(-11.18)$ & $(-9.36)$ & $(-9.84)$ & $(-3.03)$ & $(-1.71)$ & $(-1.5)$ \\
\hline \multirow[t]{2}{*}{$\gamma * g * J 1$} & 1.718 & 1.650 & 1.035 & 0.487 & 0.421 & 0.242 \\
\hline & $(4.18)$ & (3.96) & $(2.72)$ & $(3.27)$ & $(2.73)$ & $(2.15)$ \\
\hline \multirow[t]{2}{*}{$\gamma * g * J 2$} & 0.966 & 0.875 & 0.055 & -0.089 & -0.045 & -0.181 \\
\hline & (5.93) & (5.4) & $(0.37)$ & $(-1.17)$ & $(-0.59)$ & $(-2.98)$ \\
\hline \multirow[t]{2}{*}{$\gamma * g * J 3$} & 0.747 & 0.713 & -0.250 & 0.107 & 0.048 & 0.214 \\
\hline & $(4.5)$ & (3.67) & $(-1.16)$ & (3.37) & $(1.56)$ & $(3.95)$ \\
\hline \multirow[t]{2}{*}{$\gamma * g * J 4$} & 0.587 & 0.543 & -0.194 & 0.066 & 0.080 & 0.148 \\
\hline & $(3.86)$ & $(2.66)$ & $(-0.81)$ & $(1.14)$ & $(1.54)$ & (1.59) \\
\hline \multirow[t]{2}{*}{$\gamma * g * X E$} & 0.390 & 0.207 & 1.173 & 0.090 & 0.006 & 0.954 \\
\hline & (2.6) & $(1.71)$ & $(4.29)$ & $(0.46)$ & $(0.04)$ & $(4.01)$ \\
\hline \multirow[t]{4}{*}{$\gamma * g * N Y E$} & 0.230 & 0.593 & 0.198 & 0.521 & 0.675 & 0.660 \\
\hline & $(1.51)$ & $(4.22)$ & $(0.74)$ & (4.2) & $(4.71)$ & (1.5) \\
\hline & -0.001 & -0.001 & 0.007 & 0.000 & 0.000 & 0.000 \\
\hline & $(-1.88)$ & $(-2.4)$ & (3.69) & $(-0.41)$ & $(-0.72)$ & $(-0.89)$ \\
\hline \multirow[t]{2}{*}{$r_{-1: 0}$} & -0.008 & 0.003 & -0.010 & 0.012 & 0.011 & 0.012 \\
\hline & $(-3.95)$ & (1.03) & $(-4.78)$ & $(7.2)$ & $(8.32)$ & (7.49) \\
\hline \multirow[t]{2}{*}{$r_{-12:-1}$} & -0.002 & -0.005 & 0.000 & 0.000 & 0.000 & 0.000 \\
\hline & $(-1.61)$ & $(-2.29)$ & $(-0.16)$ & (1.54) & $(2.14)$ & $(2.26)$ \\
\hline \multirow[t]{2}{*}{$r_{-36:-12}$} & -0.001 & -0.003 & 0.001 & 0.000 & 0.000 & 0.000 \\
\hline & $(-1.16)$ & $(-2.84)$ & (1.58) & $(0.4)$ & $(-0.05)$ & $(-0.32)$ \\
\hline$V$ & -0.060 & -0.018 & -0.071 & 0.000 & 0.001 & -0.001 \\
\hline
\end{tabular}




\begin{tabular}{ccccccc}
\multicolumn{7}{c}{ Table 2.5 (Continued) } \\
$\ln (M E)$ & $(-4.55)$ & $(-1.65)$ & $(-7.61)$ & $(0.7)$ & $(0.93)$ & $(-1.17)$ \\
& -1.666 & -1.410 & -1.495 & 0.031 & 0.029 & 0.012 \\
& $(-13.33)$ & $(-10.48)$ & $(-12.32)$ & $(6.91)$ & $(8.53)$ & $(1.66)$
\end{tabular}

The analysis in Section 2.1 indicates that we should expect $\gamma * g$ to forecast the level of selling pressure. Nevertheless, we find that results remain statistically significant even when we forecast changes in selling pressure. In this case, we are analyzing whether the change in selling pressure of low/negative capital gains overhang stocks increases as we approach the end of the year. Panel B shows that this increase indeed occurs, as coefficients in December are all negative. The selling pressure of low overhang stocks increases over the course of December (negative coefficients), but suddenly declines in the first week of January (positive coefficient). Note that the slope on the NYE dummy interaction is positive and highly statistically significant, implying a large change in selling pressure just before the turn of the year.

In both panels we also split the data into small and large trades. We do this as past research (Lee and Ready (1991) and others) has associated small trades with buying by individual investors and large trades with buying by institutional investors. We find the reversal in selling pressure to be strong and more statistically significant in the case of small trades, but present for both subsets. Though the results for small and large trades are very similar, the January slopes in Panel A seem to be slightly higher for small trades. Interestingly, the savvy buying pressure in the last week of the year seems to come from institutional investors on Christmas Eve and from individual investors on New Year's Eve.

Past research has looked for similar links between returns and selling pressure. Ritter (1988) finds that individual investors who are customers at Merrill Lynch place more sell orders in December than in January. While this finding is consistent with tax selling, a limitation is that it focuses only on a small subgroup of investors. Sias and Starks (1997) show that individuals sell stocks at the end of the year. This evidence is consistent with 
tax-motivated selling, but they find the individuals also sell past one-year winners in December. They view this result as inconsistent with tax selling, but to the extent that return momentum is a poor proxy for capital gains overhang, it may be difficult to draw conclusions about tax-motivated selling from their results. Another limitation of Sias and Starks (1997) is that they use TAQ data from only December 1990 and January 1991.

\section{Actual Individual Trades}

We examine trading patterns by studying the actual trades of individual investors to confirm that these investors harvest (defer) capital losses (gains) based on the level of our tax-selling variables. In particular, Figure 2.1 reports the results of what is essentially a difference-in-difference test of the trading implications of equation (1). That figure shows the difference in the propensity to realize capital gains/losses in December compared to January, for different levels of $\gamma$. In particular, we split the sample into above-median and below-median $\gamma$.

We process all of the trades in the Odean dataset in the following way. We follow each stock in the database from the time it was purchased until the time it was eventually sold. We keep track of the close for that stock at the end of each day in between the purchase date and the eventual sell date, using every closing price to calculate an unrealized capital gain/loss. For each of eleven evenly-spaced bins ranging from $-100 \%$ to $>100 \%$, these unrealized gains and losses are then compared to observed realized gains and losses to measure a tendency for investors to sell as a function of capital gain/loss. Then for each bin, we subtract the January propensity to sell from the December propensity to sell. These turn-of-the-year differences to sell are plotted separately for high $\gamma$ years and low $\gamma$ years. The average value of $\gamma$ for the high $\gamma$ years subset is 0.040 , while the average value of $\gamma$ for the low $\gamma$ years subset is 0.022 .

There are two strong conclusions to draw from the figure. First, investors tend to accelerate the realization of capital losses in December (compared to January). Second, this

tendency is much higher in those years when $\gamma$ is higher. Together these two facts confirm 


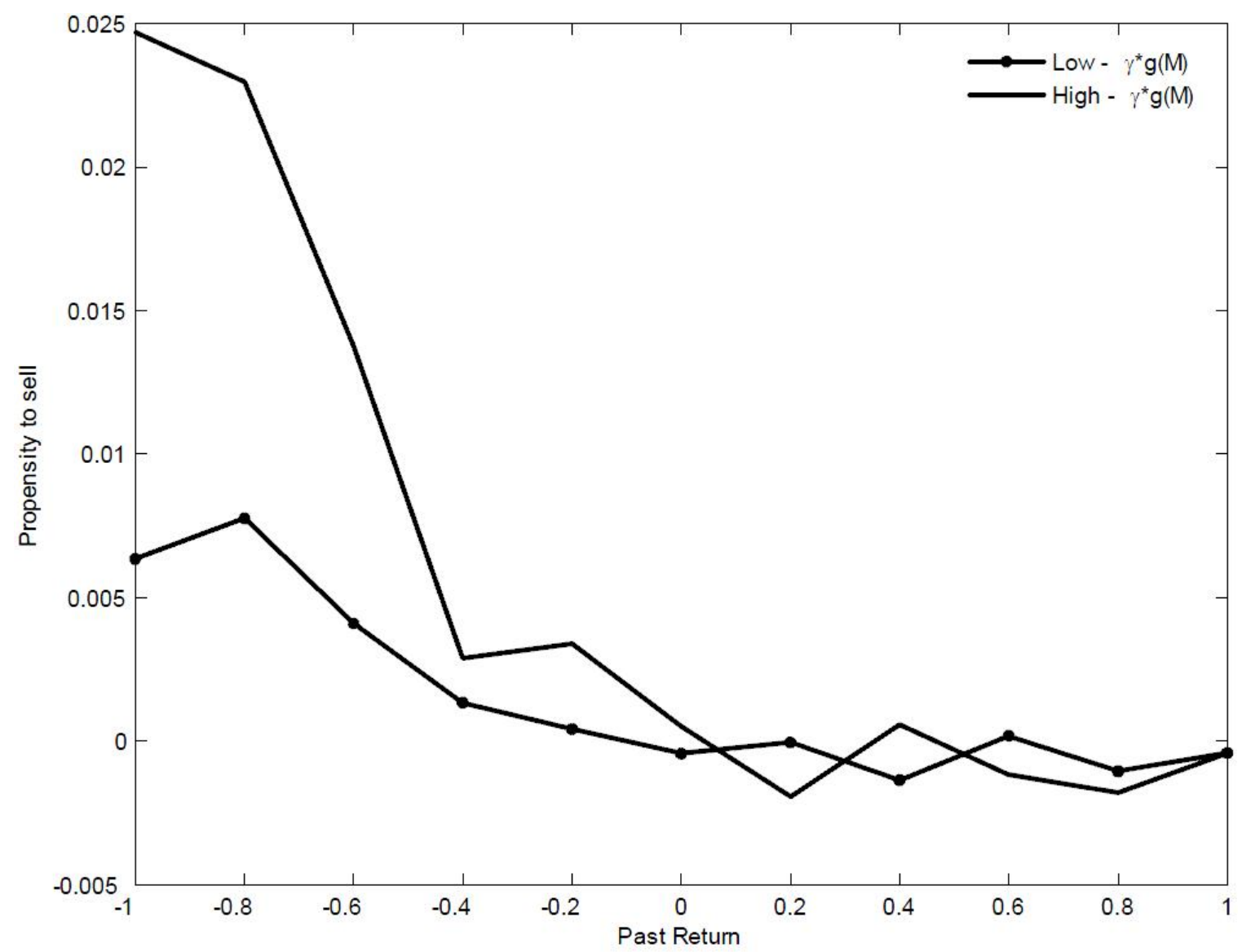

Figure 2.1: Tax-Selling Propensity

This figure shows the propensity of taxable investor to sell winners and losers at the turn of the year using the dataset studied in Odean (1998). For each stock in the dataset, we calculate a unrealized capital gain/loss from the time the investor purchased the stock until it was eventually sold. For each of eleven evenly-spaced bins ranging from $-100 \%$ to $>100 \%$, we compare these unrealized gains and losses to observed gains and losses. We then plot the difference in the percentage of realized gains and losses in December versus January, where the percentage is averaged over each return bucket. The data is split into years that are predicted to have either a low or a high tax-selling propensity for the market portfolio, $-\gamma * g(M)$, as discussed in the paper. The solid-dotted line represents the December propensity minus the January propensity for the years where the tax-selling propensity is predicted to be low and the solid line represents the December propensity minus the January propensity for the years where the tax-selling propensity is predicted to be high. 
the central prediction of our conjecture: investors' propensity to sell at the turn of the year depends on the product of the capital gains overhang, $g$, and the tax-selling premium, $\gamma$, which is a function of the interest and tax rate environment. Our framework also suggests that investors may delay realizing capital gains in high $\gamma$ years. However, because of the non-linear relation between capital gains and capital gain overhang, a relatively large capital gain results in a relatively small amount of overhang. Consequently, one would not expect variation in $\gamma$ to generate much variation in selling probabilities for stocks with unrealized capital gains, and it does not.

\subsubsection{Implications for Performance Attribution}

Our analysis has tried to measure the firm-specific and aggregate variables that drive cross-sectional and time-series patterns in average returns at the turn of the year. To do so, we have used a particular measure of firm-specific capital gains overhang and have controlled for other well-known patterns in the cross-section such as a stock's size, its book-to-market equity ratio, and its return momentum that are known to be correlated with our particular measure of a firm's capital gains overhang.

However, given this correlation, a natural complementary question to ask is the following: To what extent can the tax-selling effect drive market beta and the abnormal return associated with bets on the size, book-to-market, and momentum characteristics? To answer these questions, we first document the extent to which the market return can be forecast by our tax-selling variables. We then estimate conditional CAPM time-series regressions pricing the three Fama-French/Carhart non-market factors.

First, we test whether tax-motivated selling can explain aggregate returns in January. To do so, we measure $g_{M}$, the value-weighted average of firm-level measures of $g$. Table 2.6 shows that $\gamma * g_{M}$ does predict market returns in January in all of the specifications we consider. This effect is both statistically and economically significant. Specifically, based on the specification of Table 2.6 regression 1, a one standard deviation increase in the joint 
product of $\gamma * g_{M}$ results in a decrease in the equity premium of approximately one percent. We also report the results of specifications that control for the independent effect of $\gamma$ or $g_{M}$. Note that we find a statistically significant relationship despite the inclusion of the aggregate book-to-market variable in these regressions.

Table 2.6: Aggregate Time-Series Regression Estimates (1954-2008)

We report the results from monthly regressions forecasting the excess return on the market portfolio with our tax-selling premium variable, $\gamma$, defined in Table 2.2 and the value-weight average, $g_{M}$, of the firmlevel capital gains overhang, $g$, defined in Table 2.1. We also include in these regression the value-weight average, $B M_{M}$, of the firm-level book-to-market ratio, $B M$, also defined in Table 2.1. The sample starts in February of 1954 and ends in December 2008.

\begin{tabular}{|c|c|c|c|c|c|c|c|c|c|c|}
\hline \multicolumn{3}{|c|}{$\gamma * g_{M}$} & \multicolumn{3}{|c|}{$g_{M}$} & \multicolumn{3}{|c|}{$\gamma$} & \multirow[t]{2}{*}{$B M_{M}$} & \multirow[t]{2}{*}{$R^{2}$} \\
\hline $\mathrm{FN}$ & D & $\mathrm{J}$ & $\mathrm{FN}$ & $\mathrm{D}$ & $\mathrm{J}$ & $\mathrm{FN}$ & $\mathrm{D}$ & $\mathrm{F}$ & & \\
\hline 0.426 & 1.406 & -3.742 & & & & & & & 0.771 & 0.012 \\
\hline$(0.63)$ & $(0.86)$ & $(-2.04)$ & & & & & & & (1.64) & \\
\hline-1.304 & -2.155 & -7.359 & 0.052 & 0.104 & 0.098 & & & & 0.804 & 0.025 \\
\hline$(-1.20)$ & $(-0.76)$ & $(-2.16)$ & $(2.18)$ & (1.66) & $(1.38)$ & & & & $(1.71)$ & \\
\hline 0.612 & 1.012 & -5.550 & & & & -0.438 & -0.169 & 0.255 & 1.283 & 0.031 \\
\hline$(0.89)$ & $(0.60)$ & $(-2.81)$ & & & & $(-2.93)$ & $(-0.60)$ & $(0.86)$ & $(2.50)$ & \\
\hline
\end{tabular}

As we find that market returns are indeed affected by tax-selling behavior, we estimate conditional CAPM time-series regressions that include $\gamma * g$ as a conditioning variable. In these regressions, we analyze the three Fama-French/Carhart non-market factors. We choose these three factors because of their widespread use in academic research. In particular, these factors represent more reasonable implementations of strategies based on size, book-to-market, or momentum characteristics than the strategies implicit in our earlier cross-sectional regression tests. For comparability, we create a zero-cost overhang factor that is formed in a similar way to the momentum factor of Carhart. Specifically, each month we sort all NYSE stocks on our overhang measure and calculate 20th and 80th percentile breakpoints. We then buy all NYSE-AMEX-NASDAQ stocks that are below 
the NYSE 20th percentile and sell all NYSE-AMEX-NASDAQ stocks that are above the NYSE 80th percentile. The positions in the long and short sides are value-weight. Thus, we will be able to show both the extent to which a tax-selling premium is a component of the premiums on these well-known factors as well as the nature of the tax-selling premium on value-weight positions based on a traditional sorting approach.

Figure 2.2 plots the January return on the TAX factor for each of the years of the sample against an OLS forecast of the expected January return on the TAX factor using the product of the tax-selling premium and the factor's capital gains overhang, $\gamma * g_{T A X}$. As detailed in the figure's legend, the regression coefficient in that regression is -1.99 with an associated t-statistic of -3.52 . That regression's adjusted $R^{2}$ is $17.7 \%$. These statistics and this figure confirm that there is a time-series relation between the January return on TAX and our predicted January rebound return as well as documents that the average January return on TAX is positive. ${ }^{27}$ Moreover, these results confirm that the general conclusion from the firm-level regression analysis is robust to weighting firms by market capitalization.

The specification of our conditional CAPM regression follows from two of our results. Specifically, we have shown that 1) there is time-series and seasonal variation around the turn of the year in the cross-sectional premium for the capital gains overhang variable and 2) this variation can be observed at the market level as well. The first finding indicates that our conditional CAPM regression should have the intercept be a function of the trading strategy's forecasted December dislocation and January rebound. That premium, of course, will depend on the trading strategy's beginning-of-period capital gains overhang, the tax-selling premium which depends on the beginning-of-period tax and interest rates, and the particular month in question, as we derived in Section 2.1. Not only do we al-

\footnotetext{
${ }^{27}$ One could arguably attribute the large positive realized return (35\%) on the TAX factor in January 2001 to to the large negative return to a momentum strategy $(-24 \%)$ in January as the tech boom subsided. Regardless, the 2001 observation is not influential. In fact the $t$-statistic and $R^{2}$ increase to -4.72 and $29.08 \%$ respectively when that observation is dropped from the sample.

Note that the relation in Figure 2.2 continues to be statistically significant if one instead predicts CAPMadjusted returns instead of raw returns as in the figure. If one imposes a regression coefficient of -1 , the resulting intercept is statistically insignificant from zero under either benchmarking approach.
} 


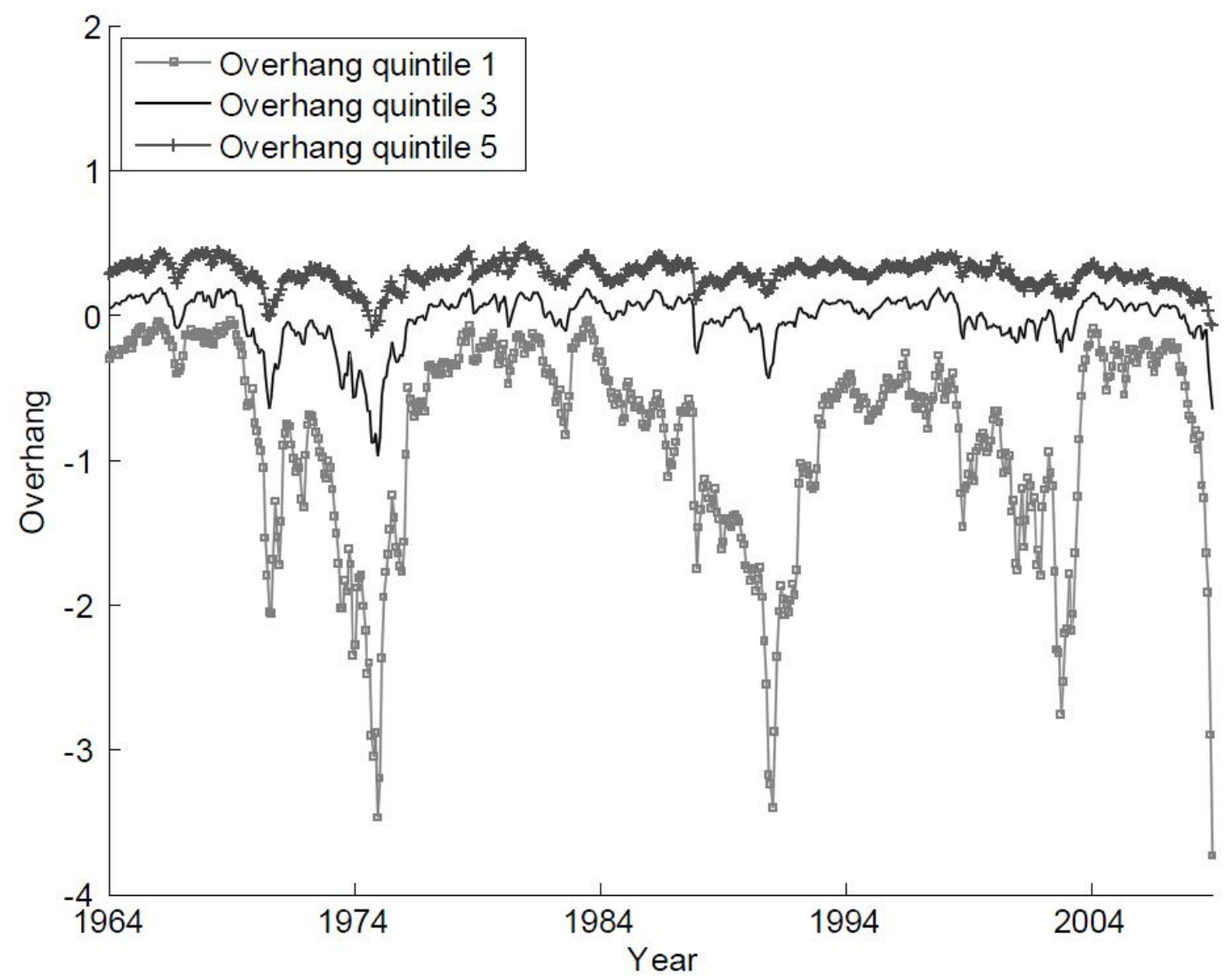

Figure 2.2: Capital Gains Overhang

This figure plots the value-weight capital gains overhang of the bottom, middle, and top capital-gainsoverhang-sorted quintile portfolios. The sorts are based on NYSE breakpoints. The sample period is January 1964 to December 2008. 
low the alpha in our CAPM regression to vary through time but we also consider time variation in the regression's market beta. Cochrane (2001) points out that a time-varying CAPM beta only affects pricing to the extent that the beta is correlated with time-variation in the market premium. Therefore, the second finding (the market's tax-selling premium forecasts the subsequent excess return on the market) indicates that our conditional CAPM regressions should have a time-varying beta that is a function of the market's forecasted December dislocation and January rebound. As at the firm level, that predictable return will depend on the market's beginning-of-period capital gains overhang, the tax-selling premium (which depends on the beginning-of-period tax and interest rates), and the particular month in question.

Table 2.7 summarizes the extent to which cross-sectional and time-series variation in tax-selling premiums drive conditional alphas and betas for the three well-known factor portfolios HML, SMB, UMD and our low-minus-high overhang portfolio, which we denote as TAX. Note that we attribute performance of the returns on the actual factors generated by Ken French (obtained from his web site). However, we can only proxy for the capital gains overhang of French's factors as not all of the stocks in the factor portfolios have the necessary data our measure requires. In particular, while our firm-level overhang measure requires five years of price and volume data, these strategies do not. Presumably, our findings would be have been strengthened if instead, we had priced the return on factors whose construction imposed a five-year data requirement as well.

The first regression of each panel in Table 2.7 first documents the extent of seasonality in the CAPM alpha of the factors being considered. For TAX, HML, and SMB, a significant portion of their average abnormal return occurs in January. For UMD, the strong average returns outside of the turn of the year are partially offset by a very large negative premium in January.

The second regression of each panel in Table 2.7 then demonstrates that variation in the market's tax-selling effect drives beta at the turn of the year. For the three factor portfolios TAX, HML, and SMB, when the market's forecasted tax-selling January rebound, $-\gamma * g_{M}$, 
is relatively high, January betas are predictably relatively high as well. ${ }^{28}$ In each of these cases, December betas are correspondingly relatively low, though only the SMB estimate is statistically significant. As one might expect from the evidence in Table 2.1, we find the opposite effect for the momentum portfolio. The January beta for the momentum portfolio is predictably higher when the market's tax-selling premium is relatively low. Since Table 2.6 shows that the market's tax-selling premium forecasts the excess return on the market, it is not surprising that controlling for this conditional beta effect reduces the absolute magnitude of the alpha of these four trading strategies in January.

\footnotetext{
${ }^{28}$ For the sake of interpretability, we normalize the time-series $\gamma * g_{M}$ so that the coefficients on $R M R F$ represent the average beta during the months in question and the coefficient on $\gamma * g_{M} * R M R F$ represent the change in beta for a one standard deviation move in $\gamma * g_{M}$.
} 
Table 2.7: Portfolio Time-Series Regression Estimates (1954-2008)

We report the results from monthly regressions forecasting the CAPM alpha for four factor portfolios using the portfolio-specific tax-selling capital gains overhang. $R M R F, S M B, H M L$, and $U M D$ are from Ken French's website. Our measurement of each factor's capital gains overhang comes from portfolios that only include stocks that have capital gains overhang data available. We interact RMRF with our measure of the market's capital gains overhang, $g_{M}$, described in Table 2.6. Dummy variables corresponding to periods of the year as well as our tax-selling premium variable, $\gamma$, are also included in the interactions. These dummy variables as well as $\gamma$ are defined in Table 2.2. $\gamma * g_{M}$ is standardized for interpretability.

\begin{tabular}{|c|c|c|c|c|c|c|}
\hline & \multicolumn{3}{|c|}{ Panel A: TAX } & \multicolumn{3}{|c|}{ Panel B: HML } \\
\hline & $(1)$ & (2) & (3) & (1) & (2) & (3) \\
\hline \multirow[t]{2}{*}{ Intercept $* F N$} & -0.027 & -0.027 & -0.028 & 0.002 & 0.002 & 0.003 \\
\hline & $(-14.32)$ & $(-14.70)$ & $(-10.32)$ & $(2.59)$ & $(2.55)$ & (1.96) \\
\hline \multirow[t]{2}{*}{ Intercept $* D$} & -0.037 & -0.032 & -0.031 & 0.003 & 0.003 & 0.000 \\
\hline & $(-6.07)$ & $(-4.99)$ & $(-3.46)$ & $(1.00)$ & $(0.97)$ & $(0.06)$ \\
\hline \multirow[t]{2}{*}{ Intercept $* J$} & 0.030 & 0.025 & 0.009 & 0.015 & 0.013 & 0.012 \\
\hline & $(4.95)$ & $(4.12)$ & $(0.96)$ & $(4.94)$ & $(4.35)$ & $(2.71)$ \\
\hline \multirow[t]{2}{*}{$\gamma * g * F N$} & & & -0.036 & & & 0.019 \\
\hline & & & $(-0.28)$ & & & $(0.30)$ \\
\hline \multirow[t]{2}{*}{$\gamma * g * D$} & & & 0.038 & & & -0.158 \\
\hline & & & $(0.11)$ & & & $(-0.88)$ \\
\hline \multirow[t]{2}{*}{$\gamma * g * J$} & & & -1.124 & & & -0.055 \\
\hline & & & $(-2.37)$ & & & $(-0.23)$ \\
\hline \multirow[t]{2}{*}{$R M R F * F N$} & & 0.284 & 0.285 & & -0.165 & -0.165 \\
\hline & & $(6.35)$ & $(6.37)$ & & $(-7.38)$ & $(-7.37)$ \\
\hline \multirow[t]{2}{*}{$R M R F * D$} & & 0.004 & 0.002 & & -0.159 & -0.149 \\
\hline & & $(0.02)$ & $(0.01)$ & & $(-1.77)$ & $(-1.64)$ \\
\hline \multirow[t]{2}{*}{$R M R F * J$} & & 0.261 & 0.224 & & -0.142 & -0.144 \\
\hline & & $(2.08)$ & $(1.77)$ & & $(-2.27)$ & $(-2.28)$ \\
\hline \multirow[t]{2}{*}{$\gamma * g_{M} * R M R F * F N$} & & -0.025 & -0.026 & & 0.022 & 0.023 \\
\hline & & $(-1.03)$ & $(-1.05)$ & & $(1.84)$ & $(1.86)$ \\
\hline \multirow[t]{2}{*}{$\gamma * g_{M} * R M R F * D$} & & -0.395 & -0.387 & & -0.086 & -0.120 \\
\hline & & $(-2.41)$ & $(-2.14)$ & & $(-1.05)$ & $(-1.32)$ \\
\hline \multirow[t]{2}{*}{$\gamma * g_{M} * R M R F * J$} & & 0.382 & 0.268 & & 0.090 & 0.084 \\
\hline & & $(6.08)$ & $(3.38)$ & & $(2.87)$ & (2.13) \\
\hline \multirow[t]{2}{*}{$R M R F$} & 0.297 & & & -0.163 & & \\
\hline & (7.15) & & & $(-8.07)$ & & \\
\hline$R^{2}$ & 0.32 & 0.35 & 0.37 & 0.12 & 0.13 & 0.13 \\
\hline
\end{tabular}




\begin{tabular}{|c|c|c|c|c|c|c|}
\hline & \multicolumn{6}{|c|}{ Table 2.7 (Continued) } \\
\hline & \multicolumn{3}{|c|}{ Panel C: SMB } & \multicolumn{3}{|c|}{ Panel D: UMD } \\
\hline & (1) & (2) & (3) & (1) & (2) & (3) \\
\hline \multirow[t]{2}{*}{ Intercept $* F N$} & 0.000 & 0.000 & 0.001 & 0.009 & 0.008 & 0.008 \\
\hline & $(0.11)$ & $(0.00)$ & $(0.85)$ & $(5.57)$ & $(5.53)$ & (3.73) \\
\hline \multirow[t]{2}{*}{ Intercept $* D$} & 0.002 & 0.003 & 0.008 & 0.020 & 0.017 & 0.014 \\
\hline & $(0.47)$ & $(0.90)$ & $(1.54)$ & $(4.02)$ & $(3.28)$ & (1.95) \\
\hline \multirow[t]{2}{*}{ Intercept $* J$} & 0.021 & 0.019 & 0.007 & -0.016 & -0.014 & -0.006 \\
\hline & $(5.70)$ & $(5.16)$ & $(1.23)$ & $(-3.33)$ & $(-2.86)$ & $(-0.82)$ \\
\hline \multirow[t]{2}{*}{$\gamma * g * F N$} & & & 0.090 & & & -0.010 \\
\hline & & & $(1.17)$ & & & $(-0.10)$ \\
\hline \multirow[t]{2}{*}{$\gamma * g * D$} & & & 0.272 & & & -0.152 \\
\hline & & & $(1.27)$ & & & $(-0.52)$ \\
\hline \multirow[t]{2}{*}{$\gamma * g * J$} & & & -0.837 & & & 0.555 \\
\hline & & & $(-2.95)$ & & & $(1.43)$ \\
\hline \multirow[t]{2}{*}{$R M R F * F N$} & & 0.127 & 0.125 & & -0.067 & -0.067 \\
\hline & & $(4.75)$ & $(4.69)$ & & $(-1.85)$ & $(-1.84)$ \\
\hline \multirow[t]{2}{*}{$R M R F * D$} & & 0.015 & -0.003 & & 0.042 & 0.052 \\
\hline & & $(0.14)$ & $(-0.03)$ & & $(0.28)$ & $(0.35)$ \\
\hline \multirow[t]{2}{*}{$R M R F * J$} & & 0.056 & 0.028 & & -0.019 & -0.001 \\
\hline & & $(0.74)$ & $(0.37)$ & & $(-0.19)$ & $(-0.01)$ \\
\hline \multirow[t]{2}{*}{$\gamma * g_{M} * R M R F * F N$} & & 0.032 & 0.034 & & 0.074 & 0.074 \\
\hline & & $(2.20)$ & $(2.30)$ & & $(3.75)$ & (3.73) \\
\hline \multirow[t]{2}{*}{$\gamma * g_{M} * R M R F * D$} & & -0.177 & -0.119 & & 0.356 & 0.324 \\
\hline & & $(-1.80)$ & $(-1.11)$ & & $(2.66)$ & $(2.20)$ \\
\hline \multirow[t]{2}{*}{$\gamma * g_{M} * R M R F * J$} & & 0.162 & 0.077 & & -0.207 & -0.151 \\
\hline & & $(4.31)$ & $(1.64)$ & & $(-4.05)$ & $(-2.33)$ \\
\hline \multirow[t]{2}{*}{$R M R F$} & 0.114 & & & -0.091 & & \\
\hline & $(4.64)$ & & & $(-2.70)$ & & \\
\hline$R^{2}$ & 0.08 & 0.12 & 0.15 & 0.09 & 0.11 & 0.12 \\
\hline
\end{tabular}

Figure 2.3 uses higher-frequency estimates of the beta of the components of the TAX bet to confirm that the link between the market risk of the TAX bet and the market's fore- 
casted tax-selling January rebound return is particularly present in the days surrounding the turn of the year. Specifically, Figure 2.3 graphs five-day rolling betas throughout December and January for low, middle, and high overhang quintile portfolios. ${ }^{29}$ When the market has a relatively high forecasted January rebound because of both a large capital loss in December and high tax and interest rates, low overhang stocks covary much more with the market in the days subsequent to the turn of the year than do high overhang stocks.

Similarly, Figure 2.3 confirms that the predictability in daily returns and selling pressure depends on the market's expected January rebound return. Figure 2.3 shows that patterns in both daily returns and selling pressure are stronger when the tax-selling effect in the market return is stronger. Specifically, when the market's expected January rebound return, $-\gamma * g_{M}$, is large, low overhang stocks display much higher selling pressure in December and more strongly outperform high overhang stocks in January. ${ }^{30}$ Again these results are more concentrated on the days very close to the turn of the year.

The third regression of each panel in Table 2.7 not only controls for time-varying beta but also attributes a portion of the remaining conditional alpha to our strategy-specific tax selling premium variable. We find that though January alphas remain economically and

\footnotetext{
${ }^{29} \mathrm{We}$ compute betas for the capital gains overhang quintile portfolios as follows. Trading days are numbered (between -20 and +20 ) around the turn of each year such that 0 is the last trading day in December and +1 is the first trading day in January. Betas are then computed versus the CRSP value-weighted market portfolio for each trading day. Thus, the day( 0 ) beta accounts for the covariance between quintile portfolio returns and market returns on the last trading day of each year. This procedure yields a series of 41 trading day betas for each quintile portfolio. We then use these series to compute trailing five-day moving averages for each quintile portfolio.

Note that Figure 2.3 plots the daily moving average betas conditional on the market's tax-selling alpha. Thus, the procedure described above is slightly modified so that the trading day betas are computed separately for years with positive versus negative expected January market rebound return. Our split compares positive versus negative rather than simply high versus low values of the January rebound return to be consistent with the corresponding regression (3) of Table 2.7 Panel A.

${ }^{30}$ The difference between the cumulative January return for the low overhang portfolio and the high overhang portfolio is $4.00 \%$ during years of a low expected January rebound return for the market and $8.72 \%$ during years of a high expected January rebound return for the market. Each of these differences is statistically significant at the $1 \%$ level. Moreover, the difference between these cumulative returns of $4.72 \%$ is significant at the $5 \%$ level ( $t$-statistic of 2.09 ).
} 


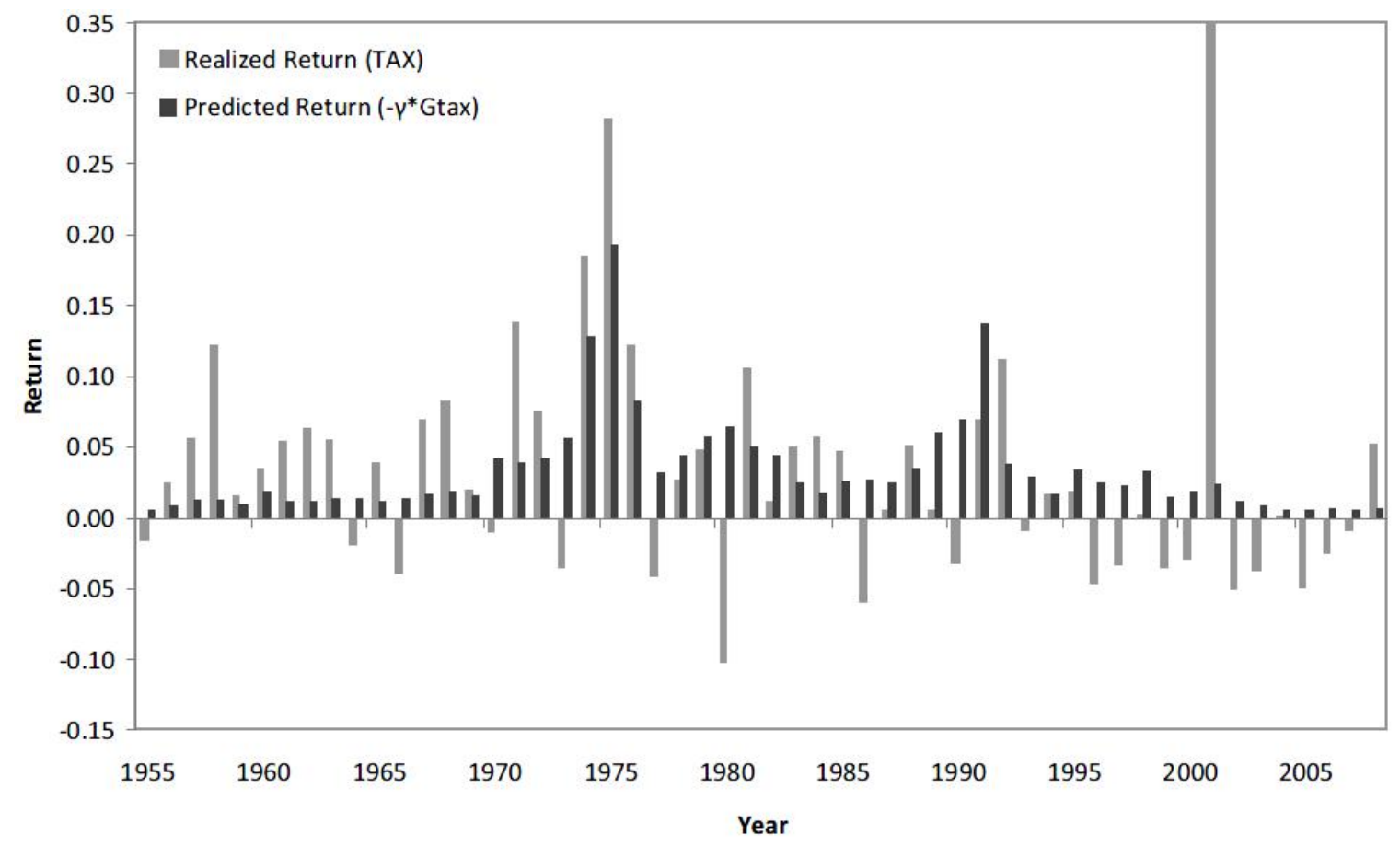

Figure 2.3: January Returns of TAX factor

This figure plots the realized January returns on our TAX factor over the course of the sample. To form TAX, each month we sort all NYSE stocks on our overhang measure and calculate 20th and 80th percentile breakpoints. We then buy all NYSE-AMEX-NASDAQ stocks that are below the NYSE 20th percentile and sell all NYSE-AMEX-NASDAQ stocks that are above the NYSE 80th percentile. The positions in the long and short sides are value-weight. In each bin, we plot next to the realized January return, our forecast of the expected January rebound based on the product of i) our tax-selling premium variable, $\gamma$, defined in Table 2.2 and ii) the net overhang for the TAX factor, $g_{T A X}$ That forecast comes from the regression, $T A X_{J A N, t}=a_{0}+a_{1} \gamma_{t-1} g_{T A X, t-1}+\varepsilon_{J A N, t}$. The estimate of $a_{0}$ is 0.00192 (t-statistic of 0.14), the estimate of $a_{1}$ is -1.99 (t-statistic of -3.52 ), and the adjusted $R^{2}$ is $17.7 \%$. 
statistically significant, they are reduced significantly in the case of SMB and UMD. The January alpha for SMB is reduced by $44 \%$, while the January alpha for UMD is reduced by $37 \%$. Interestingly, for two of the three factors, SMB and UMD, the non-tax alpha from February to November becomes statistically insignificant. However, the point estimate of the HML non-tax alpha from February to November actually increases, though by less than $13 \%$.

In summary, Table 2.7 shows that a portion of the risk and abnormal return of the Fama-French/Carhart non-market factors can be linked to our tax-selling premium, as the tax-selling effect is strong in both market and factor portfolios. These findings have important implications for those researchers examining economic stories describing timevariation in the properties of these factors. ${ }^{31}$

\subsection{Conclusion}

Our framework implies that temporary distortion in stock prices may arise because of the taxation of capital gains. In particular, we exploit the tradeoff a rational investor faces when realizing tax losses (gains) this tax year instead of next tax year in the presence of temporary downward (upward) price pressure. Optimal tax selling can generate stock return overreaction at the end of the tax year and a corresponding reversal at the beginning of the subsequent tax year. The magnitude of these predictable returns is not only a function of a stock's tax basis but also a function of interest rates and capital gains tax rates, which together bound the temporary distortion. The vast amount of literature on tax-selling at the turn of the year ignores time-series variation in the effect. The two

\footnotetext{
${ }^{31}$ For example, Chordia and Shivakumar (2004) argue that returns on momentum strategies can be explained once they are adjusted for the predictability of stock returns based on macroeconomic variables. These variables include the interest rate which is an important component of our tax-selling premium. Cooper, Gutierrez, and Hameed (2004) forecast returns on momentum strategies with the state of the market, which they define as whether the past three-year return on the market is positive or negative. That definition is clearly related to our measure of market overhang, $g_{M}$, that drives seasonal patterns in risk for the momentum factor.
} 
previous papers (Poterba and Weisbenner (2001) and Grinblatt and Moskowitz (2004)) that do examine time-series variation in the effect only look at variation resulting from the tax rate. The interest rate channel that we identify generates significantly more variation in the predicted magnitude of the effect than the tax rate channel (in fact, more than twice as much).

A variety of empirical evidence confirms this prediction. We document patterns in the cross-section of average returns at the turn of the tax year that are consistent with our story. Our main tests use U.S. data, but additional tests using U.K. data provide an important out-of-sample confirmation, as the U.K. tax and calendar year end differ. We also identify trading patterns that are consistent with tax-motivated selling driving these temporary movements in stock prices. Stocks with low capital gains overhang have more selling pressure in individuals' trades at the turn of the tax year than stocks with high capital gains overhang, and this imbalance also varies with the same function of interest rates and capital gains tax rates. Moreover, in the actual trades of investors using a large discount brokerage, the tendency to harvest losses in December rather than in January also varies with this bound. Finally, we find that these effects are also present in aggregate returns. As a consequence, performance attribution at the turn of the year is not only affected by the firm-level tradeoff, but also by distortion in measuring risk arising from this tax-selling based common factor.

Interestingly, our emphasis on the importance of the interest rate also explains why recent returns to strategies exploiting that phenomenon have been low. These low returns are not due to savvy investors eliminating the effect, but instead are explained by the rather low interest rates in the recent data. As interest rates rise, our formulation predicts that the January effect should return. 


\section{Chapter 3}

\section{Inflation Risk in Corporate Bonds}

\subsection{Introduction}

Corporate bonds in the developed world overwhelmingly carry fixed nominal face values and thus their real face values fluctuate with inflation. Given that corporate debt is largely nominal, firms can be driven into default by either a decrease in real cash flows or an increase in real liabilities. The literature has argued that real firm cash flow risk is priced into corporate bond spreads. We find that inflation risk plays at least as large a role in explaining variation in credit spreads.

The nominal nature of corporate liabilities leaves firms exposed to risk of debt deflation (Fisher (1933)) with potentially important macroeconomic feedback effects (Bernanke and Gertler (1989), Kiyotaki and Moore (1997)). We argue that credit spreads price the time-varying risk of debt deflation even in developed countries with moderate inflation environments.

Inflation risk could increase credit spreads in two ways. First, more volatile inflation increases the ex ante probability that firms will default due to high real liabilities. Second, when inflation and real cash flows are highly correlated, low real cash flows and high real liabilities tend to hit firms at the same time, increasing default rates and real investor losses. 
Higher credit spreads reflect higher expected credit losses and the greater likelihood that losses will occur in high marginal utility states.

There has been a close historical relationship between firms' cost of debt finance and inflation uncertainty in the United States, as shown in Figure 3.1. ${ }^{1}$ Both inflation uncertainty and credit spreads were high in the 1970s and 1980s and decreased dramatically during the 1990s. Our empirical results confirm this relationship in a panel of six developed countries, controlling for proxies for business conditions, real uncertainty and time-varying risk aversion.

We formally derive new, testable implications of the impact of time-varying inflation risk on credit spreads in a model with stochastic productivity and optimal but infrequent capital structure choice. In simulated data, inflation risk explains a substantial fraction of the variation in credit spreads, controlling for real uncertainty. Simulated credit spreads increase by 26 basis points (bps) if the annualized standard deviation of inflation shocks increases by 1 percentage point and by 20 bps if the inflation-stock return correlation increases by 100 percentage points.

Three key features in our model generate large, dynamic responses of credit spreads to inflation risk. First, we model both the size of inflation shocks and their correlation with real outcomes as varying over time independently of real activity.

Second, we model nominal corporate bonds with long-term maturities and persistent expected inflation, consistent with U.S. and international evidence (Ball and Cecchetti (1990), Stock and Watson (2007)). ${ }^{2}$ Combined, these two assumptions imply that small permanent shocks to inflation can have large effects on real liabilities. For instance, if log

\footnotetext{
${ }^{1}$ Figure 3.1 shows the Moody's BAA over AAA credit spread and a smoothed dispersion of GDP deflator forecasts from the Survey of Professional Forecasters. Survey dispersion has been shown to be related to subsequent inflation volatility (Zarnowitz and Lambros (1987), Bomberger (1996)). Patton and Timmermann (2010) show that inflation and growth forecasts are more dispersed when credit spreads are higher and interpret this as evidence that forecasters' beliefs are more dispersed during downturns.

${ }^{2}$ Our model takes as given the fact that most corporate bonds are nominal, implicitly assuming that switching to inflation-indexed debt is too costly in developed country inflation environments. We find an average ratio of floating rate to long-term debt of $28 \%$ for U.S. Compustat firms.
} 


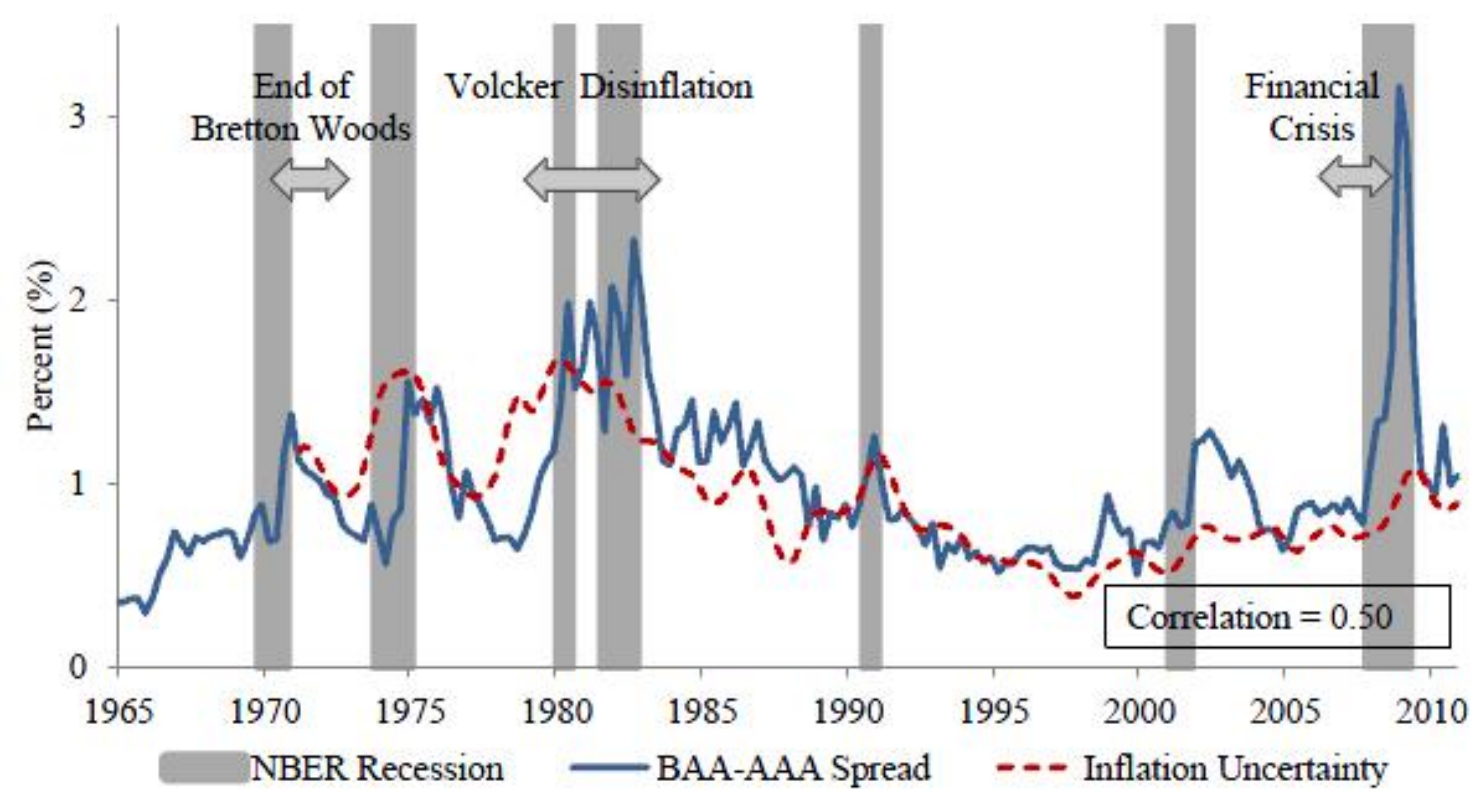

Figure 3.1: Credit Spreads and Inflation Uncertainty in the U.S.

Quarterly BAA minus AAA corporate bond spread from Moody's. Inflation uncertainty is the smoothed difference between the 75th percentile and the 25th percentile of one quarter ahead GDP Price Index inflation forecasts from the Survey of Professional Forecasters. 
inflation permanently decreases from 3 percent per annum to 1 percent, the real face value of a 10 year nominal bond at maturity increases by 22 percent.

Third, firms in our model refinance infrequently. This assumption is empirically wellfounded and helps to generate a realistic level of credit spreads. When firms can adjust leverage, they choose optimally following a textbook tradeoff theory (Gourio (2011)). When inflation risk raises the cost of debt finance, young firms in our overlapping generations model reduce leverage but old firms are unable to respond. Credit spreads of old firms therefore display a substantially stronger initial response to inflation risk than do those of new firms.

We provide new evidence that corporate bond investors price the risk of debt deflation in a panel of corporate bond spread indices from Australia, Canada, Germany, Japan, the United Kingdom, and the United States over four decades. A one standard deviation move in inflation volatility is associated with an economically meaningful increase in credit spreads of $16 \mathrm{bps,}$ while a one standard deviation move in the inflation-stock correlation is associated with a 13 bps increase in spreads. These movements are large relative to average credit spreads of 100 bps.

Controlling for other influences on credit spreads, such as business cycle variables, strengthens our results. Our proxies for inflation risk explain as much variation in credit spreads as do equity volatility and the dividend-price ratio, our proxies for real uncertainty and risk aversion. The empirical impact of inflation risk is especially large when real stock returns are low or when inflation shocks are low. Firms also appear to change their financing behavior in response to inflation risk. Consistent with theoretical predictions, firms reduce leverage and increase the share of floating rate debt when inflation is more uncertain.

Our empirical findings are consistent with financial markets perceiving an important persistent component in inflation, which makes the long-run price level highly uncertain and generates substantial inflation risk in long-run nominal assets. Our empirical results are all the more striking given that the countries in our sample are developed countries 
with relatively moderate inflation experiences. The same mechanism should be even more relevant in emerging markets with more volatile inflation.

While high inflation has been a major fear of central bankers and investors in developed economies over the past forty years, a new concern has emerged recently: the danger of a deflationary collapse in aggregate demand. The impact of deflationary fears on firms' borrowing costs becomes especially relevant if investors believe that policymakers will be unable to counteract deflation should there be another recession. Our estimates as of October 2011 suggest that 35 bps of the 126 bps U.S. credit spread can be attributed to the currently high inflation-stock correlation.

The remainder of the paper is organized as follows. After a brief literature review, Section 3.2 introduces the model. We derive firms' optimal default behavior as a function of leverage, real shocks and inflation shocks. Section 3.3 argues that inflation risk should be quantitatively important for credit spreads in a calibrated version of the model. Section 3.4 tests the empirical predictions from the model in an international panel of credit spread indices, and Section 3.5 concludes.

\subsubsection{Literature Review}

This paper builds naturally on Campbell, Sunderam, and Viceira (2011) and Pflueger and Viceira (2011) who show that inflation risk is priced into default free government bonds. Time variation in inflation volatility was first modeled by Engle (1982). There is also substantial evidence from the bond market that the cyclicality of inflation has changed over time (Li (2002), Baele, Bekaert, and Inghelbrecht (2009), David and Veronesi (2009), Viceira (2010), Wright (2010), Campbell, Sunderam, and Viceira (2011)).

This paper also speaks to a large literature on the empirical determinants of corporate bond spreads by showing that inflation risk can help explain variation in credit spreads. Collin-Dufresne, Goldstein, and Martin (2001) and Campbell and Taksler (2003) show that aggregate and idiosyncratic equity volatility are priced into corporate bond spreads. 
We add to previous structural models of credit risk such as Merton (1974), and Longstaff and Schwartz (1995) by allowing the risk of inflation to vary over time. We also contribute to the wide literature on asset pricing models with optimal leverage and default by arguing that firms should adjust their capital structure in response to time-varying inflation risk (Leland and Toft (1996), Goldstein, Ju, and Leland (2001), Hackbarth, Miao, and Morellec (2006), Chen, Collin-Dufresne, and Goldstein (2009), Bhamra, Kuehn, and Strebulaev (2010a), Bhamra, Kuehn, and Strebulaev (2010b), Gomes and Schmid (2010), Gourio (2011)). Our analysis of inflation risk and firm capital structure has analogies to households' optimal mortgage choice under inflation risk (Campbell and Cocco (2003), Koijen, van Hemert, and van Nieuwerburgh (2009)) but differs in that all assets are priced by the same representative investor.

This paper is closely related to recent models of monetary policy when firms' liabilities are nominal (Bhamra, Fisher, and Kuehn (2011), De Fiore and Tristani (2011)). Our model highlights inflation volatility and inflation cyclicality as driving credit risk and has directly testable predictions. Transition dynamics in our model increase the quantitative impact of inflation risk on credit spreads.

\subsection{A Dynamic Model of Inflation Risk in Corporate Bonds}

In this section, we motivate and describe the formal model. We assume for simplicity that all corporate bond issuance is long-term and nominal. In reality firms might adjust to changing inflation risk by issuing inflation-indexed corporate debt or by shortening their maturity structure, even though this adjustment is likely to come at a cost. Such costs could include rollover risk (He and Xiong (2010), Acharya, Gale, and Yorulmazer (2010)), short-term variability in real payments (Campbell and Cocco (2003)) or liquidity premia, such as those documented for government inflation-indexed bonds (DAmico, Kim, and Wei (2008), Fleckenstein, Longstaff, and Lustig (2010), Pflueger and Viceira (2011)). We implicitly assume that in a developed economy inflation environment these costs are 
prohibitive and firms choose to issue only nominal long-term debt.

\subsubsection{Intuition: Contingent Claim Payoff Profiles}

We illustrate our basic predictions by comparing the real payoff profiles of a nominal default-free and a nominal corporate bond in Figure 3.2. Black and Scholes (1973) and Merton (1974) show that owning a corporate bond is equivalent to owning a default-free bond and selling a put on the company's underlying assets. ${ }^{3}$

Figures 3.2(A) and 3.2(B) show that when inflation is more uncertain we predict higher credit spreads to reflect the increased payoff gap between corporate and default-free bonds. Figure 3.2(B) shows real conditional expected payoffs, averaged over different inflation levels, when inflation is uncertain but uncorrelated with real assets. When inflation is uncertain the default probability is nonzero for any underlying real asset value, and hence the payoff gap increases relative to the case with no inflation uncertainty.

Comparing Figures 3.2(C) and 3.2(D) shows that when inflation is procyclical, credit spreads should be higher. In Figure 3.2(C), inflation is high in booms, low in recessions, and perfectly correlated with real assets. The default-free nominal bond pays out especially well during recessions. The firm is more likely to default and it defaults on higher real face values, increasing expected losses for corporate bond investors. The gap between default-free and corporate bonds is especially large when real asset values are low, making corporate bond losses even riskier for risk-averse investors and potentially adding a risk premium component to corporate bond spreads.

\footnotetext{
${ }^{3}$ For simplicity in Figure 3.2 both the defaultable and default-free bonds are zero coupon with a fixed and equal nominal face value. The representative firm defaults when the real asset value falls below the real face value of liabilities and in default bond holders become the residual claimants on the firm's assets.
} 
Panel A: Inflation Volatility $=0$

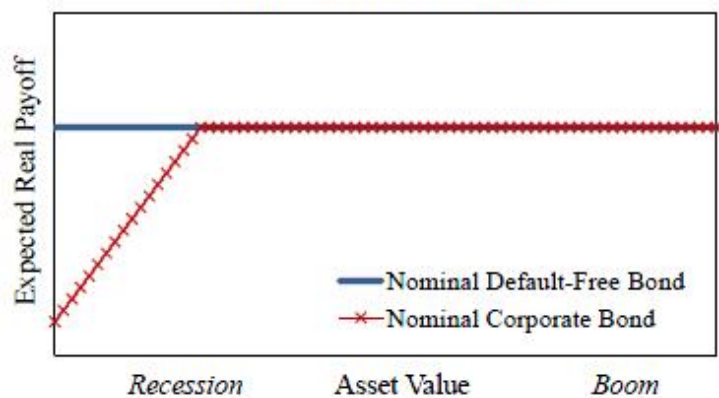

Panel C: Procyclical Inflation

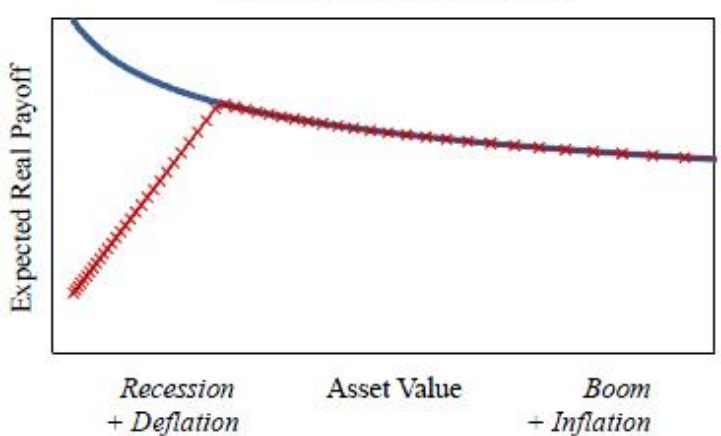

Panel B: Inflation Volatility $>0$

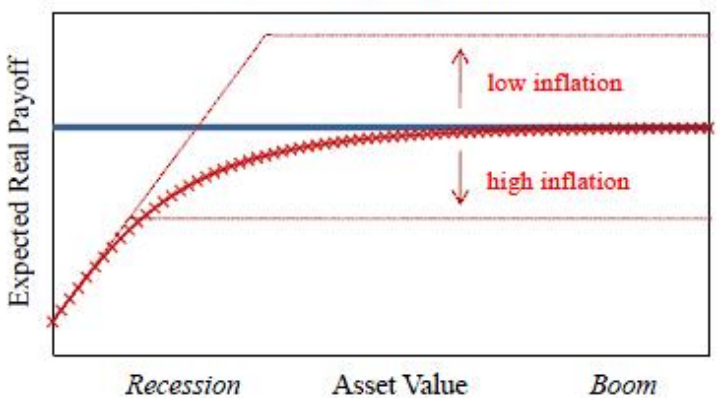

Panel D: Countercyclical Inflation

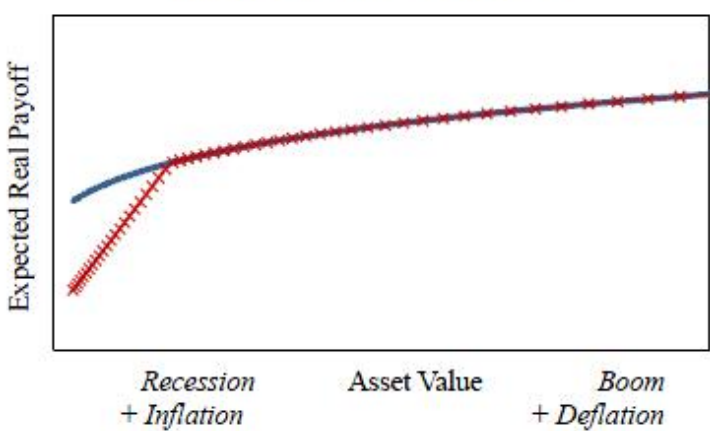

Figure 3.2: Contingent Claim Payoff Profiles

Expected real payoffs of nominal default-free and nominal corporate bonds. Expected real payoffs are conditional on the underlying real asset value and averaged over inflation realizations. Inflation volatility is set to zero in Panel A. Inflation is uncorrelated with real asset values in Panel B. Inflation shocks are perfectly positively correlated with asset values in Panel $\mathrm{C}$ and perfectly negatively correlated with asset values in Panel D. 


\subsubsection{Timing of Cohort $t$}

We model overlapping generations of firms, with each firm producing for two periods. Firms cannot adjust their capital structure in the intermediate period, so leverage is sticky. ${ }^{4}$

Figure 3.3 illustrates the timing for a firm that enters at the end of period $t$. At the end of period $t$ the firm chooses its face value of nominal two-period debt $B_{t}^{\$}$ and purchases capital $K_{t+1}^{y}$, which will be available for production at time $t+1$. The firm's newly issued corporate bonds have two periods remaining to maturity.

\begin{tabular}{|c|c|c|}
\hline$t$ & $t+1$ & $t+2$ \\
\hline $\begin{array}{l}\text { Choose nominal debt } B_{t} \\
\text { Purchase capital } K_{t+1}^{y} \\
\text { New credit spreads }\end{array}$ & $\begin{array}{l}\text { Real aggregate TFP shock } \varepsilon^{\text {TFP }}{ }_{t+1} \\
\text { Nominal aggregate shock } \varepsilon^{\pi}{ }_{t+1} \\
\text { Seasoned credit spreads }\end{array}$ & $\begin{array}{l}\text { Real and nominal aggregate } \\
\text { shocks } \varepsilon^{\text {IFP }}{ }^{+2}, \varepsilon^{\pi}{ }_{\mathrm{t}+2} \\
\text { Real idiosyncratic shocks } a^{\text {i,id }}{ }_{\mathrm{t}+2} \\
\text { Default decision }\end{array}$ \\
\hline
\end{tabular}

Figure 3.3: Timeline of Firm Cohort t

In period $t+1$, aggregate productivity and inflation shocks are realized. Each firm experiences an idiosyncratic shock to its capital stock and produces. The firm is unable to adjust its capital structure. The firm's seasoned corporate bonds have one period remaining to maturity.

In period $t+2$, firms again receive shocks and produce. At the end of period $t+2$, equity holders decide whether to default. Equity and debt holders receive payments.

\footnotetext{
${ }^{4}$ For empirical evidence on sticky leverage see Baker and Wurgler (2002), Welch (2004) and Leary and Roberts (2005).
} 


\subsubsection{Production}

Firms produce according to a Cobb-Douglas production function with capital and labor inputs. At time $t$, firm $i$ with capital $K_{t}^{i}$ and labor $N_{t}^{i}$ produces output $Y_{t}^{i}$

$$
Y_{t}^{i}=\left(z_{t} N_{t}^{i}\right)^{1-\alpha}\left(K_{t}^{i}\right)^{\alpha}
$$

Total factor productivity (TFP) $z_{t}$ is independently and identically distributed around trend growth

$$
\begin{aligned}
z_{t+1}= & \exp (\mu t) \exp \left(\varepsilon_{t+1}^{T F P}-\frac{1}{2} \sigma^{2}\right) \\
& \varepsilon_{t+1}^{T F P} \stackrel{i i d}{\sim} N\left(0, \sigma^{2}\right)
\end{aligned}
$$

We calibrate one time period to correspond to 5 years, which is close to business cycle frequency, so independent TFP shocks are a reasonable approximation. TFP trend $\mu$ is also the equilibrium trend growth rate for output and consumption in the economy.

Firm $i$ chooses its labor input optimally to maximize single period operating revenue, taking the aggregate wage rate $W_{t}$ as given.

$$
N_{t}^{i}=\arg \max _{N_{t}^{i}}\{\underbrace{Y_{t}^{i}-W_{t} N_{t}^{i}}_{\text {Operating Revenue }}\}
$$

We assume that the aggregate supply of labor is fixed at 1 , abstracting from unemployment. In equilibrium, the aggregate wage adjusts to ensure clearing of the labor market.

We define aggregate output, capital, labor and investment at time $t$ by integrating over all firms

$$
Y_{t}=\int_{i} Y_{t}^{i} d i, K_{t}=\int_{i} K_{t}^{i} d i, N_{t}=\int_{i} N_{t}^{i} d i, I_{t}=\int_{i} I_{t}^{i} d i
$$

Capital depreciates at a constant rate $\delta: K_{t+1}=I_{t}+(1-\delta) K_{t}$. We impose the resource constraint that total output is equal to the sum of aggregate consumption and investment

$$
Y_{t}=C_{t}+I_{t}
$$


Solving for the equilibrium hiring policy, total output at time $t$ is given by $Y_{t}=$ $z_{t}^{1-\alpha} K_{t}^{\alpha}$. Young and old firms are heterogenous in their capital stock. The constant returns to scale production technology implies that the return on capital from time $t$ to time $t+1$ is identical across firms and equal to

$$
R_{t+1}^{K}=\left[\alpha\left(\frac{z_{t+1}}{K_{t+1}}\right)^{1-\alpha}+(1-\delta)\right]
$$

From (4.2) the expected level and the volatility of real returns on capital are endogenously higher when the capital stock $K_{t+1}$ is low relative to trend.

\subsubsection{Inflation}

The economy is subject to inflation surprises, whose relationship with productivity shocks can change over time. Let $P_{t}$ the price level at time $t$ and $\pi_{t} \log$ inflation from time $t-1$ to time $t$ with

$$
\pi_{t}=\log \left(P_{t} / P_{t-1}\right)
$$

Consistent with U.S. and international empirical evidence (e.g. Stock and Watson (2007), Ball and Cecchetti (1990)), we model expected log inflation as following a random walk. The dynamics of expected inflation resemble a backward-looking Phillips curve, consistent with empirical evidence (Fuhrer (1997)). Inflation persistence implies that uncertainty about the price level increases with the time horizon, so inflation risk should be larger for longer maturity bonds. ${ }^{5}$

$$
\begin{aligned}
\pi_{t+1} & =\pi_{t}+\varepsilon_{t+1}^{\pi} \\
\varepsilon_{t+1}^{\pi} \mid \sigma_{t+1}^{\pi} & \sim N\left(0,\left(\sigma_{t+1}^{\pi}\right)^{2}\right) \\
\operatorname{Corr}\left(\varepsilon_{t+1}^{\pi}, \varepsilon_{t+1}^{T F P} \mid \rho_{t+1}^{\pi}\right) & =\rho_{t+1}^{\pi}
\end{aligned}
$$

\footnotetext{
${ }^{5}$ It is important for our quantitative results that expected inflation is persistent. The assumption of an exact random walk is primarily for analytical tractability.
} 
Higher $\sigma_{t}^{\pi}$ implies more uncertainty about the price level. When $\rho_{t}^{\pi}$ is positive, the relationship between inflation and real activity is upward sloping similarly to an upwardsloping Phillips curve. When $\rho_{t}^{\pi}$ is negative, the Phillips curve is unstable potentially due to supply shocks or to shifting inflation expectations.

We model time variation in $\sigma_{t}^{\pi}$ and $\rho_{t}^{\pi}$ in the simplest possible manner by assuming that they follow two-state Markov switching processes, independent of each other and of all other shocks in the economy. Inflation uncertainty $\sigma_{t}^{\pi}$ and inflation cyclicality $\rho_{t}^{\pi}$ each take a low or a high value

$$
\begin{aligned}
& \sigma_{t}^{\pi} \in\left\{\sigma^{\pi, L}, \sigma^{\pi, H}\right\} \\
& \rho_{t}^{\pi} \in\left\{\rho^{\pi, L}, \rho^{\pi, H}\right\}
\end{aligned}
$$

We write the probabilities of going from state $\sigma^{\pi, X}$ to $\sigma^{\pi, Y}$ and of going from state $\rho^{\pi, X}$ to $\rho^{\pi, Y}$ as

$$
\begin{gathered}
p\left(\sigma^{\pi, X} \rightarrow \sigma^{\pi, Y}\right) \\
p\left(\rho^{\pi, X} \rightarrow \rho^{\pi, Y}\right)
\end{gathered}
$$

\subsubsection{Default Decision}

A firm's default decision depends on its initial level of debt, aggregate real shocks, aggregate nominal shocks and idiosyncratic real shocks. Corporate debt promises a fixed nominal payment after two periods, when the firm pays a liquidating dividend.

We denote logs by small letters throughout. All firms in cohort $t$ are identical ex ante and choose the same initial log leverage ratio $l_{t}$ where $b_{t}^{\$}$ is the $\log$ nominal face value of debt

$$
l_{t}=b_{t}^{\$}-2 \pi_{t}-k_{t+1}^{y}
$$

Surprise inflation decreases the log real liabilities of an old firm at time $t+2$. The 
inflation shock in period $t+1$ enters twice because of inflation persistence.

$$
b_{t+2}^{\text {real }, \text { old }}=l_{t}+k_{t+1}^{y}-2 \varepsilon_{t+1}^{\pi}-\varepsilon_{t+2}^{\pi}
$$

Firm $i$ in cohort $t$ experiences identical and independent idiosyncratic shocks to log capital at times $t+1$ and $t+2$. We denote by $a_{t+2}^{i, i d}$ the sum of time $t+1$ and $t+2$ idiosyncratic shocks to firm $i$. Constant returns to scale production technology and firms' inability to make any capital structure decisions in the intermediate period imply that only the combined idiosyncratic shock $a_{t+2}^{i, i d}$ affects the real firm value at time $t+2$. We assume

$$
a_{t+2}^{i, i d} \sim N\left(-\frac{1}{2}\left(\sigma^{i d}\right)^{2},\left(\sigma^{i d}\right)^{2}\right)
$$

The aggregate level of capital is unaffected by idiosyncratic shocks. Using (4.2) the log real value of an old firm at the end of period $t+2$ equals

$$
v_{t+2}^{i, o l d}=k_{t+1}^{y}+r_{t+1}^{K}+r_{t+2}^{K}+a_{t+2}^{i, i d}
$$

Equity holders have the option to default on debt payments and to receive a zero liquidating dividend. They optimally decide to default if and only if the real value of the firm (4.7) is less than its real liabilities (3.17). ${ }^{6}$ Conditional on aggregate shocks, firms with the most adverse idiosyncratic shocks default

$$
a_{t+2}^{i, i d}<\underbrace{l_{t}-2 \varepsilon_{t+1}^{\pi}-\varepsilon_{t+2}^{\pi}-r_{t+1}^{K}-r_{t+2}^{K}}_{\text {Survival Threshold } a_{t+2}^{*}}
$$

Equation (3.20) formalizes the intuition developed in the introduction. Low inflation shocks $\varepsilon_{t+1}^{\pi}$ and $\varepsilon_{t+2}^{\pi}$ increase the survival threshold $a_{t+2}^{*}$ and the default rate. Low productivity shocks at times $t+1$ and $t+2$ lower real returns on capital and also increase the rate of defaults.

\footnotetext{
${ }^{6}$ The firm never finds it optimal to default in its intermediate period because no debt payments come due during the intermediate period.
} 


\subsubsection{Stochastic Discount Factor}

There exists a representative consumer with expected power utility over consumption, risk aversion $\gamma$, and discount rate $\beta$

$$
U_{t}=\mathbb{E}_{t} \sum_{s=t}^{\infty} \exp (-\beta(s-t)) \frac{C_{s}^{1-\gamma}}{1-\gamma}
$$

The two-period stochastic discount factors used for pricing two-period real and nominal payoffs are respectively

$$
\begin{aligned}
& M_{t, t+2}=\exp (-2 \beta)\left(C_{t+2} / C_{t}\right)^{-\gamma} \\
& M_{t, t+2}^{\$}=M_{t, t+2} / \exp \left(2 \pi_{t}+2 \varepsilon_{t+1}^{\pi}+\varepsilon_{t+2}^{\pi}\right)
\end{aligned}
$$

\subsubsection{Capital Structure Choice}

Firms choose leverage according to a standard tradeoff view of capital structure. We follow Gourio (2011) in assuming that firms receive benefits $\chi>1$ for each dollar of debt issued. Equity holders of cohort $t$ firms choose capital $K_{t+1}^{y}$ and nominal liabilities $B_{t}^{\$}$ subject to the budget constraint

$$
K_{t+1}^{y}=S_{t}+\chi q_{t} B_{t}^{\$}
$$

$S_{t}$ is the value of new equity at time $t$ and $q_{t}$ is the price of two-period nominal bonds at time $t$. For a higher benefit of debt $\chi$, equity holders have a stronger incentive to raise leverage.

Some authors have argued that tax benefits explain only a portion of observed leverage ratios (Graham (2000)), while others have argued that tax benefits are comparable in magnitude to bankruptcy costs (Almeida and Philippon (2007)). We interpret $\chi$ as including more general benefits and costs of debt, such as constraining managers from empire-building and reducing informational asymmetries (Jensen and Meckling (1976), Myers (1977), Myers and Majluf (1984), Jensen (1986)). 
The benefits of debt are counteracted by bankruptcy costs. We assume that debt investors only recover a constant fraction $\theta<1$ of firm value in bankruptcy, see also Leland (1994). When the recovery rate $\theta$ is lower equity holders have an incentive to choose lower leverage. An interior optimal leverage ratio exists if bankruptcy costs are sufficiently large relative to debt benefits. We formally assume that $\theta \chi<1$ ((Gourio (2011)).

By imposing the resource constraint (3.6) we follow (Gourio (2011)) in implicitly assuming that bankruptcy costs and debt benefits are redistributive and do not have a direct effect on output. This is a simplifying assumption and its effect in the model should be small, as long as time variation in default rates and nominal leverage ratios is small.

Let the functions $H, h$, and $\Omega$ give the default probability, marginal default probability, and average defaulted firm value conditional on the survival threshold $a_{t+2}^{*}$

$$
\begin{aligned}
H\left(a_{t+2}^{*}\right) & =\mathbb{P}\left(a_{t+2}^{i, i d}<a_{t+2}^{*}\right) \\
h\left(a_{t+2}^{*}\right) & =H^{\prime}\left(a_{t+2}^{*}\right) \\
\Omega\left(a_{t+2}^{*}\right) & =\mathbb{E}\left(\exp \left(a_{t+2}^{i, i d}\right) \mathbb{I}\left(a_{t+2}^{i, i d}<a_{t+2}^{*}\right)\right)
\end{aligned}
$$

where $\mathbb{I}$ denotes the indicator function. The price of a nominal long-term corporate bond at time $t$ then equals the expected discounted value of cash flows. A lower default probability $H\left(a_{t+2}^{*}\right)$ and a higher expected recovery $\theta \frac{\Omega\left(a_{t+2}^{*}\right)}{\exp \left(a_{t+2}^{*}\right)}$ increase the ex ante price of the bond.

$$
q_{t}=\mathbb{E}_{t}\left[M_{t, t+2}^{\$}(1-\underbrace{H\left(a_{t+2}^{*}\right)}_{\text {Default Rate }}+\underbrace{\theta \frac{\Omega\left(a_{t+2}^{*}\right)}{\exp \left(a_{t+2}^{*}\right)}}_{\text {Recovery }})\right]
$$

Equity holders equate the marginal benefit of raising another dollar of debt with the increase in bankruptcy costs according to the first-order condition

$$
0=\underbrace{-\chi(1-\theta) \mathbb{E}_{t}\left(M_{t, t+2}^{\$} h\left(a_{t+2}^{*}\right)\right)}_{\text {Marginal Bankruptcy Cost }}+\underbrace{(\chi-1) \mathbb{E}_{t}\left(M_{t, t+2}^{\$}\left(1-H\left(a_{t+2}^{*}\right)\right)\right)}_{\text {Marginal Benefit of Debt }}
$$


Firms choose the optimal level of capital, yielding the first-order condition

$$
\begin{aligned}
1 & =\mathbb{E}_{t}\left[M_{t, t+2} R_{t+1}^{K} R_{t+2}^{K} F_{t+2}\right] \\
F_{t+2} & =1-\underbrace{(1-\theta \chi) \Omega\left(a_{t+2}^{*}\right)}_{\text {Bankruptcy Cost }}+\underbrace{(\chi-1) \exp \left(a_{t+2}^{*}\right)\left(1-H\left(a_{t+2}^{*}\right)\right)}_{\text {Benefit of Debt }}
\end{aligned}
$$

The Euler equation (4.11) says that the expected discounted return on capital, adjusted for bankruptcy costs and benefits of debt by the factor $F_{t+2}$, equals 1 .

Inflation affects the first-order conditions (4.13) and (4.11) through its impact on the survival threshold $a_{t+2}^{*}$. When inflation is more volatile or more procyclical the default threshold becomes more volatile and marginal bankruptcy costs increase in (4.13). While equity holders do not incur any bankruptcy costs upon default, debt investors require compensation for bankruptcy costs ex ante, incentivizing firms to reduce leverage ratios.

\subsection{Calibrated Model}

\subsubsection{Parameter Values and Model Moments}

We present two model calibrations, which solve for the effects of inflation volatility and inflation cyclicality individually. Model 1 focuses on stochastic inflation volatility and holds the correlation between inflation shocks and TFP shocks constant at 0 . Model 2 holds the volatility of inflation constant but assumes that the inflation-TFP correlation varies.

We focus on moderate inflation volatility to highlight the relevance of inflation risk for credit spreads even in a stable inflation environment. In Model 1 the standard deviation of annual inflation expectation shocks switches between $0 \%$ and $2 \%$. The higher volatility of $2 \%$ corresponds approximately to the U.S. experience in the early 1980 s and is fifty percent smaller than the U.K. inflation volatility during the late 1970s according to our empirical estimates. To focus on the impact of inflation volatility we set the inflation-TFP correlation to zero. Volatility states are persistent, consistent with a five year autoregressive coefficient 
for U.S. inflation volatility of 0.5 . The volatility process spends about two-thirds of its time in the low state.

In Model 2 we assume that the inflation-TFP correlation follows a symmetric process, switching between -0.6 and 0.6 , within the range of our empirical estimates for the inflation-stock return correlation in developed countries. ${ }^{7}$ We study the impact of inflation cyclicality with moderate inflation uncertainty of $1 \%$ p.a. The average duration for each state is 15 years, consistent with three different regimes over a forty year period.

Parameter values are summarized in Table 3.1. We face a tradeoff in choosing the length of the time period. Five year time periods imply that seasoned corporate bond durations are slightly shorter than their empirical counterparts and that firm leverage and investment are constant for ten year periods. ${ }^{8}$ We choose standard values for the capital share, depreciation and the discount rate (Cooley and Prescott (1995)). We choose a risk aversion of 10; the upper bound of plausible coefficients of risk aversion considered by Mehra and Prescott (1985). As argued before in Figure 3.2 a high risk aversion is not crucial for our results. We constrain trend growth to be equal to average U.S. real GDP growth between 1970 and 2009. The recovery rate in bankruptcy equals $40 \%$, consistent with the empirical evidence in Altman (2006). ${ }^{9}$ The debt benefit parameter is a free parameter and we choose $\chi=1.4$ to generate empirically plausible default rates. Almeida and Philippon (2007) calculate that tax benefits account for approximately $16 \%$ of the debt value, so our high benefits incorporate significant agency benefits of debt.

\footnotetext{
${ }^{7}$ See Table 3.4 .

${ }^{8}$ Welch (2004) finds that the mechanistic effects of stock returns can explain about $40 \%$ of movements in leverage ratios over a five-year horizon. Baker and Wurgler (2002) find that corporations are likely to raise more equity when their market valuations are relatively higher and that these effects can explain leverage ten years out.

${ }^{9} \mathrm{~A}$ recovery rate in the range of $40 \%$ to $50 \%$ is also consistent with the evidence in Cremers, Driessen, and Maenhout (2008), Glover (2011) and Coval, Jurek, and Stafford (2009).
} 
Table 3.1: Model Parameters

* denotes parameters reported in per annum units. Annualized inflation volatility is the standard deviation of a one year inflation shock. Given that the state at time $\mathrm{t}$ is $\mathrm{X}, \mathrm{p}(\mathrm{X} \rightarrow \mathrm{X})$ denotes the probability that the state at time $\mathrm{t}+1$ is also $\mathrm{X}$.

\begin{tabular}{|c|c|c|}
\hline \multicolumn{3}{|l|}{ General Parameters } \\
\hline Period Length & & 5 years \\
\hline Discount Rate & $\beta$ & $3 \% *$ \\
\hline Risk Aversion & $\gamma$ & 10 \\
\hline Capital Share & $\alpha$ & 0.33 \\
\hline Depreciation & $\delta$ & $8 \% *$ \\
\hline Trend Growth & $\mu$ & $2.8 \% *$ \\
\hline Volatility of TFP Shock & $\sigma$ & $26 \% *$ \\
\hline Recovery Rate & $\theta$ & 0.40 \\
\hline Tax Benefit of Debt & $\chi$ & 1.40 \\
\hline Idiosyncratic Volatility & $\sigma^{i d}$ & $17 \% *$ \\
\hline \multicolumn{3}{|c|}{ Model 1: Time-Varying Inflation Volatility } \\
\hline Inflation-TFP Correlation & $\rho^{\pi}$ & 0.00 \\
\hline High Inflation Volatility & $\sigma^{\pi, H}$ & $2 \% *$ \\
\hline Low Inflation Volatility & $\sigma^{\pi, L}$ & $0 \% *$ \\
\hline Persistence of $\sigma^{\pi, H}$ & $p\left(\sigma^{\pi, H} \rightarrow \sigma^{\pi, H}\right)$ & 0.60 \\
\hline Persistence of $\sigma^{\pi, L}$ & $p\left(\sigma^{\pi, L} \rightarrow \sigma^{\pi, L}\right)$ & 0.80 \\
\hline \multicolumn{3}{|c|}{ Model 2: Time-Varying Inflation TFP Correlation } \\
\hline Inflation Volatility & $\sigma^{\pi}$ & $1 \% *$ \\
\hline High Inflation-TFP Correlation & $\rho^{\pi, H}$ & 0.60 \\
\hline Low Inflation-TFP Correlation & $\rho^{\pi, L}$ & -0.60 \\
\hline Persistence of $\rho^{\pi, H}$ & $p\left(\rho^{\pi, H} \rightarrow \rho^{\pi, H}\right)$ & 0.70 \\
\hline Persistence of $\rho^{\pi, L}$ & $p\left(\rho^{\pi, L} \rightarrow \rho^{\pi, L}\right)$ & 0.70 \\
\hline
\end{tabular}

Table 3.2 reports calibrated asset price moments together with empirical U.S. moments 
from 1970 to $2009 .{ }^{10}$ The high volatility of TFP shocks and idiosyncratic shocks generate plausible levels of aggregate and idiosyncratic equity market volatility. We do not attempt to explain the equity volatility puzzle (Shiller (1971), LeRoy and Porter (1981)), which can be resolved if consumption and dividend growth contain a time-varying long-run component (e.g. Bansal and Yaron (2004)) or if preferences induce persistent fluctuations in risk premia (e.g. Campbell and Cochrane (1999)).

Table 3.2: Empirical and Model Moments

Empirical moments correspond to U.S. data from 1970 to 2009. Equity volatility is the standard deviation of 10 year $\log$ nominal equity returns minus the 10 year log nominal government yield. Firm volatility is the standard deviation of idiosyncratic 10 year log nominal stock returns of non-defaulted firms. The equity premium is the average 10 year log nominal equity return minus the 10 year log nominal government yield (adjusted for Jensen's Inequality). Seasoned credit spreads are computed as the Moody's BAA minus AAA corporate bond index yield. The historical default probability for 10 year investment grade bonds is from Almeida and Philippon (2007) for the U.S. between 1970 and 2001. Leverage is the aggregate book leverage ratio computed as long-term debt plus short-term debt divided by total assets from Compustat.

\begin{tabular}{lrrr}
\hline & Empirical & Model 1 & Model 2 \\
\hline & U.S. 1970-2009 & Time-Varying $\sigma^{\pi}$ & Time-Varying $\rho^{\pi}$ \\
Equity Volatility (\% Ann.) & $18.4 \%$ & $18.5 \%$ & $18.0 \%$ \\
Firm Volatility (\% Ann.) & $47.2 \%$ & $29.3 \%$ & $29.0 \%$ \\
Equity Premium (\% Ann.) & $2.90 \%$ & $7.82 \%$ & $7.83 \%$ \\
$y_{t}^{g o v, 10}-r_{t}$ & $2.50 \%$ & $2.80 \%$ & $2.72 \%$ \\
$y_{t}^{\text {gov } 10}-y_{t}^{\text {gov }, 5}$ & $0.25 \%$ & $1.16 \%$ & $1.08 \%$ \\
New Credit Spread & & $1.18 \%$ & $1.23 \%$ \\
Seasoned Credit Spread & $1.01 \%$ & $1.64 \%$ & $1.53 \%$ \\
Default Probability & $0.52 \%$ & $0.45 \%$ & $0.40 \%$ \\
Leverage & $25 \%$ & $41 \%$ & $40 \%$ \\
\hline
\end{tabular}

We interpret model leverage to include a broad range of liabilities, including pension li-

\footnotetext{
${ }^{10}$ We simulate 250 runs of length 100 . Both model and empirical equity returns are defined as 10 year log nominal equity returns in excess of the continuously compounded ten year nominal interest rate.
} 
abilities and leases, which lead model book leverage to differ from our empirical proxy for book leverage. Pension obligations played a significant role for firms seeking bankruptcy protection during the 2000 s, illustrating their relevance for credit risk. ${ }^{11}$

We compare the average Moody's BAA over AAA spread, which is based on secondary market prices rather than prices at issuance, to the model seasoned credit spread. Recent papers have argued that structural models of credit risk can only explain a small portion of empirical credit spreads while matching historically low default rates (Huang and Huang (2002)). We obtain high credit spreads with plausible default rates due to volatile TFP shocks and to high risk aversion. Leverage ratios of model seasoned firms are heterogeneous across firms and credit spreads are convex in leverage ratios, so the cross-section of firms further raises average credit spreads (Bhamra, Kuehn, and Strebulaev (2010a), and (Bhamra, Kuehn, and Strebulaev 2010b)).

In the calibrated model, we can quantify how large a liquidity premium on inflationindexed debt is required so firms prefer issuing nominal debt over inflation-indexed debt. Assume that the benefits from corporate inflation protected securities (CIPS) are less than those on nominal corporate bonds $\chi^{C I P S}<\chi$. In annualized 10 year CIPS yields this translates into a liquidity premium of $\frac{\log \chi-\log \chi^{C I P S}}{10}$ relative to annualized 10 year nominal corporate bond yields.

The survival threshold for a deviating firm that decides to issue CIPS instead of nominal bonds does not depend on surprise inflation and it chooses optimal leverage according to a first-order condition analogous to (4.13). The deviating firm takes the stochastic discount factor $M_{t, t+2}$ and the aggregate return on capital $r_{t+1}^{K}, r_{t+2}^{K}$ as given. Equity investor are unwilling to invest into the deviating firm if and only if the expected discounted return on capital, adjusted for default costs and benefits of debt, is less than that for the aggregate firm

$$
\mathbb{E}_{t}\left[M_{t+2} R_{t+1}^{K} R_{t+2}^{K} F_{t+2}^{C I P S}\right]<E_{t}\left[M_{t+2} R_{t+1}^{K} R_{t+2}^{K} F_{t+2}\right]
$$

\footnotetext{
${ }^{11}$ See Maynard (2005) for pension negotiations in United Air's bankruptcy. Jin, Merton, and Bodie (2006) argue that firms' equity risk reflects the risk of a firm's pension plan.
} 
where $F_{t+2}^{C I P S}$ is defined analogously to $F_{t+2}$,. When (3.32) holds, no firm decides to issue inflation-indexed debt in equilibrium.

In Model 1, no firm switches to inflation-indexed debt if inflation-indexed bonds command a liquidity premium of at least 29 bps. The corresponding threshold in Model 2 is 22 bps. These bounds on liquidity premia are in line with estimated liquidity premia on 10 year U.S. Treasury Inflation Protected Securities (Pflueger and Viceira (2012)).

\subsubsection{Model Implications for Credit Spreads}

Figure 3.4 illustrates the relationship between credit risk, inflation risk, inflation shocks and stock returns implied by the model. The asymmetric nature of credit risk suggests that inflation risk should affect corporate bond spreads most strongly when credit risk is already high, whether this is due to adverse real or nominal shocks. Throughout this section we focus on seasoned credit spreads, which take into account non-optimal and heterogeneous firm leverage ratios and correspond most closely to empirical secondary market prices of corporate debt. We plot average seasoned credit spreads and default rates against stock returns and inflation shocks when inflation volatility is time-varying (Panel A) and when inflation cyclicality is time-varying (Panel B). ${ }^{12}$

As shown in Figure 3.4(A), default rates and credit spreads increase in periods with high inflation volatility, especially when stock returns are low and when inflation is surprisingly low. The intuition is that the put option in defaultable bonds is significantly larger when inflation is volatile, similarly to the contingent claim payoff in Figure 3.2(B).

Figure 3.4(B) shows that when inflation is procyclical, simulated average defaults and credit spreads are higher. Analogously to the contingent claim payoff plots in Figures 3.2(C) and 3.2(D), expected defaults are small for a large range of stock returns but increase rapidly for negative stock returns. This increase is more pronounced for the procyclical inflation regime. Credit spreads in the procyclical inflation regime also decrease

\footnotetext{
${ }^{12}$ We simulate 500 runs of length 100.
} 
in the shock to inflation expectations. Intuitively, corporate bonds are especially exposed to downside inflation risk.

Figure 3.5 shows dynamic responses of new and seasoned credit spreads, new book leverage, and investment to a shock to inflation risk. ${ }^{13}$ Seasoned credit spreads increase substantially in response to a shock to either the inflation volatility or the inflation-TFP correlation. Seasoned credit spreads subsequently mean-revert because firms are gradually able to adjust their leverage ratios, counteracting the direct effect of the shock on seasoned credit spreads. Endogenous choice of leverage also implies that new credit spreads do not move with inflation risk. The investment to capital ratio does not react to an increase in inflation risk because the increase in bankruptcy costs in the Euler equation (4.11) is small.

To better understand the quantitative impact of inflation risk on model credit spreads, we run regressions on simulated data. Table 3.3 shows regressions of model seasoned credit spreads onto inflation risk, real risk, inflation shocks, and real shocks. We choose our variables to resemble empirical proxies as closely as possible. We include the modelimplied inflation-stock correlation, which is endogenous and closely related to the inflationTFP correlation, as a proxy for inflation risk in Table 3.3(B). ${ }^{14}$

\footnotetext{
${ }^{13}$ We average over 62,500 simulations of length ten with a full set of macroeconomic shocks in the background. In Panel A, inflation volatility jumps to the high value of $2 \%$ p.a. from its steady state distribution in period 0 . Inflation volatility mean reverts to its stochastic steady state in periods 1 through 7 . Panel B is constructed similarly.

${ }^{14}$ Empirical observations may be correlated over time and across countries, making it hard to map the length of a simulated regression into an empirical number of observations. We report means and standard deviations of regression slopes on simulated data of length 100. The simulation size corresponding approximately to 40 years of independent bi-annual data from five countries. To ensure that regressors are never perfectly collinear we add small measurement errors to the inflation shock and inflation risk variables. The standard deviations of the model measurement errors are approximately $2 \%$ of the standard deviations of the underlying parameters.
} 
Panel A: Time-Varying Inflation Volatility (Model 1)
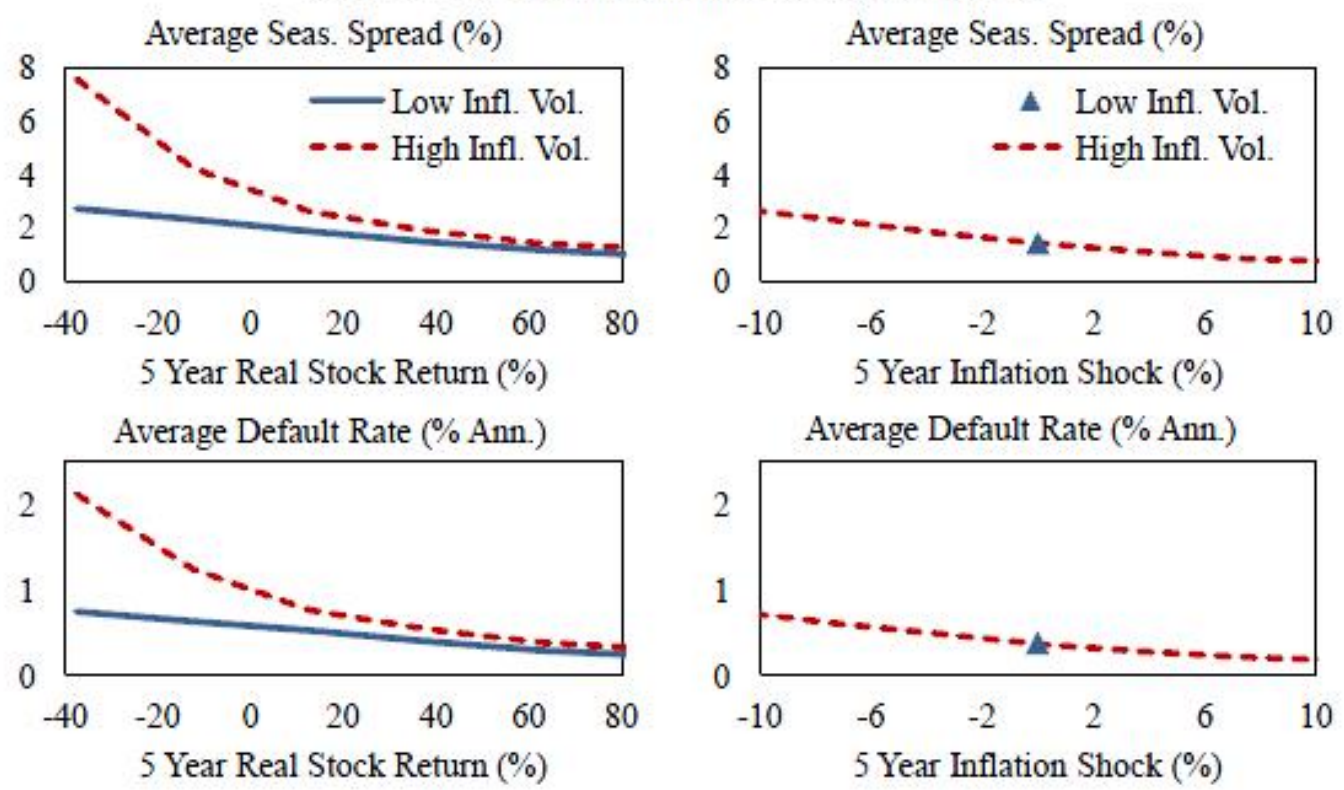

Panel B: Time-Varying Inflation Cyclicality (Model 2)
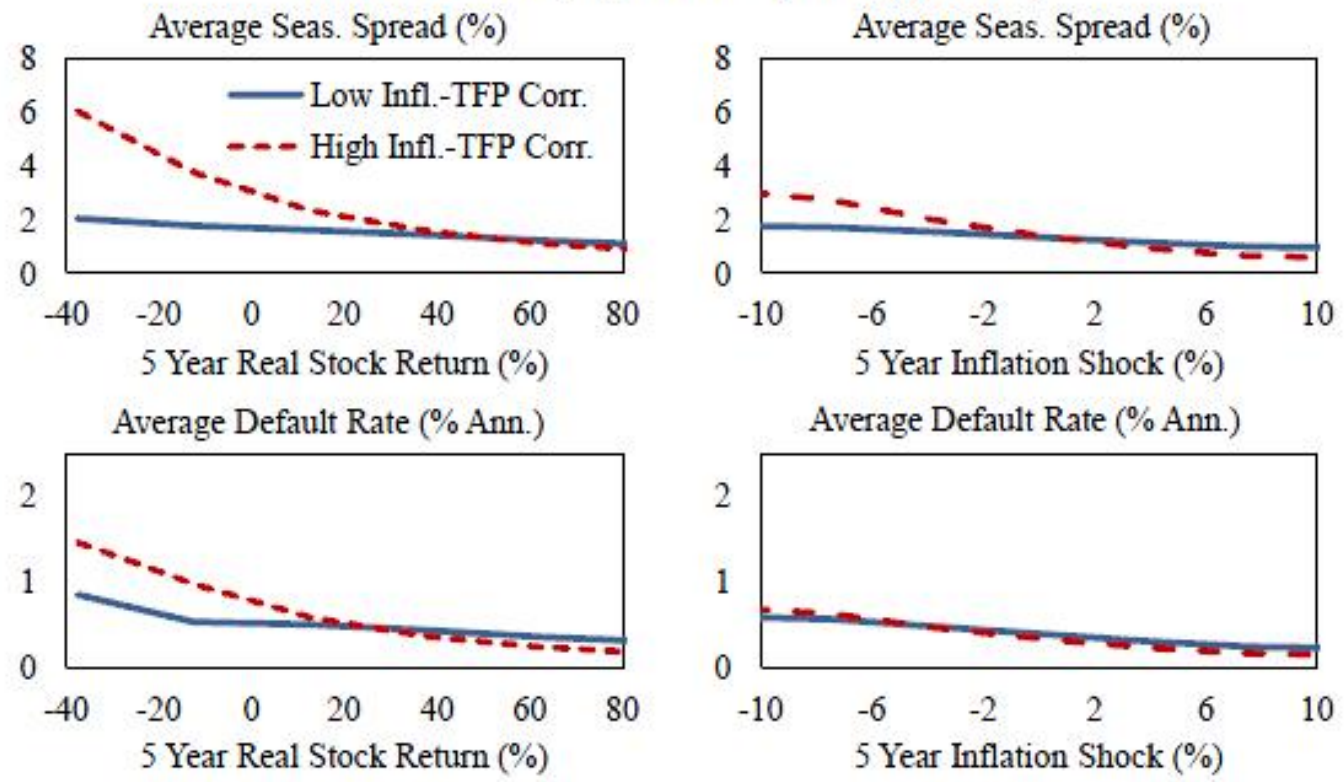

Figure 3.4: Model Credit Spreads, Stock Returns and Inflation Shocks

Simulated average credit spreads and default rates versus stock returns and inflation shocks. In Panel A, inflation volatility switches between $0 \%$ p.a. and $2 \%$ p.a., and inflation is uncorrelated with TFP shocks. In Panel B, inflation volatility is constant at $1 \%$ p.a., and the inflation-TFP correlation switches between -0.6 and 0.6. 
Panel A: Inflation Volatility Shock (Model 1)
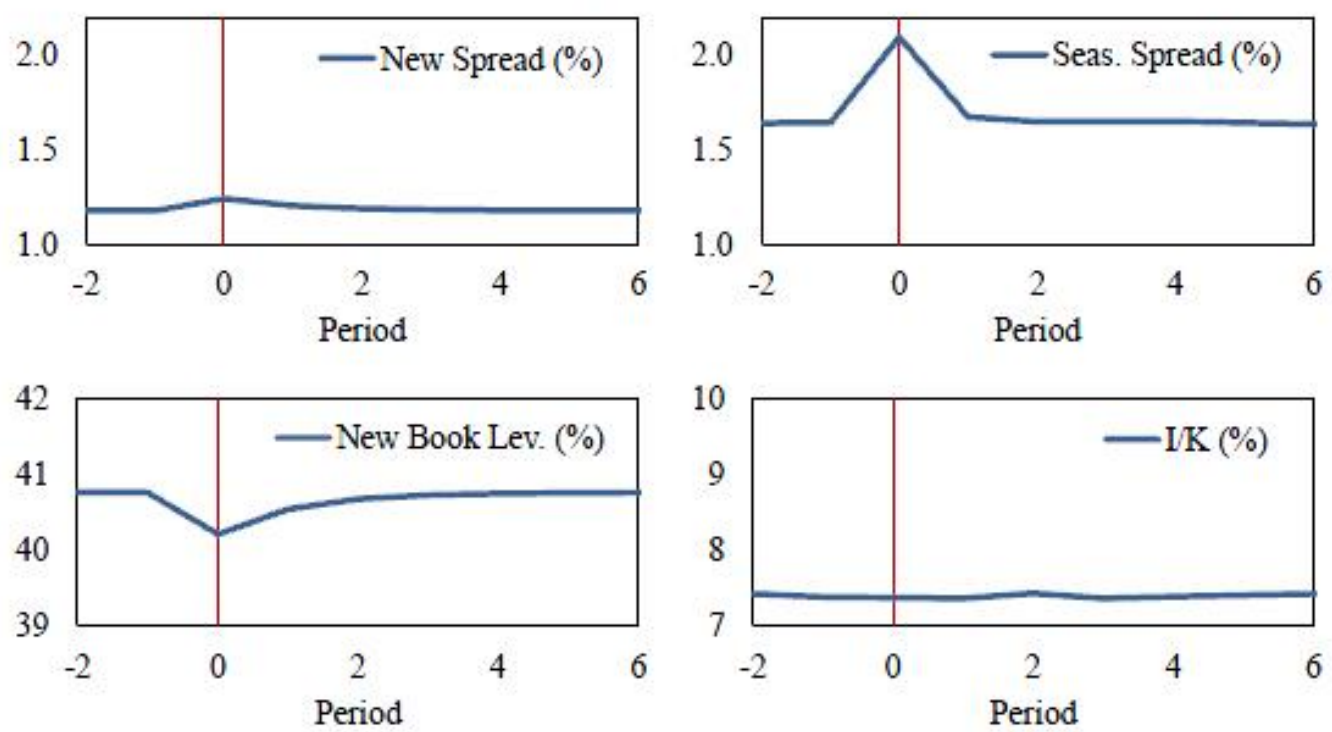

Panel B: Inflation-TFP Correlation Shock (Model 2)
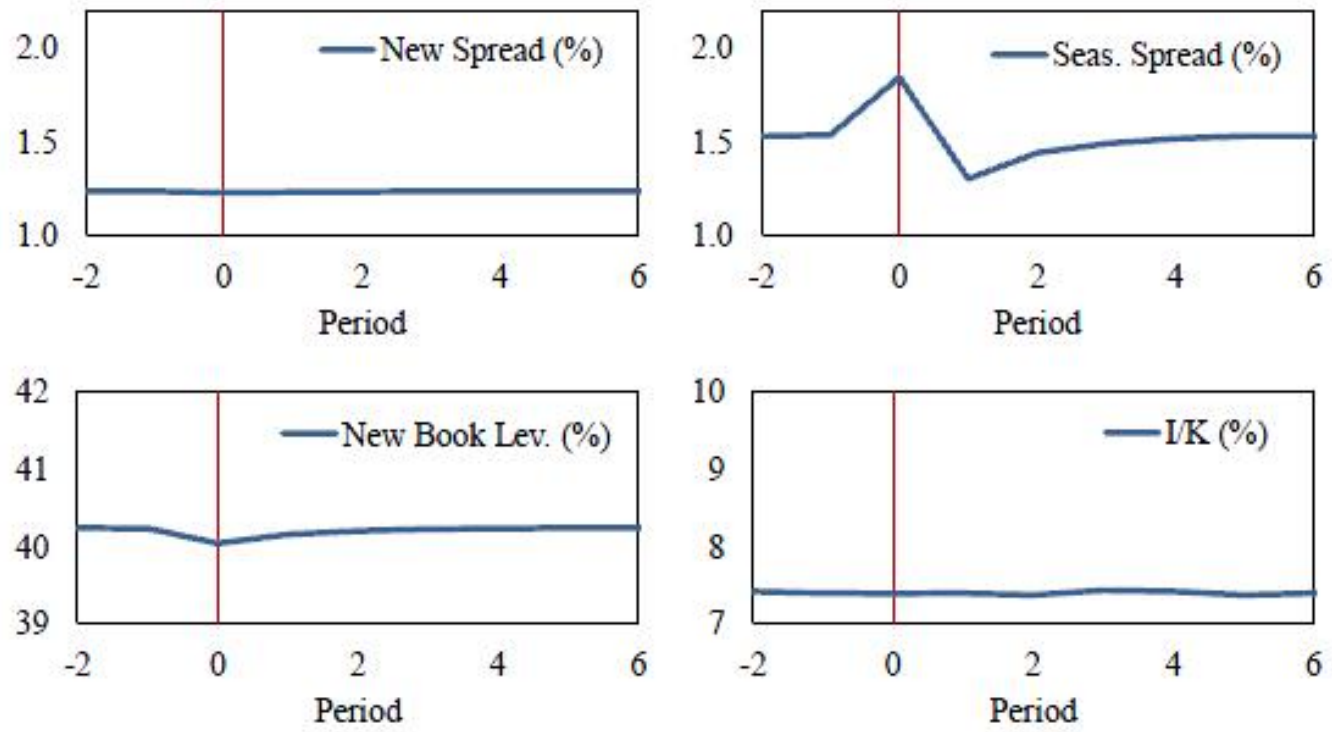

Figure 3.5: Model Impulse Responses

In period 0 of Panel A, the inflation volatility jumps from its stochastic steady state to $2 \%$ p.a. and mean reverts in subsequent periods. In Panel A, the inflation-TFP correlation is constant at zero. In period 0 of Panel B, the inflation-TFP correlation jumps from its stochastic steady state to 0.6. In Panel B, inflation volatility is constant at $1 \%$ p.a. Impulse responses are averaged over 62,500 simulations. 
Table 3.3: Model Credit Spread Regressions

Equity returns are one-period log seasoned equity returns. Inflation shocks are one-period changes in $\log$ inflation expectations. Equity return volatility is the standard deviation of log real returns on seasoned equity. The inflation-stock correlation is the correlation between log seasoned equity returns and shocks to $\log$ inflation expectations. The dividend-price ratio is the expected return on seasoned equity. In Panel A, inflation volatility switches between $0 \%$ p.a. and $2 \%$ p.a., and the inflation-TFP correlation is zero. In Panel $\mathrm{B}$, inflation volatility is constant at $1 \%$ p.a., and the inflation-TFP correlation switches between -0.6 and 0.6 .

\begin{tabular}{|c|c|c|c|c|}
\hline \multicolumn{5}{|c|}{ Panel A: Time-Varying Inflation Volatility (Model 1) } \\
\hline \multirow[t]{2}{*}{ Equity Return (\% Ann.) } & -0.02 & -0.01 & -0.02 & -0.01 \\
\hline & $(0.00)$ & $(0.00)$ & $(0.00)$ & $(0.00)$ \\
\hline \multirow[t]{2}{*}{ Inflation Shock (\% Ann.) } & & -0.11 & -0.10 & -0.11 \\
\hline & & $(0.03)$ & $(0.03)$ & $(0.03)$ \\
\hline \multirow[t]{2}{*}{ Equity Volatility (\% Ann.) } & & & 0.08 & 0.02 \\
\hline & & & $(0.07)$ & $(0.07)$ \\
\hline \multirow[t]{2}{*}{ Dividend-Price Ratio (\% Ann.) } & & & 0.17 & 0.29 \\
\hline & & & $(0.15)$ & $(0.14)$ \\
\hline \multirow[t]{2}{*}{ Inflation Volatility (\% Ann.) } & & & & 0.26 \\
\hline & & & & $(0.11)$ \\
\hline \multirow[t]{2}{*}{ Constant } & 2.39 & 2.26 & 1.06 & 1.29 \\
\hline & $(0.29)$ & $(0.14)$ & $(0.49)$ & $(0.50)$ \\
\hline$R^{2}$ & 0.27 & 0.76 & 0.83 & 0.86 \\
\hline \multicolumn{5}{|c|}{ Panel B: Time-Varying Inflation-TFP Correlation (Model 2) } \\
\hline \multirow[t]{2}{*}{ Equity Return (\% Ann.) } & -0.02 & -0.01 & -0.02 & -0.02 \\
\hline & $(0.00)$ & $(0.00)$ & $(0.00)$ & $(0.00)$ \\
\hline \multirow[t]{2}{*}{ Inflation Shock (\% Ann.) } & & -0.09 & -0.09 & -0.09 \\
\hline & & 0.01 & $(0.01)$ & $(0.01)$ \\
\hline \multirow[t]{2}{*}{ Equity Volatility (\% Ann.) } & & & 0.11 & 0.05 \\
\hline & & & $(0.04)$ & $(0.06)$ \\
\hline \multirow[t]{2}{*}{ Dividend-Price Ratio (\% Ann.) } & & & 0.12 & 0.24 \\
\hline & & & $(0.11)$ & $(0.14)$ \\
\hline \multirow[t]{2}{*}{ Inflation Volatility (\% Ann.) } & & & & 0.20 \\
\hline & & & & $(0.13)$ \\
\hline \multirow[t]{2}{*}{ Constant } & 2.25 & 2.18 & 0.83 & 1.22 \\
\hline & $(0.18)$ & $(0.12)$ & $(0.31)$ & $(0.41)$ \\
\hline$R^{2}$ & 0.31 & 0.72 & 0.80 & 0.81 \\
\hline
\end{tabular}


Table 3.3(A) shows that time-varying inflation volatility contributes to time variation in model credit spreads. The equity return, the inflation shock, equity volatility, the dividendprice ratio and inflation volatility enter with the expected signs. Since firms are unable to adjust leverage in the intermediate period, lagged equity returns and inflation shocks proxy for seasoned firms' leverage ratios. They can jointly account for three fourths of all variation in seasoned credit spreads. It is unsurprising that we can explain almost all variation in seasoned credit spreads because the simulation generates model credit spreads as a function of real and nominal shocks. At the same time we would not expect this result to carry over to our empirical analysis, especially if empirical nominal and real shocks are imperfectly measured.

The slope with respect to inflation volatility is positive and large. A one percentage point increase in the standard deviation of annual inflation shocks on leads to an economically significant increase in credit spreads of $26 \mathrm{bps}$. When adding inflation volatility to the model regression in Table 3.3(A), the $R^{2}$ increases by three percentage points to $86 \%$.

Inflation cyclicality also has a substantial effect on model credit spreads in Table 3.3(B). The credit spread increases by $20 \mathrm{bps}$ as the inflation-stock return correlation increases by 100 percentage points. The $R^{2}$ increases by one additional percentage point.

Taken together, our model credit spreads are highly sensitive to inflation risk even for moderate levels of inflation volatility. Increases in either inflation volatility or inflation cyclicality induce substantial increases in seasoned credit spreads and lead firms to reduce their leverage ratios. Endogenous adjustment in leverage implies that credit spreads mean revert after a shock to inflation risk. The model predicts that the impact of inflation risk on credit spreads is asymmetric and largest in periods of low stock returns and in periods of negative shocks to inflation expectations. 


\subsection{Empirical Tests}

We test the model predictions in an international panel of credit spread indices. We construct empirical credit spreads, inflation volatility and inflation-stock correlations for a panel of six developed economies: Australia, Canada, Germany, Japan, the U.K., and the U.S. Time-series and cross-country variation in inflation risk are substantial, allowing us to test the predictions in this international context.

Our baseline regressions test the key prediction that corporate bond spreads should be higher on average when inflation is more volatile or more procyclical, while controlling for other factors that are likely to enter into credit spreads.

\subsubsection{Data Description}

We obtain corporate bond yield indices, government bond yield indices, GDP growth, stock returns and CPI inflation from Global Financial Data (GFD). ${ }^{15}$ Corporate bond spread indices with approximate durations between 5 and 15 years are the difference between corporate bond yields and comparable duration government bond yields, both continuously compounded. ${ }^{16}$

We use the Moody's BAA over AAA corporate bond spread for the U.S. to control for time-varying liquidity. Comparable data are not available internationally, but international

\footnotetext{
${ }^{15}$ According to GFD, the original sources for government bond yields are the Reserve Bank of Australia, Bank of Canada, Deutsche Bundesbank, Bank of Japan, Bank of England, and Federal Reserve Bank. The original inflation sources are the Australian Bureau of Statistics, Statistics Canada, German Statistisches Bundesamt, Japanese Statistics Bureau, UK Central Statistical Office, and US Bureau of Labor Statistics. Stock returns correspond to the following equity indices: Australia ASX Accumulation Index, Canada S\&P/TSX-300 Total Return Index, Germany CDAX Total Return Index, Japan Topix Total Return Index, United Kingdom FTSE All-Share Return Index, and United States S\&P 500 Total Return Index. We are extremely grateful to Yoichi Matsubayashi for providing us with Japanese corporate bond yield data.

${ }^{16}$ Durations are estimated from bond maturities assuming that bonds sell at par following Campbell, Lo, and MacKinlay (1997), p. 408. The U.S. credit spread is computed as the Moody's BAA over AAA credit spread to adjust for liquidity and tax effects. For a description of the Moody's credit spreads, see http://credittrends.moodys.com/chartroom.asp?r=3. Table 4.9 in the Appendix lists further details on the corporate bond data sources and durations.
} 
government bond markets may also not enjoy the extreme liquidity of U.S. Treasuries, so the liquidity differential between government bonds and corporate bonds is likely to be smaller. ${ }^{17}$ Corporate bond spreads during the financial crisis plausibly also indicated heightened credit risk, as evidenced by the fact that in 2009 5.4\% of all Moody's rated corporate bond issuers defaulted (Moodys (2011)). Note that the structure of corporate bond markets varies significantly across countries. ${ }^{18}$

We obtain empirical proxies for each country's equity volatility, inflation volatility, and inflation-stock correlation using rolling backward-looking three year windows of quarterly real stock returns and inflation innovations. Unexpected inflation is the residual from a regression of quarterly log inflation onto its own four lags and seasonal dummies. Quarterly real stock return shocks are obtained as the residual from regressing quarterly real stock returns onto their own first lag.

We interpret the time variation in our ability to forecast inflation as a measure of inflation volatility. Stock and Watson (2008) argue that the performance of auto-regressions for predicting inflation is inferior to other models and has varied over time. Since we require an estimate of the time variation in inflation predictability but not of the best inflation forecast, a simple and transparent model for inflation seems advantageous. Our main results are very similar when we instead predict inflation using survey forecasts or a model of

\footnotetext{
${ }^{17}$ Chen, Collin-Dufresne, and Goldstein (2009) study the BAA over AAA spread for the same reason. Elton, Gruber, Agrawal, and Mann (2001) attribute 23 bps of the 10-year BBB spread to state and local taxes. They also note that the number of dealer quoted AAA bonds is very small and therefore noisy. Longstaff, Mithal, and Neis (2005) present evidence from Corporate Default Swaps that default risk accounts for the majority of the corporate bond spread across all rating categories, while Bao, Pan, and Wang (2011) argue that the illiquidity premium in highly-rated U.S. bonds increased substantially during the recent financial crisis. For a decomposition of interest rate swap spreads into liquidity and credit factors see Duffie and Singleton (1997).

${ }^{18}$ Corporate bond markets in the countries covered have previously been described and studied by central bank economists. For an analysis of the Japanese corporate bonds market, see Hattori, Koyama, and Yonetani (2001), who argue that default risk of the individual issuer is the most important determinant of corporate bond spreads in Japan after 1997. Reserve Bank of Australia Bulletin (2001) provides an overview of the Australian corporate bond market. Galati and Tsatsaronis (2001) and De Bondt and Lichtenberger (2003) study the transition of the Euro corporate bond market during the introduction of the Euro.
} 
the type suggested by Atkeson and Ohanian (2001). We use consumer prices to measure inflation risk, but our main results are robust to using different inflation indices.

Ideally, our model calls for an empirical measure of long-run inflation risk that updates quickly. Our empirical measures represent a compromise between shorter lags, smaller measurement error and a smaller cyclical component of inflation risk. We might partly reflect the risk of cyclical inflation fluctuations, acting similarly to measurement error and biasing our coefficient estimates downward.

Our regressions control for lagged stock returns, GDP growth, unemployment and lagged inflation surprises. We explicitly control for equal-weighted market leverage ratios of non-financial Compustat firms over a shorter time period. ${ }^{19}$

We control for the volatility of a stock market index and for idiosyncratic stock return volatility, when available. We follow Campbell, Lettau, Malkiel, and Xu (2001) in decomposing individual daily stock returns into a market component, an industry component, and a firm component. Idiosyncratic volatility is calculated as the volatility of the firm component over the past quarter, averaged over all individual stocks. ${ }^{20}$

In our model the dividend-price ratio helps to capture the time-varying risk of equity returns, while in a model of time-varying risk aversion, such as in Campbell and Cochrane (1999), it serves as a proxy for aggregate risk aversion. We therefore control for the dividend-price ratio from Datastream. ${ }^{21}$

\footnotetext{
${ }^{19}$ Data for the U.S. and Canada are from Compustat North America and CRSP. Data for all other countries are from Compustat Global. We divide annual book debt values from the previous year end by the sum of the same book debt and quarterly market equity. Following Baker and Wurgler (2002), we define book debt as the sum of total liabilities and preferred stock minus deferred taxes and convertible debt. When preferred stock is missing, we use the redemption value of preferred stock. Corporate bond yield indices, such as the Moody's long-term yield indices, weight observations equally and therefore we control for equal-weighted market leverage.

${ }^{20}$ We obtain U.S. stock returns from CRSP, Canadian stock returns from Datastream, and all other country stock returns from Compustat Global. Industries are defined according to GIC classification codes.

${ }^{21}$ For a given MSCI index, the dividend yield is computed as the market-value weighted average dividend yield of all of its constituents. The dividend yield for an individual stock is based on its most recent annualized dividend rate (i.e., dividends per share) divided by the current share price.
} 
Campbell, Sunderam, and Viceira (2011) have argued that the co-movement between nominal government bond returns and stock returns reflects time-varying inflation risk. If nominal long-term bond yields reflect long-term inflation expectations, the negative of the bond-stock return correlation may give another, quickly updating, measure of inflation cyclicality that focuses on the long-run component of inflation and that may be less sensitive to measurement error. However, the volatility of nominal government bond returns and the bond-stock correlation may also reflect real interest rate risk and, therefore also serve as important controls. We construct high frequency measures of bond return volatility and the bond-stock correlation from daily or weekly government bond and stock returns over the past quarter, using the highest frequency available. ${ }^{22}$

Figure 4.4 in the Appendix compares the bond-stock correlation for the U.S. and the U.K. the breakeven-stock return correlation. Inflation risk, as captured by the breakeven inflation-stock return correlation, moves very closely with the bond-stock return correlation, supporting our interpretation of the bond-stock correlation as an additional measure of inflation risk. At the same time breakeven inflation also contains an inflation risk premium and a liquidity premium (Pflueger and Viceira (2011)).

In addition to the leverage choice explicitly modeled, real firms may be able to adjust their capital structure along numerous margins. We construct measures of aggregate book leverage and the share of floating rate debt from Compustat and Compustat Global and use the equity share in new financing from Baker and Wurgler (2000). ${ }^{23}$ When firms refinance infrequently, book leverage is less subject to market fluctuations than market

\footnotetext{
${ }^{22}$ Bond volatility and the bond-stock correlation report the annualized standard deviation of changes in long-term nominal government bond yields and the correlation between changes in nominal government bond yields and stock returns, respectively. These measures are also equal to the volatility of government bond returns scaled by the bond duration and the negative of the correlation between government bond returns and stock returns, where bond returns are approximated using changes in yields. Our choice of units ensures that the inflation risk component in the bond volatility and the bond-stock correlation are comparable to the inflation-derived measures of inflation risk.

${ }^{23} \mathrm{We}$ set missing floating rate observations to zero to obtain aggregate floating rate shares consistent with the literature (Chernenko and Faulkender (2011)). The time-series behavior of the floating rate share is similar when instead excluding missing observations.
} 
leverage and we therefore use book leverage to capture firms' target leverage ratio. We compute aggregate book leverage ratios by summing book debt across all non-financial firms and dividing by the sum of aggregated total assets.

We compute aggregate investment to capital ratios by summing capital expenditures across all non-financial firms and divide by aggregated PP\&E at the end of the previous year, taking into account the reporting lag. ${ }^{24}$

\subsubsection{Summary Statistics}

Summary statistics in Table 3.4 reveal that both the volatility and the cyclicality of inflation have varied substantially over time in each country.

Average annualized inflation volatility ranges from $100 \mathrm{bps}$ for Germany to $161 \mathrm{bps}$ for the U.K. Inflation volatility displays significant time variation within each country with standard deviations ranging from 42 bps to $70 \mathrm{bps}$. The highest inflation volatility in our sample of 412 bps occurs in the U.K. during the 1970s.

The inflation-stock correlation, our measure of the slope of the Phillips curve, is negative or zero on average in every country. Its time variation within each country is substantial, with within country standard deviations of around 0.30 .

\footnotetext{
${ }^{24}$ Philippon (2009) and Polk and Sapienza (2009) construct similar investment variables.
} 
Table 3.4: Summary Statistics

Credit spreads are computed as yields on investment grade corporate bond indices in excess of durationmatched nominal government bond yields, both continuously compounded. For the U.S. we show the Moody's BAA over AAA spread. Inflation volatility is the annualized standard deviation of three years of quarterly inflation innovations. The inflation-stock correlation is computed using three years of quarterly inflation and stock return innovations. Inflation innovations are residuals from regressing quarterly inflation onto its own four lags and seasonal dummies. Stock return innovations are residuals from regressing the quarterly real stock return onto its own first lag. Equity volatility is the annualized standard deviation of quarterly real stock return innovations. Dividend-price ratios are from MSCI. Idiosyncratic volatility is computed using one quarter of daily individual stock returns and GIC sector classifications and follows the methodology of Campbell et. al. (2001). Compustat equal-weighted market leverage is computed as total debt divided by total debt plus market value of equity. We approximate daily or weekly government bond log returns using changes in continuously compounded yields. Government bond volatility is the annualized standard deviation of daily or weekly nominal government bond returns over the past quarter divided by bond duration. The bond-stock correlation is the negative of the correlation between daily or weekly government bond returns and stock returns over the past quarter. All volatilities are standard deviations.

\begin{tabular}{llrrrrrr}
\hline \multicolumn{7}{c}{ Panel A: Long Sample Period Variables } \\
\hline & & Australia & Canada & Germany & Japan & U.K. & U.S. \\
Start Date & & $1989 . Q 1$ & $1969 . Q 4$ & $1969 . Q 4$ & $1973 . Q 1$ & $1969 . Q 4$ & $1969 . Q 4$ \\
End Date & & $2010 . Q 2$ & $2010 . Q 4$ & $2010 . Q 4$ & $2010 . Q 2$ & $2010 . Q 4$ & $2010 . Q 4$ \\
Credit Spread (\%) & mean & 0.93 & 1.02 & 0.63 & 0.33 & 1.26 & 1.01 \\
& std & 0.57 & 0.42 & 0.65 & 0.28 & 0.91 & 0.42 \\
& min & 0.05 & 0.44 & -0.21 & -0.42 & 0.15 & 0.50 \\
& max & 2.57 & 3.39 & 3.99 & 1.06 & 5.87 & 3.17 \\
Inflation Vol. (\%, Ann.) & mean & 1.21 & 1.19 & 1.00 & 1.33 & 1.61 & 1.22 \\
& std & 0.39 & 0.43 & 0.36 & 0.77 & 0.87 & 0.58 \\
& min & 0.70 & 0.45 & 0.48 & 0.42 & 0.70 & 0.42 \\
& max & 2.09 & 1.97 & 2.11 & 3.72 & 4.12 & 2.93 \\
Inflation-Stock Correl. & mean & -0.18 & -0.04 & -0.15 & 0.00 & -0.11 & -0.27 \\
& std & 0.28 & 0.34 & 0.31 & 0.27 & 0.31 & 0.34 \\
& min & -0.61 & -0.77 & -0.83 & -0.56 & -0.70 & -0.90
\end{tabular}




\begin{tabular}{|c|c|c|c|c|c|c|c|}
\hline \multicolumn{8}{|c|}{ Table 3.4 (Continued) } \\
\hline & $\max$ & 0.43 & 0.66 & 0.63 & 0.51 & 0.59 & 0.55 \\
\hline \multirow[t]{4}{*}{ Equity Vol. (\%, Ann.) } & mean & 14.93 & 16.16 & 19.42 & 19.61 & 18.52 & 15.99 \\
\hline & std & 7.53 & 5.50 & 7.58 & 6.32 & 8.03 & 5.32 \\
\hline & $\min$ & 6.72 & 7.87 & 7.80 & 5.51 & 5.85 & 5.66 \\
\hline & $\max$ & 37.15 & 27.40 & 40.20 & 36.04 & 44.41 & 27.99 \\
\hline \multirow[t]{4}{*}{ Div.-Price Ratio (\%, Ann.) } & mean & 3.85 & 2.96 & 3.39 & 1.30 & 4.26 & 3.12 \\
\hline & std & 0.87 & 1.00 & 1.12 & 0.66 & 1.24 & 1.32 \\
\hline & $\min$ & 2.82 & 0.99 & 1.67 & 0.43 & 2.11 & 1.14 \\
\hline & $\max$ & 6.95 & 5.67 & 6.20 & 2.86 & 10.46 & 6.14 \\
\hline \multicolumn{8}{|c|}{ Panel B: Short Sample Period Variables } \\
\hline & & Australia & Canada & Germany & Japan & U.K. & U.S. \\
\hline Start Date & & 1989.Q1 & 1989.Q1 & 1990.Q1 & 1989.Q1 & 1989.Q1 & 1989.Q1 \\
\hline End Date & & 2010.Q2 & 2010.Q2 & 2010.Q2 & 2010.Q2 & 2010.Q2 & 2010.Q2 \\
\hline \multirow[t]{4}{*}{ Bond Vol. (\%, Ann.) } & mean & 0.80 & 0.66 & 0.54 & 0.49 & 0.66 & 0.72 \\
\hline & std & 0.22 & 0.18 & 0.17 & 0.20 & 0.21 & 0.22 \\
\hline & $\min$ & 0.42 & 0.28 & 0.28 & 0.19 & 0.30 & 0.40 \\
\hline & $\max$ & 1.62 & 1.32 & 0.97 & 1.18 & 1.42 & 1.54 \\
\hline \multirow[t]{4}{*}{ Bond-Stock Correl. } & mean & -0.04 & 0.00 & -0.09 & 0.11 & -0.03 & -0.04 \\
\hline & std & 0.35 & 0.32 & 0.39 & 0.31 & 0.41 & 0.42 \\
\hline & $\min$ & -0.65 & -0.62 & -0.84 & -0.69 & -0.80 & -0.77 \\
\hline & $\max$ & 0.78 & 0.68 & 0.72 & 0.64 & 0.72 & 0.77 \\
\hline \multirow[t]{4}{*}{ Idiosync. Vol. (\%, Ann.) } & mean & 22.23 & 26.80 & 26.24 & 31.28 & 18.28 & 25.95 \\
\hline & std & 12.03 & 5.20 & 9.02 & 7.46 & 12.36 & 7.61 \\
\hline & $\min$ & 5.02 & 19.69 & 15.91 & 19.08 & 4.04 & 16.26 \\
\hline & $\max$ & 57.68 & 54.67 & 54.95 & 58.00 & 52.75 & 50.39 \\
\hline \multirow[t]{4}{*}{ Leverage (\%) } & mean & 17.89 & 22.58 & 41.23 & 34.28 & 21.45 & 23.11 \\
\hline & std & 6.25 & 6.11 & 13.51 & 6.69 & 3.94 & 3.91 \\
\hline & $\min$ & 8.69 & 12.70 & 21.72 & 19.59 & 13.84 & 16.84 \\
\hline & $\max$ & 40.76 & 35.53 & 63.12 & 47.40 & 31.67 & 33.67 \\
\hline
\end{tabular}


Credit spreads average around 100 bps and have within country standard deviations between 36 bps to 91 bps. Rare negative values in Japanese and German credit spreads are most likely due to measurement error. The correlations of international credit spreads with U.S. credit spreads range from -0.21 for Japan to 0.55 for the U.K. As shown in Table 4.10 in the Appendix, international time series of credit spreads and inflation risk are not perfectly correlated with U.S. time series, effectively increasing our number of observations relative to an analysis of the U.S. time series.

Figure 3.6 plots time series of credit spreads and inflation volatility. The co-movement between international credit spreads and inflation volatility over time is apparent for most countries in our sample. Figure 3.6 also suggests a cross-sectional relationship between inflation volatility and credit spreads. As noted in the introduction, U.S. inflation volatility and credit spreads were both high in the 1970s and 1980s. We now see that both inflation volatility and credit spreads were even more elevated in the U.K. during the same period.

Figure 3.7 documents visually the relationship between credit spreads and the inflationstock correlation in our international data. For ease of comparison the inflation-stock correlation is scaled to have the same mean and standard deviation as credit spreads in each country. The U.S. inflation-stock return correlation was mostly negative during the 1970s and 1980s, indicating that supply shocks and shifting inflation expectations moved inflation and real outcomes in opposite directions. In contrast, the inflation-stock correlation was positive during much of the 1990s and 2000s, potentially as a result of smaller macroeconomic shocks or more stable monetary policy. In particular, two periods of high inflation-stock return correlations during the early 2000s and during the financial crisis coincided with high credit spreads. The co-movement between the inflation-stock return correlation and credit spreads is also visually apparent for other countries, even if our estimate of the inflation-stock return correlation contains measurement error. For instance, in Germany the inflation-stock correlation and credit spreads show very similar low-frequency movements with decreases during the 1970s and 1980s and steep increases 

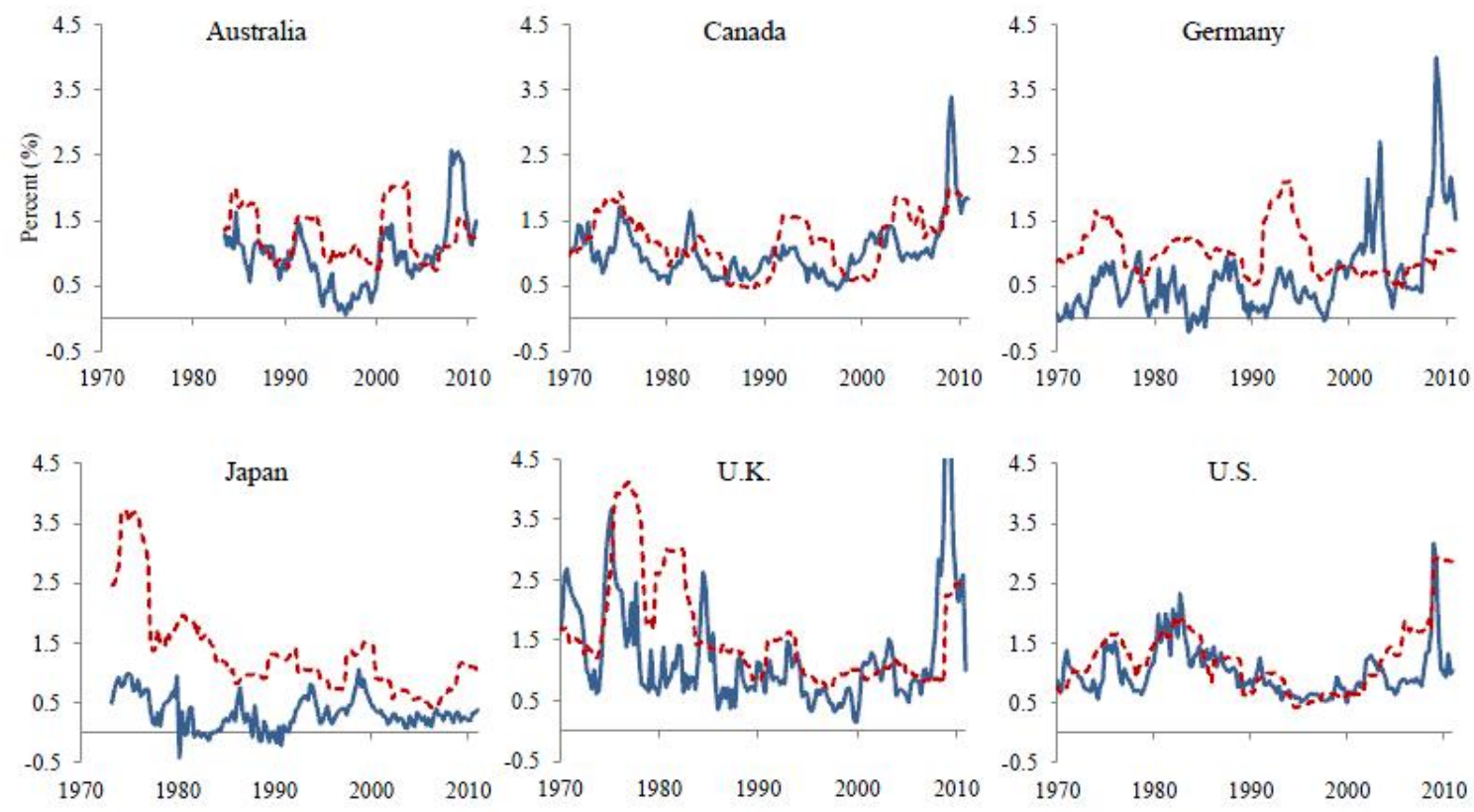

—Credit Spread (\%) --- Inflation Volatility (\% Ann.)

Figure 3.6: International Credit Spreads and Inflation Volatility

Quarterly credit spreads (bold) and inflation volatility (dashed) for Australia, Canada, Germany, Japan, the U.K., and the U.S. Credit spreads are investment grade corporate bond index yields in excess of durationmatched nominal government bond yields, except for the U.S. which is the Moody's BAA minus AAA spread. All yields are continuously compounded. Inflation volatility is computed using a 3 year backwardlooking window of quarterly inflation surprises. Both variables are shown in percentage units. 
during the 1990s and 2000s. ${ }^{25}$
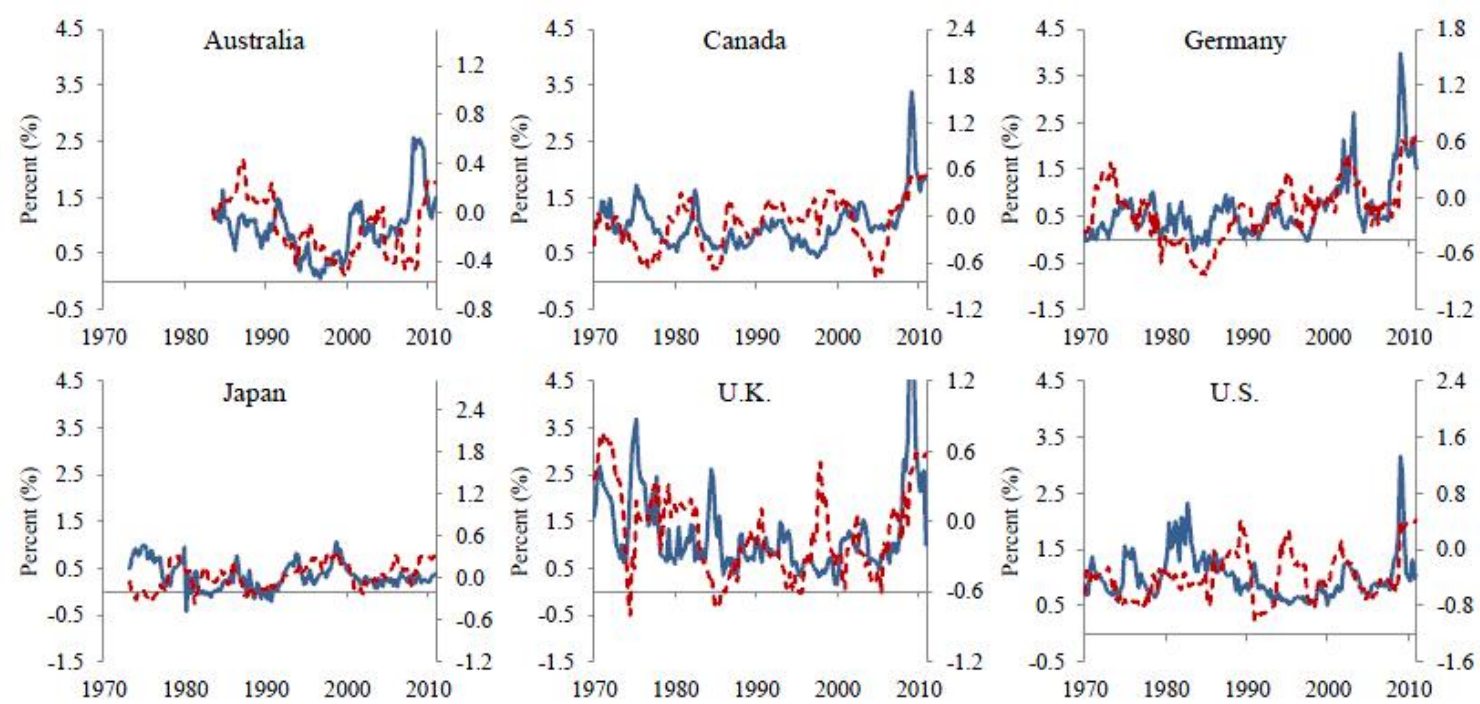

Credit Spread (\%, Left Axis) - - - Inflation-Stock Correlation (Right Axis)

Figure 3.7: International Credit Spreads and Inflation-Stock Correlation

Quarterly credit spreads (bold) and inflation-stock correlation (dashed) for Australia, Canada, Germany, Japan, U.K., and U.S. Credit spreads are investment grade corporate bond index yields in excess of durationmatched nominal government bond yields, except for the U.S. which is the Moody's BAA-AAA spread. All yields are continuously compounded. The inflation-stock correlation is computed using a 3-year backwardlooking window of quarterly inflation surprises and stock returns.

\subsubsection{Testing for Inflation Risk in Credit Spreads}

Our benchmark regressions in Table 3.5(A) provide evidence that credit spreads increase in both inflation volatility and the inflation-stock correlation, while controlling for proxies for real uncertainty, time-varying risk aversion, and the business cycle. Equity volatility and the dividend-price ratio, our proxies for real uncertainty and time-varying

\footnotetext{
${ }^{25}$ Using bond-market derived measures Wright (2010) argues that the cyclicality of inflation has increased since 1990 in most developed countries.
} 
risk aversion, both enter with the expected signs and jointly explain $12 \%$ of the variation in credit spreads after controlling for country fixed effects. We find that inflation volatility and the inflation-stock correlation jointly can explain as much variation in credit spreads as can our proxies for real uncertainty and time-varying risk aversion, raising the residual $\mathrm{R}^{2}$ to $27 \%$ (after taking out fixed effects).

Since inflation uncertainty might move over the business cycle and with changes in inflation, it is important to control for proxies for real economic activity and shocks to inflation expectations. In the model, positive real returns and inflation surprises reduce real leverage ratios and therefore reduce credit spreads. Column (4) shows our benchmark estimate, which controls for lagged inflation shocks, stock returns, GDP growth and change in unemployment. Adding controls to our regression increases the residual $\mathrm{R}^{2}$ by another ten percentage points and improves the precision of the estimated slope on the inflation-stock correlation.

The empirical estimates in Table 3.5 indicate a large effect of inflation volatility and the inflation-stock correlation on credit spreads, consistent with the model. The empirical slope coefficients on inflation volatility and the inflation-stock correlation are within two standard deviations of the model slope coefficients in Table 3.4. The slope coefficient on inflation volatility is especially close to the theoretical coefficient. 
Table 3.5: Credit Spreads and Inflation Risk (1969.Q4-2010.Q4)

Panel A includes the following countries: Canada, Germany, Japan, the U.K., and the U.S. Panel B includes the U.S. only. Panel A reports Driscoll and Kraay (1998) standard errors accounting for cross-country correlation and 16 lags. We estimate time fixed effects by time demeaning all left-hand side and right-hand side variables and again report Driscoll and Kraay (1998) standard errors with 16 lags. Residual R-squareds reflect explanatory power in excess of fixed effects. Panel B reports Newey-West standard errors with 16 lags in parentheses. Controls include quarterly and three year inflation innovations, stock returns, GDP growth, and three year change in unemployment. Japan data starts in 1973.Q1. Variables are constructed as described in Table 3.4. * and ** denote significance at the $1 \%$ and $5 \%$ levels, respectively.

\begin{tabular}{|c|c|c|c|c|c|c|}
\hline \multicolumn{7}{|c|}{ Panel A: International } \\
\hline \multirow[t]{2}{*}{ Equity Volatility (\% Ann.) } & $0.02 * *$ & $0.02 *$ & $0.02 *$ & $0.02 *$ & $0.02 * *$ & $0.02 * *$ \\
\hline & $(0.01)$ & $(0.01)$ & $(0.01)$ & $(0.01)$ & $(0.01)$ & $(0.01)$ \\
\hline \multirow[t]{2}{*}{ Dividend-Price Ratio (\% Ann.) } & $0.12 * *$ & $0.07 *$ & $0.10^{*}$ & $0.18 * *$ & $0.15^{*}$ & $0.12 * *$ \\
\hline & $(0.03)$ & $(0.03)$ & $(0.04)$ & $(0.05)$ & $(0.08)$ & $(0.03)$ \\
\hline \multirow[t]{2}{*}{ Inflation Volatility (\% Ann.) } & & $0.22 * *$ & $0.20 * *$ & $0.34 * *$ & $0.19 * *$ & $0.24 * *$ \\
\hline & & $(0.08)$ & $(0.06)$ & $(0.08)$ & $(0.06)$ & $(0.06)$ \\
\hline \multirow[t]{2}{*}{ Inflation-Stock Correlation } & & & $0.62 * *$ & $0.42 * *$ & $0.42 * *$ & $0.30 *$ \\
\hline & & & $(0.22)$ & $(0.12)$ & $(0.11)$ & $(0.12)$ \\
\hline Residual R2 & 0.12 & 0.16 & 0.27 & 0.39 & 0.20 & 0.36 \\
\hline Controls & No & No & No & Yes & Yes & Yes \\
\hline Country Fixed Effects & Yes & Yes & Yes & Yes & Yes & Yes \\
\hline Time Fixed Effects & No & No & No & No & Yes & No \\
\hline \multirow[t]{2}{*}{ Excluding 2008-2010 } & No & No & No & No & No & Yes \\
\hline & \multicolumn{3}{|c|}{ Panel B: U.S. } & & & \\
\hline \multirow[t]{2}{*}{ Equity Volatility (\% Ann.) } & 0.01 & 0.00 & 0.00 & 0.00 & 0.00 & \\
\hline & $(0.01)$ & $(0.01)$ & $(0.01)$ & $(0.01)$ & $(0.01)$ & \\
\hline \multirow[t]{2}{*}{ Dividend-Price Ratio (\% Ann.) } & $0.14 * *$ & $0.10^{*}$ & $0.11 * *$ & 0.06 & $0.08^{*}$ & \\
\hline & $(0.05)$ & $(0.04)$ & $(0.04)$ & $(0.03)$ & $(0.04)$ & \\
\hline \multirow[t]{2}{*}{ Inflation Volatility (\% Ann.) } & & $0.39 * *$ & $0.38 * *$ & $0.32 * *$ & $0.38 * *$ & \\
\hline & & $(0.08)$ & $(0.08)$ & $(0.05)$ & $(0.08)$ & \\
\hline \multirow[t]{2}{*}{ Inflation-Stock Correlation } & & & 0.11 & 0.14 & $0.30 *$ & \\
\hline & & & $(0.10)$ & $(0.08)$ & $(0.13)$ & \\
\hline$R^{2}$ & 0.22 & 0.47 & 0.48 & 0.66 & 0.69 & \\
\hline Controls & No & No & No & Yes & Yes & \\
\hline Excluding 2008-2010 & No & No & No & No & Yes & \\
\hline
\end{tabular}


A 50 bps move in inflation volatility, approximately to one standard deviation in the U.S., is associated with a 16 bps increase in empirical credit spreads. A one standard deviation move in the inflation-stock correlation (30 percentage points) is associated with a 13 bps increase in credits spreads. The magnitudes are economically meaningful relative to average credit spreads of around 100 bps.

The reported standard errors take into account potential cross-country correlation, heteroskedasticity, and serial autocorrelation. We compute standard errors according to Driscoll and Kraay (1998)s extension of Newey and West (1987) with 16 lags. ${ }^{26}$

Our benchmark estimates might reflect both time-series and cross-country variation in inflation risk. Adding time fixed effects to the benchmark regression confirms our previous visual impression that cross-country variation helps in estimating the empirical relationship between credit spreads and inflation risk. The slope coefficients onto inflation volatility and the inflation-stock return correlation remain similar in magnitude and significant. ${ }^{27}$ This finding also helps to alleviate concerns that the results might be driven by any global omitted variable, such as global real interest rate risk or global growth risk.

Excluding the financial crisis, the coefficients on inflation volatility and the inflationstock correlation decrease in magnitude, but inflation risk remains economically and statistically significant in the pre-crisis subsample. From our theoretical analysis, we would expect that inflation risk should have especially large effects on credit spreads during crises, but it appears that the empirical relationship between credit spreads and inflation risk is not solely driven by the most recent financial crisis.

We also report estimates for the U.S. time series, which might be especially familiar to readers. ${ }^{28}$ Table $3.5(\mathrm{~B})$ shows that credit spreads are clearly related to inflation risk in

\footnotetext{
${ }^{26}$ Hoechle (2007) provides a Stata routine.

${ }^{27}$ We estimate the time fixed effects regression by first time demeaning all left-hand side and right-hand side variables. We again report Driscoll and Kraay (1998) standard errors with 16 lags.

${ }^{28}$ Table 4.11 in the Appendix shows that all results in Table 3.5 are robust to computing the U.S. credit spread with respect to a duration-matched government bond yield.
} 
the U.S., although the smaller sample size decreases the statistical power of the tests. The regression $\mathrm{R}^{2}$ increases from $22 \%$ to $48 \%$ as we add inflation volatility and the inflationstock correlation as explanatory variables to our proxies for real risk and time-varying risk aversion. The slope on inflation volatility is large, significant, and comparable to the slope in the international regression. The inflation-stock correlation enters positively but is only significant for the pre-crisis subsample. While both U.S. credit spreads and the U.S. inflation-stock correlation were high during the financial crisis, the inflation-stock correlation remained high after the financial crisis. It therefore did not capture the significant decline in U.S. credit spreads in 2010.

The sensitivities of credit risk with respect to real growth shocks and inflation shocks play crucial roles in our proposed mechanism. Table 3.6 spells out the coefficient estimates on the proxies for real and nominal shocks, that are included as controls in Table 3.5. Quarterly inflation shocks consistently enter negatively, providing support for the model mechanism. Magnitudes are comparable to the slope of credit spreads onto inflation shocks in the model. Three year inflation shocks enter negatively in the U.S. but not internationally, potentially due to the comovement between the level of inflation and long-run inflation uncertainty (Ball and Cecchetti, 1990). As shown in Figure 4.5 in the Appendix, the relationship between U.S. inflation shocks and credit spreads is clearest during the recent financial crisis, when a rapid fall in consumer prices coincided with high credit spreads. However, column (4) in Table 3.6 indicates that U.S. credit spreads also have an inverse relationship with quarterly inflation shocks during the pre-crisis period. The coefficients on real growth variables need to be interpreted with caution because of collinearity between different real activity variables, but quarterly GDP growth enters consistently with a negative sign. 
Table 3.6: Inflation and Growth Controls (1969.Q4-2010.Q4)

This table reports the coefficient estimates on control variables in Table 3.5(A), columns (4) and (6), and Table 3.5(B), columns (4) and (5). * and ** denote significance at the $1 \%$ and $5 \%$ levels, respectively. All variables are as described in Table 3.4 .

\begin{tabular}{|c|c|c|c|c|}
\hline & International & International & U.S. & U.S. \\
\hline Credit Spread (\%) & (1) & (2) & (3) & (4) \\
\hline \multirow[t]{2}{*}{ Quarterly Inflation Shock } & $-0.06 *$ & -0.02 & $-0.14 * *$ & $-0.08^{*}$ \\
\hline & $(0.03)$ & $(0.02)$ & $(0.04)$ & $(0.04)$ \\
\hline \multirow[t]{2}{*}{3 Year Inflation Shock } & 0.01 & 0.02 & -0.02 & -0.00 \\
\hline & $(0.01)$ & $(0.01)$ & $(0.02)$ & $(0.02)$ \\
\hline \multirow[t]{2}{*}{ Quarterly Real Stock Return } & -0.00 & 0.00 & -0.00 & $0.00 *$ \\
\hline & $(0.00)$ & $(0.00)$ & $(0.00)$ & $(0.00)$ \\
\hline \multirow[t]{2}{*}{3 Year Real Stock Return } & -0.00 & -0.00 & -0.00 & 0.00 \\
\hline & $(0.00)$ & $(0.00)$ & $(0.00)$ & $(0.00)$ \\
\hline \multirow[t]{2}{*}{ Quarterly GDP Growth } & -0.43 & -0.11 & $-0.59 *$ & $-0.34 *$ \\
\hline & $(0.24)$ & $(0.12)$ & $(0.23)$ & $(0.13)$ \\
\hline \multirow[t]{2}{*}{3 Year GDP Growth } & $-0.06 * *$ & $-0.05 * *$ & $0.10^{*}$ & 0.04 \\
\hline & $(0.02)$ & $(0.02)$ & $(0.04)$ & $(0.05)$ \\
\hline \multirow[t]{2}{*}{3 Year Change Unemployment } & -0.04 & -0.00 & 0.03 & $0.06^{*}$ \\
\hline & $(0.03)$ & $(0.02)$ & $(0.02)$ & $(0.03)$ \\
\hline Country Fixed Effects & Yes & Yes & & \\
\hline Excluding 2008-2010 & No & Yes & No & Yes \\
\hline
\end{tabular}

Our proposed mechanism implies that the impact of inflation risk on credit spreads should be especially strong when either real stock returns or inflation surprises are low. Figure 3.8 explores these predictions using a non-parametric approach and provides an empirical analogue to the theoretical relationships in Figure 3.4.

We construct the left panel in Figure 3.8(A) by splitting observations in each country into quintiles of real stock returns and into equal-sized subsamples for high and low inflation volatility. We sort by three year real stock returns for consistency with the construction of the inflation risk variables. Normalizing credit spreads in the middle real stock return 
Panel A: Inflation Volatility Regimes
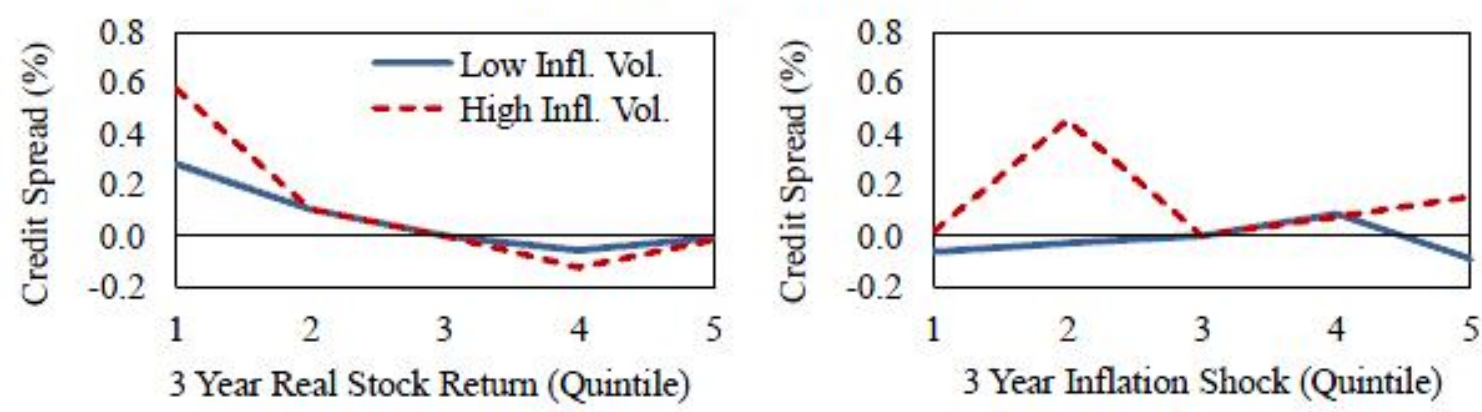

Panel B: Inflation-Stock Correlation Regimes
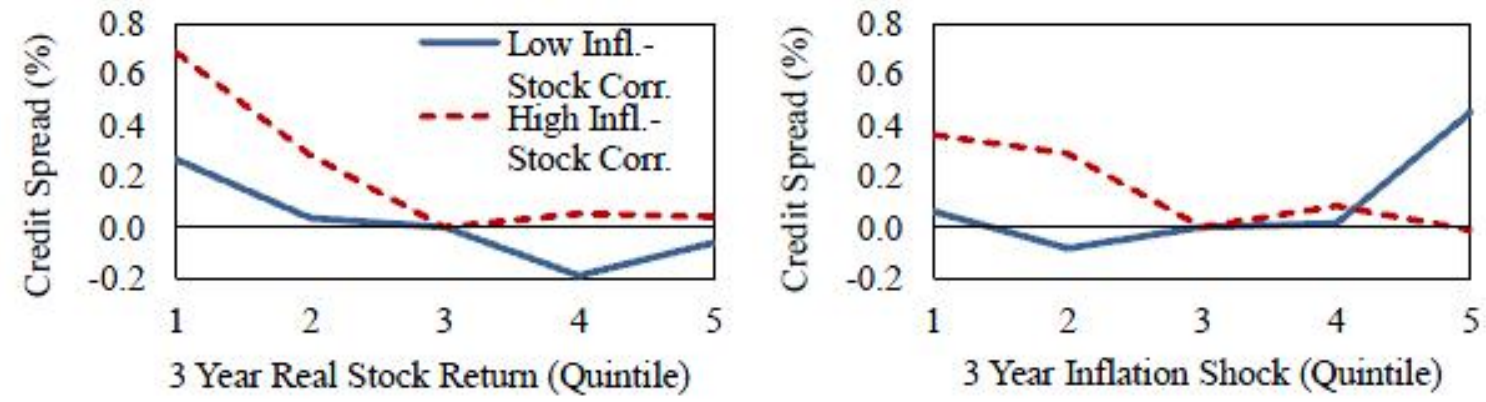

Figure 3.8: Empirical Credit Spreads, Stock Returns and Inflation Shocks

Empirical credit spreads versus real stock returns and inflation shocks averaged across Australia, Canada, Germany, Japan, the U.K., and the U.S. for different inflation risk regimes. In Panel A, credit spreads across countries are averaged for both low and high inflation volatility regimes within quintiles of 3 year real stock returns and 3 year inflation shocks. In Panel B, credit spreads across countries are averaged for both low and high inflation-stock correlation regimes within quintiles of 3 year real stock returns and 3 year inflation shocks. Low and high inflation risk regimes are defined relative to median values within each country. Credit spreads are normalized to zero in the middle quintile for both inflation risk regimes. A horizontal line is shown at $0 \mathrm{bps}$. 
quintile to zero focuses on the comparison between credit spread slopes across inflation risk regimes. The panel averages credit spreads across all countries within each inflation risk regime and quintile. The other panels are constructed similarly, instead sorting by the inflation-stock correlation and the three year inflation shock.

The empirical relationships between credit spreads, stock returns and inflation shocks in Figure 3.8 bear striking resemblance to the theoretical relationships in Figure 3.4. The left panel in Figure 3.8(A) shows that credit spreads disproportionately increase with inflation volatility when real stock returns are low. The slope of credit spreads is identical across high and low inflation volatility regimes for the top four quintiles of stock returns. However, the gap between credit spreads in the high and low inflation volatility regimes widens to $20 \mathrm{bps}$ in the lowest stock return quintile, indicating a larger put option in defaultable bonds when inflation uncertainty is greater.

The right panel of Figure 3.8(A) similarly suggests that the impact of inflation volatility on credit spreads is larger when inflation is surprisingly low, even if the largest difference in credit spreads obtains in the second-lowest quintile of inflation shocks rather than the lowest.

Figure 3.8(B) shows that inflation cyclicality also impacts credit spreads most strongly when real stock returns and inflation shocks are low. The gap between credit spreads in high and low inflation-stock correlation regimes widens to $40 \mathrm{bps}$ in the lowest stock return quintile. Finally, credit spreads in the high inflation-stock correlation regime are higher in the lowest inflation shock quintile than in the middle inflation shock quintile by $30 \mathrm{bps}$, even if the volatility of the average credit spreads across quintiles suggest that these averages may be estimated noisily.

The empirical magnitudes in Figure 3.8 are large compared to our benchmark empirical results. However, they are smaller than the theoretical magnitudes shown in Figure 3.4. Besides measurement error, one potential reason is that in Figure 3.8 we average the above median and below median inflation risk regimes. For instance in Figure 3.8(A) the average inflation volatility increases by only 0.73 percentage points from the low to the 
high inflation volatility regimes, while in Figure 3.4(A) we are able to look at the extremes in inflation volatility directly and the inflation volatility differential is 2 percentage points.

\subsubsection{Robustness of Benchmark Results}

Table 3.7 shows that our benchmark results are robust to including idiosyncratic equity volatility, market leverage, the return volatility of nominal government bonds, and the bond-stock correlation, available over a shorter sample period starting in 1989.

Table 3.7: Credit Spread Regressions with Additional Controls (1989.Q1-2010.Q4)

Panel A includes the following countries: Australia, Canada, Germany, Japan, the U.K., and the U.S. Panel B includes the U.S. only. Panel A reports Driscoll and Kraay (1998) standard errors accounting for crosscountry correlation and 16 lags. We estimate time fixed effects by time-demeaning all left-hand side and right-hand side variables and again report Driscoll and Kraay (1998) standard errors with 16 lags. Residual R-squareds reflect explanatory power in excess of fixed effects. Panel B reports Newey-West standard errors with 16 lags in parentheses. Controls include quarterly and three year inflation innovations, stock returns, GDP growth, and three year change in unemployment. Germany data starts in 1990.Q1. Variables are constructed as described in Table 3.4. * and ** denote significance at the $1 \%$ and $5 \%$ levels, respectively.

\begin{tabular}{rrrrrrr}
\hline \multicolumn{7}{c}{ Panel A: International } \\
\hline Credit Spread (\%) & $(1)$ & $(2)$ & $(3)$ & $(4)$ & $(5)$ & $(6)$ \\
Idiosyncratic Volatility (\% Ann.) & $0.03^{* *}$ & $0.02^{* *}$ & $0.01^{*}$ & 0.01 & 0.00 & 0.01 \\
& $(0.01)$ & $(0.01)$ & $(0.01)$ & $(0.01)$ & $(0.01)$ & $(0.00)$ \\
Dividend-Price Ratio (\% Ann.) & $0.38^{*}$ & $0.30^{*}$ & $0.33^{* *}$ & $0.29^{* *}$ & $0.25^{* *}$ & $0.09^{* *}$ \\
& $(0.19)$ & $(0.14)$ & $(0.11)$ & $(0.10)$ & $(0.09)$ & $(0.02)$ \\
& $-0.02^{*}$ & $-0.02^{*}$ & $-0.01^{*}$ & $-0.01^{*}$ & $-0.01^{* *}$ & $-0.01^{* *}$ \\
& $(0.01)$ & $(0.01)$ & $(0.01)$ & $(0.00)$ & $(0.00)$ & $(0.00)$ \\
Lnflation Volatility (\% Ann.) & & $0.43^{* *}$ & $0.33^{* *}$ & $0.33^{* *}$ & 0.11 & $0.12^{* *}$ \\
& & $(0.12)$ & $(0.08)$ & $(0.07)$ & $(0.07)$ & $(0.04)$ \\
Inflation-Stock Correlation & & $0.50^{* *}$ & $0.32^{* *}$ & $0.26^{* *}$ & $0.16^{*}$ & $0.13^{* *}$ \\
& & $(0.09)$ & $(0.05)$ & $(0.05)$ & $(0.07)$ & $(0.04)$ \\
Bond Volatility (\% Ann.) & & & 0.31 & 0.25 & 0.31 & -0.03 \\
& & & $(0.16)$ & $(0.15)$ & $(0.18)$ & $(0.04)$
\end{tabular}


Table 3.7 (Continued)

\begin{tabular}{|c|c|c|c|c|c|c|}
\hline \multirow[t]{2}{*}{ Bond-Stock Correlation } & & & $0.74 * *$ & $0.69 * *$ & $0.44^{*}$ & $0.36 * *$ \\
\hline & & & $(0.16)$ & $(0.19)$ & $(0.21)$ & $(0.06)$ \\
\hline Residual R2 & 0.28 & 0.41 & 0.54 & 0.57 & 0.21 & 0.40 \\
\hline Controls & No & No & No & Yes & Yes & Yes \\
\hline Country Fixed Effects & Yes & Yes & Yes & Yes & Yes & Yes \\
\hline Time Fixed Effects & No & No & No & No & Yes & No \\
\hline Excluding 2008-2010 & No & No & No & No & No & Yes \\
\hline \multicolumn{7}{|c|}{ Panel B: U.S. } \\
\hline Credit Spread (\%) & (1) & (2) & (3) & (4) & (5) & \\
\hline \multirow[t]{2}{*}{ Idiosyncratic Volatility (\% Ann.) } & 0.03 & 0.02 & 0.01 & 0.01 & -0.00 & \\
\hline & $(0.03)$ & $(0.02)$ & $(0.01)$ & $(0.00)$ & $(0.00)$ & \\
\hline \multirow[t]{2}{*}{ Dividend-Price Ratio (\% Ann.) } & 0.20 & 0.08 & 0.10 & 0.05 & $-0.07 * *$ & \\
\hline & $(0.30)$ & $(0.15)$ & $(0.10)$ & $(0.03)$ & $(0.02)$ & \\
\hline \multirow[t]{2}{*}{ Leverage (\%) } & -0.01 & 0.02 & 0.02 & $0.02 * *$ & $0.03 * *$ & \\
\hline & $(0.05)$ & $(0.02)$ & $(0.02)$ & $(0.01)$ & $(0.01)$ & \\
\hline \multirow[t]{2}{*}{ Inflation Volatility (\% Ann.) } & & $0.51 * *$ & $0.40 * *$ & $0.48 * *$ & $0.30 * *$ & \\
\hline & & $(0.05)$ & $(0.07)$ & $(0.05)$ & $(0.04)$ & \\
\hline \multirow[t]{2}{*}{ Inflation-Stock Correlation } & & 0.07 & -0.03 & -0.17 & -0.03 & \\
\hline & & $(0.10)$ & $(0.09)$ & $(0.09)$ & $(0.04)$ & \\
\hline \multirow[t]{2}{*}{ Bond Volatility (\% Ann.) } & & & $0.53 * *$ & $0.39 * *$ & $0.18^{*}$ & \\
\hline & & & $(0.16)$ & $(0.10)$ & $(0.08)$ & \\
\hline \multirow[t]{2}{*}{ Bond-Stock Correlation } & & & 0.12 & 0.02 & 0.03 & \\
\hline & & & $(0.06)$ & $(0.06)$ & $(0.02)$ & \\
\hline$R^{2}$ & 0.17 & 0.73 & 0.80 & 0.90 & 0.74 & \\
\hline Controls & No & No & No & Yes & Yes & \\
\hline Excluding 2008-2010 & No & No & No & No & Yes & \\
\hline
\end{tabular}

The bond-stock correlation enters positively and significantly with a large regression coefficient, offering additional evidence for the strong relevance of inflation risk for corporate bond spreads. The bond volatility enters positively but is only marginally significant. 
The residual $\mathrm{R}^{2}$ increases by fourteen percentage points to $54 \%$ when adding these two explanatory variables. At the same time the coefficients on inflation volatility remain significant and show small decreases in magnitude, indicating that inflation risk is priced into corporate bonds above and beyond real interest rate risk.

Controlling for time fixed effects helps us to isolate further the inflation risk component from a global real interest rate risk component in the bond market derived variables. If financial markets are highly integrated across the six developed countries in our sample, real interest rate risk should be equated across countries. ${ }^{29}$ The coefficient on the bondstock correlation remains large and significant with country fixed effects, suggesting that the bond-stock correlation contains a significant country-specific inflation risk component, which is priced into corporate bond spreads across countries. Adding time fixed effects renders the inflation volatility and the inflation-stock correlation insignificant, reflecting the limited cross-country variation in these variables over the shorter time period.

In the Appendix we report additional tests. The main results in Table 3.5 also hold in changes and we find that empirical changes in credit spreads are negatively related to lagged inflation risk. Credit spreads fully mean revert over a horizon of five years, consistent with the model.

Further robustness checks, including individual country regressions, different inflation indices and empirical proxies for inflation shocks, HP filtered explanatory variables, and different measures for real uncertainty are reported in the Appendix.

\subsubsection{Implications for Capital Structure}

If investors demand compensation for bearing credit risk associated with inflation, firms should adjust their capital structure accordingly. The financing choice of firms in our model is highly simplified, but in reality firms can reduce their exposure to fluctua-

\footnotetext{
${ }^{29}$ For instance, Wright (2010) uses an assumption along these lines in his analysis of international interest rate risk premia.
} 
tions in real liabilities along multiple dimensions.

Issuing equity instead of debt reduces leverage and the inflation exposure of firms' liabilities. Indeed, we see in Figure 3.9(B) that the share of equity issuance was especially high during periods of volatile inflation in the 1970s and 1980s.

The issuance of floating-rate debt offers firms the possibility of indexing interest payments to nominal interest rates, even if face values are still fixed in nominal terms, and therefore also helps to reduce inflation risk of firms' liabilities. The floating-rate share of long-term debt among U.S. Compustat firms, shown in Figure 3.9(A), appears related to inflation uncertainty. It peaked during the 1970s, came down during the 1980s and 1990s and increased subsequently. ${ }^{30}$

Formally testing the relationship between aggregate book leverage and inflation risk yields evidence consistent with firms adjusting their book leverage downwards when inflation is more volatile. In contrast to market leverage, book leverage should be less exposed to mechanical effects of stock returns and therefore give a more reliable measure of firms' intended leverage ratio. Leverage data are annual, with the U.S. time series available starting in 1970 and international data available starting in 1994.

Table 3.8(A) shows a significant negative relationship between leverage and inflation volatility. The results look similar for the longer U.S. time series and for the international panel. We control for three year stock returns, inflation surprises, GDP growth and change in unemployment, as before. A one standard deviation move in inflation volatility is associated with a 1.5 percentage point decrease in leverage. The slope of leverage onto inflation volatility is larger than in the model but imprecisely estimated. We find no relationship between leverage and the inflation-stock correlation, which is consistent with the relative magnitudes in the model in Figure 3.5.

\footnotetext{
${ }^{30}$ Only $60 \%$ of Compustat firms report floating-rate debt, so the floating rate debt share may be subject to time-varying reporting bias.
} 

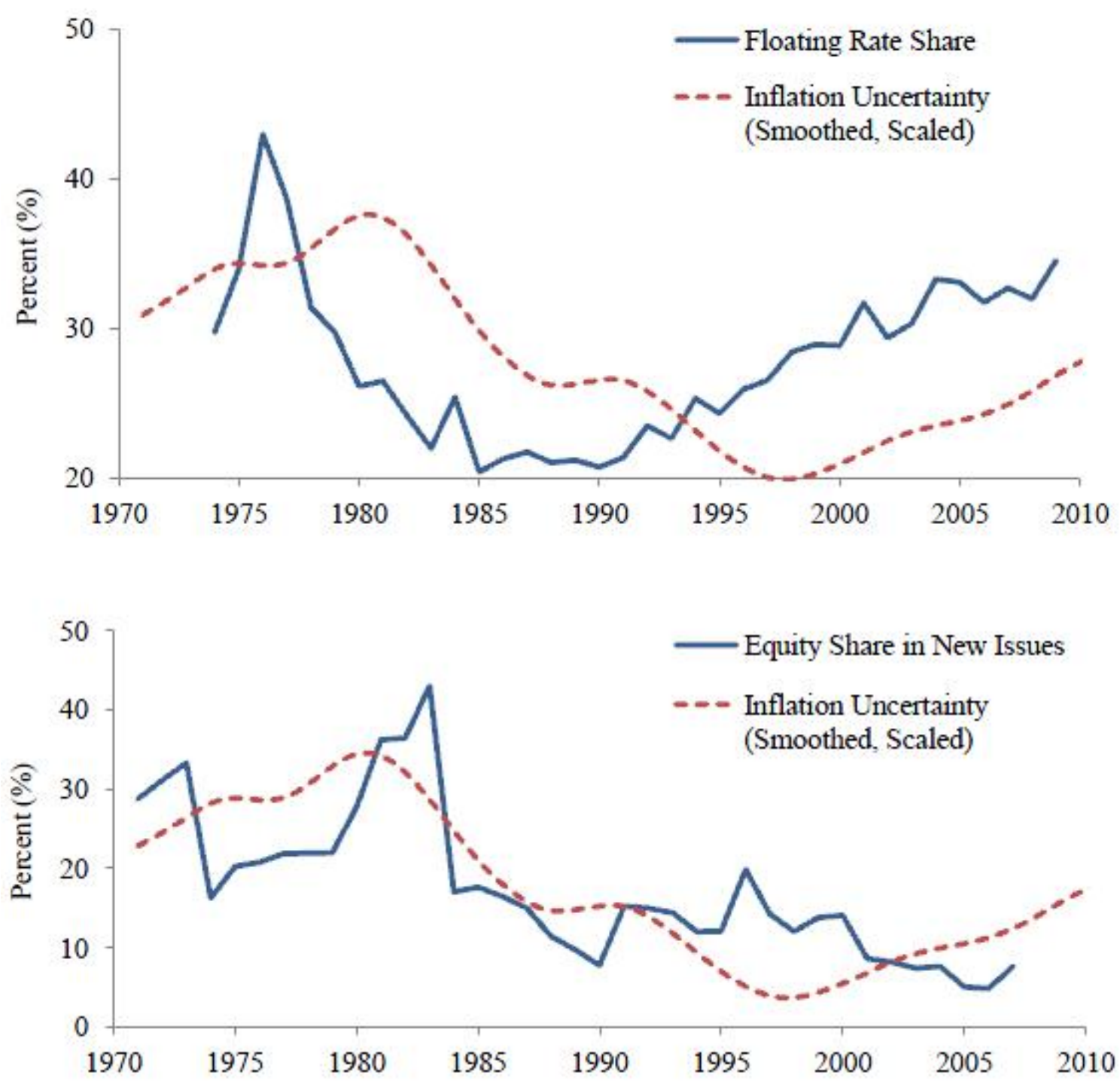

Figure 3.9: Capital Structure and Inflation Uncertainty in the U.S.

Floating rate debt as a share of long-term debt aggregated over all non-financial firms from Compustat (19742009). Missing floating rate values are set to zero. Equity share (1971-2007) in new issues is from Baker and Wurgler (2000). Inflation uncertainty is the difference between the 75th percentile and the 25 th percentile of one quarter ahead GDP Price Index inflation forecasts from the Survey of Professional Forecasters. Inflation uncertainty is Hodrick Prescott filtered with smoothing parameter 1,600 and scaled to have the same mean and standard deviation as the floating rate share (or equity share). 
Table 3.8: Leverage and Investment Regressions

Aggregate book leverage from Compustat and Compustat Global is computed by summing book debt across all non-financial firms and dividing by the sum of aggregated total assets. Aggregate investment to capital is computed by summing capital expenditures across all non-financial firms and dividing by aggregated PP\&E at the end of the previous year. International regressions include the following countries: Canada, Germany, Japan, the U.K., and the U.S. International data is annual 1994-2009. U.S. data is annual 1970-2009. Driscoll and Kraay (1998) standard errors adjusted for cross-country correlation with 4 lags in parentheses. U.S. regressions report Newey-West standard errors with 4 lags. Residual R-squareds reflect explanatory power in excess of fixed effects. Variables are constructed as described in Table 3.4. * and ** denote significance at the $5 \%$ and $1 \%$ levels, respectively.

Panel A: Leverage

\begin{tabular}{|c|c|c|c|c|}
\hline \multicolumn{5}{|c|}{ Panel A: Leverage } \\
\hline & (1) & (2) & (3) & (4) \\
\hline Book Leverage (\%) & \multicolumn{2}{|c|}{ International 1994-2009 } & \multicolumn{2}{|c|}{ U.S. 1970-2009 } \\
\hline \multirow[t]{2}{*}{ Lag Inflation Volatility (\% Ann.) } & $-2.26 * *$ & $-2.54 * *$ & $-3.86^{* *}$ & $-3.04 * *$ \\
\hline & $(0.65)$ & $(0.35)$ & $(0.76)$ & $(0.82)$ \\
\hline \multirow[t]{2}{*}{ Lag Inflation-Stock Correlation } & $2.83^{*}$ & 2.26 & 0.83 & 1.02 \\
\hline & $(1.01)$ & $(1.57)$ & $(1.60)$ & $(1.87)$ \\
\hline \multirow[t]{2}{*}{ Lag Change T-bill (\%) } & & -0.27 & & -0.22 \\
\hline & & $(0.27)$ & & $(0.39)$ \\
\hline Residual R2 & 0.12 & 0.18 & 0.39 & 0.53 \\
\hline Controls & No & Yes & No & Yes \\
\hline Country Fixed Effects & Yes & Yes & & \\
\hline \multicolumn{5}{|c|}{ Panel B: Investment } \\
\hline & (1) & (2) & (3) & (4) \\
\hline Investment / Capital (\%) & \multicolumn{2}{|c|}{ International 1994-2009 } & \multicolumn{2}{|c|}{ U.S. 1970-2009 } \\
\hline \multirow[t]{2}{*}{ Lag Inflation Volatility (\% Ann.) } & $-2.66 * *$ & -0.40 & -0.43 & 1.28 \\
\hline & $(0.83)$ & $(0.67)$ & $(1.03)$ & $(0.82)$ \\
\hline \multirow[t]{2}{*}{ Lag Inflation-Stock Correlation } & $-1.98 * *$ & -1.17 & -1.99 & -0.11 \\
\hline & $(0.59)$ & $(0.65)$ & $(1.64)$ & $(0.87)$ \\
\hline \multirow[t]{2}{*}{ Lag Stock Market Q } & & 0.03 & & $6.82 * *$ \\
\hline & & $(0.61)$ & & (1.13) \\
\hline Residual R2 & 0.28 & 0.64 & 0.05 & 0.76 \\
\hline Controls & No & Yes & No & Yes \\
\hline Country Fixed Effects & Yes & Yes & & \\
\hline
\end{tabular}


While our calibrated model predicts no adjustment in investment to inflation risk, investment is important for macroeconomic outcomes and we therefore explore the empirical relationship between investment and inflation risk. Fischer and Modigliani (1978) suggest that inflation uncertainty might lead to shortening of financial contracts and reduce investment. We find no robust relationship between inflation risk and investment in Table 3.8(B), consistent with our model.

\subsection{Conclusion}

This paper argues both theoretically and empirically that uncertainty about the longrun price level and the relationship of inflation with the business cycle are major macroeconomic determinants of corporate bond spreads. Using data on international corporate bond spreads, we provide new evidence that corporate bond investors price the risk of debt deflation.

In a real business cycle model with time-varying inflation risk, inflation persistence generates large effects of inflation risk on credit spreads. Firms reduce their leverage ratios when inflation risk increases, so credit spreads mean revert after a shock to inflation risk.

As of October 2011, the BAA minus AAA U.S. credit spread was 126 bps, or 25 basis points spread above our sample average, suggesting that investors were reluctant to hold corporate bonds. The corporate bond spread seems especially high given that equity valuations were high relative to their historical average. ${ }^{31}$ We can rationalize this discrepancy, if one believes that policymakers will be unable to counteract deflation should another recession arrive. Our measures of inflation cyclicality were close to all-time highs, and our benchmark estimates attribute about 35 of the 126 bps credit spread to the inflationstock correlation.

\footnotetext{
${ }^{31}$ The S\&P500 index dividend-price ratio was about three-fourths of a standard deviation below its sample average.
} 
Our results suggest fruitful avenues for further research. This paper suggests that investors attach an economically meaningful price to financial distress associated with deflation, highlighting the importance of better understanding the macroeconomic and monetary policy determinants. A decomposition of time-varying inflation risk into macroeconomic shocks, such as cost push shocks and shocks to aggregate demand, and time-varying monetary policy, could be of particular interest to central banks around the world.

Given the strong aggregate empirical results in this paper it seems promising to study the impact of time-varying inflation risk on the cross-section of firms' optimal capital structure.

Finally, our analysis suggests that corporate bond spreads may be useful measures of investors' deflationary concerns and for gauging central banks' credibility in counteracting deflation. This is particularly relevant given recent renewed concerns about a deflationary drop in aggregate demand and about ineffectiveness of traditional monetary policy at the zero lower bound. 


\section{Chapter 4}

\section{Appendices}

\subsection{Appendix to Chapter 1: Intraday Stock Volatility and Retail Trading Activity}

\subsubsection{Simulated RVR}

The hypothetical RVR distributions reported in Table 1.1 are generated from the following Monte Carlo simulation procedure. I assume 20 trading days, 1,000 steps per trading day, zero drift, and normally distributed shocks. First, I draw 20,000 shocks to generate the sequence of intraday stock price movements. Second, I store the day return and range return for each of these 20 trading days. Third, I compute the ratio of the variance of day returns to the variance of range returns. I repeat these steps 10,000 times which yields a distribution of RVR values. Finally, I record RVR values at different percentiles of this distribution.

It should be noted that assuming zero drift and normally distributed shocks are actually quite conservative assumptions. A greater drift or fatter-tailed shocks would in fact correspond to lower simulated values of RVR, which would effectively make the empirical distribution of RVR look even higher in magnitude. The intuition for why these alternative 
assumptions would reduce hypothetical RVR values is as follows. With a higher drift or with more extreme shocks, day returns and range returns are more likely to approach one another. 
Table 4.1: Decile RVR Abnormal Returns (1992 - 2010)

This table reports abnormal returns of monthly RVR decile portfolios for the period June 1992 through December 2010. At the end of each month, stocks are ranked in ascending order on the basis of RVR computed over that month. The ranked stocks are then assigned to one of ten decile portfolios, which are constructed either value-weighted (Panel A) or equal-weighted (Panel B). Excess returns are simply monthly returns in excess of the one-month Treasury bill rate. 3-factor alphas correspond to alphas from the Fama and French (1993) model. 4-factor alphas incrementally control for the momentum factor following Carhart (1997). 5-factor alphas further control for the Pastor and Stambaugh (2003) liquidity factor. Returns and alphas are shown in monthly percent, with t-statistics shown below in brackets.

Panel A: Value-weighted returns

\begin{tabular}{rrrrrrrrrrrr}
\hline & $\mathrm{D} 1$ & $\mathrm{D} 2$ & $\mathrm{D} 3$ & $\mathrm{D} 4$ & $\mathrm{D} 5$ & $\mathrm{D} 6$ & $\mathrm{D} 7$ & $\mathrm{D} 8$ & $\mathrm{D} 9$ & $\mathrm{D} 10$ & $\mathrm{~L} / \mathrm{S}$ \\
\hline \multirow{2}{*}{ Excess return } & 0.25 & 0.32 & 0.54 & 0.31 & 0.32 & 0.55 & 0.73 & 0.67 & 0.74 & 0.85 & 0.60 \\
& {$[0.7]$} & {$[1.0]$} & {$[1.7]$} & {$[1.0]$} & {$[1.0]$} & {$[1.7]$} & {$[2.3]$} & {$[2.1]$} & {$[2.3]$} & {$[2.7]$} & {$[2.3]$} \\
3-factor alpha & -0.24 & -0.17 & 0.07 & -0.19 & -0.18 & 0.05 & 0.24 & 0.19 & 0.26 & 0.39 & 0.64 \\
& $-[1.2]$ & $-[1.2]$ & {$[0.6]$} & $-[1.9]$ & $-[1.6]$ & {$[0.4]$} & {$[2.4]$} & {$[1.6]$} & {$[2.2]$} & {$[2.8]$} & {$[2.4]$} \\
4-factor alpha & -0.34 & -0.17 & 0.04 & -0.23 & -0.21 & 0.10 & 0.27 & 0.18 & 0.26 & 0.37 & 0.70 \\
& $-[1.8]$ & $-[1.2]$ & {$[0.3]$} & $-[2.2]$ & $-[1.9]$ & {$[0.9]$} & {$[2.7]$} & {$[1.5]$} & {$[2.1]$} & {$[2.7]$} & {$[2.7]$} \\
5-factor alpha & -0.25 & -0.13 & 0.05 & -0.22 & -0.22 & 0.12 & 0.24 & 0.16 & 0.24 & 0.38 & 0.63 \\
& $-[1.3]$ & $-[0.9]$ & {$[0.4]$} & $-[2.1]$ & $-[1.9]$ & {$[1.1]$} & {$[2.3]$} & {$[1.3]$} & {$[2.0]$} & {$[2.7]$} & {$[2.4]$} \\
\hline
\end{tabular}

Panel B: Equal-weighted returns

\begin{tabular}{lrrrrrrrrrrr}
\hline & $\mathrm{D} 1$ & $\mathrm{D} 2$ & $\mathrm{D} 3$ & $\mathrm{D} 4$ & $\mathrm{D} 5$ & $\mathrm{D} 6$ & $\mathrm{D} 7$ & $\mathrm{D} 8$ & $\mathrm{D} 9$ & $\mathrm{D} 10$ & $\mathrm{~L} / \mathrm{S}$ \\
\hline \multirow{2}{*}{ Excess return } & 0.54 & 0.51 & 0.58 & 0.62 & 0.70 & 0.76 & 0.81 & 0.92 & 0.88 & 1.09 & 0.55 \\
& {$[1.6]$} & {$[1.4]$} & {$[1.6]$} & {$[1.6]$} & {$[1.7]$} & {$[1.9]$} & {$[2.0]$} & {$[2.3]$} & {$[2.1]$} & {$[2.6]$} & {$[2.4]$} \\
3-factor alpha & 0.02 & -0.07 & -0.03 & -0.02 & 0.04 & 0.11 & 0.15 & 0.26 & 0.21 & 0.44 & 0.43 \\
& {$[0.1]$} & $-[0.5]$ & $-[0.2]$ & $-[0.1]$ & {$[0.3]$} & {$[0.7]$} & {$[0.9]$} & {$[1.6]$} & {$[1.2]$} & {$[2.2]$} & {$[2.0]$} \\
4-factor alpha & -0.26 & -0.25 & -0.17 & -0.15 & -0.06 & 0.04 & 0.09 & 0.23 & 0.18 & 0.46 & 0.72 \\
& $-[2.5]$ & $-[2.6]$ & $-[1.9]$ & $-[2.1]$ & $-[0.9]$ & {$[0.4]$} & {$[1.2]$} & {$[3.0]$} & {$[2.1]$} & {$[3.8]$} & {$[4.3]$} \\
5-factor alpha & -0.24 & -0.27 & -0.19 & -0.16 & -0.08 & 0.05 & 0.08 & 0.22 & 0.17 & 0.45 & 0.69 \\
& $-[2.4]$ & $-[2.8]$ & $-[2.1]$ & $-[2.1]$ & $-[1.1]$ & {$[0.6]$} & {$[1.0]$} & {$[2.8]$} & {$[1.9]$} & {$[3.6]$} & {$[4.1]$} \\
\hline
\end{tabular}


Table 4.2: Residual RVR Abnormal Returns (1992 - 2010)

This table reports abnormal returns of monthly quintile spread portfolios formed on residual RVR for the period June 1992 through December 2010. At the end of each month, stocks are ranked in ascending order on the basis of residual RVR computed over that month. The ranked stocks are then assigned to one of five quintile portfolios. Abnormal returns are calculated based on the four-factor model of Carhart (1997). Residual RVR is the residual from regressing RVR onto log size, log book-to-market, past twelve-month return (excluding the recent month), past one-month return, stock return volatility, and turnover. Alphas are shown in monthly percent, with t-statistics shown below in brackets.

\begin{tabular}{ccccccc}
\multicolumn{7}{c}{ Panel A: Value-weighted returns } \\
\hline & Q1 & Q2 & Q3 & Q4 & Q5 & L/S \\
\hline Excess return & 0.62 & 0.44 & 0.46 & 0.71 & 0.72 & 0.09 \\
& {$[1.7]$} & {$[1.3]$} & {$[1.5]$} & {$[2.3]$} & {$[2.5]$} & {$[0.4]$} \\
3-factor alpha & 0.02 & -0.14 & -0.09 & 0.19 & 0.20 & 0.18 \\
& {$[0.1]$} & $-[1.5]$ & $-[1.2]$ & {$[2.3]$} & {$[2.1]$} & {$[0.9]$} \\
4-factor alpha & 0.06 & -0.14 & -0.09 & 0.17 & 0.22 & 0.15 \\
& {$[0.5]$} & $-[1.4]$ & $-[1.2]$ & {$[2.0]$} & {$[2.2]$} & {$[0.8]$} \\
5-factor alpha & 0.07 & -0.11 & -0.08 & 0.17 & 0.24 & 0.17 \\
& {$[0.5]$} & $-[1.1]$ & $-[1.0]$ & {$[1.9]$} & {$[2.4]$} & {$[0.8]$} \\
\hline
\end{tabular}

Panel B: Equal-weighted returns

\begin{tabular}{rrrrrrr}
\hline & Q1 & Q2 & Q3 & Q4 & Q5 & L/S \\
\hline Excess return & 0.70 & 0.72 & 0.77 & 0.87 & 1.01 & 0.32 \\
& {$[1.8]$} & {$[1.9]$} & {$[2.0]$} & {$[2.4]$} & {$[2.7]$} & {$[2.8]$} \\
3-factor alpha & -0.14 & -0.13 & -0.08 & 0.07 & 0.21 & 0.35 \\
& $-[1.6]$ & $-[1.8]$ & $-[1.1]$ & {$[0.8]$} & {$[2.1]$} & {$[3.0]$} \\
4-factor alpha & -0.08 & -0.05 & 0.01 & 0.17 & 0.34 & 0.41 \\
& $-[0.9]$ & $-[0.7]$ & {$[0.1]$} & {$[2.4]$} & {$[3.9]$} & {$[3.7]$} \\
5-factor alpha & -0.09 & -0.07 & 0.00 & 0.14 & 0.34 & 0.43 \\
& $-[1.0]$ & $-[1.1]$ & {$[0.0]$} & {$[2.0]$} & {$[3.8]$} & {$[3.7]$} \\
\hline
\end{tabular}




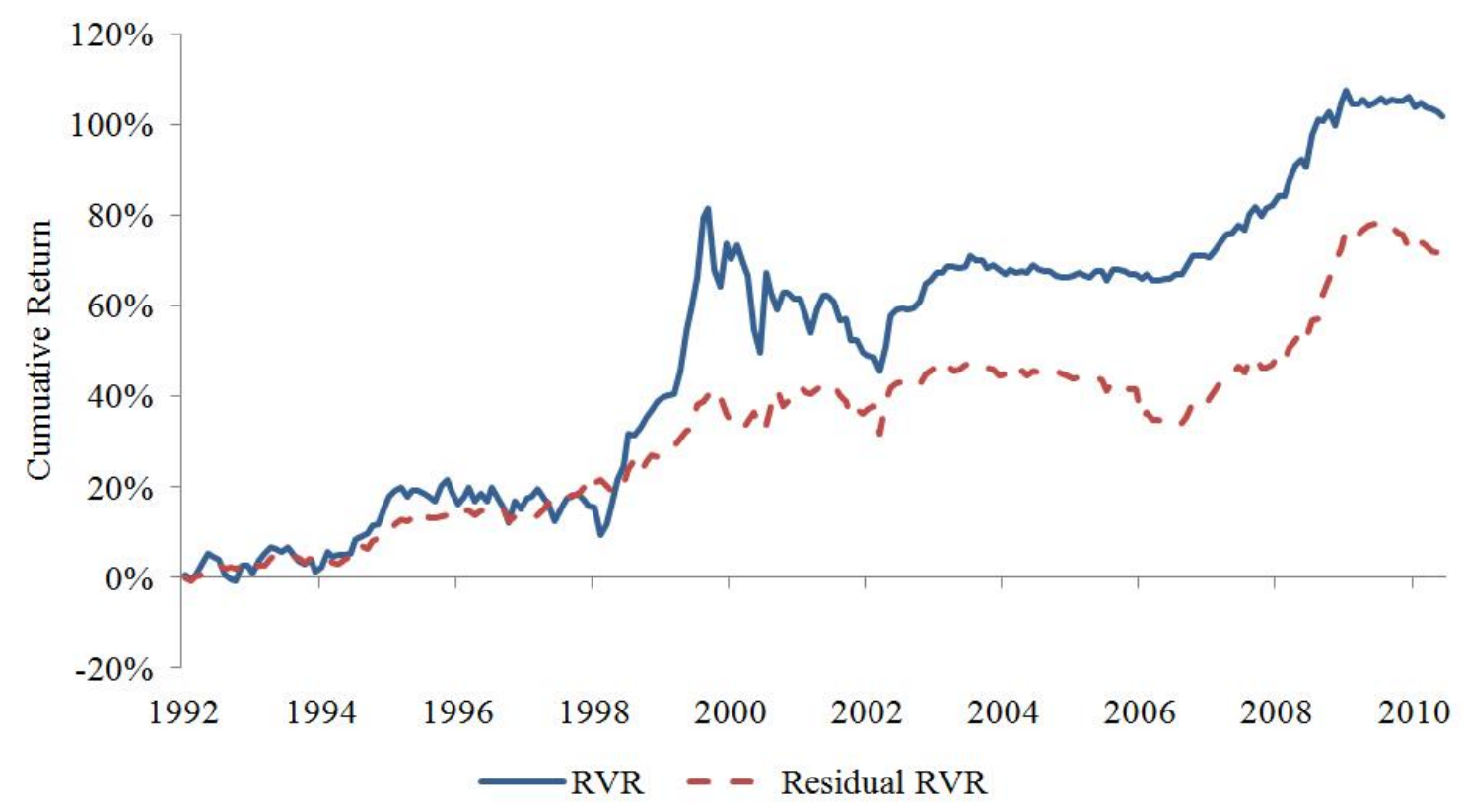

Figure 4.1: RVR and Residual RVR Returns

This figure plots cumulative returns for quintile spread portfolios formed on RVR and residual RVR. Residual RVR is the residual from regressing RVR onto log size, log book-to-market, past twelve-month return (excluding the recent month), past one-month return, stock return volatility, and turnover. 


\subsection{Appendix to Chapter 2: How Tax and Interest Rates Drive Stock Returns at the Turn of the Tax Year}

\subsubsection{Alternative Specifications of the Tax-selling Premium}

In this section, we analyze the behavior of our proposed variable $\gamma$ and its relation to interest rates and capital gains tax rates in the US data. The analysis in the main body of the paper is based on the one-year Fama-Bliss interest rate, but we also considered other proxies for interest rates. These alternatives are auto loans, personal loans, and credit card loans. Data are from G.19 Consumer Credit from Federal Reserve Statistical Release. Auto loans are 48-month new auto loans provided by commercial banks. Personal loans are 24-month personal loans provided by commercial banks. The last data item is credit card loans from credit card companies. The data items can be found in the table on terms of credit at commercial banks and finance companies from the Federal Reserve website. Data are seasonally unadjusted.

Interest rate, capital gains tax rate and the resulting $\gamma$ are plotted in Figure 4.2 using the one-year Fama-Bliss interest rate. Figure 4.3 plots the resulting $\gamma^{\prime} s$ for each of four alternative interest proxies that also include credit risk. All five proxies for $\gamma$ appear persistent but stationary. Generally speaking, the significant common variation in the five proxies for $\gamma$ over this period suggests a possibly large time-series variation in the incentives for tax-motivated selling. One advantage of the Fama-Bliss proxy is that this is the only proxy with the desired constant one-year horizon. Nevertheless, all versions are highly correlated. The alternative to the Fama-Bliss $\gamma$ with the lowest correlation is the credit card $\gamma$, but correlation remains high at 0.73 . A noticeable difference is seen in 2008 when the Fama-Bliss $\gamma$ is at its lowest level, but all the other measures remain relatively stable relative to the previous year or even show an increase as in the case of Auto Financing. In 2008, one might expect (and in actuality there was) a wide cross-sectional variation in interest rates among individuals as there was a wide range of credit worthiness. 


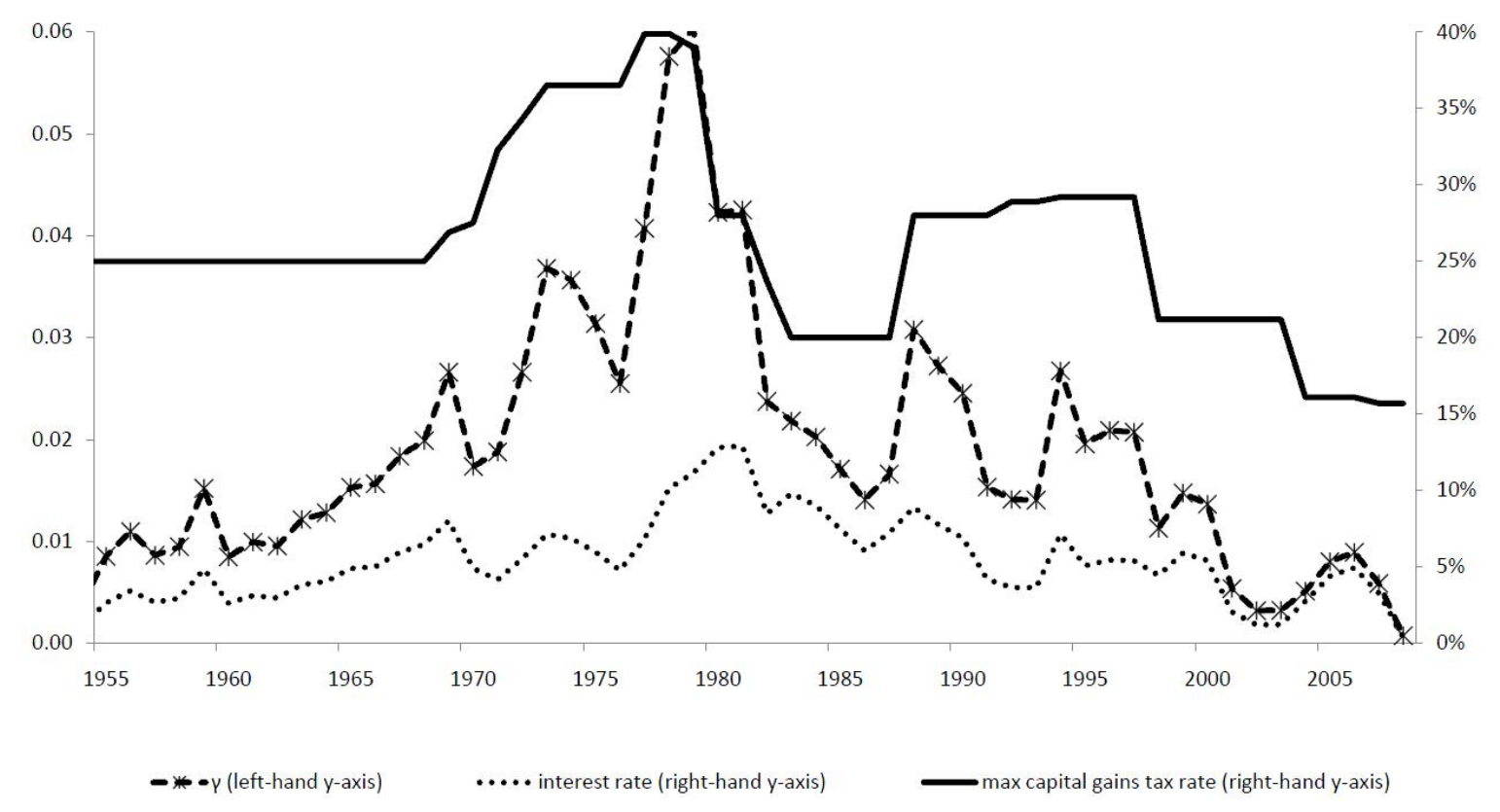

Figure 4.2: Time-series of the tax-selling premium, the interest rate, and the capital gains tax rate at the turn of the year

This figure shows the evolution of the tax-selling premium $(\gamma)$ and its two components over the period 19542008. These components are the marginal seller's interest rate, proxied by the one-year Fama-Bliss interest rate, and the marginal seller's tax rate, proxied by the maximum capital gains tax rate. 


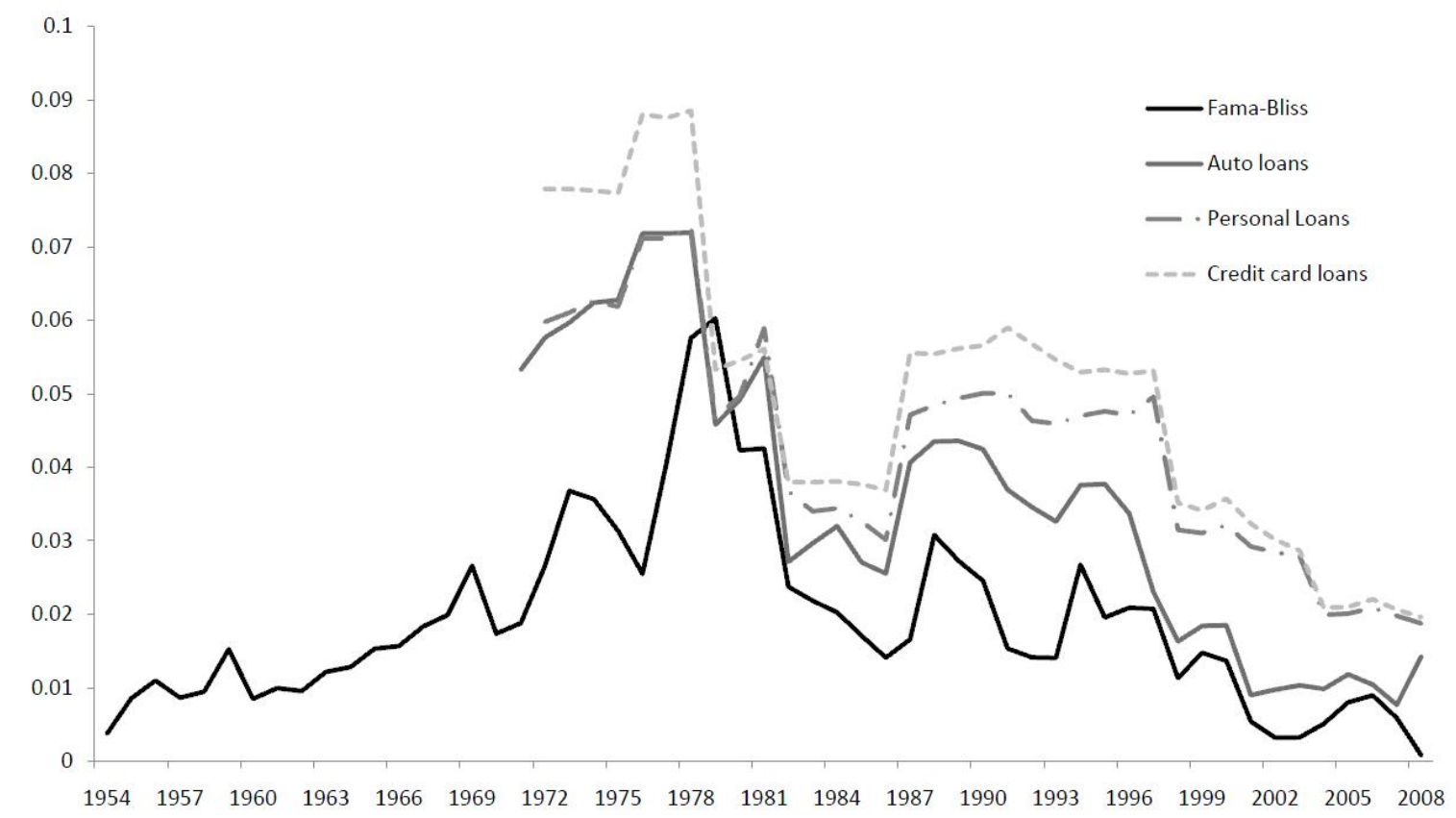

Figure 4.3: Time-series of the tax-selling premium, the interest rate, and the capital gains tax rate at the turn of the year

This figure shows the evolution of the tax-selling premium $(\gamma)$ and its two components over the period 19542008. These components are the marginal seller's interest rate, proxied by the one-year Fama-Bliss interest rate, and the marginal seller's tax rate, proxied by the maximum capital gains tax rate. 
We find that most of the time-series variation in $\gamma$ is due to changes in interest rates, although capital gains tax rates also explain part of variation. Table 4.3 also provides regression analysis of the relation between $\gamma$ and its components. The linear model explains $97 \%$ of the variation in $\gamma$. A variance decomposition analysis based on this regression shows that interest rates explain $51 \%$ of the total variation in $\gamma$, showing interest rates are more important than tax rates in explaining the variation in $\gamma$. Table 4.3 also reports descriptive statistics for our tax-selling variable, $\gamma$, as well as for its two components. Interest rates had significant variation during this time period. The maximum capital gains tax rate varies from $20 \%$ to almost $40 \%$ over this period. While not shown, most of the time-variation in the U.K. version of $\gamma$ is also due to changes in interest rates since the U.K. capital gains tax rate changes only once in our sample. 
Table 4.3: Descriptive Statistics and Correlations of Macro Variables (1954-2003)

We compute the tax-selling premium, $\gamma=\tau \frac{(1-B)}{(1-B \tau)}$, using the highest long-term capital gains tax rate, $\tau$, from the IRS and the one-year interest rate, $r$, from the Fama-Bliss dataset to compute a one-year discount factor, $B$. As the tax rate changes at most once a year, we report below sample characteristics of $\gamma$ and its components as well as regression output using values as of the end of December of each year. Therefore the sample consists of 55 years of data from 1954 to 2008. T-statistics are in parentheses. Panel A shows simple descriptive statistics. Panel B estimates the linear relation between interest rates and capital gains tax rates. Panel $\mathrm{C}$ shows that a linear approximation explains $95 \%$ of the variance in $\gamma$. Panel D shows that interest rates explain most of the variation in $\gamma$.

Descriptive Statistics

\begin{tabular}{rrrrrr}
\hline Variable & N & Mean & StdDev & Minimum & Maximum \\
\hline$r$ & 55 & 0.055 & 0.028 & 0.004 & 0.129 \\
$\tau$ & 55 & 0.261 & 0.061 & 0.157 & 0.399 \\
$\gamma$ & 55 & 0.019 & 0.013 & 0.001 & 0.060 \\
\hline
\end{tabular}

\begin{tabular}{rrrc} 
& \multicolumn{3}{c}{ Regression: $r=a+b \tau+e$} \\
\hline & Intercept & $\tau$ & $R^{2}$ \\
\hline Coefficient & 0.029 & 0.102 & 0.04 \\
t-statistic & $(1.82)$ & $(1.72)$ & \\
\hline
\end{tabular}

\begin{tabular}{rrrrr}
\multicolumn{5}{c}{ Regression: $\gamma=a+b r+c \tau+e$} \\
\hline Intercept & $r$ & $\tau$ & $R^{2}$ \\
\hline Coefficient & -0.026 & 0.299 & 0.110 & 0.95 \\
t-statistic & $(-14.93)$ & $(19.56)$ & $(15.86)$ & \\
\hline
\end{tabular}

Variance Decomposition of $\gamma=a+b r+c \tau+e$

\begin{tabular}{rrrr}
\multicolumn{4}{c}{ Variance Decomposition of $\gamma=a+b r+c \tau+e$} \\
\hline$R^{2}=$ & $b^{2} \frac{\operatorname{Var}(r)}{\operatorname{Var}(\gamma)}$ & $+c^{2} \frac{\operatorname{Var}(\tau)}{\operatorname{Var}(\gamma)}$ & $+2 b c \frac{\operatorname{Cov}(r, \tau)}{\operatorname{Var}(\gamma)}$ \\
\hline 0.95 & 0.42 & 0.28 & 0.25 \\
\hline
\end{tabular}




\subsubsection{Estimated Taxes and Tax-loss Selling}

In this section, we analyze whether the interest rate channel remains the important driver of time variation in turn-of-the-year mispricing linked to tax-loss selling once quarterly estimated tax payments are taken into account. The typical tax payer prepays the majority of their tax through a wage withholding system where tax is automatically subtracted from gross income by an employer. For income which is not subject to withholding such as gains from the sale of assets, taxpayers are required to make quarterly estimated tax payments. These estimated tax payments are due on April 15, June 15, September 15, and January 15. The analysis in the main body of the paper ignores these quarterly payments. If a significant number of investors must pay estimated taxes, there are at least two concerns.

The first concern follows directly from the fact that the last quarterly estimated tax payment for the current tax year (year $t$ ) is due January 15 of year $t+1$ and the first estimated tax payment for the subsequent tax year (year $t+1)$ is due April 15 of year $t+1$. Thus it may be the case that deferring a sale from December of year $t$ to January of year $\mathrm{t}+1$ only moves the tax consequences arising from the sale from January 15 to April 15 . This deferral of only three months is significantly less than the 12 months assumed in the analysis in the paper.

However, a careful examination of the tax code indicates that this concern is mitigated by the fact that estimated tax payments for each quarter are not necessarily tied directly to income in that quarter. Instead, the general rule determining the minimum year $\mathrm{t}+1$ quarterly estimated tax payment is that it must be the smaller of $22.5 \%$ of whatever year $\mathrm{t}+1$ 's tax turns out to be or $25 \%$ of the tax paid in year t (see page 48 of IRS Publication 505). ${ }^{1}$ The ability to tie the subsequent year $\mathrm{t}+1$ 's estimated tax payments to the previous year t's tax is commonly called the safe harbor rule. For those investors who take advantage of the

\footnotetext{
${ }^{1}$ Taxpayers with adjusted gross income more than $\$ 150,000$ (\$75,000 if married filing a separate return) compare $22.5 \%$ of this years tax to $27.5 \%$ of last year's tax in order to calculate the minimum estimated tax payment.
} 
safe harbor rule, the estimated tax payment due in April as well as the three subsequent estimated tax payments are completely insensitive to the increase in tax owed for year $t+1$ by the deferred sale. Any additional tax on that sale is only due on April 15 th of year $t+2$.

Of course, if it is not optimal for a taxpayer to take advantage of the safe harbor rule, quarterly estimated tax payments will depend on the tax consequences of the sale. However, the first quarterly estimated tax payment in April would only increase by $22.5 \%$ of the tax increase (as $67.5 \%$ will be spread evenly over the three subsequent quarterly estimated tax payments and $10 \%$ will be due in April of year $t+2)$. As a consequence, though estimated tax payments are paid quarterly, the effective discounting will still be at a longer horizon than quarterly and thus the benefit of deferring the sale still significant.

Table 4.4 measures the effective discounting horizon when delaying a sale from December year $\mathrm{t}$ to January year $\mathrm{t}+1$ under the current quarterly estimated tax payment system. We study the four cases that arise when the investor does or does not qualify for the safe harbor rule in tax years $t$ and $t+1$. Case 1 of Table 4.4 involves a safe harbor for year $\mathrm{t}$ as well as a safe harbor for year $\mathrm{t}+1$. Selling a winner in January of year $t+1$ would not make the investor pay more estimated taxes in year $\mathrm{t}+1$ due to the safe harbor. ${ }^{2}$ Instead, the investor would pay capital gains tax in the following year's tax return, therefore April 15th at $\mathrm{t}+2$ (15 months and 15 days later) without a penalty. Assuming that selling in December of year $t$ implies a payment in April 15th at $t+1$, the relevant discount horizon is then 12 months (15.5 months -3.5 months). In Case 1, one could realize an unlimited amount of capital gains at the beginning of year $t+1$ but pay taxes on those gains more than a year later.

Case 2 of Table 4.4 involves safe harbor for year $t$ but no safe harbor for year $t+1$. The investor pays $90 \%$ of any increase to current year's taxes spread evenly to the next four tax quarters and the remaining $10 \%$ is paid on April 15 th of year $t+2$. The average discount

\footnotetext{
${ }^{2}$ All else equal, estimated taxes for year $t+1$ will increase if the investor realizes the gain in December of year t. For the sake of simplicity, we ignore this consequence of the decision to defer sale of the stock to January of $t+1$. Note, however, that this consequence further increases the benefit of delaying capital gains and accelerating capital losses at the turn of the year.
} 
horizon is thus 5.03 months. As the investor sells more and more capital gains, he or she would eventually move back to Case 1 with the relevant discounting becoming again 12 months.

Case 3 of Table 4.4 involves no safe harbor for year $t$ but safe harbor for year $t+1$. This case corresponds to an effective discounting period longer than that assumed in the main analysis as the investor compares a tax payment of $90 \%$ in January 15th of year $t+1$ and $10 \%$ in April 15th of year $\mathrm{t}+1$ to a $100 \%$ payment in April 15th of year $\mathrm{t}+2$. In this case, the relevant discounting horizon is 14.7 months. $^{3}$ Finally, case 4 of Table 4.4 involves no safe harbor for year $t$ as well as no safe harbor for year $t+1$. In this case, the relevant discounting period is 7.73 months.

\footnotetext{
${ }^{3}$ Again, we ignore the consequences on estimated taxes for $t+1$. However, again this consequence further increases the benefit of delaying capital gains and accelerating capital losses at the turn of the year.
} 


\section{Table 4.4: Safe Harbor Case}

We show the relevant discount horizon for an investor who is deciding whether to realize a capital gain/loss before or after the turn of the year from $t$ to $t+1$. Our analysis studies the four possible cases that arise depending upon whether the investor can take advantage of the safe harbor rule in year $t$ and $t+1$.

\begin{tabular}{|c|c|c|c|c|c|c|c|}
\hline & \multicolumn{2}{|c|}{$\begin{array}{l}\text { Safe Harbor Rule } \\
\text { applies in tax year }\end{array}$} & \multicolumn{2}{|c|}{$\begin{array}{c}\text { Sell Stock in } \\
\text { December of year } t\end{array}$} & \multicolumn{2}{|c|}{$\begin{array}{c}\text { Sell Stock in } \\
\text { January of year } t+1\end{array}$} & \multirow{2}{*}{$\begin{array}{c}\text { Relevan } \\
\text { Discoun } \\
\text { Horizon }\end{array}$} \\
\hline & $t$ & $t+1$ & tax due & at Month & tax due & at Month & \\
\hline & & & $100 \%$ & 3.5 & $100 \%$ & 15.5 & \\
\hline \multirow[t]{6}{*}{ Case 1} & Yes & Yes & & 3.5 & & 15.5 & 12 \\
\hline & & & $100 \%$ & 3.5 & $22.5 \%$ & 3.5 & \\
\hline & & & & & $22.5 \%$ & 6.5 & \\
\hline & & & & & $22.5 \%$ & 8.5 & \\
\hline & & & & & $22.5 \%$ & 12.5 & \\
\hline & & & & & $10 \%$ & 15.5 & \\
\hline \multirow[t]{3}{*}{ Case 2} & Yes & No & & 3.5 & & 8.525 & 5.025 \\
\hline & & & $90 \%$ & 0.5 & $100 \%$ & 15.5 & \\
\hline & & & $10 \%$ & 3.5 & & & \\
\hline \multirow[t]{6}{*}{ Case 3} & No & Yes & & 0.8 & & 15.5 & 14.7 \\
\hline & & & $90 \%$ & 0.5 & $22.5 \%$ & 3.5 & \\
\hline & & & $10 \%$ & 3.5 & $22.5 \%$ & 6.5 & \\
\hline & & & & & $22.5 \%$ & 8.5 & \\
\hline & & & & & $22.5 \%$ & 12.5 & \\
\hline & & & & & $10 \%$ & 15.5 & \\
\hline Case 4 & No & No & & 0.8 & & 8.525 & 7.725 \\
\hline
\end{tabular}

Taken together, these cases indicate that even if the marginal investor is paying quarterly estimated taxes, in two of the four typical cases, the effective discounting horizon is a year or more and in no case is the effective discounting horizon three months. Thus we conclude that it is not obviously the case that the presence of quarterly estimated taxes invalidates our annual approach. Nevertheless, we re-estimated our main results using a quarterly discount rate instead of an annual discount rate. We found that the statistical 
significance of our results remains effectively the same. However, the absolute magnitude of the coefficients on the relevant December and January dummies are now implausibly high. We conclude that an annual rather than a quarterly discounting horizon is a more plausible description of the data.

The second concern is that the deferral around the other estimated tax quarters should matter as well, not just the deferral at the end of the year. This concern seems unlikely however, as the discussion above makes it clear that estimated tax payments for each quarter are not necessarily tied directly to income in that quarter. If an investor is using the safe harbor rule, then the quarterly timing of the sale is clearly irrelevant. Moreover, even if it is not optimal for the investor to use the safe harbor rule, estimated tax payments are made based on the annual estimated tax.

There are two caveats to that conclusion. Firstly, estimated tax payments do not have to start until the taxpayer has income on which he or she will owe income tax. As a consequence, an investor can delay paying estimated tax by delaying his or her initial capital gains realization. Secondly, the IRS does recognize that some investors may not receive income evenly throughout the year and, as a consequence, allows investors the option to vary their estimated tax payments with their realized income. This approach to determining estimated taxes is dubbed the annualized income installment method (AIIM) by the IRS. Note that AIIM is not a requirement to match estimated tax payments to realized income but is instead only an option. As a consequence, this method will typically only be used for those investors who both expect to have a significant increase in income near the end of the tax year and who, relatively speaking, paid a lot of tax last year. Investors who expect to have a predictable decrease in income near the end of the year are generally better off not using the annualized income installment method. Additionally, our impression is that in practice this method is not used nearly as much as the general rule above. ${ }^{4}$

\footnotetext{
${ }^{4}$ There exist ways in which a tax-savvy investor can minimize the present value of his or her taxes more effectively than through AIIM. For example, an investor who only has capital gains realizations as income can skip a year between those capital gains realizations, never pay estimated tax, realize unlimited amounts of capital gains, yet never be subject to penalty.
} 
Despite the fact that many investors pay equal installments for their estimated tax (whether due to a safe harbor or not), we re-estimated our main results introducing dummies for turn-of-the-tax-quarter. We found no evidence of a turn-of-the-tax-quarter effect. To increase power, we would ideally exploit variation in the rules concerning estimated tax payments. We were unable to find good documentation as to how rules concerning estimated taxes have varied over time. However, even if the rules have not changed, the relative importance of the safe harbor aspect of the estimated tax payment rules should vary over time with economic conditions. However, we did not find that the regression coefficients when interacted with a dummy (equal to 1 if the current year has any month classified as a NBER recession and the previous year did not) showed any evidence of a turn-of-the-tax-quarter effect.

\subsubsection{Anticipated Changes in Captial Gains Tax Rates}

We also analyzed whether incorporating anticipated tax rate changes at the turn of the year affect our conclusions. In some cases, investors knew with near certainty at the end of December what the capital gains tax rate would be in January. If that is the case then it is straightforward to show that our tax-selling premium, $\gamma=\tau \frac{(1-B)}{(1-B \tau)}$, becomes $\gamma=\frac{\left(\tau_{t}-\tau_{t+1} B\right)}{\left(1-B \tau_{t+1}\right)}$. We reestimated Table 2.2 from the main paper using this two-tax-rate formulation The major tax rate changes which were retroactive were the years 1976, 1997, and 2003. For those three major tax rate changes we continue to use the one-rate formulation. Of course, it is possible that even retroactive tax rates were anticipated so we also used the two-tax-rate formula in every case. Ultimately, we found no evidence of that anticipated tax rate changes affected our conclusions. 


\subsection{Appendix to Chapter 3: Inflation Risk in Corporate Bonds}

\section{A.1 Optimal Choice of Labor}

From the firm's single period optimization we obtain the first-order condition with respect to labor

$$
(1-\alpha) z_{t}^{1-\alpha}\left(\frac{K_{t}^{i}}{N_{t}^{i}}\right)^{\alpha}=W_{t}
$$

The capital to labor ratio is constant across firms and equal to $K_{t}$. Substituting back into operating revenue gives firm $i^{\prime} s$ one-period equilibrium revenue as $\alpha K_{t}^{i}\left(\frac{z_{t}}{K_{t}}\right)^{1-\alpha}$. The expression for the equilibrium return on capital follows as

$$
R_{t+1}^{K}=\left[\alpha\left(\frac{z_{t+1}}{K_{t+1}}\right)^{1-\alpha}+(1-\delta)\right]
$$

\section{A.2 First-Order Conditions}

The time $t+2$ real cash flow of a corporate bond issued by firm $i$ at time $t$ is

$$
\frac{\left(1-\mathbb{I}\left\{a_{t+2}^{i, i d}<a_{t+2}^{*}\right\}\right)}{\exp \left(2 \pi_{t}+2 \varepsilon_{t+1}^{\pi}+\varepsilon_{t+2}^{\pi}\right)}+\theta \frac{K_{t+1}^{y}}{B_{t}^{\$}} R_{t+1}^{K} R_{t+2}^{K} \exp \left(a_{t+2}^{i, i d}\right) \mathbb{I}\left\{a_{t+2}^{i, i d}<a_{t+2}^{*}\right\}
$$

The time $t$ price of the bond is given by the expected stochastic discounted value of real cash flows

$$
\begin{aligned}
q_{t}= & \mathbb{E}_{t}\left[M_{t, t+2}^{\$}\left(1-H\left(a_{t+2}^{*}\right)\right)\right] \\
& +\theta \mathbb{E}_{t}\left[M_{t, t+2} \frac{K_{t+1}^{y}}{B_{t}^{\$}} R_{t+1}^{K} R_{t+2}^{K} \Omega\left(a_{t+2}^{*}\right)\right]
\end{aligned}
$$

The expression for the survival threshold then implies

$$
q_{t}=\mathbb{E}_{t}\left[M_{t, t+2}^{\$}(1-\underbrace{H\left(a_{t+2}^{*}\right)}_{\text {Default Rate }}+\underbrace{\theta \frac{\Omega\left(a_{t+2}^{*}\right)}{\exp \left(a_{t+2}^{*}\right)}}_{\text {Recovery }})\right]
$$


Equity holders maximize

$$
\mathbb{E}_{t}\left[M_{t, t+2} \max \left(V_{t+2}^{i, o l d}-B_{t}^{\$} \exp \left(-2 \pi_{t}-2 \varepsilon_{t+1}^{\pi}-\varepsilon_{t+2}^{\pi}\right), 0\right)\right]-S_{t}
$$

subject to

$$
\begin{aligned}
& v_{t+2}^{i, \text { old }}=k_{t+1}^{y}+r_{t+1}^{K}+r_{t+2}^{K}+a_{t+2}^{i, i d} \\
& K_{t+1}^{y}=S_{t}+\chi q_{t} B_{t}^{\$}
\end{aligned}
$$

Given constant returns to scale and no equity issuance costs, the net equity value (4.6) will equal zero in equilibrium, reflecting free entry. Substituting (4.7), (4.8), and (4.5) into (4.6) we can rewrite the firm's problem as maximizing

$$
\exp \left(2 \pi_{t}\right) K_{t+1}^{y} L_{t} \mathbb{E}_{t}\left[M_{t, t+2}^{\$}\left(\begin{array}{c}
\exp \left(-a_{t+2}^{*}\right)+(\chi-1)\left(1-H\left(a_{t+2}^{*}\right)\right) \\
+(\chi \theta-1) \Omega\left(a_{t+2}^{*}\right) \exp \left(-a_{t+2}^{*}\right)
\end{array}\right)\right]-K_{t+1}^{y}
$$

Differentiating (4.9) with respect to $K_{t+1}^{y}$ while holding constant the initial leverage ratio $L_{t}$ gives:

$$
0=\exp \left(2 \pi_{t}\right) L_{t} \mathbb{E}_{t}\left[M_{t, t+2}^{\$}\left(\begin{array}{c}
\exp \left(-a_{t+2}^{*}\right)+(\chi-1)\left(1-H\left(a_{t+2}^{*}\right)\right) \\
+(\chi \theta-1) \Omega\left(a_{t+2}^{*}\right) \exp \left(-a_{t+2}^{*}\right)
\end{array}\right)\right]-1
$$

Using $a_{t+2}^{*}=l_{t}-2 \varepsilon_{t+1}^{\pi}-\varepsilon_{t+2}^{\pi}-r_{t+1}^{K}-r_{t+2}^{K}$ for the survival threshold gives the first-order condition for capital with $F_{t+2}$ as in the main text

$$
1=\mathbb{E}_{t}\left[M_{t, t+2} R_{t+1}^{K} R_{t+2}^{K} F_{t+2}\right]
$$

Differentiating (4.9) with respect to $L_{t}$ while holding constant the level of capital $K_{t+1}^{y}$ gives:

$$
0=\left(1+\frac{\partial}{\partial a_{t+2}^{*}}\right) \mathbb{E}_{t}\left[\left(M_{t, t+2}^{\$}\left(\begin{array}{c}
\exp \left(-a_{t+2}^{*}\right)+(\chi-1)\left(1-H\left(a_{t+2}^{*}\right)\right) \\
+(\chi \theta-1) \Omega\left(a_{t+2}^{*}\right) \exp \left(-a_{t+2}^{*}\right)
\end{array}\right)\right)\right]
$$


Using $\frac{\partial}{\partial a_{t+2}^{*}} \Omega\left(a_{t+2}^{*}\right)=\exp \left(a_{t+2}^{*}\right) h\left(a_{t+2}^{*}\right)$ gives the first-order condition with respect to leverage

$$
0=-\chi(1-\theta) \mathbb{E}_{t}\left(M_{t, t+2}^{\$} h\left(a_{t+2}^{*}\right)\right)+(\chi-1) \mathbb{E}_{t}\left(M_{t, t+2}^{\$}\left(1-H\left(a_{t+2}^{*}\right)\right)\right)
$$

\section{A.3 Numerical Solution Method}

Define rescaled variables relative to trend productivity $\exp (\mu t)$

$$
\tilde{K}_{t}=\frac{K_{t}}{\exp (\mu t)}, \tilde{C}_{t}=\frac{C_{t}}{\exp (\mu t)}, \tilde{Y}_{t}=\frac{Y_{t}}{\exp (\mu t)}, \tilde{z}_{t}=\frac{z_{t}}{\exp (\mu t)}
$$

We denote $\operatorname{logs}$ by lower case letters. Since $\tilde{z}_{t}$ is identically and independently distributed, our only state variable is end of period total wealth $\tilde{W}=\tilde{Y}+(1-\delta) \tilde{K}$. We use projection methods to solve for the two policy functions for leverage and consumption (Aruoba, Fernandez-Villaverde, and Rubio-Ramirez (2006)). A recursive equilibrium has to satisfy the two first-order conditions (4.13) and (4.11) with the additional dynamics $\tilde{K}_{t+1}=\left(\tilde{W}_{t}-\tilde{C}_{t}\right) \exp (-\mu)$. We define $E R(\tilde{w})$ as the expected two-period return on capital in a model with zero inflation volatility. We then solve for both log detrended consumption $\tilde{c}$ and scaled leverage $L / E R$ as polynomials of degree two in log detrended wealth $\tilde{w}$ by minimizing the errors of the first-order conditions along a grid of 19 nodes for $\tilde{w}$. Intuitively, the survival threshold is related to the ratio of leverage over the two-period return on capital and the scaling makes the survival threshold well-behaved.

\subsubsection{Additional Empirical Results}

Tables 4.1 through 4.15 report additional detailed data sources, summary statistics and robustness checks. Table 4.1 shows details of the corporate bond data. Table 4.2 shows cross-country correlations of credit spreads, inflation volatility and the inflation-stock correlation and the cross-correlation between inflation volatility and the inflation-stock correlation. Table 4.3 shows that the benchmark empirical results are remarkably consistent across countries. Table 4.4 shows that the benchmark empirical results hold up in a 
Swamy (1970) random coefficients model. Table 4.5 shows inter-quantile regressions and suggests that the impact of inflation risk on credit spreads is larger for periods with high credit spreads. Table 4.5 supports our graphical findings that the impact of inflation risk on credit spreads are asymmetric. Table 4.6 shows that our benchmark empirical results become slightly stronger if we calculate the U.S. credit spread as the BAA over government spread instead of subtracting the AAA corporate bond yield. This is intuitive if AAA bond yields contain a small credit risk component. Table 4.7 shows that our main empirical results hold up if we control for GDP volatility instead of equity volatility. Table 4.8 shows that our results are robust to smoothing our proxies for inflation volatility and the inflation-stock correlation. Table 4.9 shows that the empirical results with additional controls in Table 3.7 in the main text are robust to smoothing our proxies for equity market volatility, idiosyncratic volatility, bond volatility, the bond-stock correlation, inflation volatility and the inflation-stock correlation. Tables 4.8 and 4.9 suggest that in particular the low frequency movements in inflation risk are priced into corporate bond spreads. Tables 4.10 and 4.11 show that empirical results are robust to alternate inflation forecasting models and alternate inflation indices. Tables 4.12 and 4.13 show that the main empirical results hold up in changes. Moreover, high inflation volatility and inflation-stock correlation predict a decrease in credit spreads. Comparing the magnitude of the coefficients in Table 4.12 to the benchmark results in Table 3.5 in the main text shows that credit spreads fully mean revert after a period of 5 years.

To better understand the contribution of the changing composition of the credit spread index, we would ideally like to run similar regressions using credit returns. In Table 4.14 we find that corporate bond excess returns are negatively related to changes in inflation volatility and to changes in the inflation-stock correlation over 3-5 horizons. Inflation volatility does not predict returns on U.S. corporate bonds in excess of government bond returns. There is some evidence that the inflation-stock correlation predicts corporate bond excess returns, indicating that the impact of the inflation-stock correlation on credit spreads contains a risk-premium component. 
Table 4.15 sorts each country's observations into high medium and low inflation volatility and inflation-stock correlation. Credit spreads increase from low to high inflation volatility and from low to high inflation-stock correlation. Credit spreads tend to be highest when both inflation volatility and the inflation-stock correlation are high, suggesting that inflation volatility and inflation cyclicality interact to increase corporate bond spreads.

\section{Table 4.5: International Corporate Bond Spread Data Sources}

This table reports details on the underlying international corporate bond spread data. Assumptions for corporate bond maturities are based on data descriptions provided by the listed data sources. Government bond maturities are taken as given from Global Financial Data. Time-varying corporate and government bond durations are approximated based on the loglinear methodology of Campbell, Lo, and Mackinlay (1997). This table reports average durations.

\begin{tabular}{rlrrrrr}
\hline Country & Dorp. Bond & $\begin{array}{r}\text { Corp. } \\
\text { Maturity }\end{array}$ & $\begin{array}{r}\text { Corp. } \\
\text { Duration }\end{array}$ & $\begin{array}{r}\text { Govt. } \\
\text { Maturity }\end{array}$ & $\begin{array}{r}\text { Govt. } \\
\text { Duration }\end{array}$ & Sample \\
\hline Australia & Economist; Telstra & 10 & 6.9 & 10 & 7.3 & 1983.Q3 - 2010.Q4 \\
Canada & Bank of Canada; Datastream & 20 & 10.4 & 15 & 9.6 & $1960 . Q 1$ - 2010.Q4 \\
Germany & Bundesbank & 6 & 5.1 & 6 & 5.2 & $1967 . Q 1$ - 2010.Q4 \\
Japan & Nikkei Corp. Bond Index & 10 & 8.2 & 10 & 8.3 & 1973.Q1 - 2010.Q4 \\
U.K. & Financial Times; Economist & 15 & 8.7 & 10 & 7.3 & 1960.Q1 - 2010.Q4 \\
U.S. & Moody's BAA, AAA & 25 & 11.4 & N/A & N/A & 1960.Q1 - 2010.Q4 \\
\hline
\end{tabular}


Table 4.6: Correlation Among Key Variables (1969.Q4-2010.Q4)

This table reports correlations among credit spreads, inflation volatility, and inflation-stock correlation across countries.

\begin{tabular}{rrrrrr}
\multicolumn{6}{c}{ Panel A: Credit Spread } \\
\hline Canada & Germany & Japan & U.K. & U.S. \\
\hline Germany & 1.00 & & & & \\
Japan & 0.65 & 1.00 & & & \\
U.K. & 0.03 & 0.06 & 1.00 & & \\
U.S. & 0.41 & 0.56 & 0.10 & 1.00 & \\
\hline \multicolumn{7}{c}{0.40} & -0.21 & 0.55 & 1.00 \\
\hline & Panel B: Inflation Volatility & & \\
\hline Canada & 1.00 & & & & \\
Germany & 0.36 & 1.00 & & & \\
Japan & 0.18 & 0.36 & 1.00 & & \\
U.K. & 0.26 & 0.25 & 0.58 & 1.00 & \\
U.S. & 0.50 & 0.09 & 0.07 & 0.46 & 1.00 \\
\hline
\end{tabular}

Panel C: Inflation-Stock Correlation

\begin{tabular}{rrrrrr}
\hline & Canada & Germany & Japan & U.K. & U.S. \\
\hline Canada & 1.00 & & & & \\
Germany & 0.33 & 1.00 & & & \\
Japan & 0.38 & 0.14 & 1.00 & & \\
U.K. & 0.33 & 0.37 & 0.21 & 1.00 & \\
U.S. & 0.40 & 0.42 & 0.18 & 0.16 & 1.00 \\
\hline
\end{tabular}

Panel D: Inflation Volatility vs. Inflation-Stock Correlation

\begin{tabular}{rrrrrr}
\hline & Canada & Germany & Japan & U.K. & U.S. \\
\hline Canada & -0.11 & 0.09 & -0.20 & -0.19 & 0.11 \\
Germany & 0.45 & -0.08 & -0.07 & -0.14 & 0.10 \\
Japan & 0.07 & -0.19 & -0.37 & -0.22 & 0.06 \\
U.K. & 0.17 & -0.18 & 0.33 & 0.35 & 0.34 \\
U.S. & -0.13 & -0.24 & -0.29 & -0.19 & 0.16 \\
\hline
\end{tabular}


Table 4.7: Individual Country Credit Spreads and Inflation Risk (1969.Q4-2010.Q4)

Newey-West standard errors with 16 lags in parentheses. Controls include quarterly and three year inflation innovations, stock returns, GDP growth, and three year change in unemployment. Japan data starts in 1973.Q1. Variables are constructed as described in Table 3.4. * and ** denote significance at the $1 \%$ and $5 \%$ levels, respectively.

\begin{tabular}{rrrrrr}
\hline Credit Spread (\%) & Canada & Germany & Japan & U.K. & U.S. \\
\hline Equity Volatility (\% Ann.) & $0.03^{* *}$ & 0.00 & -0.01 & 0.04 & 0.00 \\
& $(0.01)$ & $(0.01)$ & $(0.01)$ & $(0.02)$ & $(0.01)$ \\
Dividend-Price Ratio (\% Ann.) & 0.07 & $0.18^{* *}$ & $-0.15^{* *}$ & $0.37^{* *}$ & 0.06 \\
& $(0.04)$ & $(0.06)$ & $(0.05)$ & $(0.14)$ & $(0.03)$ \\
Inflation Volatility (\% Ann.) & $0.63^{* *}$ & $0.58^{* *}$ & -0.02 & -0.01 & $0.32^{* *}$ \\
& $(0.14)$ & $(0.14)$ & $(0.17)$ & $(0.22)$ & $(0.05)$ \\
Inflation-Stock Correlation & $0.57^{* *}$ & $0.72^{* *}$ & $0.37^{* *}$ & $1.19^{* *}$ & 0.14 \\
& $(0.09)$ & $(0.20)$ & $(0.10)$ & $(0.37)$ & $(0.08)$ \\
$R^{2}$ & 0.74 & 0.73 & 0.48 & 0.54 & 0.66 \\
Controls & Yes & Yes & Yes & Yes & Yes \\
\hline
\end{tabular}


Table 4.8: Credit Spread Regressions with Random Coefficients (1969.Q4-2010.Q4)

This table reports quarterly regressions of credit spreads onto explanatory variables estimated using the random coefficients regression model. Bootstrap standard errors are computed with 200 replications. * and ** denote significance at the 5\% and 1\% level, respectively. Japan data starts 1973.Q1. Standard errors are not corrected for time-series correlation.

\begin{tabular}{rrrrrrrrrr}
\hline & \multicolumn{3}{c}{ Combined } & \multicolumn{7}{c}{ Country-Specific } \\
\hline Credit Spread (\%) & $(1)$ & $(2)$ & $(3)$ & Canada & Germany & Japan & U.K. & U.S. \\
Equity Vol. (\% Ann.) & $0.02^{* *}$ & $0.01^{*}$ & $0.02^{* *}$ & 0.03 & 0.02 & 0.01 & 0.02 & 0.02 \\
& $(0.00)$ & $(0.01)$ & $(0.00)$ & & & & & \\
Div.-Price Ratio (\%) & $0.12^{* *}$ & $0.07^{* *}$ & $0.10^{* *}$ & 0.04 & 0.16 & -0.03 & 0.20 & 0.01 \\
& $(0.03)$ & $(0.02)$ & $(0.04)$ & & & & & \\
Inflation Vol. (\% Ann.) & & $0.26^{* *}$ & 0.19 & 0.46 & -0.06 & 0.25 & -0.02 & 0.39 \\
& & $(0.08)$ & $(0.11)$ & & & & & \\
Inflation-Stock Correl. & & & $0.63^{* *}$ & 0.45 & 1.13 & 0.37 & 1.10 & 0.42 \\
& & & $(0.21)$ & & & & & \\
Constant & 0.14 & 0.00 & 0.04 & -0.11 & 0.00 & -0.10 & 0.26 & 0.94 \\
& $(0.15)$ & $(0.10)$ & $(0.08)$ & & & & & \\
\hline
\end{tabular}


Table 4.9: Inter-Quantile Regressions

This table reports inter-quantile credit spread regressions. Variables are constructed as described in Table 3.4. * and ** denote significance at the $1 \%$ and $5 \%$ levels, respectively. Standard errors are not corrected for time-series correlation.

\begin{tabular}{rrrr}
\hline Credit Spread (\%) & 75th - 25th & 50 th -25 th & 75th -50 th \\
\hline Equity Volatility (\% Ann.) & $0.02 * *$ & $0.01 * *$ & $0.01 *$ \\
& $(0.00)$ & $(0.00)$ & $(0.00)$ \\
Dividend-Price Ratio (\% Ann.) & $0.14 * *$ & 0.04 & $0.11 * *$ \\
& $(0.03)$ & $(0.02)$ & $(0.03)$ \\
Inflation Volatility (\% Ann.) & $0.25 * *$ & $0.12 * *$ & $0.12 *$ \\
& $(0.07)$ & $(0.04)$ & $(0.05)$ \\
Inflation-Stock Correlation & $0.27 * *$ & $0.11 *$ & $0.16 *$ \\
& $(0.08)$ & $(0.04)$ & $(0.06)$ \\
Constant & $-(0.22)$ & $-(0.05)$ & $-(0.17)$ \\
& $(0.12)$ & $(0.07)$ & $(0.13)$ \\
\hline
\end{tabular}


Table 4.10: U.S. BAA Over Government Spread (1969.Q4-2010.Q4)

Data and standard errors as in Table 3.5 in the main text. In this table, the U.S. credit spread is computed as the BAA over government spread instead of the BAA over AAA spread.

Panel A: International

\begin{tabular}{rrrrrrr}
\hline Credit Spread (\%) & $(1)$ & $(2)$ & $(3)$ & $(4)$ & $(5)$ & $(6)$ \\
\hline Equity Volatility (\% Ann.) & $0.03^{* *}$ & $0.02^{*}$ & $0.02^{*}$ & $0.02^{*}$ & $0.02^{*}$ & $0.02^{* *}$ \\
& $(0.01)$ & $(0.01)$ & $(0.01)$ & $(0.01)$ & $(0.01)$ & $(0.01)$ \\
Dividend-Price Ratio (\% Ann.) & $0.08^{*}$ & 0.03 & 0.06 & $0.13^{* *}$ & 0.11 & $0.08^{*}$ \\
& $(0.04)$ & $(0.04)$ & $(0.04)$ & $(0.05)$ & $(0.07)$ & $(0.04)$ \\
Inflation Volatility (\% Ann.) & & $0.25^{* *}$ & $0.22^{* *}$ & $0.32^{* *}$ & $0.20^{* *}$ & $0.20^{* *}$ \\
& & $(0.09)$ & $(0.06)$ & $(0.10)$ & $(0.04)$ & $(0.06)$ \\
Inflation-Stock Correlation & & & $0.66^{* *}$ & $0.49 * *$ & $0.45^{* *}$ & $0.37^{* *}$ \\
& & & $(0.22)$ & $(0.13)$ & $(0.10)$ & $(0.13)$ \\
Residual R2 & 0.26 & 0.30 & 0.39 & 0.47 & 0.18 & 0.49 \\
Controls & No & No & No & Yes & Yes & Yes \\
Country Fixed Effects & Yes & Yes & Yes & Yes & Yes & Yes \\
Time Fixed Effects & No & No & No & No & Yes & No \\
Excluding 2008-2010 & No & No & No & No & No & Yes \\
\hline & & & & & &
\end{tabular}

Panel B: U.S.

\begin{tabular}{rrrrrr}
\hline Credit Spread (\%) & $(1)$ & $(2)$ & $(3)$ & $(4)$ & $(5)$ \\
\hline Equity Volatility (\% Ann.) & $0.03^{*}$ & 0.02 & 0.02 & 0.01 & 0.02 \\
& $(0.01)$ & $(0.01)$ & $(0.01)$ & $(0.01)$ & $(0.01)$ \\
Dividend-Price Ratio (\% Ann.) & 0.02 & -0.02 & 0.00 & -0.10 & -0.08 \\
& $(0.07)$ & $(0.07)$ & $(0.06)$ & $(0.06)$ & $(0.07)$ \\
Inflation Volatility (\% Ann.) & & $0.43^{* *}$ & $0.38^{* *}$ & 0.24 & $0.27^{*}$ \\
& & $(0.14)$ & $(0.14)$ & $(0.12)$ & $(0.13)$ \\
Inflation-Stock Correlation & & & 0.41 & $0.52^{* *}$ & $0.70^{* *}$ \\
& & & $(0.21)$ & $(0.14)$ & $(0.18)$ \\
$R^{2}$ & 0.07 & 0.23 & 0.28 & 0.58 & 0.52 \\
Controls & No & No & No & Yes & Yes \\
Excluding 2008-2010 & No & No & No & No & Yes \\
\hline
\end{tabular}


Table 4.11: Controlling for GDP Volatility (1969.Q4-2010.Q4)

Data and standard errors as in Table 3.5 in the main text. In this table, real uncertainty is measured by the annualized standard deviation of quarterly GDP growth over the past three years.

Panel A: International

\begin{tabular}{rrrrrrr}
\hline Credit Spread (\%) & $(1)$ & $(2)$ & $(3)$ & $(4)$ & $(5)$ & $(6)$ \\
\hline Dividend-Price Ratio (\% Ann.) & 0.05 & 0.04 & 0.08 & $0.13^{* *}$ & 0.15 & $0.08^{*}$ \\
& $(0.05)$ & $(0.04)$ & $(0.05)$ & $(0.05)$ & $(0.09)$ & $(0.03)$ \\
GDP Volatility (\% Ann.) & $0.24^{* *}$ & 0.16 & 0.12 & $0.11^{*}$ & 0.12 & $0.14^{*}$ \\
& $(0.08)$ & $(0.10)$ & $(0.07)$ & $(0.06)$ & $(0.09)$ & $(0.06)$ \\
Inflation Volatility (\% Ann.) & & $0.19^{*}$ & 0.15 & $0.28^{* *}$ & $0.15^{*}$ & $0.22^{* *}$ \\
& & $(0.09)$ & $(0.09)$ & $(0.08)$ & $(0.06)$ & $(0.06)$ \\
Inflation-Stock Correlation & & & $0.61^{* *}$ & $0.39^{* *}$ & $0.48^{* *}$ & $0.31^{*}$ \\
& & & $(0.20)$ & $(0.12)$ & $(0.12)$ & $(0.14)$ \\
Residual R2 & 0.12 & 0.14 & 0.24 & 0.35 & 0.17 & 0.31 \\
Controls & No & No & No & Yes & Yes & Yes \\
Time Fixed Effects & No & No & No & No & Yes & No \\
Excluding 2008-2010 & No & No & No & No & No & Yes \\
\hline & & & & & &
\end{tabular}

Panel B: U.S.

\begin{tabular}{rrrrrr}
\hline Credit Spread (\%) & $(1)$ & $(2)$ & $(3)$ & $(4)$ & $(5)$ \\
\hline Dividend-Price Ratio (\% Ann.) & 0.03 & 0.07 & 0.07 & 0.06 & 0.07 \\
& $(0.05)$ & $(0.05)$ & $(0.05)$ & $(0.04)$ & $(0.04)$ \\
GDP Volatility (\% Ann.) & $0.32^{* *}$ & 0.12 & 0.12 & 0.05 & 0.11 \\
& $(0.10)$ & $(0.09)$ & $(0.09)$ & $(0.10)$ & $(0.08)$ \\
Inflation Volatility (\% Ann.) & & $0.33^{* *}$ & $0.32^{* *}$ & $0.30^{* *}$ & $0.36^{* *}$ \\
& & $(0.08)$ & $(0.08)$ & $(0.06)$ & $(0.07)$ \\
Inflation-Stock Correlation & & & 0.09 & 0.11 & $0.26^{* *}$ \\
& & & $(0.08)$ & $(0.07)$ & $(0.08)$ \\
$R^{2}$ & 0.36 & 0.49 & 0.49 & 0.66 & 0.70 \\
Controls & No & No & No & Yes & Yes \\
Excluding 2008-2010 & No & No & No & No & Yes \\
\hline
\end{tabular}


Table 4.12: Smoothed Inflation Risk (1969.Q4-2010.Q4)

Data and standard errors are as in Table 3.5 in the main text. In this table inflation volatility and the inflationstock correlation are smoothed through an HP filter with smoothing parameter 500 to smooth out quarter by quarter movements.

Panel A: International

\begin{tabular}{rrrrrrr}
\hline Credit Spread (\%) & $(1)$ & $(2)$ & $(3)$ & $(4)$ & $(5)$ & $(6)$ \\
\hline Equity Volatility (\% Ann.) & $0.03^{*}$ & $0.02^{*}$ & 0.02 & 0.02 & 0.02 & $0.03^{* *}$ \\
& $(0.01)$ & $(0.01)$ & $(0.01)$ & $(0.01)$ & $(0.01)$ & $(0.01)$ \\
Dividend-Price Ratio (\% Ann.) & $0.12^{* *}$ & $0.07^{*}$ & $0.13^{* *}$ & $0.18^{* *}$ & $0.16^{*}$ & $0.13^{* *}$ \\
& $(0.03)$ & $(0.03)$ & $(0.05)$ & $(0.04)$ & $(0.07)$ & $(0.03)$ \\
Inflation Volatility (\% Ann.) & & $0.22^{* *}$ & $0.15^{*}$ & $0.26^{*}$ & 0.15 & $0.24^{*}$ \\
& & $(0.08)$ & $(0.07)$ & $(0.10)$ & $(0.08)$ & $(0.09)$ \\
Inflation-Stock Correlation & & & $0.92^{* *}$ & $0.63^{* *}$ & $0.70^{* *}$ & $0.47^{*}$ \\
& & & $(0.30)$ & $(0.19)$ & $(0.18)$ & $(0.19)$ \\
Residual R2 & 0.11 & 0.14 & 0.27 & 0.36 & 0.20 & 0.37 \\
Controls & No & No & No & Yes & Yes & Yes \\
Country Fixed Effects & Yes & Yes & Yes & Yes & Yes & Yes \\
Time Fixed Effects & No & No & No & No & Yes & No \\
Excluding 2008-2010 & No & No & No & No & No & Yes \\
\hline & & & & & &
\end{tabular}

Panel B: U.S.

\begin{tabular}{rrrrrr}
\hline Credit Spread (\%) & $(1)$ & $(2)$ & $(3)$ & $(4)$ & $(5)$ \\
\hline Equity Volatility (\% Ann.) & 0.01 & -0.00 & 0.00 & -0.01 & 0.00 \\
& $(0.01)$ & $(0.01)$ & $(0.01)$ & $(0.01)$ & $(0.01)$ \\
Dividend-Price Ratio (\% Ann.) & $0.14^{* *}$ & $0.11^{*}$ & $0.12^{* *}$ & 0.05 & 0.06 \\
& $(0.05)$ & $(0.04)$ & $(0.04)$ & $(0.03)$ & $(0.04)$ \\
Inflation Volatility (\% Ann.) & & $0.38^{* *}$ & $0.35^{* *}$ & $0.25^{* *}$ & $0.40^{* *}$ \\
& & $(0.08)$ & $(0.08)$ & $(0.06)$ & $(0.07)$ \\
Inflation-Stock Correlation & & & 0.15 & 0.31 & $0.97^{* *}$ \\
& & & $(0.21)$ & $(0.21)$ & $(0.26)$ \\
$R^{2}$ & 0.20 & 0.41 & 0.42 & 0.64 & 0.73 \\
Controls & No & No & No & Yes & Yes \\
Excluding 2008-2010 & No & No & No & No & Yes \\
\hline & & & & &
\end{tabular}


Table 4.13: Credit Spread Regressions with Add'1. Controls Smoothed (1989.Q1-2010.Q4)

Data and standard errors are as in Table 3.8 in the main text. In this table, market volatility, idiosyncratic volatility, bond volatility, bond-stock correlation, inflation volatility, and inflation-stock correlation are smoothed through an HP filter with smoothing parameter 500 to smooth out quarter by quarter movements.

\begin{tabular}{|c|c|c|c|}
\hline Credit Spread (\%) & (1) & (2) & (3) \\
\hline \multirow[t]{2}{*}{ Market Volatility (\% Ann.) } & 0.01 & -0.02 & 0.01 \\
\hline & $(0.01)$ & $(0.01)$ & $(0.01)$ \\
\hline \multirow[t]{2}{*}{ Idiosyncratic Volatility (\% Ann.) } & $0.01 *$ & -0.00 & $0.01 *$ \\
\hline & $(0.00)$ & $(0.01)$ & $(0.00)$ \\
\hline \multirow[t]{2}{*}{ Dividend-Price Ratio (\% Ann.) } & $0.37 * *$ & $0.23^{*}$ & $0.37 * *$ \\
\hline & $(0.09)$ & $(0.09)$ & $(0.09)$ \\
\hline \multirow[t]{2}{*}{ Leverage (\%) } & -0.00 & -0.01 & -0.00 \\
\hline & $(0.01)$ & $(0.01)$ & $(0.01)$ \\
\hline \multirow[t]{2}{*}{ Inflation Volatility (\% Ann.) } & $0.33 * *$ & -0.12 & $0.33 * *$ \\
\hline & $(0.12)$ & $(0.21)$ & $(0.12)$ \\
\hline \multirow[t]{2}{*}{ Inflation-Stock Correlation } & $0.24 * *$ & 0.06 & $0.24 * *$ \\
\hline & $(0.08)$ & $(0.11)$ & $(0.08)$ \\
\hline \multirow[t]{2}{*}{ Bond Volatility (\% Ann.) } & 0.59 & 0.39 & 0.59 \\
\hline & $(0.46)$ & $(0.47)$ & $(0.46)$ \\
\hline \multirow[t]{2}{*}{ Bond-Stock Correlation } & $1.41 * *$ & $1.52 *$ & $1.41 * *$ \\
\hline & $(0.52)$ & $(0.66)$ & $(0.52)$ \\
\hline \multicolumn{4}{|l|}{$R^{2}$} \\
\hline Controls & Yes & Yes & Yes \\
\hline Country Fixed Effects & Yes & Yes & Yes \\
\hline Time Fixed Effects & No & Yes & No \\
\hline Excluding 2008-2010 & No & No & Yes \\
\hline
\end{tabular}


Table 4.14: International CPI and PPI Inflation (1969.Q4-2010.Q4)

This table reports quarterly regressions of credit spreads onto explanatory variables for the following countries: Canada, Germany, Japan, U.K., and U.S. Inflation shocks are computed as inflation minus rolling four-quarter inflation following Atkeson and Ohanian (2001). These shocks are then used to compute alterntative measures of inflation volatility and inflation-stock correlation. Inflation in Panel A is based on CPI data, and inflation in Panel B is based on PPI data.

Panel A: International CPI Inflation

\begin{tabular}{rrrrrrr}
\hline Equity Volatility (\% Ann.) & $0.02^{* *}$ & $0.02^{* *}$ & $0.02^{*}$ & 0.02 & $0.02^{*}$ & $0.02^{* *}$ \\
& $(0.01)$ & $(0.01)$ & $(0.01)$ & $(0.01)$ & $(0.01)$ & $(0.01)$ \\
Dividend-Price Ratio (\% Ann.) & $0.11^{* *}$ & $0.08^{* *}$ & $0.11^{*}$ & $0.16^{* *}$ & 0.15 & $0.11^{* *}$ \\
& $(0.03)$ & $(0.03)$ & $(0.04)$ & $(0.05)$ & $(0.08)$ & $(0.04)$ \\
Inflation Volatility (\% Ann.) & & $0.14^{*}$ & $0.12^{*}$ & $0.19^{* *}$ & 0.07 & $0.14^{* *}$ \\
& & $(0.06)$ & $(0.06)$ & $(0.06)$ & $(0.06)$ & $(0.05)$ \\
Inflation-Stock Correlation & & & $0.52^{*}$ & $0.37 * *$ & $0.40^{* *}$ & $0.24^{* *}$ \\
& & & $(0.22)$ & $(0.10)$ & $(0.10)$ & $(0.09)$ \\
Residual R2 & 0.12 & 0.15 & 0.23 & 0.33 & 0.18 & 0.32 \\
Controls & No & No & No & Yes & Yes & Yes \\
Time Fixed Effects & No & No & No & No & Yes & No \\
Excluding 2008-2010 & No & No & No & No & No & Yes \\
\hline
\end{tabular}

Panel B: International PPI Inflation

\begin{tabular}{rrrrrrr}
\hline Equity Volatility (\% Ann.) & $0.02^{* *}$ & 0.01 & 0.01 & 0.01 & $0.02^{* *}$ & $0.02^{*}$ \\
& $(0.01)$ & $(0.01)$ & $(0.01)$ & $(0.01)$ & $(0.01)$ & $(0.01)$ \\
Dividend-Price Ratio (\% Ann.) & $0.11^{* *}$ & $0.10^{* *}$ & $0.10^{* *}$ & $0.15^{* *}$ & $0.20^{*}$ & $0.12^{* *}$ \\
& $(0.03)$ & $(0.03)$ & $(0.03)$ & $(0.04)$ & $(0.09)$ & $(0.03)$ \\
Inflation Volatility (\% Ann.) & & $0.13^{* *}$ & $0.13^{* *}$ & $0.12^{* *}$ & $0.08^{* *}$ & $0.09^{* *}$ \\
& & $(0.04)$ & $(0.03)$ & $(0.02)$ & $(0.03)$ & $(0.03)$ \\
Inflation-Stock Correlation & & & $0.23^{*}$ & 0.17 & 0.04 & $0.25^{*}$ \\
& & & $(0.11)$ & $(0.13)$ & $(0.16)$ & $(0.11)$ \\
Residual R2 & 0.11 & 0.29 & 0.30 & 0.36 & 0.15 & 0.30 \\
Controls & No & No & No & Yes & Yes & Yes \\
Country Fixed Effects & Yes & Yes & Yes & Yes & Yes & Yes \\
Time Fixed Effects & No & No & No & No & Yes & No \\
Excluding 2008-2010 & No & No & No & No & No & Yes \\
\hline & & & & & &
\end{tabular}


Table 4.15: U.S. CPI and PPI Inflation (1969.Q4-2010.Q4)

These regressions are analogous to Table 4.14 for the U.S. time series. Regressions are run using NeweyWest standard errors with 16 lags. * and ** denote significance at the 5\% and $1 \%$ level, respectively.

Panel A: U.S. CPI Inflation

\begin{tabular}{rrrrrr}
\hline Credit Spread (\%) & $(1)$ & $(2)$ & $(3)$ & $(4)$ & $(5)$ \\
\hline Equity Volatility (\% Ann.) & 0.01 & 0.01 & 0.01 & 0.00 & 0.00 \\
& $(0.01)$ & $(0.01)$ & $(0.01)$ & $(0.01)$ & $(0.01)$ \\
Dividend-Price Ratio (\% Ann.) & $0.14^{* *}$ & $0.13^{* *}$ & $0.13^{* *}$ & 0.07 & 0.08 \\
& $(0.05)$ & $(0.04)$ & $(0.04)$ & $(0.04)$ & $(0.04)$ \\
Inflation Volatility (\% Ann.) & & $0.31^{* *}$ & $0.31^{* *}$ & $0.23^{* *}$ & $0.28^{* *}$ \\
& & $(0.06)$ & $(0.06)$ & $(0.05)$ & $(0.06)$ \\
Inflation-Stock Correlation & & & 0.02 & 0.14 & 0.26 \\
& & & $(0.09)$ & $(0.07)$ & $(0.15)$ \\
$R^{2}$ & 0.22 & 0.47 & 0.47 & 0.63 & 0.66 \\
Controls & No & No & No & Yes & Yes \\
Excluding 2008-2010 & No & No & No & No & Yes \\
\hline & & & & &
\end{tabular}

Panel B: U.S. PPI Inflation

\begin{tabular}{rrrrrr}
\hline Credit Spread (\%) & $(1)$ & $(2)$ & $(3)$ & $(4)$ & $(5)$ \\
\hline Equity Volatility (\% Ann.) & 0.01 & -0.00 & -0.00 & -0.00 & -0.01 \\
& $(0.01)$ & $(0.01)$ & $(0.01)$ & $(0.01)$ & $(0.01)$ \\
Dividend-Price Ratio (\% Ann.) & $0.14^{* *}$ & $0.17^{* *}$ & $0.17^{* *}$ & $0.10^{*}$ & $0.12^{* *}$ \\
& $(0.05)$ & $(0.05)$ & $(0.05)$ & $(0.04)$ & $(0.04)$ \\
Inflation Volatility (\% Ann.) & & $0.08^{* *}$ & $0.08^{* *}$ & 0.04 & $0.12^{* *}$ \\
& & $(0.02)$ & $(0.02)$ & $(0.02)$ & $(0.03)$ \\
Inflation-Stock Correlation & & & 0.14 & $0.21^{*}$ & $0.40^{* *}$ \\
& & & $(0.11)$ & $(0.10)$ & $(0.11)$ \\
$R^{2}$ & 0.20 & 0.38 & 0.39 & 0.60 & 0.61 \\
Controls & No & No & No & Yes & Yes \\
Excluding 2008-2010 & No & No & No & No & Yes \\
\hline & & & & &
\end{tabular}


Table 4.16: U.S. Credit Spread Changes (1969.Q4-2010.Q4)

These regressions are analogous to Table 3.9 in the main text for the U.S. time series. Standard errors are Newey-West with $16+\mathrm{n}$ lags in parentheses. $*$ and $* *$ denote significance at the $5 \%$ and $1 \%$ level, respectively.

Panel A: Credit Spread Changes onto Contemporaneous Changes

\begin{tabular}{rrrrr}
\hline$\Delta$ Credit Spread (\%) & $(1)$ & $(2)$ & $(3)$ & $(4)$ \\
\hline Horizon (Quarters) & 1 & 4 & 12 & 20 \\
$\Delta$ Equity Volatility (\% Ann.) & -0.01 & 0.02 & 0.00 & 0.01 \\
& $(0.01)$ & $(0.01)$ & $(0.00)$ & $(0.01)$ \\
$\Delta$ Dividend-Price Ratio (\% Ann.) & $0.38^{* *}$ & 0.15 & 0.09 & $0.28^{* *}$ \\
& $(0.08)$ & $(0.10)$ & $(0.13)$ & $(0.06)$ \\
$\Delta$ Inflation Volatility (\% Ann.) & $0.61^{* *}$ & $0.50^{* *}$ & $0.31^{* *}$ & $0.40^{* *}$ \\
& $(0.07)$ & $(0.11)$ & $(0.10)$ & $(0.11)$ \\
$\Delta$ Inflation-Stock Correlation & 0.11 & 0.10 & $0.18^{*}$ & $0.23^{* *}$ \\
& $(0.09)$ & $(0.08)$ & $(0.07)$ & $(0.08)$ \\
$R^{2}$ & 0.33 & 0.45 & 0.58 & 0.68 \\
Controls & Yes & Yes & Yes & Yes \\
\hline
\end{tabular}

Panel B: Credit Spread Changes onto Lagged Variables

\begin{tabular}{rrrrr}
\hline$\Delta$ Credit Spread (\%) & $(1)$ & $(2)$ & $(3)$ & $(4)$ \\
\hline Horizon (Quarters) & 1 & 4 & 12 & 20 \\
Lag Equity Volatility (\% Ann.) & -0.00 & $-0.02^{*}$ & -0.01 & 0.01 \\
& $(0.00)$ & $(0.01)$ & $(0.01)$ & $(0.01)$ \\
Lag Dividend-Price Ratio (\% Ann.) & 0.01 & -0.09 & $-0.19^{* *}$ & $-0.21^{*}$ \\
& $(0.03)$ & $(0.05)$ & $(0.05)$ & $(0.10)$ \\
Lag Inflation Volatility (\% Ann.) & -0.04 & -0.00 & 0.09 & $-0.58^{* *}$ \\
& $(0.03)$ & $(0.07)$ & $(0.24)$ & $(0.22)$ \\
Lag Inflation-Stock Correlation & -0.07 & -0.16 & -0.22 & -0.36 \\
& $(0.06)$ & $(0.13)$ & $(0.21)$ & $(0.23)$ \\
$R^{2}$ & 0.18 & 0.44 & 0.35 & 0.48 \\
Controls & Yes & Yes & Yes & Yes \\
\hline & & & &
\end{tabular}


Table 4.17: U.S. Credit Return Regressions

Corporate bond returns and government bond returns are from Ibbotson return indices. Equity returns are in excess of long-term bond returns. Newey-West standard errors with 16 lags in parentheses. Controls include quarterly and three year inflation innovations, stock returns, GDP growth, and three year change in unemployment. Variables are constructed as described in Table 3.4. * and ** denote significance at the $1 \%$ and 5\% levels, respectively.

Panel A: Contemporaneous Changes

\begin{tabular}{rrrrrrr}
\hline$r e t_{t, t+n}^{c o r p}-r e t_{t, t+n}^{\text {gov }}(\%)$ & $(1)$ & $(2)$ & $(3)$ & $(4)$ & $(5)$ & $(6)$ \\
\hline Horizon (in quarters) & 1 & 1 & 1 & 4 & 12 & 20 \\
$\Delta$ Equity Volatility (\% Ann.) & -0.16 & -0.11 & 0.06 & 0.02 & -0.04 & 0.03 \\
& $(0.12)$ & $(0.12)$ & $(0.10)$ & $(0.10)$ & $(0.09)$ & $(0.11)$ \\
$\Delta$ Inflation Volatility (\% Ann.) & & $-2.70^{*}$ & -1.08 & -1.05 & $-5.36^{* *}$ & $-4.84^{* *}$ \\
& & $(1.07)$ & $(1.58)$ & $(1.84)$ & $(1.27)$ & $(1.11)$ \\
$\Delta$ Inflation-Stock Correlation & & -0.99 & 0.44 & -0.47 & $-3.94 * *$ & $-3.97 *$ \\
& & $(1.33)$ & $(0.85)$ & $(1.46)$ & $(1.46)$ & $(1.81)$ \\
rett,t+ngov (\%) & & & $-0.17^{* *}$ & -0.08 & -0.16 & -0.31 \\
& & & $(0.04)$ & $(0.06)$ & $(0.09)$ & $(0.16)$ \\
rett, $\mathrm{t}+$ ncorp (\%) & & & $0.03^{* *}$ & 0.08 & -0.10 & -0.24 \\
& & & $(0.01)$ & $(0.06)$ & $(0.11)$ & $(0.17)$ \\
Constant & -0.15 & -0.11 & 0.18 & 0.54 & $2.61 * *$ & $5.23 * *$ \\
& $(0.14)$ & $(0.14)$ & $(0.22)$ & $(0.74)$ & $(0.63)$ & $(1.62)$ \\
\hline
\end{tabular}

Panel B: Return Predictive Regressions

\begin{tabular}{rrrrrrr}
\hline$r e t_{t, t+n}^{c o r p}-r e t_{t, t+n}^{\text {gov }}(\%)$ & $(1)$ & $(2)$ & $(3)$ & $(4)$ & $(5)$ & $(6)$ \\
\hline Horizon (in quarters) & 1 & 1 & 1 & 4 & 12 & 20 \\
Lag Equity Volatility (\% Ann.) & 0.1 & 0.1 & 0.08 & 0.07 & -0.03 & -0.04 \\
& $(0.05)$ & $(0.05)$ & $(0.05)$ & $(0.05)$ & $(0.05)$ & $(0.07)$ \\
Lag Dividend-Price Ratio (\% Ann.) & 0.1 & 0.10 & 0.14 & 0.29 & -0.16 & -0.20 \\
& $(0.09)$ & $(0.14)$ & $(0.21)$ & $(0.38)$ & $(0.32)$ & $(0.36)$ \\
Lag Inflation Volatility (\% Ann.) & & 0.44 & 0.07 & -0.14 & -0.09 & -0.34 \\
& & $(0.48)$ & $(0.40)$ & $(0.45)$ & $(0.78)$ & $(1.17)$ \\
Lag Inflation-Stock Correlation & & 1.96 & $2.43^{*}$ & $1.46^{*}$ & -0.69 & -0.40 \\
& & $(1.19)$ & $(1.01)$ & $(0.68)$ & $(0.62)$ & $(0.54)$ \\
$R^{2}$ & 0.05 & 0.11 & 0.18 & 0.08 & 0.05 & 0.02 \\
Controls & No & No & Yes & Yes & Yes & Yes \\
\hline
\end{tabular}


Table 4.18: Decomposition of Inflation Risk Regimes

Credit spreads are averaged within categories of low, medium and high inflation volatility as well as inflationstock correlation regimes. Low, medium and high inflation risk regimes are defined according to the bottom, middle and top third of the distribution, respectively. The right-hand table reports the relative frequency, or time spent, in each regime.

\section{Credit Spread (\%)}

Inflation Volatility

\begin{tabular}{cccccc}
\multirow{2}{*}{ Australia } & & Low & Med & High & Low \\
& Low & 0.61 & 1.05 & 0.98 & $11 \%$ \\
& Med & 0.61 & 0.75 & 1.09 & $5 \%$ \\
& High & 0.87 & 1.19 & 1.37 & $7 \%$
\end{tabular}

Canada Low 0.68

Med $\quad 0.80$

High $\quad 0.93$

Germany Low 0.38

Med 0.56

High $\quad 0.98$

Japan

$\begin{array}{ll}\text { Low } & 0.20 \\ \text { Med } & 0.29 \\ \text { High } & 0.27\end{array}$

U.K.

$\begin{array}{ll}\text { Low } & 0.60 \\ \text { Med } & 1.00 \\ \text { High } & 0.98\end{array}$

U.S. Low 0.74

Med 0.83

High $\quad 0.73$
0.94

0.94

1.00

0.40

0.60

1.48

0.07

0.34

0.44

1.00

0.92

1.58

0.87

0.95

1.07
1.16

0.88

1.56

0.29

0.62

0.36

0.57

0.03

0.40

1.85

1.48

1.96

$5 \%$

$15 \%$

$13 \%$

$9 \%$

$13 \%$

$11 \%$

$10 \%$

$16 \%$

$7 \%$

1.14

1.42

1.53
Time Spent (\% of Obs.)

Inflation Volatility

$\begin{array}{cc}\text { Med } & \text { High } \\ 9 \% & 2 \% \\ 7 \% & 11 \% \\ 7 \% & 9 \%\end{array}$

$10 \%$

$16 \%$

$13 \%$

$7 \%$

$10 \%$

$10 \%$

$13 \%$

$15 \%$

$10 \%$

$9 \%$

$11 \%$

$9 \%$

$10 \%$

$14 \%$

$10 \%$

$10 \%$

$13 \%$

$9 \%$

$18 \%$

$5 \%$

$9 \%$

$8 \%$

$6 \%$

$21 \%$

$12 \%$

$16 \%$

$6 \%$ 
Figure 4.4 shows the close comovement between the bond-stock correlation and the breakeven-stock correlation in the U.S. and in the U.K. Figure 4.5 shows the inverse relationship between quarterly inflation shocks and credit spreads in the U.S.

Figure 4.6 shows that the U.S. Phillips curve was steeper whenever the 3 year lagged inflation stock correlation was higher. It also shows that inflation shocks were larger in magnitude when the three year lagged inflation volatility was higher.

Figure 4.7 investigates the relationship between inflation risk regimes and defaults for the U.S. Unfortunately data availability is limited and the evidence is consequently noisy. The bottom left panel shows evidence consistent with theory. Defaults are downward sloping in stock returns when inflation is procyclical but upward sloping in stock returns when inflation is countercyclical. In particular, default rates were low in the 1970s when inflation was countercyclical but they were high during the early 2000s, which were characterized by procyclical inflation.

\subsubsection{Computation of Asset Prices}

Our simulations require the computation of asset prices along a three-dimensional grid for $\tilde{w}$, the leverage ratio of seasoned firms, and the inflation risk regime. We compute asset prices along a dense grid of size $70 \times 35 \times 2$. This grid covers seasoned leverage ratios from 0.1 to 1.9 and the full solution range for $\tilde{w}$. In our simulations, we compute asset prices by interpolating linearly over this grid. 


\section{U.S.}

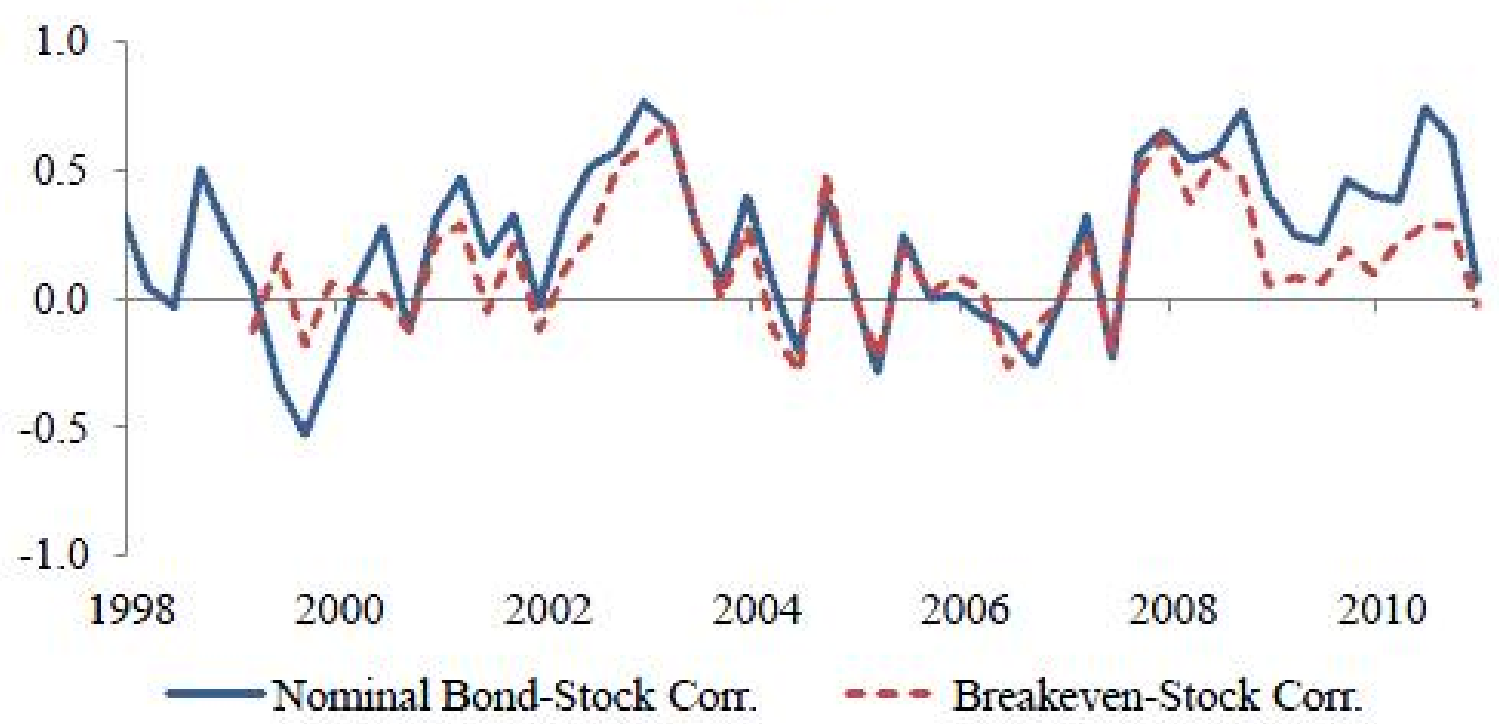

U.K.

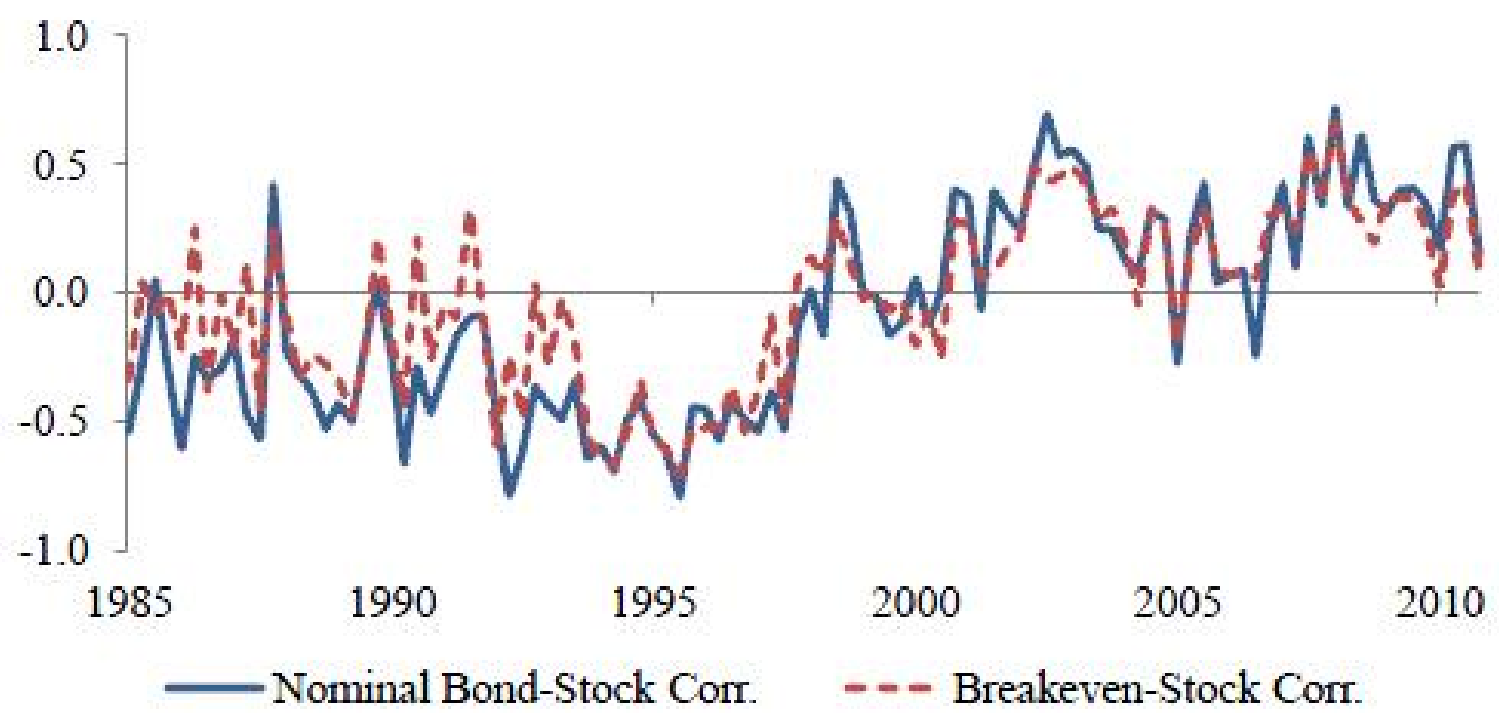

Figure 4.4: Breakeven-Stock Correlation

Breakeven inflation correlation computed from daily changes in breakeven and daily log stock returns. Breakeven is the difference between continuously compounded zero coupon nominal and inflation-indexed government yields. 10 year yields from Gurkaynak, Sack and Wright (2010) and 15 year U.K. yields from Anderson and Sleath (2001). 


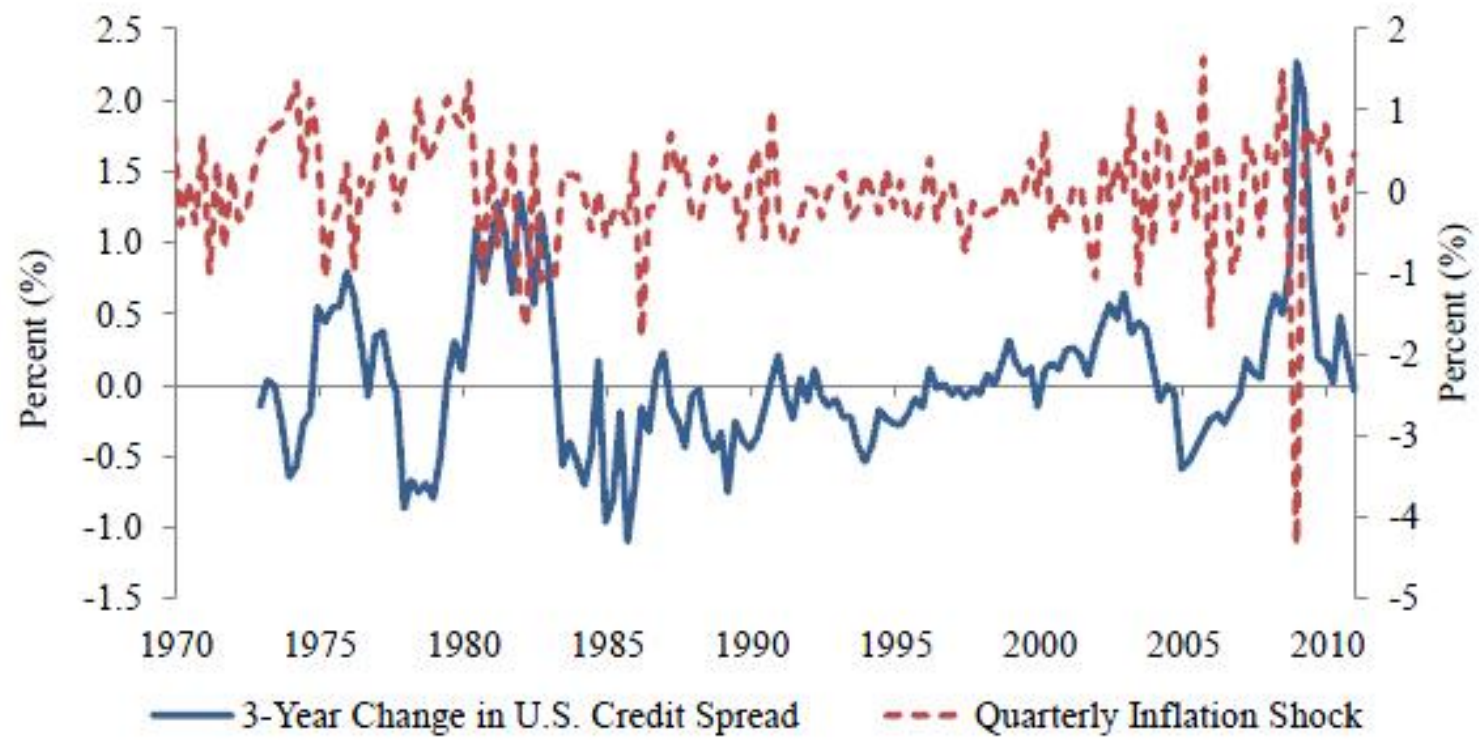

Figure 4.5: U.S. Credit Spreads and Inflation Shocks

Three year changes in the Moody's BAA over AAA credit spreads and quarterly inflation shocks extracted.

\section{Bond Prices and Credit Spreads}

We compute prices of 10 year and 5 year default free bonds according to

$$
\begin{aligned}
q_{t}^{\text {gov }, 10} & =\exp \left(-2\left(\beta+\gamma \mu+\pi_{t}\right)\right) \mathbb{E}_{t}\left[\left(\frac{\tilde{C}_{t+2}}{\tilde{C}_{t}}\right)^{-\gamma} \exp \left(-2 \varepsilon_{t+t}^{\pi}-\varepsilon_{t+2}^{\pi}\right)\right] \\
q_{t}^{g o v, 5} & =\exp \left(-\left(\beta+\gamma \mu+\pi_{t}\right)\right) \mathbb{E}_{t}\left[\left(\frac{\tilde{C}_{t+1}}{\tilde{C}_{t}}\right)^{-\gamma} \exp \left(-\varepsilon_{t+t}^{\pi}\right)\right]
\end{aligned}
$$

The price of new 10 year corporate bonds is given by

$$
\begin{aligned}
q_{t}^{\text {corp }, \text { new }}= & \exp \left(-2\left(\beta+\gamma \mu+\pi_{t}\right)\right) \\
& \times \mathbb{E}_{t}\left[\left(\frac{\tilde{C}_{t+2}}{\tilde{C}_{t}}\right)^{-\gamma} \frac{1-H\left(a_{t+2}^{*}\right)+\theta \frac{\Omega\left(a_{t+2}^{*}\right)}{\exp \left(a_{t+2}^{*}\right)}}{\exp \left(2 \varepsilon_{t+t}^{\pi}+\varepsilon_{t+2}^{\pi}\right)}\right]
\end{aligned}
$$

New corporate bonds issued by cohort $t-1$ firms become seasoned corporate bonds at time $t$. The calculation of seasoned 5 year corporate bond yields is complicated by firm 


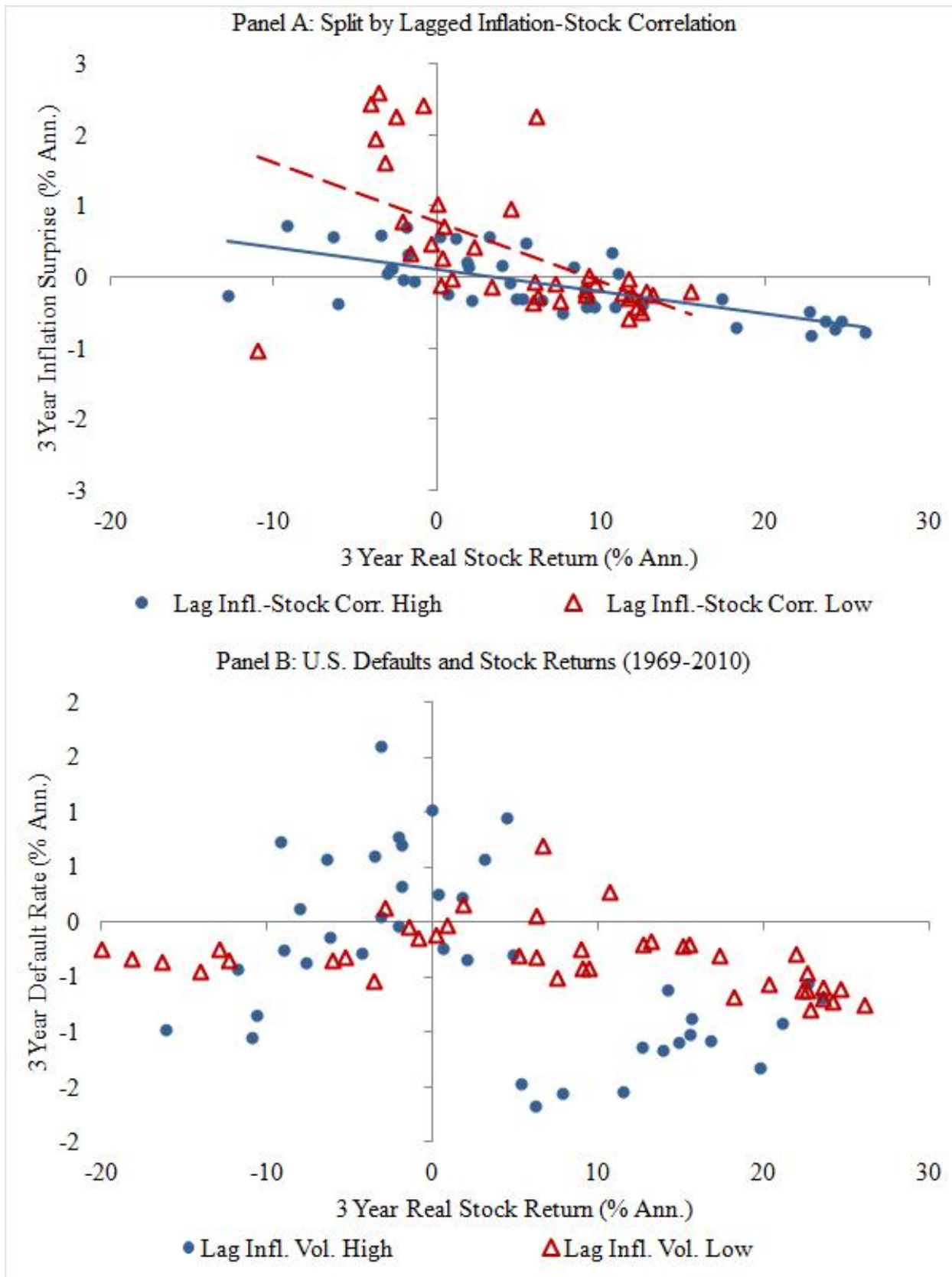

Figure 4.6: U.S. Stock Return Phillips Curve and Lagged Inflation Risk

3 year inflation surprises are computed as the sum of 12 lags of quarterly inflation surprises. Quarterly inflation surprises are residuals from regressing quarterly log inflation onto its own 12 lags and seasonal dummies. In Panel A (Panel B) we split the sample according to whether the 12 month lagged inflationstock correlation (or inflation volatility) is in the highest $25 \%$ and lowest $25 \%$ of realized values. Linear trend lines are shown for subsamples in Panel A. 

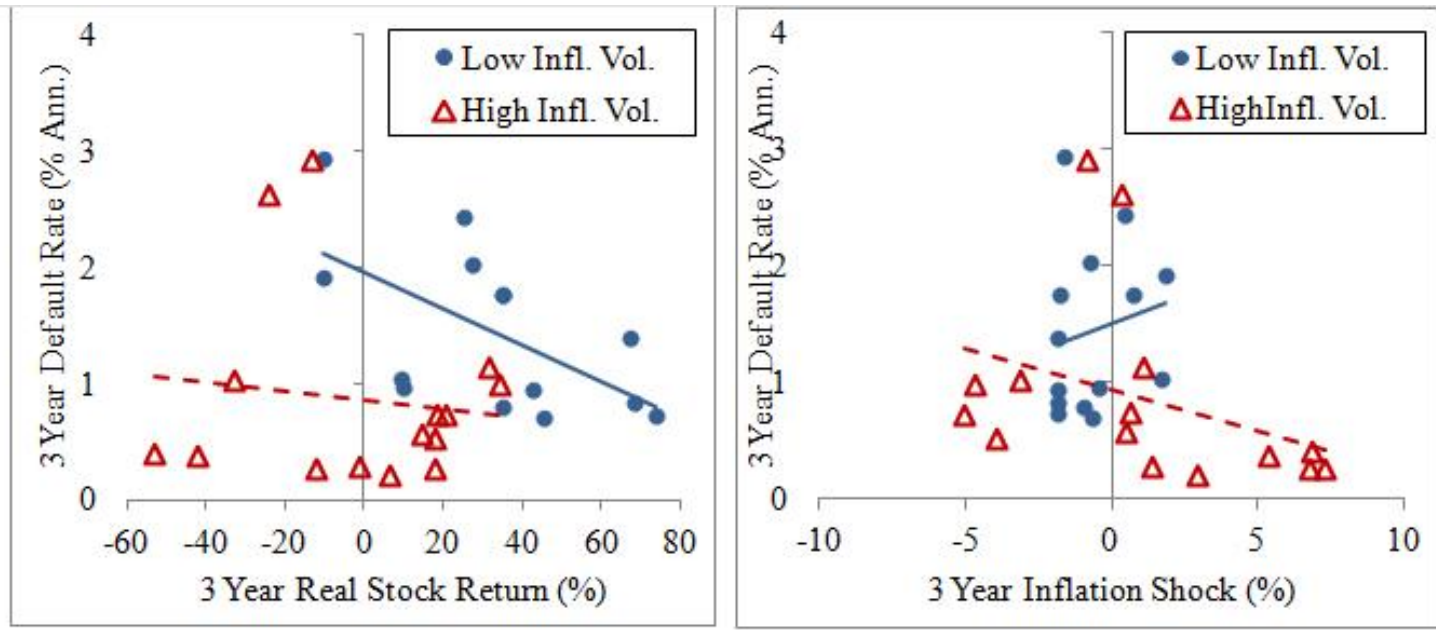

Panel B: Inflation-Stock Correlation Regimes

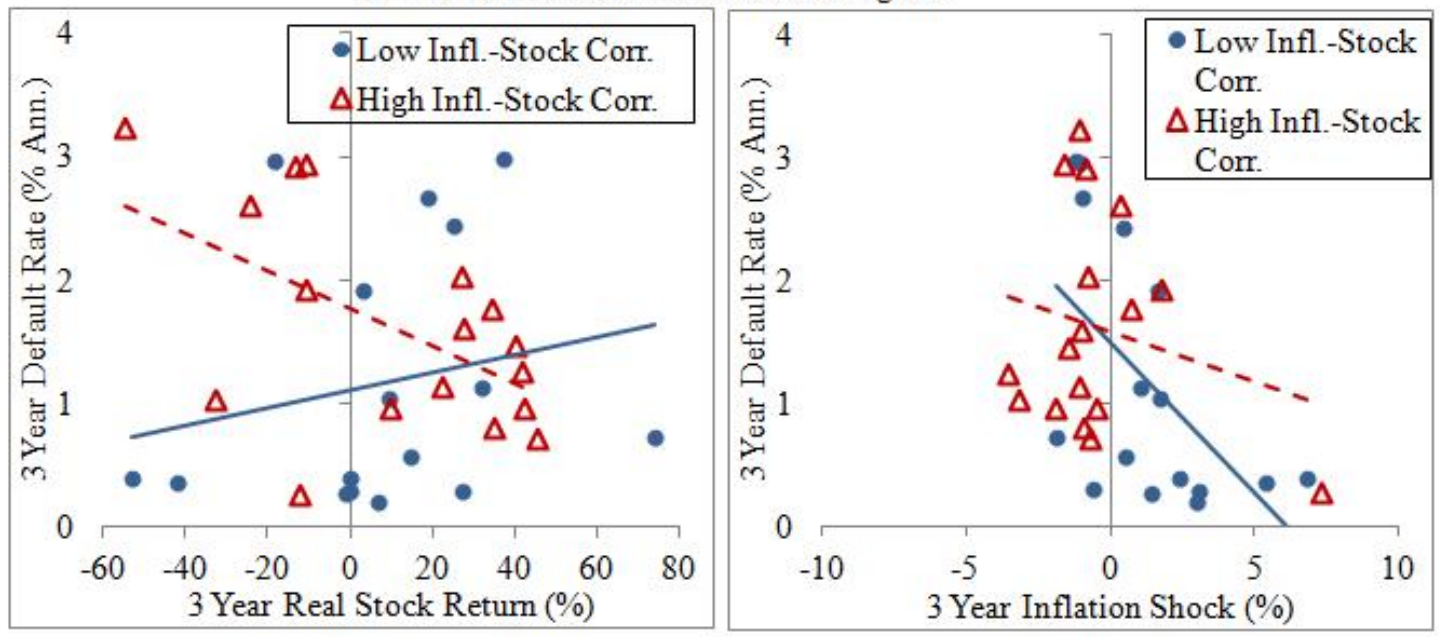

Figure 4.7: Defaults, Stock Returns and Inflation Shocks

Three year averages of annual default rates from Moody's (2011). Annual issuer-weighted default rates reflect all investment grade and speculative grade defaults. High and low inflation risk correspond to the upper and lower thirds of the empirical distribution of inflation volatility or the inflation-stock correlation. Inflation volatility greater than $1.41 \%$ p.a. is considered high and less than $0.95 \%$ p.a. is considered low. An inflation-stock correlation greater than -0.19 is considered high and less than -0.43 is considered low. 
heterogeneity induced by idiosyncratic firm shocks. We denote the combined idiosyncratic shock to firm $i$ in cohort $t-1$ by $a_{t+1}^{i, i d}$. We think of it as the sum of two independent and identically distributed shocks revealed in periods $t$ and $t+1$

$$
\begin{aligned}
a_{t+1}^{i, i d}= & a_{t}^{i, 1}+a_{t+1}^{i, 2} \\
& a_{t}^{i, 1}, a_{t+1}^{i, 2} \stackrel{i n d}{\sim} N\left(-\frac{1}{4}\left(\sigma^{i d}\right)^{2}, \frac{1}{2}\left(\sigma^{i d}\right)^{2}\right)
\end{aligned}
$$

For a given idiosyncratic shock $a_{t}^{i, 1}$, firm $i$ defaults at time $t+1$ if and only if

$$
a_{t+1}^{i, 2}<a_{t+1}^{*}-a_{t}^{i, 1}
$$

The time $t$ price of a seasoned bond issued by firm $i$ then is

$$
\begin{aligned}
q_{t}^{i, \text { seas }}= & \exp \left(-\left(\beta+\gamma \mu+\pi_{t}\right)\right) \\
& \times \mathbb{E}_{t}\left[\left(\frac{\tilde{C}_{t+1}}{\tilde{C}_{t}}\right)^{-\gamma} \frac{1-G\left(a_{t+1}^{*}, a_{t}^{i, 1}\right)+\theta \frac{W\left(a_{t+1}^{*}, a_{t}^{i, 1}\right)}{\exp \left(a_{t+1}^{*}\right)}}{\exp \left(\varepsilon_{t+t}^{\pi}\right)}\right]
\end{aligned}
$$

The functions $G$ and $W$ are defined as the conditional analogues of the functions $H$ and $\Omega$

$$
\begin{aligned}
G(x) & =\mathbb{P}\left[a_{t+1}^{i, i d}<x \mid a_{t}^{i, 1}\right] \\
W(x) & =\mathbb{E}\left[\exp \left(a_{t+1}^{i, i d}\right) I\left(a_{t+1}^{i, i d}<x\right) \mid a_{t}^{i, 1}\right]
\end{aligned}
$$

We compute the new corporate bond spread at time $t$ as

$$
\operatorname{spread}_{t}^{\text {new }}=-\frac{1}{10} \log q_{t}^{\text {corp,new }}+\frac{1}{10} \log q_{t}^{\text {gov }, 10}
$$

We compute the average seasoned corporate bond spread by numerically integrating over the density of the idiosyncratic shock $a_{t}^{i, 1}$.

$$
\operatorname{spread}_{t}^{\text {seas }}=\int\left(-\frac{1}{5} \log q_{t}^{i, \text { seas }}+\frac{1}{5} \log q_{t}^{\text {gov }, 5}\right) d F\left(a_{t}^{i, 1}\right)
$$

We approximate the integral in (4.23) using the Gauss-Hermite methodology with 7 nodes. 


\section{Book Leverage and Investment to Capital}

In Figure 3.5 in the main text we show impulse responses for new book leverage and the investment to capital ratio. We obtain new book leverage by discounting the nominal face value of debt by the long-term nominal risk free rate

$$
L_{t}^{b o o k}=L_{t} \exp \left(2 \pi_{t}\right) q_{t}^{g o v, 10}
$$

The investment to capital ratio is computed as

$$
(I / K)_{t}=\frac{\tilde{W}_{t}-\tilde{C}_{t}-(1-\delta) \tilde{K}_{t}}{\tilde{W}_{t}-\tilde{C}_{t}}
$$

\section{Idiosyncratic Equity Volatility}

In Table 3.2 in the main text we report the idiosyncratic volatility of ten year equity returns conditional on not defaulting. The time $t$ real cash flow to equity holders of firm $i$ in cohort $t-2$ conditional on not defaulting is

$$
K_{t-1}^{y} \underbrace{R_{t-1}^{K} R_{t}^{K}}_{\text {Return on Capital }}(\underbrace{\exp \left(a_{t}^{i d, i}\right)}_{\text {Idiosyncratic Shock }}-\underbrace{\exp \left(a_{t}^{*}\right)}_{\text {Debt Payment }})
$$

The idiosyncratic volatility of log real stock returns conditional on not defaulting is therefore given by

$$
\sigma_{t}^{\text {Firm }}=\frac{1}{\sqrt{10}} \operatorname{Var}\left[\log \left(\exp \left(a_{t}^{i d, i}\right)-\exp \left(a_{t}^{*}\right)\right) \mid a_{t}^{i d, i} \geq a_{t}^{*}, a_{t}^{*}\right]
$$

\section{Dividend-Price Ratio, Equity Volatility, and Inflation-Stock Correlation}

In Table 3.3 in the main text we show regressions that include the model dividend-price ratio, model equity volatility and the model inflation-stock correlation. Since the left-hand side of our regression has seasoned credit spreads, we focus on the moments of seasoned 
equity returns on the right-hand side. The real equity dividend at time $t+1$ averaged over all cohort $t-1$ firms is given by

$$
K_{t}^{y} R_{t}^{K} R_{t+1}^{K}\left(1-\exp \left(a_{t+1}^{*}\right)\left(1-H\left(a_{t+1}^{*}\right)\right)-\Omega\left(a_{t+1}^{*}\right)\right)
$$

The time $t$ price of seasoned equity is therefore equal to

$$
\begin{aligned}
S_{t}^{\text {seas }}= & \exp (-(\beta+\gamma \mu)) \times K_{t}^{y} R_{t}^{K} \\
& \times \mathbb{E}_{t}\left[\left(\frac{\tilde{C}_{t+1}}{\tilde{C}_{t}}\right)^{-\gamma} R_{t+1}^{K}\left(1-\exp \left(a_{t+1}^{*}\right)\left(1-H\left(a_{t+1}^{*}\right)\right)-\Omega\left(a_{t+1}^{*}\right)\right)(4\right.
\end{aligned}
$$

Log seasoned real equity returns from time $t$ to time $t+1$ are then equal to

$$
r_{t+1}^{e q, \text { seas }}=r_{t+1}^{K}+\log \left(1-\exp \left(a_{t+1}^{*}\right)\left(1-H\left(a_{t+1}^{*}\right)\right)-\Omega\left(a_{t+1}^{*}\right)\right)-\left(s_{t}^{\text {seas }}-k_{t}^{y}\right)
$$

where $s_{t}^{\text {seas }}$ is the log seasoned equity price at time $t$. We compute the seasoned dividendprice ratio as the expected log return on seasoned equity

$$
D P_{t}^{\text {seas }}=\mathbb{E}_{t}\left[r_{t+1}^{\text {eq,seas }}\right]
$$

Seasoned equity volatility is the backward-looking annualized standard deviation of $\log$ real seasoned stock returns conditional on the inflation risk regime

$$
\sigma_{t}^{e q, \text { seas }}=\frac{\sqrt{\mathbb{V a r}\left[r_{t}^{\text {seas }, e q} \mid \sigma_{t}^{\pi}, \rho_{t}^{\pi}, \tilde{w}_{t-1}, L_{t-1}^{\text {old }}\right]}}{\sqrt{5}}
$$

The inflation-stock correlation is the backward-looking correlation between shocks to $\log$ inflation expectations and log seasoned real stock returns conditional on the inflation risk regime

$$
\rho_{t}^{e q, \pi}=\operatorname{Corr}\left[r_{t}^{\text {seas }, e q}, \varepsilon_{t}^{\pi} \mid \sigma_{t}^{\pi}, \rho_{t}^{\pi}, \tilde{w}_{t-1}, L_{t-1}^{\text {old }}\right]
$$




\section{References}

Abel, Andrew B., Jan C. Eberly, and Stavros Panageas, 2007, Optimal Inattention to the Stock Market, American Economic Review, Papers and Proceedings, 97(2), 244-249.

Acharya, Viral V., D. Gale, and T. Yorulmazer, 2010, Rollover Risk and Market Freezes , NBER Working Paper w15674.

Ait-Sahalia, Yacine, and J. Yu, 2009, High Frequency Market Microstructure Noise Estimates and Liquidity Measures, Annals of Applied Statistics, Vol. 3, No. 1, pp. 422-457.

Almeida, Heitor, and T. Philippon, 2007, The Risk-Adjusted Cost of Financial Distress , Journal of Finance 62(6):2557-2586.

Altman, Edward, 2006, Default Recovery rates and LGD in Credit Risk Modeling and Practice: An Updated Review of the Literature and Empirical Evidence, NYU, mimeo.

Ameriks, John and Stephen Zeldes, 2004, How do household portfolio shares vary with age?, Working paper, Columbia University.

Amihud, Y., 2002, Illiquidity and stock returns: Cross-section and time-series effects, Journal of Financial Markets 5, 31-56.

Anton, Miguel and Christopher Polk, 2010, Connected Stocks, Working paper, London School of Economics. 
Atkeson, Andrew, and L.E. Ohanian, 2001, Are Phillips Curves Useful for Forecasting Inflation? , Federal Reserve Bank of Minneapolis Quarterly Review 25(1):2-11.

Baele, Lieven, G. Bekaert, and K. Inghelbrecht, 2009, The Determinants of Stock and Bond Return Comovements , NBER Working Paper w15260.

Baker, Malcolm, and J. Wurgler, 2002, Market Timing and Capital Structure , Journal of Finance 57(1):1-32.

Baker, Malcom, X. Pan, and J. Wurgler, 2012, The Effect of Reference Point Prices on Mergers and Acquisitions, Journal of Financial Economics.

Ball, Laurence, and S. Cecchetti, 1990, Inflation and Uncertainty at Long and Short Horizons , Brookings Papers on Economic Activity 1:215-245 .

Bansal, Ravi, and A. Yaron, 2004, Risks for the Long Run: A Potential Resolution of Asset Pricing Puzzles, Journal of Finance 59(4):1481-1509.

Barber, Brad M., T. Odean, and N. Zhu, 2009, Do Retail Trades Move Markets?, Review of Financial Studies, 2009, Vol. 22, 1, 151-186.

Barber, Brad M., T. Odean, and N. Zhu, 2009, Systematic Noise, Journal of Financial Markets, 2009, Vol. 12, 547-569.

Barber, Brad M., and T. Odean, 2000, Trading is hazardous to your wealth: The common stock investment performance of individual investors, Journal of Finance 55:773-806.

Barber, Brad M., and T. Odean, 2008, All that Glitters: The Effect of Attention and News on the Buying Behavior of Individual and Institutional Investors, Review of Financial Studies, Vol. 21, 2, 785-818.

Bernanke, Ben, and M. Gertler, 1989, Agency Costs, Net Worth, and Business Fluctuations , American Economic Review 79(1):14-31. 
Bhamra, Harjoat S., A. J. Fisher, and L. Kuehn, 2011, Monetary Policy and Corporate Default, University of British Columbia, mimeo.

Bhamra, Harjoat S., L. Kuehn, and I. A. Strebulaev, 2010a, The Levered Equity Risk Premium and Credit Spreads: A Unified Framework, Review of Financial Studies 23 (2):645-703.

Bhamra, Harjoat S., L. Kuehn, and I. A. Strebulaev, 2010b, Long Run Risks, Credit Markets, and Financial Structure , American Economic Review: Papers \& Proceedings 100:547-551.

Black, Fischer, and M. Scholes, 1973, The Pricing of Options and Corporate Liabilities , Journal of Political Economy 81:637-654.

Blouin, Jennifer, Jana Raedy, and Douglas Shackelford, 2003, Capital gains taxes and equity trading: Empirical Evidence, Journal of Accounting Research 41, 611-651.

Bossaerts, Peter and Robert M. Dammon, 1994, Tax-Induced Intertemporal Restrictions on Security Returns, Journal of Finance 49, 1347-1372.

Branch, Ben, 1977, A Tax Loss Trading Rule, Journal of Business 50, 198-207.

Campbell, John Y., A. Sunderam, and L. M. Viceira, 2011, Inflation Bets or Deflation Hedges? The Changing Risks of Nominal Bonds, Harvard University, mimeo.

Campbell, John Y., A. W. Lo, and A. C. MacKinlay, 1997, The Econometrics of Financial Markets, Princeton University Press .

Campbell, John Y., M. Lettau, B. G. Malkiel, and Y. Xu, 2001, Have Individual Stocks Become More Volatile? An Empirical Exploration of Idiosyncratic Risk , Journal of Finance 56(1):1-43.

Campbell, John Y., and G. B. Taksler, 2003, Equity Volatility and Corporate Bond Yields , Journal of Finance 58(6):2321-2349. 
Campbell, John Y., and J. Cocco, 2003, Household Risk Management and Optimal Mortgage Choice , Quarterly Journal of Economics 118(4):1449-1494.

Campbell, John Y., and J. H. Cochrane, 1999, By Force of Habit: A ConsumptionBased Explanation of Aggregate Stock Market Behavior, Journal of Political Economy 107(2):205-251.

Carhart, M., 1997, On persistence in mutual fund performance, Journal of Finance 52, 57-82.

Carhart, Mark, 1997, On Persistence in Mutual Fund Performance, Journal of Finance 52, 57-82.

Chan, K. C., 1986, Can Tax-Loss Selling Explain the January Seasonal in Stock Returns?, Journal of Finance 41, 1115-1128.

Chen, Long, P. Collin-Dufresne, and R. S. Goldstein, 2009, On the Relationship Between the Credit Spread Puzzle and the Equity Premium Puzzle, Review of Financial Studies 22(9):3367-3409.

Chernenko, Sergey, and M. Faulkender, 2011, The Two Sides of Derivatives Usage: Hedging and Speculating with Interest Rate Swaps, Journal of Financial and Quantitative Analysis, forthcoming.

Chordia, Tarun and Lakshmanan Shivakumar, 2002, Momentum, Business Cycle, and Time-varying Expected Returns, Journal of Finance 57, 985-1019.

Cochrane, John H., Asset Pricing, Princeton University Press, 2001.

Collin-Dufresne, Pierre, R. S. Goldstein, and J. S. Martin, 2001, The Determinants of Credit Spread Changes, Journal of Finance 56(6):2177-2207 .

Constantinides, George, 1983, Capital Market Equilibrium with Personal Tax, Econometrica 51, 611-636. 
Constantinides, George, 1984, Optimal Stock Trading with Personal Taxes: Implications for Prices and the Abnormal January Returns, Journal of Financial Economics 13, 6589.

Cooley, Thomas F., and E.C. Prescott, 1995, Frontiers of Business Cycle Research, Princeton University Press .

Cooper, Michael J., Roberto C. Gutierrez Jr., and Allaudeen Hameed, 2004, Market States and Momentum, Journal of Finance 59, 1345-1365.

Coval, Joshua D., J. Jurek, and E. Stafford, 2009, Economic Catastrophe Bonds , American Economic Review 99(3):628-666.

Coval, Joshua and Erik Stafford, 2007, Asset Fire Sales (and Purchases) in Equity Markets, Journal of Financial Economics 86, 479-512.

Cremers, Martijn, J. Driessen, and P. Maenhout, 2008, Explaining the Level of Credit Spreads: Option-Implied Jump Risk Premia in a Firm Value Model, Review of Financial Studies 21(5):2209-2242.

Cushing, David and Ananth Madhavan, 2001, The Hidden Cost of Trading at the Close, Institutional Investor Journals (Spring 2001): Transaction Costs.

D’Amico, Stefania, D. H. Kim, and M. Wei, 2008, Tips from TIPS: The Informational Content of Treasury Inflation-Protected Security Prices, BIS Working Papers, No 248.

Da, Z., J. Engelberg, and P. Gao, 2011, In Search of Attention, Journal of Finance 66, 1461-1499.

Dai, Zhonglan, Edward Maydew, Douglas A. Shackelford, and Harold H. Zhang, Capital Gains Taxes and Asset Prices: Capitalization or Lock-In?, forthcoming Journal of Finance. 
Dammon, Robert M. and Chester S. Spatt, 1996, The Optimal Trading and Pricing of Securities with Asymmetric Capital Gains Taxes and Transactions Costs, Review of Financial Studies 9, 921-952.

Dammon, Robert M., Chester S. Spatt, and Harold H. Zhang, 2001, Optimal Consumption and Investment with Capital Gains Taxes, Review of Financial Studies 14, 483-616.

Dammon, Robert M., Chester S. Spatt, and Harold H. Zhang, 2004, Optimal Asset Location and Allocation with Taxable and Tax-Deferred Investing, Journal of Finance 59, 999-1037.

Dammon, Robert M., Kenneth B. Dunn, and Chester S. Spatt, 1989, A Reexamination of the Value of Tax Options, Review of Financial Studies 2, 341-372.

David, Alexander, and P. Veronesi, 2009, What Ties Return Volatilities to Price Valuations and Fundamentals?, NBER Working Paper w15563.

De Bondt, Gabe, and J. Lichtenberger, 2003, The Euro Area Corporate Bond Market: Where Do We Stand Since the Introduction of the Euro? , European Business Organization Law Review 4:517-539.

De Fiore, Fiorella, P. Teles, and O. Tristani, 2011, Monetary Policy and the Financing of Firms , American Economic Journal: Macroeconomics 3: 112-142.

DeLong, J., A. Shleifer, L. Summers, and R. Waldmann, 1990, Noise Trader Risk in Financial Markets, Journal of Political Economy 98, 703-738.

Driscoll, John C., and A. C. Kraay, 1998, Consistent Covariance Matrix Estimation With Spatially Dependent Panel Data, Review of Economics and Statistics 80(4):549-560.

Duffie, Darrell, Presidential Address: Asset Price Dynamics with Slow-Moving Capital, Journal of Finance 45, 1237-1267. 
Duffie, Darrell, and K. J. Singleton, 1997, An Econometric Model of the Term Structure of Interest-Rate Swap Yields , Journal of Finance 52:1287-1321.

Dyl, Edward E., 1977, Capital Gains Taxation and Year-End Stock Market Behavior, Journal of Finance 32, 165-175.

Ellul, Andrew, Pab Jotikasthira, and Christian T. Lundblad, 2010, Regulatory Pressure and Fire Sales in the Corporate Bond Market, Working paper.

Elton, Edwin J., M.J. Gruber, D. Agrawal, and C. Mann, 2001, Explaining the Rate Spread on Corporate Bonds , Journal of Finance 56(1):247-278 .

Engle, Robert F., 1982, Autoregressive Conditional Heteroskedasticity with Estimates of the Variance of United Kingdom Inflation, Econometrica 50(4):987-1007 .

Fama, E. and K. French, 1988, Permanent and Temporary Components of Stock Prices, Journal of Political Economy 96, 246-273.

Fama, E., and French, K., 1992, The cross-section of expected stock returns, Journal of Finance 47, 427-465.

Fama, E., and French, K., 1993, Common risk factors in the returns on stocks and bonds, Journal of Financial Economics 33, 3-56.

Fama, Eugene F. and Kenneth R. French, 1992, The Cross Section of Expected Stock Returns, Journal of Finance 47, 427-465.

Fama, Eugene F. and Kenneth R. French, 1993, Common Risk Factors in the Returns on Stocks and Bonds, Journal of Financial Economics 33, 3-56.

Fama, Eugene F., and K. R. French, 1989, Business Conditions and Expected Returns on Stocks and Bonds, Journal of Financial Economics 25:23-49. 
Feenberg, Daniel R., and Elizabeth Coutts, 1993, An Introduction to the TAXSIM model, Journal of Policy Analysis and Management 12, 189-194.

Fischer, Stanley, and F. Modigliani, 1978, Towards an Understanding of the Real Effects and Costs of Inflation, Review of World Economics 114(4):810-833.

Fisher, Irving, 1933, The Debt-Deflation Theory of Great Depressions , Econometrica 1(4):337-357.

Fleckenstein, Matthias, F. A. Longstaff, and H. Lustig, 2010, Why Does the Treasury Issue TIPS? The Tips-Treasury Bond Puzzle , NBER working paper w16358.

Frazzini, Andrea, 2006, The Disposition Effect and Under-reaction to News, Journal of Finance 61, 2017-2046.

French, K. and R. Roll, 1986, Stock return variances: The arrival of information and the reaction of traders, Journal of Financial Economics 17, 5-26.

Fuhrer, Jeffrey C., 1997, The (Un)Importance of Forward-Looking Behavior in Price Specifications, Journal of Money, Credit, and Banking 29(3):338-350.

Gabaix, Xavier and David Laibson, 2002, The 6D Bias and the Equity-Premium Puzzle, NBER Macroeconomics Annual 2001, Bernanke, Ben S. and Kenneth Rogoff, eds. MIT Press, Volume 16. Cambridge and London.

Galati, Gabriele, and K. Tsatsaronis, 2001, The Impact of the Euro on Europe's Financial Markets, BIS Working Paper No 100.

Garman, M. B., and M. J. Klass, 1980, On the estimation of security price volatilities from historical data, Journal of Business 53, 67-78.

Gervais, Simon, R. Kaniel, and D. H. Mingelgrin, 2001, The High-Volume Return Premium, Journal of Finance 56, 877-919. 
Glover, Brent, 2011, The Expected Cost of Default, University of Pennsylvania, mimeo.

Goldstein, Robert, N. Ju, and H. Leland, 2001, An EBIT-Based Model of Dynamic Capital Structure, Journal of Business 74(4):483-512.

Gomes, Joao, and M. Schmid, 2010, Levered Returns , Journal of Finance 65(2):467-494.

Gompers, Paul, and Andrew Metrick, 2001, Institutional Ownership and Equity Prices, Quarterly Journal of Economics 116, 229-259.

Gourio, Francois, 2011, Credit Risk and Disaster Risk , Boston University, mimeo.

Graham Benjamin, and David L. Dodd, 1934, Security Analysis, First Edition, Mc-Graw Hill, New York.

Graham, John R., 2000, How Big Are the Tax Benefits of Debt? , Journal of Finance 60(5):1901:1941.

Grinblatt, Mark, and Bing Han, 2005, Prospect Theory, Mental Accounting, and Momentum, Journal of Financial Economics 78, 311-333.

Grinblatt, Mark, and Tobias J. Moskowitz, 2004, Predicting stock price movements from past returns: the role of consistency and tax-loss selling, Journal of Financial Economics 71, 541-579.

Guenther, David, and Michele Willenborg, 1999, Capital gains tax rates and the cost of capital for small business: Evidence from the IPO market, Journal of Financial Economics 53, 385-408.

Hackbarth, Dirk, J. Miao, and E. Morellec, 2006, Capital Structure, Credit Risk, and Macroeconomic Conditions , Journal of Financial Economics 82:519-550. 
Hattori, Masazumi, K. Koyama, and T. Yonetani, 2001, Analysis of Credit Spread in Japan's Corporate Bond Market, BIS Papers No. 5, The Changing Shape of Fixed Income Markets: A Collection of Studies by Central Bank Economists.

He, Zhiguo, and W. Xiong, 2010, Rollover Risk and Credit Risk , NBER Working Paper w15653.

Heston, Steven L., R. Korajczyk, and R. Sadka, 2010, Intraday Patterns in the Crosssection of Stock Returns, Journal of Finance 65, 1369-1407.

Hoechle, Daniel, 2007, Robust Standard Errors for Panel Regressions with CrossSectional Dependence, Stata Journal 7(ii):1-31.

Huang, Jing-zhi, and M. Huang, 2002, How Much of the Corporate-Treasury Yield Spread is Due to Credit Risk?, Stanford University, mimeo.

Huang, Lixin, and Hong Liu, 2007, Rational Inattention and Portfolio Selection, Journal of Finance, 62(4), 1999-2040.

Hvidkjaer, Soren, 2002, A Trade-Based Analysis of Momentum, Unpublished Working paper, University of Maryland.

Hvidkjaer, Soren, 2005, Small Trades and the Cross-Section of Stock Returns, AFA 2007 Chicago Meetings Paper.

Ivković, Zoran, James Poterba, and Scott Weisbenner, 2004, Tax-Motivated Trading by Individual Investors, Unpublished Working paper.

Jegadeesh, Narasimhan, and Sheridan Titman, 1993, Returns to Buying Winners and Selling Losers: Implications for Stock Market Efficiency, Journal of Finance 48, 65-91.

Jensen, Michael C., 1986, Agency Costs of Free Cash Flow, Corporate Finance, and Takeovers , American Economic Review 76(2):323-329. 
Jensen, Michael C., and W. H. Meckling, 1976, Theory of the Firm: Managerial Behavior, Agency Costs and Ownership Structure, Journal of Financial Economics 3(4):305-360.

Jin, Li, 2006, Capital Gain Tax Overhang and Price Pressure, Journal of Finance 61, 13991431.

Jin, Li, R. C. Merton, and Z. Bodie, Do a firm's equity returns reflect the risk of its pension plan? , Journal of Financial Economics 81:1-26.

Jones, Charles P., Douglas K. Pearce, and Jack W. Wilson, 1987, Can Tax Loss Selling Explain the January Effect? A Note, Journal of Finance 42, 453-61.

Keim, Donald, 1983, Size related anomalies and stock return seasonality: further empirical evidence, Journal of Financial Economics 12, 13-32.

Kiyotaki, Nobuhiro, and J. Moore, 1997, Credit Cycles , Journal of Political Economy $105(2): 211-248$.

Klein, Peter, 2001a, The capital gain lock-in effect and equilibrium returns, Journal of Public Economics 71, 355-378.

Klein, Peter, 2001b, The capital gain lock-in effect and long-horizon return reversal, Journal of Financial Economics 59, 33-62.

Koijen, Ralph S.J., O. Van Hemert, and S. Van Nieuwerburgh, 2009, Mortgage Timing, Journal of Financial Economics 3:292-324.

Kumar, A., and C. M. Lee, 2006, Retail Investor Sentiment and Return Comovements, Journal of Finance 61, 2451-2486.

Lakonishok, Josef, and Seymour Smidt, 1986, Volume for Winners and Losers: Taxation and Other Motives for Stock Trading, Journal of Finance 41, 951-974. 
LeRoy, Stephen F., and R. Porter, 1981, The Present Value Relation: Tests Based on Variance Bounds, Econometrica 49:555-577.

Leary, Mark T., and M. R. Roberts, 2005, Do Firms Rebalance Their Capital Structures? , Journal of Finance 60(6):2575-2619.

Lee, Charles M.C. and Mark J. Ready, 1991, Inferring Trade Direction from Intraday Data, Journal of Finance 46, 733-746.

Leland, Hayne E., and K. B. Toft, 1996, Optimal Capital Structure, Endogenous Bankruptcy, and the Term Structure of Credit Spreads , Journal of Finance 51(3):9871019.

Leland, Mark T., 1994, Corporate Debt Value, Bond Covenants and Optimal Capital Structure , Journal of Finance 49(4):1213-1252.

Li, Lingfeng, 2002, Macroeconomic Factors and the Correlation of Stock and Bond Returns, Yale ICF Working Paper No. 02-46.

Lo, A. W. and C. MacKinlay (1988) Stock Market Prices Do Not Follow Random Walks: Evidence from a Simple Specification Test, Review of Financial Studies 1, 41-66.

Longstaff, Francis A., and E. S. Schwartz, 1995, A Simple Approach to Valuing Risky Fixed and Floating Rate Debt , Journal of Finance 50(3):789-819.

Lou, Dong, 2009, A Flow-Based Explanation for Return Predictability, Working paper, London School of Economics.

Maynard, Micheline, United Air Wins Right to Default on Its Employee Pension Plans, The New York Times, May 11, 2005.

Mehra, Rajnish, and E. C. Prescott, 1985, The Equity Premium: A Puzzle , Journal of Monetary Economics 15:145-161. 
Merton, Robert C., 1971, Optimum consumption and portfolio rules in a continuous-time model, Journal of Economic Theory, 3(4), 373-413.

Merton, Robert C., 1973, Theory of Rational Option Pricing, The Bell Journal of Economics and Management Science 4(1):141-183.

Merton, Robert C., 1974, On the Pricing of Corporate Debt: The Risk Structure of Interest Rates , Journal of Finance 29(1):449-470.

Mitchell, Mark, Lasse Pedersen, and Todd Pulvino, 2007, Slow moving capital, American Economic Review 97, 215-220.

Mitchell, Mark, Todd Pulvino, and Erik Stafford, 2004, Price pressure around mergers, Journal of Finance 59, 31-63.

Mitchell, Olivia S., Gary R. Mottola, Stephen P. Utkus, and Takeshi Yamaguchi, 2006, The inattentive participant: Portfolio trading behavior in 401(k) plans, Working paper, University of Pennsylvania.

Moody's, 2011, Corporate Default and Recovery Rates, 1920-2010. Moody's Investor Service, Global Credit Research.

Myers, Stewart C., 1977, Determinants of Corporate Borrowing , Journal of Financial Economics 5(2):147-175.

Myers, Stewart C., and Nicholas S. Majluf, 1984, Corporate Financing and Investment Decisions when Firms Have Information that Investors Do Not Have , Journal of Financial Economics 13(2):187-221.

Newey, Whitney K., and K. D. West, 1987, A Simple, Positive Semi-Definite, Heteroskedasticity and Autocorrelation Consistent Covariance Matrix , Econometrica 55: 703-708. 
Odean, Terrance, 1998, Are investors reluctant to realize their losses?, Journal of Finance $53,1775-1798$.

Odean, Terrance, 1999, Do investors trade too much?, American Economic Review 127998.

Parkinson, M., 1980, The extreme value method for estimating the variance of the rate of return, Journal of Business, 53, 61-65.

Pastor, L., and R. Stambaugh, 2003, Liquidity Risk and Expected Stock Returns, Journal of Political Economy, 111, 642-685.

Patton, Andrew J., and A. Timmermann, 2010, Why Do Forecasters Disagree? Lessons from the Term structure of Cross-Sectional Dispersion , Journal of Monetary Economics 57(7):803-820.

Petersen, Mitchell, 2009, Estimating standard errors in finance panel data sets: Comparing approaches, Review of Financial Studies 22, 435-480.

Pflueger, Carolin E., and L. M. Viceira, 2011, An Empirical Decomposition of Risk and Liquidity in Nominal and Inflation-Indexed Government Bonds , NBER Working Paper w16892.

Philippon, Thomas, 2009, The Bond Market's $q$, Quarterly Journal of Economics 124(3):1011-1056.

Polk, Christopher, and P. Sapienza, 2009, The Stock Market and Corporate Investment: A Test of Catering Theory, Review of Financial Studies 22(1):187-217.

Poterba, James M., and Scott J. Weisbenner, 2001, Capital Gains Tax Rules, Tax-Loss Trading, and Turn-of-the-Year Returns, Journal of Finance 56, 353-368.

Reese, William A., Jr., 1998, Capital gains taxation and stock market activity: Evidence from IPO's, Journal of Finance 53, 1799-1820. 
Reinganum, Marc, 1983, The Anomalous Stock Market Behavior of Small Firms in January: Empirical Tests of Tax-Loss Selling Effects, Journal of Financial Economics 12, 89-104.

Reinganum, Marc, and Alan C. Shapiro, 1987, Taxes and stock return seasonality: Evidence from the London Stock Exchange, Journal of Business 60, 281-295.

Reis, Ricardo, 2006, Inattentive Consumers, Journal of Monetary Economics, 53(8), 17611800.

Ritter, Jay R., 1988, The buying and selling behavior of individual investors at the turn of the year, Journal of Finance 43, 701-717.

Rogers, W. H., 1983. Analyzing complex survey data. Rand Corporation memorandum. Santa Monica, CA.

Rogers, W. H., 1993. Regression standard errors in clustered samples. Stata Technical Bulletin Reprints STB-13 - STB-18, 88-94.

Roll, Richard, 1983. The turn-of-the-year effect and the return premia of small firms, Journal of Portfolio Management 9, 18-28.

Rozeff, Michael F. and William R. Kinney, 1976, Capital Market Seasonality: The Case of Stock Returns, Journal of Financial Economics 3, 379-402.

Scholes, Myron, 1972, The market for corporate securities: Substitution versus price pressure and the effects of information on stock prices, Journal of Business 45, 179-211.

Schultz, P., 1985, Personal income taxes and the January effect: small firm stock returns before the War Revenue Act of 1917: A note, Journal of Finance 40, 333-343.

Shiller, Robert J., 1971, Do Stock Prices Move Too Much to be Justified by Subsequent Changes in Dividends?, American Economic Review 71:421-436. 
Shimko, David C., N. Tejima, and D. R. van Deventer, 1993 The Pricing of Risky Debt when Interest Rates are Stochastic, Journal of Fixed Income 3(2):58-65 .

Shleifer, Andrei, 1986, Do Demand Curves for Stocks Slope Down?, Journal of Finance 41, 579-590.

Shleifer, Andrei, and Robert W. Vishny, 1997, The Limits of Arbitrage, Journal of Finance $52,35-55$.

Sialm, Clemons, 2007, Investment taxes and equity returns, Working paper, University of Michigan.

Sias W. Richard, and Laura T. Starks, 1997, Individuals and Institutions at the Turn-ofthe-year, Journal of Finance 52, 1543-1562.

Sims, Theodore, 1995, Taxation, optimization, and the January seasonal effect (and other essays in taxation and finance), Ph.D. dissertation, Massachusetts Institute of Technology, Department of Economics.

Stock, James H., and M. Watson, 2007, Why has US Inflation Become Harder to Forecast? , Journal of Money Credit and Banking 39(1):3-33.

Stock, James H., and M. Watson, 2008, Phillips Curve Inflation Forecasts , NBER Working Paper w14322.

Stokey, Nancy L., 2009, The Economics of Inaction: Stochastic Control Models with Fixed Costs. Princeton University Press, Princeton NJ.

Thompson, Samuel B., Simple formulas for standard errors that cluster by both firm and time, forthcoming Journal of Financial Economics.

Viceira, Luis M., 2010, Bond Risk, Bond Return Volatility, and the Term Structure of Interest Rates , International Journal of Forecasting, forthcoming. 
Wachtel, Sidney B., 1942, Certain observations on seasonal movements in stock prices, Journal of Business 15, 184-193.

Welch, Ivo, 2004, Capital Structure and Stock Returns , Journal of Political Economy 112(1):106-130.

Wright, Jonathan H., 2010, Term Premia and Inflation Uncertainty: Empirical Evidence from an International Panel Dataset , American Economic Review 101:1514-1534 